Prepared in cooperation with the Bureau of Reclamation and Interagency Ecological Program

\title{
Synthesis of Studies in the Fall Low-Salinity Zone of the San Francisco Estuary, September-December 2011
}

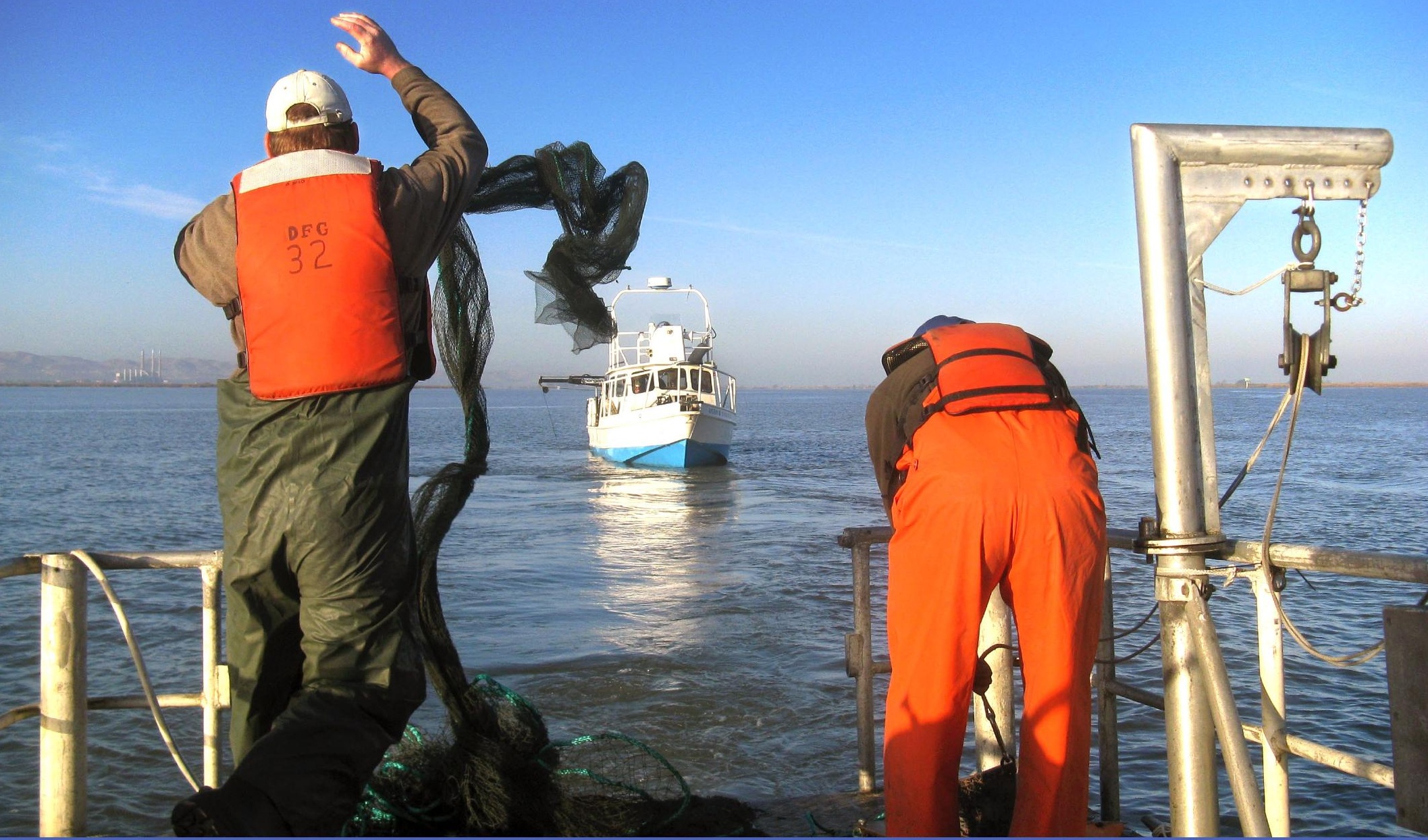

Scientific Investigations Report 2014-5041 
Cover. California Department of Fish and Wildlife personnel deploying the net for fall midwater-trawl sampling simultaneously with data collection for the fall low-salinity habitat investigations in the following boat by personnel of the University of California, Davis and the U.S. Bureau of Reclamation. 


\title{
Synthesis of Studies in the Fall Low- Salinity Zone of the San Francisco Estuary, September-December 2011
}

By Larry R. Brown', Randall Baxter ${ }^{2}$, Gonzalo Castillo ${ }^{3}$, Louise Conrad ${ }^{4}$, Steven Culberson ${ }^{3}$, Gregg Erickson ${ }^{2}$, Frederick Feyrer ${ }^{5}$, Stephanie Fong ${ }^{6}$, Karen Gehrts ${ }^{4}$, Lenny Grimaldo ${ }^{5}$, Bruce Herbold ${ }^{7}$, Joseph Kirsch ${ }^{3}$, Anke Mueller-Solger ${ }^{8}$, Steven B. Slater ${ }^{2}$, Ted Sommer ${ }^{4}$, Kelly Souza ${ }^{2}$, and Erwin Van Nieuwenhuyse ${ }^{5}$

\author{
${ }^{1}$ U.S. Geological Survey \\ ${ }^{2}$ California Department of Fish and Wildlife \\ ${ }^{3}$ U.S. Fish and Wildlife Service \\ ${ }^{4}$ California Department of Water Resources \\ ${ }^{5}$ U.S. Bureau of Reclamation \\ ${ }^{6}$ Central Valley Regional Water Quality Control Board \\ ${ }^{7}$ U.S. Environmental Protection Agency \\ ${ }^{8}$ Delta Stewardship Council
}

In Cooperation with the Bureau of Reclamation and Interagency Ecological Program

Scientific Investigations Report 2014-5041

\author{
U.S. Department of the Interior \\ U.S. Geological Survey
}




\title{
U.S. Department of the Interior SALLY JEWELL, Secretary
}

\section{U.S. Geological Survey \\ Suzette M. Kimball, Acting Director}

\author{
U.S. Geological Survey, Reston, Virginia: 2014
}

For more information on the USGS - the Federal source for science about the Earth, its natural and living resources, natural hazards, and the environment, visit http://www.usgs.gov or call 1-888-ASK-USGS.

For an overview of USGS information products, including maps, imagery, and publications, visit http://www.usgs.gov/pubprod

To order this and other USGS information products, visit http://store.usgs.gov

Any use of trade, firm, or product names is for descriptive purposes only and does not imply endorsement by the U.S. Government.

Although this information product, for the most part, is in the public domain, it also may contain copyrighted materials as noted in the text. Permission to reproduce copyrighted items must be secured from the copyright owner.

Suggested citation:

Brown, L.R., Baxter, R., Castillo, G., Conrad, L., Culberson, S., Erickson, G., Feyrer, F., Fong, S., Gehrts, K., Grimaldo, L., Herbold, B., Kirsch, J., Mueller-Solger, A., Slater, S., Souza, K., and Van Nieuwenhuyse, E., 2014, Synthesis of studies in the fall low-salinity zone of the San Francisco Estuary, September-December 2011: U.S. Geological Survey Scientific Investigations Report 2014-5041, 136 p., http://dx.doi.org/10.3133/sir20145041

ISSN 2328-0328 (online) 


\section{Contents}

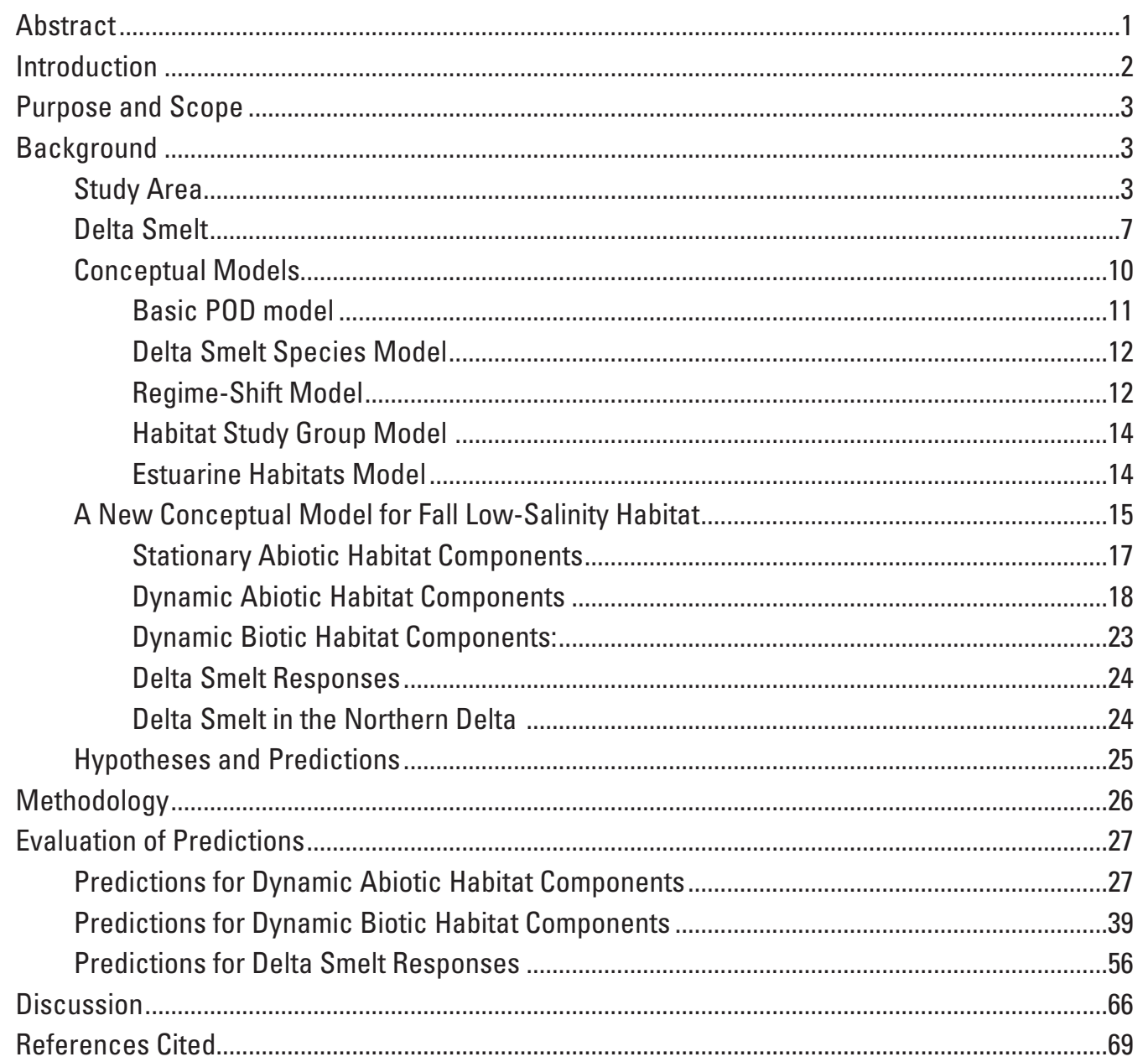




\section{Contents}

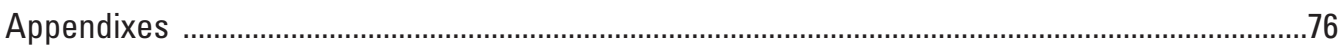

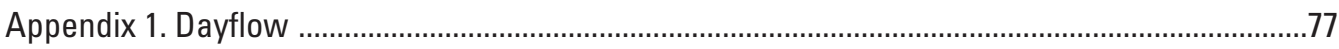

Appendix 2. Surface Area and Maps of the Low-Salinity Zone ....................................................79

Low-Salinity Zone Area and Depth Analysis.......................................................................

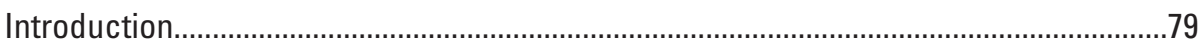

LSZ Habitat Area and Depth Calculation Approach .........................................................79

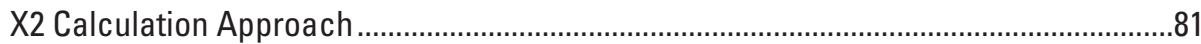

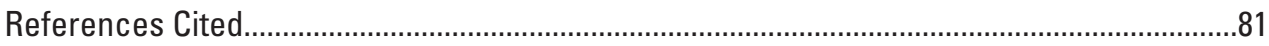

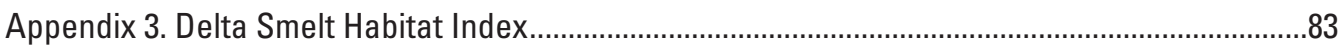

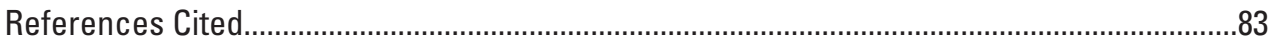

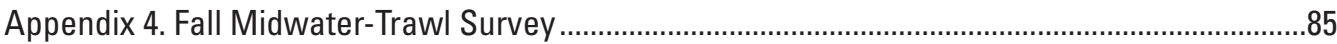

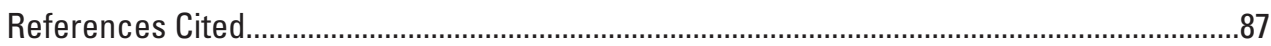

Appendix 5. U.S. Geological Survey Sediment Monitoring and Analysis.....................................111

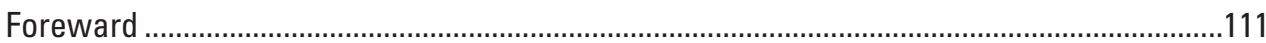

Preliminary Analysis of Suspended-Sediment Concentration and Turbidity in the Fall Low-Salinity Zone of the San Francisco Estuary........................................111

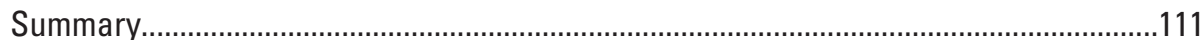

Does X2 Position Affect Suspended-Sediment Concentration? ....................................111

Has Suspended-Sediment Concentration Changed Between 1994 and 2011? .............111

Is the Confluence or Suisun Bay More Turbid? ...........................................................114

Is Suisun Bay or the Cache Slough/Liberty Island Complex More Turbid?....................118

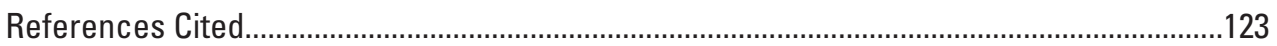

Appendix 6. Environmental Monitoring Program ..................................................................125

Appendix 7. U.S. Geological Survey Water-Quality Monitoring .....................................................128

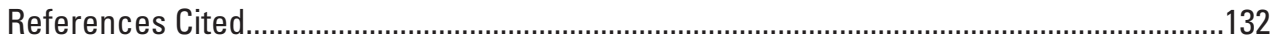

Appendix 8. California Department of Fish and Wildlife Fish Sampling........................................133 


\section{Figures}

1. Schematic showing the adaptive management cycle ....................................................

2. Map showing San Francisco Bay Estuary. Also shown are locations corresponding to different values of $\mathrm{X} 2$, which is the horizontal distance in kilometers from the Golden Gate up the axis of the estuary to where tidally averaged near-bottom salinity is 2

3. Map showing Sacramento-San Joaquin Delta, Suisun Bay, and associated areas ........5

4. Graph of delta smelt abundance index from the fall midwater-trawl survey ....................6

5. Graph of trends in abundance indices for four pelagic fishes from 1967 to 2012 based on the fall midwater-trawl survey, a California Department of Fish and Wildlife survey that samples the upper San Francisco Estuary for $A$, striped

6. Illustration showing simple conceptual diagram of the delta smelt annual life cycle.

7. Maps showing location of the fall low-salinity zone (LSZ), where most delta smelt are found: $A$, under high outflow conditions, when the LSZ overlaps the Suisun region, and $B$, under low outflow conditions, when the LSZ overlaps the river confluence.

8. Diagram showing the basic conceptual model for the pelagic organism decline ..........11

9. Illustration showing delta smelt species-specific model: $A$, summer conditions;

$B$, fall conditions; $C$, winter conditions; and $D$, spring conditions

10. Illustration showing regime-shift model from Baxter and others (2010).

The model assumes that ecological regime shift in the Delta results from

$A$, changes in environmental drivers that lead to $B$, profoundly altered biological communities.

11. Diagram showing Habitat Study Group model of effects of fall low-salinity habitat position, as indexed by $\mathrm{X} 2$ on delta smelt through changes in habitat quantity and quality.

12. Illustration showing estuarine habitat conceptual model (modified from Peterson, 2003)

13. Illustration showing spatially explicit conceptual model for the western reach of the modern delta smelt range in the fall: interacting stationary and dynamic habitat features drive delta smelt responses

14. Maps showing $A$, Location of the low-salinity zone (salinity 1-6) when X2 is at 85 kilometers. $B$, Percentage of day that the low-salinity zone occupies different areas

15. Maps showing $A$, Location of the low-salinity zone (salinity 1-6) when X2 is at 74 kilometers. $B$, Percentage of day that the low-salinity zone occupies different areas

16. Maps showing $A$, Location of the low-salinity zone (salinity 1-6) when X2 is at 81 kilometers. $B$, Percentage of day that the LSZ occupies different areas.

17. Graphs showing daily $\mathrm{X} 2$ for $A, 2005-2006$ and $B, 2010-2011$ 


\section{Figures-Continued}

18. Graphs showing daily Delta outflow for $A, 2005-2006$ and $B, 2010-2011$

19. Graphs showing daily surface area of the depth-averaged low-salinity zone (salinity 1-6) for $A$, 2005-2006 and B, 2010-2011

20. Graph showing daily delta smelt habitat index for the fall (September-December) for 2005, 2006, 2010, and 2011

21. Graphs showing daily net flow past Jersey Point on the San Joaquin River for $A, 2005-2006$ and $B, 2010-2011$. .32

22. Secchi depth data collected during the fall midwater-trawl survey: $A$, September-October; and $B$, November-December.

23. Graphs showing turbidity data collected during the fall midwater-trawl survey: $A$, September-October; and $B$, November-December.

24. Graph showing percentage of data showing a turbid bay and clear confluence, September-December 2011, calculated from the product of hourly deviations of specific conductance and suspended-sediment concentration from tidally averaged values.

25. Graph showing near-surface suspended-sediment concentration at Mallard Island, September-October mean values, 1994-2011

26. Graphs showing surface-water temperature at fall midwater-trawl sampling sites during monthly sampling for the $A$, salinity $1-6$, low-salinity zone; $B$, salinity less than 1 , freshwater region; $C$, salinity greater than 6 ; and $D$, Cache Slough and Sacramento River Deep Water Ship Channel

27. Graphs showing ammonium concentrations as nitrogen from the Environmental Monitoring Program: $A$, September-October and $B$, November-December..

28. Graphs showing ammonium as nitrogen data from U.S. Geological Survey monthly sampling cruises: $A$, September-October and $B$, November-December

29. Graphs showing ammonium as nitrogen concentrations in fall 2011 from samples collected during the fall midwater-trawl survey:

$A$, September-October and $B$, November-December

30. Graphs showing nitrite plus nitrate as nitrogen concentrations in September-October and November-December from the Environmental Monitoring Program: $A$, September-October and $B$, November-December...

31. Graphs showing nitrite plus nitrate as nitrogen concentrations from samples collected during monthly U.S. Geological Survey cruises: $A$, September-October and $B$, November-December.

32. Graphs showing nitrite plus nitrate as nitrogen concentrations in fall 2011 from the samples collected during the fall midwater-trawl survey: $A$, September-October and $B$, November-December.

33. Graphs showing chlorophyll- $\alpha$ concentrations from the Environmental Monitoring Program: $A$, September-October and $B$, November-December

34. Graphs showing chlorophyll- $\alpha$ concentrations from samples collected during monthly U.S. Geological Survey cruises: $A$, September-0ctober and $B$, November-December

35. Graphs showing chlorophyll- $\alpha$ concentration in 2011 from samples collected during the fall midwater-trawl: $A$, September-October and $B$, November-December. 


\section{Figures-Continued}

36. Graph showing continuous in-situ fluorescence measurements (a method to estimate chlorophyll- $\alpha$ concentrations) from September to December 2011 for Rio Vista Bridge and Mallard Island.

37. Graph showing occurrence of floating Microcystis at fall midwater-trawl sampling stations for September to December 2010 and 2011

38. Graphs showing mean biomass per unit effort of juvenile and adult calanoid copepods for Environmental Monitoring Program samples for: $A$, September; $B$, October; $C$, November; $D$, December

39. Graphs showing mean biomass per unit effort of juvenile and adult cyclopoid copepods for Environmental Monitoring Program samples for: $A$, September; $B$, October; $C$, November; $D$, December

40. Graphs showing stomach contents of delta smelt captured in the fall midwater-trawl survey in 2011 containing calanoid and cyclopoid copepods for: $A$, September; $B$, October; $C$, November; $D$, December.

41. Graphs showing stomach contents of delta smelt captured in the fall midwater-trawl survey in 2011 containing harpacticoid copepods, cladocerans, mysids, amphipods, and other prey for: $A$, September; $B$, October; $C$, November; $D$, December

42. Graphs showing mean biomass per unit effort of juvenile and adult calanoid copepods, cyclopoid copepods, cladocerans, and mysids for Environmental Monitoring Program samples.

43. Graphs showing filtration rates (a function of biomass and temperature) for Potamocorbula amurensis (blue) and Corbicula fluminea (orange) in $A$, October 2009; $B$, October 2010; and C, October 2011

44. Graphs showing biomass for Potamocorbula amurensis and Corbicula fluminea combined during the October sampling periods in $A$, western Suisun Marsh; $B$, the flooded islands; $C$, Grizzly/Honker Bay shallows; and $D$, the confluence region..

45. Graphs showing turnover rates for Potamocorbula amurensis and Corbicula fluminea combined during the October in $A$, western Suisun Marsh; $B$, the flooded islands; $C$, Grizzly/Honker Bay shallows; and $D$, the confluence region

46. Graphs showing distribution of delta smelt captured in the fall midwater-trawl survey for: $A, 2005 ; B, 2006 ; C, 2010 ; D, 2011$

47. Graphs showing plots of delta smelt abundance indices by year for $A$, the spring Kodiak-trawl survey; $B$, 20-millimeter survey; $C$, summer townet survey; and $D$, fall midwater-trawl survey.....

48. Graphs showing ratios of delta smelt abundance indices used as indicators of survival by year for $A$, summer townet survey divided by fall midwater-trawl survey in previous year; and $B$, fall midwater-trawl survey divided by summer townet survey.

49. Graphs showing ratios of delta smelt abundance indices used as indicators of survival and recruitment: $A$, spring Kodiak-trawl survey divided by fall midwater-trawl survey in previous year; $B, 20$-millimeter survey divided by spring Kodiak-trawl survey; and $C$, summer townet survey divided by spring Kodiak-trawl survey 


\section{Figures-Continued}

1-1. Map showing sites used in Dayflow calculations.

2-1. Model domain showing daily averaged depth-averaged salinity and daily averaged depth of the low-salinity zone on April 5, 1994, when X2 was approximately 75 .

2-2. Map showing transects along the axis of northern San Francisco Bay used to measure X2 in the UnTRIM Bay-Delta model. X2 is the horizontal distance from the Golden Gate up the axis of the estuary to where tidally averaged near-bottom salinity is 2 .

4-1. Map showing locations of fall midwater-trawl sampling stations in the San Francisco Bay estuary.

4-2. Illustration showing Microcystis abundance visual-ranking system utilized during the fall midwater-trawl sampling

5-1. Graph showing near-surface suspended-sediment concentration at Mallard Island as a function of X2, September-0ctober mean values, 1994-2011.

5-2. Graph showing near-surface suspended-sediment concentration at Mallard Island, September-October mean values, 1994-2011.

5-3. Graph showing suspended-sediment concentration near the bottom of Suisun Cutoff, September-October 1995 and 2011

5-4. Graph showing suspended-sediment concentration in Grizzly Bay, September 1995 and 2011

5-5. Graph showing standardized deviations of near-surface hourly specific conductance and suspended-sediment concentration from tidally averaged values at Mallard Island, September-October 2011

5-6. Graph showing percentage of data showing a turbid Suisun Bay and clear confluence, September-December 2011

5-7. Graph showing annual percentage of specific conductance and suspended-sediment concentration data from Mallard Island within the upper right and lower left quadrants of figure 5-5 showing turbid waters to the west of Mallard Island (Suisun Bay) and clear waters to the east (confluence), as a function of X2, September and October 1994-2011. 


\section{Figures-Continued}

5-8. Graph showing annual percentage of specific conductance and

suspended-sediment concentration data from Mallard Island within the upper right and lower left quadrants of figure 5-5 showing turbid waters to the west of Mallard Island (Suisun Bay) and clear waters to the east (confluence), as a function of mean specific conductance, September-October 1994-2011

5-9. Graph showing annual percentage of specific conductance and suspended-sediment concentration data from Mallard Island within the upper right and lower left quadrants of figure 5-5 showing turbid waters to the west of Mallard Island (Suisun Bay) and clear waters to the east (confluence), as a function of mean wind speed, September-0ctober 1994-2011.

5-10. Boxplots of turbidity in Suisun Bay and the Cache Slough complex, September-December 2011.

5-11. Boxplots of turbidity in Suisun Bay and the Cache Slough complex, September-October 2011

5-12. Graphs showing wind-speed squared and turbidity, September-December 2011 .......121

5-13. Boxplots of turbidity at Mallard Island and the Cache Slough complex, September-0ctober 2010 and 2011

6-1. Map showing sites sampled by the Environmental Monitoring Program for water-quality constituents that were included in data analysis for this report

7-1. Map showing sites sampled by the U.S. Geological Survey water-quality monitoring program for water-quality constituents.

8-1. Map showing sites sampled by the California Department of Fish and Wildlife spring Kodiak-trawl survey

8-2. Map showing sites sampled by the California Department of Fish and Wildlife 20-millimeter survey

8-3. Map showing sites sampled by the California Department of Fish and Wildlife summer townet survey 


\section{Tables}

1. Predicted qualitative and quantitative outcomes of the fall low-salinity habitat component of the Reasonable and Prudent Alternative based on three levels of X2 (modified from U.S. Bureau of Reclamation, 2012)....

2. Data sources with references to appendixes $1-8$, where more detailed methods can be found .

3. Mean and standard deviation for $\mathrm{X} 2$, delta outflow, surface area of low salinity zone and the delta smelt habitat index

4. Estimated mean and standard deviation of growth rates of delta smelt from August to December 2011 based on otolith analysis from four regions of the San Francisco Estuary: salinity less than 1, salinity 1-6, salinity greater than 6, and Cache Slough/Sacramento River Deepwater Ship Channel....

5. Assessments of predicted qualitative and quantitative outcomes for September to 0 ctober of the fall low-salinity habitat component of the Reasonable and Prudent Alternative based on three levels of the action

1-1. Responsible agencies and data used as input to the Dayflow program ..........................77

2-1. Estimates of the area of the low-salinity zone for specified X2 ......................................

3-1. Delta smelt habitat index values for specified X2 .......................................................

4-1. Locations of fall midwater-trawl sampling stations in the San Francisco estuary ..........86

4-2. Surface-water temperature, Secchi depth, turbidity, and Microcystis rating data collected during the fall midwater-trawl sampling survey in 2005, 2006, 2010, and 2011

4-3. Nitrite plus nitrate as nitrogen, ammonium as nitrogen, and chlorophyll- $\alpha$, by salinity group, from water samples collected during the fall midwater-trawl sampling survey in 2011

5-1. Station names, site identifiers, site codes, and data sources for analyses presented in this appendix.

6-1. Latitude and longitude of Environmental Monitoring Program discrete and continuous water-quality monitoring sites utilized in this report

6-2. Nitrite plus nitrate as nitrogen, ammonium as nitrogen, and chlorophyll- $\alpha$, by salinity group, from water samples collected during Environmental Monitoring Program sampling in 2005, 2006, 2010, and 2011

6-3. In-situ fluoresence at Rio Vista Bridge and Mallard Island for September-December 2011 (provided as a Microsoft Exce ${ }^{\circledR}$ File)

7-1. Latitude and longitude of U.S. Geologic Survey water-quality monitoring sites utilized in this report.

7-2. Ammonium, ammonium as nitrogen, nitrite plus nitrate, nitrite plus nitrate as nitrogen, and chlorophyll- $\alpha$, by salinity group, from water samples collected by the U.S. Geological Survey in 2005, 2006, 2010, and 2011

8-1. Annual values of delta smelt abundance indices for the fall midwater-trawl survey, spring Kodiak-trawl survey, 20-millimeter $(\mathrm{mm})$ survey, and summer townet survey and values for selcted ratios of abundance indices 


\section{Conversion Factors}

SI to Inch/Pound

\begin{tabular}{lcl}
\hline \multicolumn{1}{c}{ Multiply } & By & \multicolumn{1}{c}{ To obtain } \\
\hline millimeter $(\mathrm{mm})$ & Length & inch (in.) \\
meter $(\mathrm{m})$ & 0.03937 & foot $(\mathrm{ft})$ \\
kilometer $(\mathrm{km})$ & 3.281 & mile $(\mathrm{mi})$ \\
\hline & 0.6214 & \\
\hline hectare $(\mathrm{ha})$ & Area & acre \\
hectare $(\mathrm{ha})$ & 2.471 & square mile $\left(\mathrm{mi}^{2}\right)$ \\
\hline & 0.003861 & quart $(\mathrm{qt})$ \\
\hline liter $(\mathrm{L})$ & Volume & cubic foot $\left(\mathrm{ft}^{3}\right)$ \\
cubic meter $\left(\mathrm{m}^{3}\right)$ & 1.057 & acre-foot $(\mathrm{acre}-\mathrm{ft})$ \\
cubic meter $\left(\mathrm{m}^{3}\right)$ & 35.31 & \\
\hline cubic meter per second $\left(\mathrm{m}^{3} / \mathrm{s}\right)$ & 0.0008107 & cubic foot per second $\left(\mathrm{ft}^{3} / \mathrm{s}\right)$ \\
\hline gram $(\mathrm{g})$ & Flow rate & ounce, avoirdupois $(\mathrm{oz})$ \\
\hline
\end{tabular}

Temperature in degrees Celsius $\left({ }^{\circ} \mathrm{C}\right)$ may be converted to degrees Fahrenheit ( $\left.{ }^{\circ} \mathrm{F}\right)$ as follows:

${ }^{\circ} \mathrm{F}=\left(1.8 x^{\circ} \mathrm{C}\right)+32$

Specific conductance is given in microsiemens per centimeter at 25 degrees Celsius $\left(\mu \mathrm{S} / \mathrm{cm}\right.$ at $\left.25^{\circ} \mathrm{C}\right)$.

Concentrations of chemical constituents in water are given either in milligrams per liter ( $\mathrm{mg} / \mathrm{L}$ ) or micrograms per liter ( $\mu \mathrm{g} / \mathrm{L})$. 


\section{Abbreviations}

\begin{tabular}{|c|c|}
\hline 20-mm & 20-millimeter survey \\
\hline AMP & adaptive management plan \\
\hline $\mathrm{BiOp}$ & Biological Opinion \\
\hline BPUE & biomass per unit effort \\
\hline CDFW & California Department of Fish and Wildlife \\
\hline CDWR & California Department of Water Resources \\
\hline CVP & Central Valley Project \\
\hline Delta & Sacramento-San Joaquin Delta \\
\hline DWSC & deep water ship channel \\
\hline EMP & Environmental Monitoring Program \\
\hline ETM & estuarine turbidity maximum \\
\hline FLaSH & fall low-salinity habitat \\
\hline FMWT & fall midwater trawl \\
\hline $\mathrm{GF} / \mathrm{F}$ & glass fiber filter \\
\hline HSG & Habitat Study Group \\
\hline IEP & Interagency Ecological Program \\
\hline LIW & Liberty Island Shallows \\
\hline LOESS & locally weighted-regression scatterplot smoothing \\
\hline LSH & low-salinity habitat \\
\hline LSZ & low-salinity zone \\
\hline MAF & million acre feet \\
\hline MAST & Management, Analysis, and Synthesis Team \\
\hline $\mathrm{Ml}$ & Mallard Island \\
\hline NDOI & net Delta outflow index \\
\hline $\mathrm{NH}_{4}-\mathrm{N}$ & ammonium as nitrogen \\
\hline NRC & National Research Council \\
\hline NTU & nephelometric turbidity unit \\
\hline OMR & Old and Middle River \\
\hline POD & pelagic organism decline \\
\hline RFU & relative fluorescence unit \\
\hline RPA & Reasonable and Prudent Alternative \\
\hline SFE & San Francisco Estuary \\
\hline SKT & spring Kodiak-trawl \\
\hline SRDWSC & Sacramento River Deep Water Ship Channel \\
\hline SSC & suspended-sediment concentration \\
\hline Suisun region & Suisun Bay and associated embayments \\
\hline SWAMP & Surface Water Ambient Monitoring Program \\
\hline SWP & State Water Project \\
\hline SWRCB & State Water Resources Control Board \\
\hline TNS & summer townet survey \\
\hline UCD & University of California at Davis \\
\hline UCS & Upper Cache Slough \\
\hline USBR & U.S. Bureau of Reclamation \\
\hline USFWS & U.S. Fish and Wildlife Service \\
\hline $\mathrm{X} 2$ & $\begin{array}{l}\text { the horizontal distance in kilometers from the Golden Gate up the axis } \\
\text { of the estuary to where tidally averaged near-bottom salinity is } 2\end{array}$ \\
\hline
\end{tabular}




\title{
Synthesis of Studies in the Fall Low-Salinity Zone of the San Francisco Estuary, September-December 2011
}

\author{
By Larry R. Brown, Randall Baxter, Gonzalo Castillo, Louise Conrad, Steven Culberson, Gregg Erickson, \\ Frederick Feyrer, Stephanie Fong, Karen Gehrts, Lenny Grimaldo, Bruce Herbold, Joseph Kirsch, Anke \\ Mueller-Solger, Steven B. Slater, Ted Sommer, Kelly Souza, and Erwin Van Nieuwenhuyse
}

\section{Abstract}

In fall 2011, a large-scale investigation (fall low-salinity habitat investigation) was implemented by the Bureau of Reclamation in cooperation with the Interagency Ecological Program to explore hypotheses about the ecological role of low-salinity habitat in the San Francisco Estuary-specifically, hypotheses about the importance of fall low-salinity habitat to the biology of delta smelt Hypomesus transpacificus, a species endemic to the San Francisco Estuary and listed as threatened or endangered under federal and state endangered species legislation. The Interagency Ecological Program is a consortium of 10 agencies that work together to develop a better understanding of the ecology of the Estuary and the effects of the State Water Project and Federal Central Valley Project operations on the physical, chemical, and biological conditions of the San Francisco Estuary. The fall low-salinity habitat investigation constitutes one of the actions stipulated in the Reasonable and Prudent Alternative issued with the 2008 Biological Opinion of the U.S. Fish and Wildlife Service, which called for adaptive management of fall SacramentoSan Joaquin Delta outflow following "wet" and "above normal" water years to alleviate jeopardy to delta smelt and adverse modification of delta smelt critical habitat. The basic hypothesis of the adaptive management of fall low-salinity habitat is that greater outflows move the low-salinity zone (salinity 1-6), an important component of delta smelt habitat, westward and that moving the low-salinity zone westward of its position in the fall of recent years will benefit delta smelt, although the specific mechanisms providing such benefit are uncertain. An adaptive management plan was prepared to guide implementation of the adaptive management of fall low-salinity habitat and to reduce uncertainty.

This report has three major objectives:

- To provide a summary of the results from the first year of coordinated fall low-salinity habitat studies and monitoring.
- To provide a synthesis of the results of the fall lowsalinity habitat studies and other ongoing research and monitoring, to determine if the available information supports the hypotheses behind the adaptive management of fall low-salinity habitat as set forth in the adaptive management plan.

- To begin to put the results from the fall low-salinity habitat studies into context within the larger body of knowledge regarding the San Francisco Estuary and, in particular, the upper San Francisco Estuary, including the Sacramento-San Joaquin Delta, Suisun Bay, and associated embayments.

The basic approach of this report is to evaluate predictions derived from the hypotheses included in the conceptual model developed within the adaptive management plan. All available data from studies and monitoring conducted in fall 2011 and similar data from fall 2006, which was the most recent wet year preceding 2011, were considered. Data from 2005 and 2010 were also considered, to include the conditions antecedent to those years.

Many of the predictions either could not be evaluated with the data available, or the needed data were not collected. Most of the predictions that could be addressed involved either the abiotic habitat components (that is, the physical environment) or delta smelt responses. In general, the fall low-salinity habitat investigation has been largely inconclusive as of the writing of this report. This is not to be unexpected in the first year of what is intended to be a multi-year adaptive-management effort. This report can be viewed as the first chapter of a "living document" that is to be continually updated as part of the adaptive management cycle. The results of this report, especially predictions with insufficient data for evaluation, indicate a number of science-based approaches to improve the fall low-salinity habitat investigations:

- Develop a method of measuring "hydrodynamic complexity." This concept is central to a number of the predictions that could not be evaluated. 
- Determine if wind speed warrants a stand-alone prediction. The wind-speed prediction is directly related to the turbidity predictions, and wind is only one of several factors important for determining turbidity.

- Determine the correct spatial and temporal scale or scales necessary for monitoring and for studies to address the predicted abiotic and biotic responses. Many of the assessments in this report were based on monthly sampling of dynamic habitat components, such as phytoplankton and zooplankton populations, that can change on daily scales.

- Address the nutrient predictions as part of developing a phytoplankton production model that includes nutrient cycling and other important processes, if feasible. At a minimum develop a mechanistic conceptual model to support more processed-based interpretations of data or design of new studies, rather than making simple predictions of increase or decrease.

- Determine if studies of predation rates are feasible in areas where there are delta smelt.

\section{Introduction}

In fall 2011, a large scale investigation was implemented by the U.S. Bureau of Reclamation (Reclamation) in cooperation with the Interagency Ecological Program (IEP) to explore hypotheses about the ecological role of low-salinity habitat (LSH) in the San Francisco Estuary (SFE) (FLaSH, fall lowsalinity habitat investigations) and, specifically, hypotheses about the importance of LSH to the biology of delta smelt Hypomesus transpacificus, a species endemic to the SFE and listed as threatened under the Federal Endangered Species Act and as endangered under the California Endangered Species Act. The Interagency Ecological Program is a consortium of 10 agencies that work together to develop a better understanding of the ecology of the estuary and the effects of the State Water Project and Federal Central Valley Project operations on the physical, chemical, and biological conditions of the San Francisco Estuary (http://www.water.ca.gov/iep/about/ aboutiep.cfm). The FLaSH studies and other activities were motivated by a Biological Opinion (BiOp) on Central Valley Project (CVP) and State Water Project (SWP) operations issued by the US Fish and Wildlife Service (USFWS) in 2008 (U.S. Fish and Wildlife Service, 2008). The BiOp concluded that aspects of those operations jeopardize the continued existence of delta smelt and adversely modify delta smelt critical habitat. One of the actions stipulated in the Reasonable and Prudent Alternative (RPA) issued with the BiOp called for adaptive management of fall Sacramento-San Joaquin Delta
(Delta) outflow (hereafter "fall outflow") following "wet" and "above normal" water years (see "Background" section for explanation of water-year types) to alleviate jeopardy to delta smelt and adverse modification of delta smelt critical habitat (hereafter, fall low-salinity habitat component of the RPA). The basic hypothesis of the fall low-salinity habitat component of the RPA is that greater outflows move the LSH westward and that moving LSH westward of its position in the fall of recent years will benefit delta smelt, although the specific mechanisms providing such benefit are uncertain. An adaptive management plan (AMP) was prepared to guide implementation of the fall low-salinity habitat component of the RPA (U.S. Bureau of Reclamation, 2012) and to reduce uncertainty. The adaptive management of fall outflow specifically refers to actions in September and October that manipulate the position of the LSZ. However, delta smelt are sampled from September to mid-December, and this longer time span is often included in the report, especially when addressing the biology of the species.

The AMP was designed in accordance with the Department of Interior guidelines for design and implementation of adaptive management strategies (Williams and others, 2009). Adaptive management strategies share a cyclical design: (1) problem assessment, including development of conceptual and quantitative models; (2) design, evaluation, and implementation of actions; (3) monitoring of outcomes; (4) evaluation of outcomes; and (5) modification of problem assessment and models in response to learning from the actions (fig. 1). Because the range of hypotheses being explored by the FLaSH is broad, Reclamation, in cooperation with IEP, perceived the need for a broad synthesis of the FLaSH studies, ongoing IEP monitoring and research, ongoing research funded by other entities, and previous studies in the San Francisco Estuary. This report is the first such synthesis, and regular updates are expected as part of the annual AMP cycle.

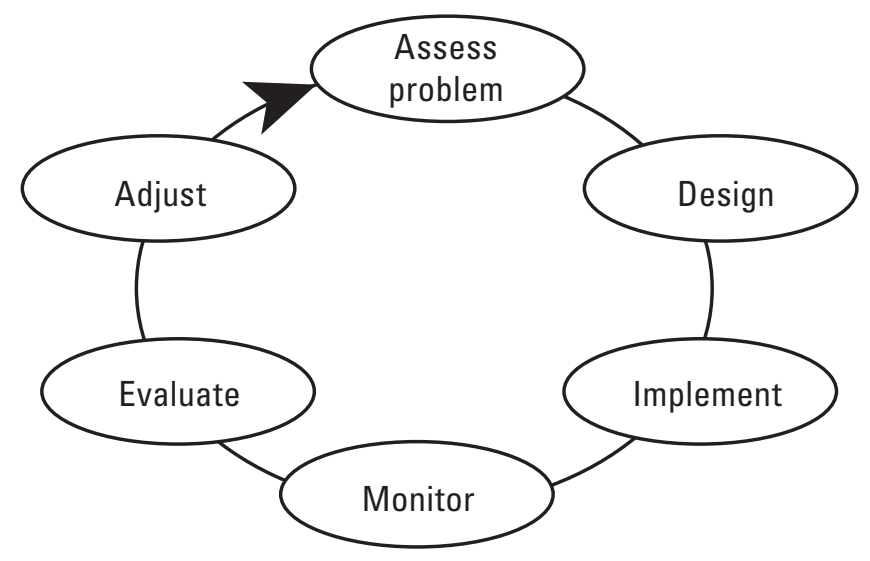

Figure 1. The adaptive management cycle (modified from Williams and others, 2009). 


\section{Purpose and Scope}

This report has three major objectives. The first is to provide a summary of the results from the first year of coordinated FLaSH studies and monitoring. Because many of the fall 2011 studies included time-intensive sample analyses, data processing, and data analysis steps, the report also documents the status of ongoing study elements that were not completed in time to provide results for this report. The second major objective is to provide a synthesis of the results, to determine whether the results of the FLaSH studies and other ongoing research and monitoring programs support the hypotheses fundamental to the fall low-salinity habitat component of the RPA as set forth in the AMP (U.S. Bureau of Reclamation, 2012, and "Background" section of this report). The final major objective is to begin to put the results from the FLaSH studies into context within the larger body of knowledge about the SFE (fig. 2), particularly the upper SFE, including the Sacramento-San Joaquin Delta (Delta) and Suisun Bay and associated embayments (Suisun region; fig. 3). Results also need to be evaluated within the context of both intra-annual and inter-annual conditions and processes. For example, even if fall conditions appeared ideal, it would be unrealistic to expect an increase in the fall delta smelt population if conditions for spawning were exceptionally poor during the preceding spring. For this reason, we specifically included 2010, the calendar year before the first year of the FLaSH investigation. We also considered 2005-2006 because 2006 was the most recent wet year prior to the FLaSH investigation. In addition, as part of data integration and assessment in this report, new areas of interest warranting study are identified, and problems with previously implemented studies recognized, if any. This report notes areas where improvement is needed and identifies additional data needs for fully understanding the efficacy of the fall low-salinity habitat component of the RPA. This report does not recommend which improvements or new studies should be undertaken by the responsible management agencies; however, the report aims to provide a sound basis for making such decisions.

The overall scope of this report is broad; however, the focus is on the low-salinity zone (LSZ) and delta smelt LSH. Because FLaSH is focused on delta smelt, the LSZ is defined as the area of the upper SFE where salinity ranges from 1 to 6 . Generally, this is considered the optimal salinity range for delta smelt (Bennett, 2005), although the fish also are found outside of this core range (Feyrer and others, 2007; Kimmerer and others, 2009; Sommer and others, 2011b). Reference to the LSZ is specific to the area of the estuary with salinity of 1 to 6 , although the concept of LSH includes many properties in addition to salinity that characterize the environment supporting delta smelt. Clearly, there are no physical barriers between the LSZ and areas with lesser or greater salinity.
Indeed, exchange of energy, organic and inorganic constituents, and organisms between the LSZ and areas of lesser and greater salinity could be critical to the productivity of LSH. The concept of habitat clearly includes all such exchanges and their effect on other components of the environment. When not considered in the context of delta smelt, we refer to the LSZ rather than LSH. This is important because other organisms have different requirements for salinity and other habitat components, and their optima need not correspond with those of delta smelt.

Because the FLaSH investigation was implemented in fall 2011, that period is the focus of this report. However, IEP monitoring and studies, as well as other studies, have been ongoing in the SFE for many years, providing the opportunity to put the $2011 \mathrm{FLaSH}$ studies into a broader temporal context. In fact, this broad perspective is likely to be critical to understanding how management of fall LSH can contribute to the protection and recovery of delta smelt. This report represents the first step in addressing this broader scope. Although the AMP focuses on the fall because the management action of interest takes place in the fall, future reports could consider the entire annual life cycle of delta smelt so that the interactive effects of other seasons can be understood. A more complete integration of life stages and seasonal effects in future reports, if the FLaSH investigation continues, would provide an improved understanding of the key factors influencing delta smelt populations. As already noted, we specifically focus on fall 2006 for comparison with fall 2011. The 2 years were both considered wet years, but there was not a comparable increase in the delta smelt population index in 2006 as in 2011 (fig. 4). We also include the antecedent year in both cases to allow assessment of how such conditions could have affected the observed results. We also note that the results of the FLaSH studies are important for other fish populations besides delta smelt and will broaden our understanding of the entire estuary. This broader scope will be addressed as part of a separate, but related, effort undertaken by the IEP Management, Analysis, and Synthesis Team (MAST).

\section{Background}

\section{Study Area}

The SFE (fig. 2) is the largest estuary on the west coast of North America, and it has been characterized as one of the best studied estuaries in the world (for example, Conomos, 1979; Hollibaugh, 1996; Feyrer and others, 2004). Like other estuaries around the world, the SFE has been highly modified by human development and extraction of resources (Lotze and others, 2006). The most notable changes are the loss of wetlands, inputs of contaminant, alterations of hydrodynamics 


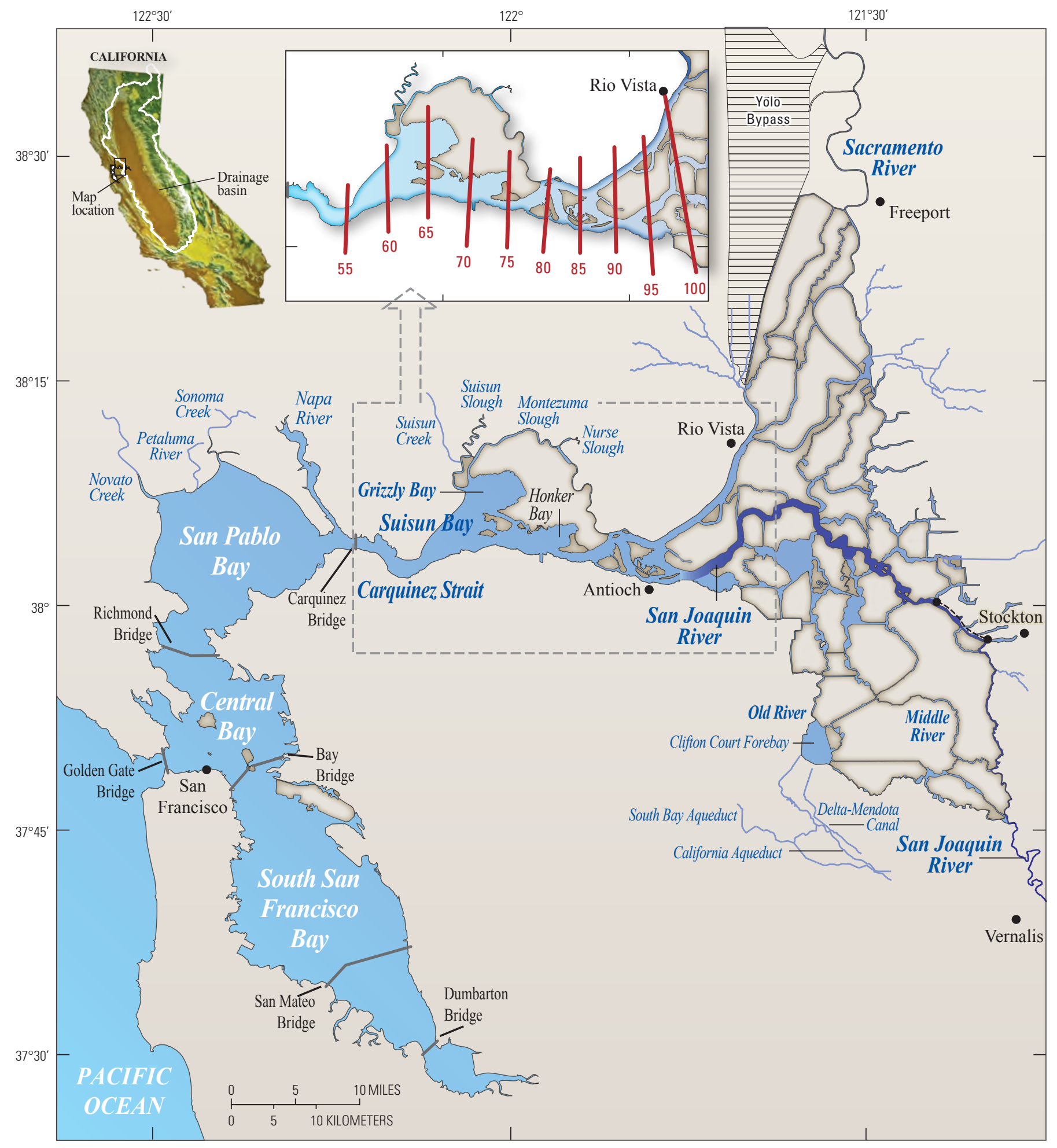

Jeanne Dileo, USGS, Menlo Park

\section{EXPLANATION}

--- inset of Suisun Bay and the western Delta

Locations corresponding to different values of $\mathrm{X} 2$

Figure 2. San Francisco Bay Estuary. Also shown are locations corresponding to different values of $X 2$, which is the horizontal distance in kilometers from the Golden Gate up the axis of the estuary to where tidally averaged near-bottom salinity is 2 (adapted from Jassby and others, 1995). 


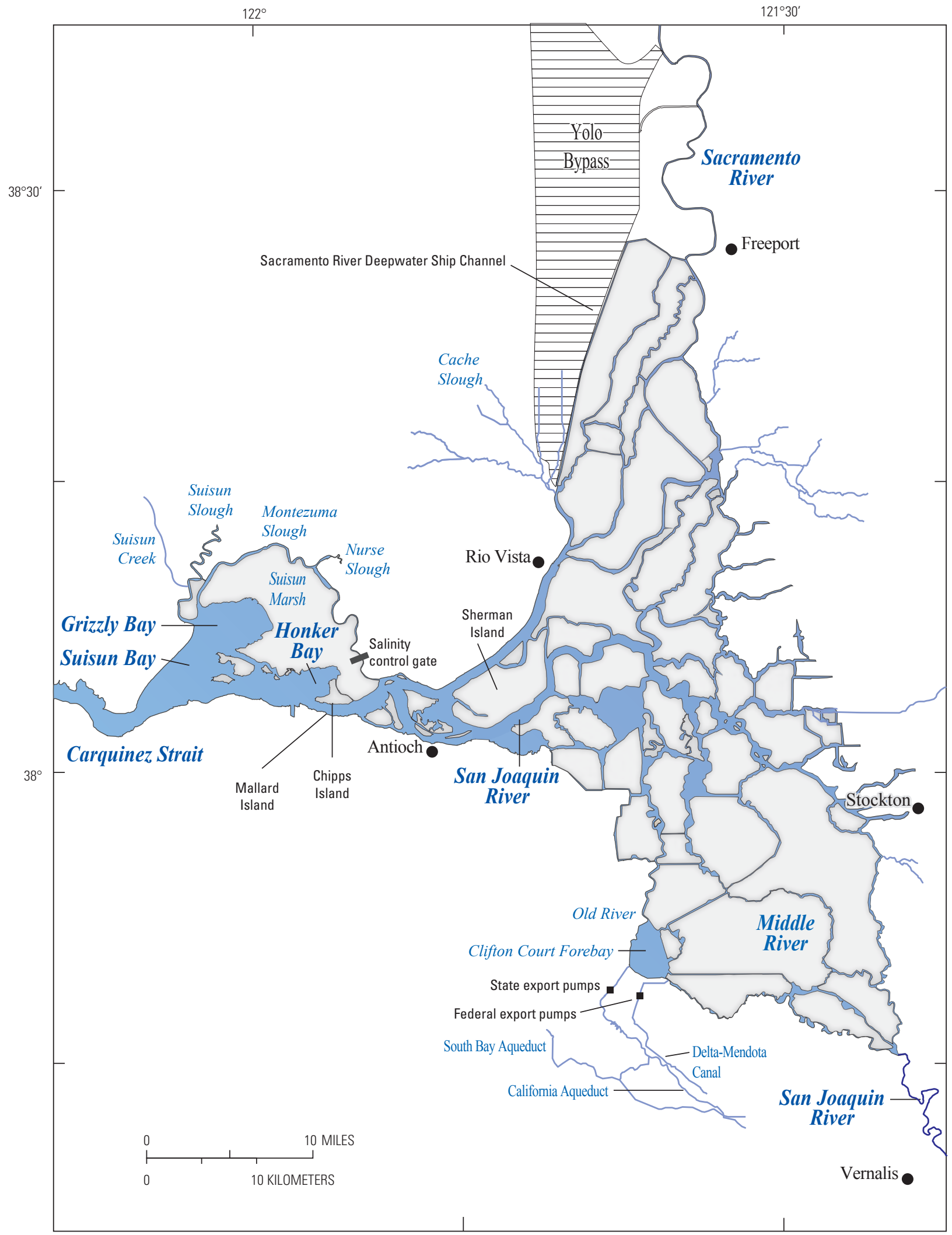

Modified from fig. 2 (Jeanne Dileo, USGS, Menlo Park) by Larry Brown

Figure 3. Sacramento-San Joaquin Delta, Suisun Bay, and associated areas. 


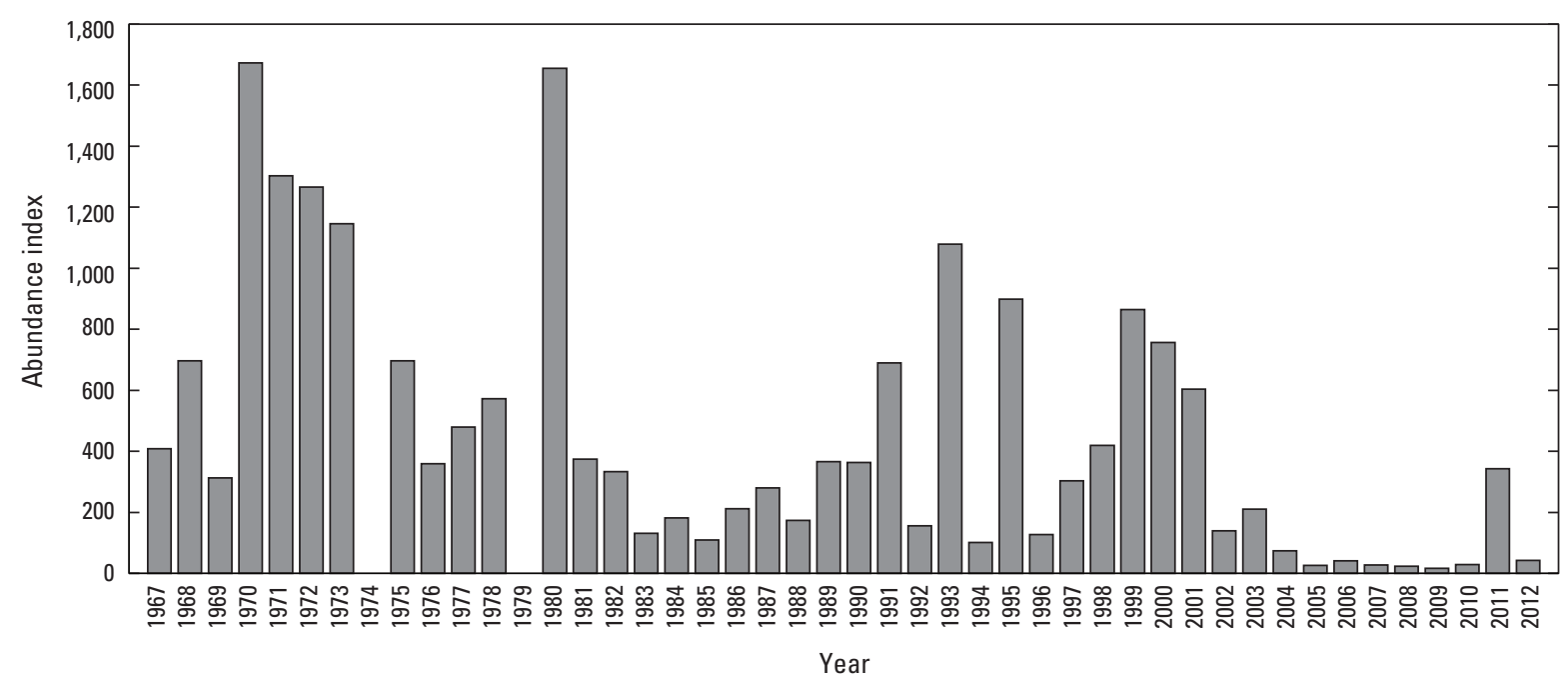

Figure 4. Delta smelt abundance index from the fall midwater-trawl survey (appendix 4). The survey was not done in 1974 or 1979.

for diversion of water, and both accidental and deliberate introductions of species (Bennett and Moyle, 1996; Brown and Moyle, 2005; Baxter and others, 2010; National Research Council, 2012). These changes and others have been implicated in declines of terrestrial and aquatic resources, including fishes. Many of these anthropogenic changes took place before the advent of modern regulations and management, when the primary focus of resource development was providing human benefits.

This report focuses on the upper SFE, principally the Delta and Suisun region (fig. 3). Historically, the northern portion of the Delta was dominated by the Sacramento River and associated floodplains, flood basins, low natural levees, and seasonal and permanent wetlands (Whipple and others, 2012). The southern portion of the Delta was dominated by the smaller San Joaquin River, associated distributary channels, and dead-end sloughs. As development progressed in the Delta, higher levees were constructed to protect farmlands. Formerly isolated larger channels were connected, while many smaller channels were disconnected from historic channel networks. Deep new channels were dredged to facilitate shipping to and from the ports of Stockton and Sacramento. Large-scale water development, primarily the CVP and SWP, resulted in further changes, primarily the installation and operation of large water-diversion facilities in the southern Delta (fig. 3).

The current configuration of the Delta includes a complex network of interconnected channels between leveed islands (fig. 3). A few such islands have flooded, leaving pockets of open water within the Delta. Most of the channels are relatively shallow, except for the dredged, deepwater ship channel in the San Joaquin River to the Port of Stockton and a similar channel in the Sacramento River to the Port of Sacramento (Sacramento River deepwater ship channel, SRDWSC). The SRDWSC splits from the main Sacramento River just upstream of the town of Rio Vista and follows the lower portion of Cache Slough north, through the Yolo Basin, to the port (fig. 3). Cache Slough continues northwest and is associated with Liberty Island, which is now flooded, and several tributary creeks and sloughs; it also serves as the connection between the Yolo Bypass and the Sacramento River (fig. 2). The Yolo Bypass is a flood bypass located in the historical Yolo flood basin (Whipple and others, 2012). It diverts high Sacramento River flows associated with winter storms around the City of Sacramento and also provides important floodplain habitat for Chinook salmon, splittail, and other native fishes (Sommer and others, 2001; Sommer and others, 2003; Feyrer and others, 2006).

The region where the Sacramento and San Joaquin rivers join (confluence region) was once dominated by sinuous sloughs and low, tidally inundated islands and wetlands (Whipple and others, 2012). Today, the waterways of this region are disconnected from most of the former wetland areas and are generally deep and uniform in bathymetry with relatively narrow channels compared to the Suisun region (fig. 3). The Suisun region includes Suisun, Grizzly, and Little Honker bays. This region is also connected to Suisun Marsh, to the north, through Suisun and Montezuma sloughs. The Suisun region then connects to San Pablo and San Francisco bays through Carquinez Strait. 


\section{Delta Smelt}

Early information on the delta smelt population was collected as part of sampling and monitoring programs related to water development and striped bass, Morone saxatilis, management (Erkkila and others, 1950; Radtke, 1966; Stevens and Miller, 1983). Striped bass is an exotic species but is also a popular sport fish that supported an economically valuable sport fishing industry when development of the CVP and SWP began (Moyle, 2002). These early monitoring efforts, subsequently consolidated with other activities under the auspices of the IEP, provided sufficient information on the decline of delta smelt (Moyle and others, 1992) to support a petition for listing under the Federal Endangered Species Act. The delta smelt was listed as threatened under the Federal Endangered Species Act in 1993 (U.S. Fish and Wildlife Service, 1993). Reclassification from threatened to endangered was determined to be warranted, but was precluded by other higher priority listing actions in 2010 (U.S. Fish and Wildlife Service, 2010b). The species was listed as threatened under the state endangered species statute in 1993, and the status was changed from threatened to endangered in 2009 (California Fish and Game Commission, 2009). Subsequent declines in the delta smelt population, in concert with three other pelagic fishes (fig. 5), increased concern for avoiding jeopardy and achieving recovery of delta smelt. These declines are often referred to as the pelagic organism decline (POD; Sommer and others, 2007; Baxter and others, 2008, 2010).

The delta smelt is endemic to the SFE and is the most estuary-dependent of the native fish species (Moyle and others, 1992; Bennett, 2005). Delta smelt are slender-bodied fish typically reaching 60-70 millimeters $(\mathrm{mm})$ standard length (SL) with a maximum size of about 120-mm SL. Delta smelt feed primarily on planktonic copepods, mysids, amphipods, and cladocerans. Most delta smelt complete the majority of their life cycle in the LSZ of the upper estuary and use the freshwater portions of the upper estuary primarily for spawning and rearing of larval and early post-larval fish (fig. 6; Dege and Brown, 2004; Bennett, 2005). The continued global existence of the species is dependent upon its ability to successfully grow, develop, survive, and reproduce in the SFE. The current range of juvenile and sub-adult delta smelt includes the Cache Slough area, the SRDWSC and Sacramento River in the northern Delta, the confluence region in the western Delta, and the Suisun region (fig. 7). Historically, juvenile and sub-adult delta smelt also inhabited the central and southern Delta during the summer and fall months (Erkkila and others, 1950), but they are now rare in those areas during that period (Bennett, 2005; Nobriga and others, 2008; Sommer and others, 2011b). Juvenile and sub-adult delta smelt live mostly in the LSZ and are most abundant at salinity 1-2 (Bennett, 2005; Sommer and others, 2011b). While delta smelt can complete their entire life cycle in fresh water, the bulk of the juvenile and subadult delta smelt population is associated with the LSZ, indicating that salinities of 1-6 are most favorable for the physiology of that life stage. Delta smelt are generally not found above salinity 14 (Swanson and others, 2000); however, recent studies have shown that, under laboratory conditions, Delta Smelt can survive in seawater (Komoroske and others, 2014). For comparison, seawater is generally salinity 33 near the California coast. The location of the LSZ in the estuary is indexed by $\mathrm{X} 2$, which is the horizontal distance in kilometers from the Golden Gate up the axis of the estuary to where tidally averaged near-bottom salinity is 2 (Jassby and others, 1995).

Upstream migration of maturing adults generally begins in the late fall or early winter, and most spawning takes place from early April through mid-May (Bennett, 2005; Sommer and others, 2011b). Most larval delta smelt move downstream with the tides until they reach favorable rearing habitat in the LSZ (Dege and Brown, 2004). As noted earlier, some fish remain in upstream reaches year round, including the Cache Slough region, the SRDWSC, and the central Delta region (Sommer and others 2011b), although the contribution of these fish to population production is unknown. A very small percentage of delta smelt survive into a second year and potentially spawn in one or both years (Bennett, 2005).

Summer physical habitat has been described by Nobriga and others (2008); the summer (June-July) distribution of delta smelt is determined by areas that have appropriate salinity, but also have appropriate turbidity and temperatures. Similarly, Feyrer and others $(2007,2010)$ found the distribution of delta smelt to be associated with salinity and turbidity during fall months (September through mid-December). Kimmerer and others (2009), Sommer and others (2011b), and Merz and others (2011) expanded on these studies by examining the habitat associations and geographic distribution patterns of delta smelt for each of the major IEP fish-monitoring surveys. Overall, these studies demonstrated that most delta smelt reside in the LSZ in the summer and fall, with a center of distribution near the salinity 2 isohaline, but move upstream during winter and spring months for spawning and early development in freshwater.

The year-round presence of delta smelt in the Cache Slough and SRDWSC (fig. 3) was unexpected on the basis of previous work, and it was unknown whether such fish constituted a separate, self-sustaining population of fish or a group of fish expressing natural variability within the delta smelt life history (Sommer and others 2011b). Fisch (2011) determined that individuals collected from this region were not genetically unique compared to delta smelt captured from other regions of the system; rather, there is a single, panmictic delta smelt population in the estuary. Although not conclusive, this finding indicates that freshwater resident delta smelt do not form a separate, self-sustaining population. Rather, it seems likely that the life history of delta smelt includes the ability to rear in fresh water if other factors are favorable; however, the absence of delta smelt from riverine non-tidal habitats upstream of the Delta indicates that there are limits on freshwater residence. 


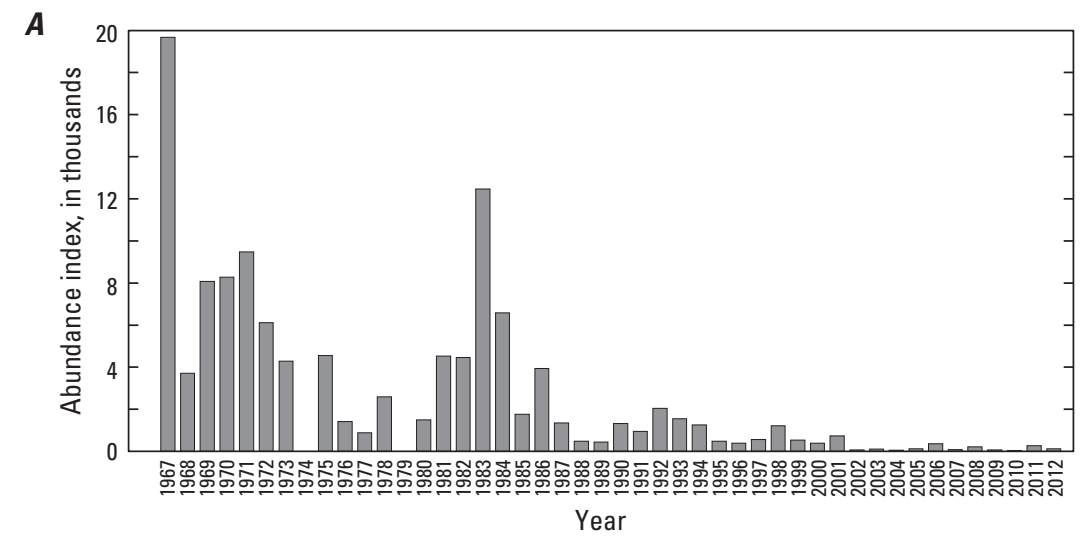

B

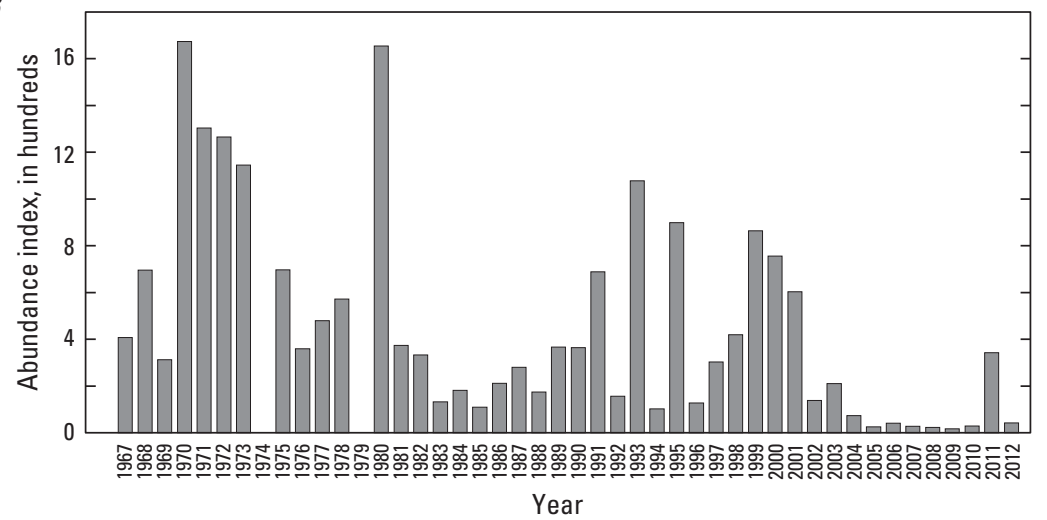

C

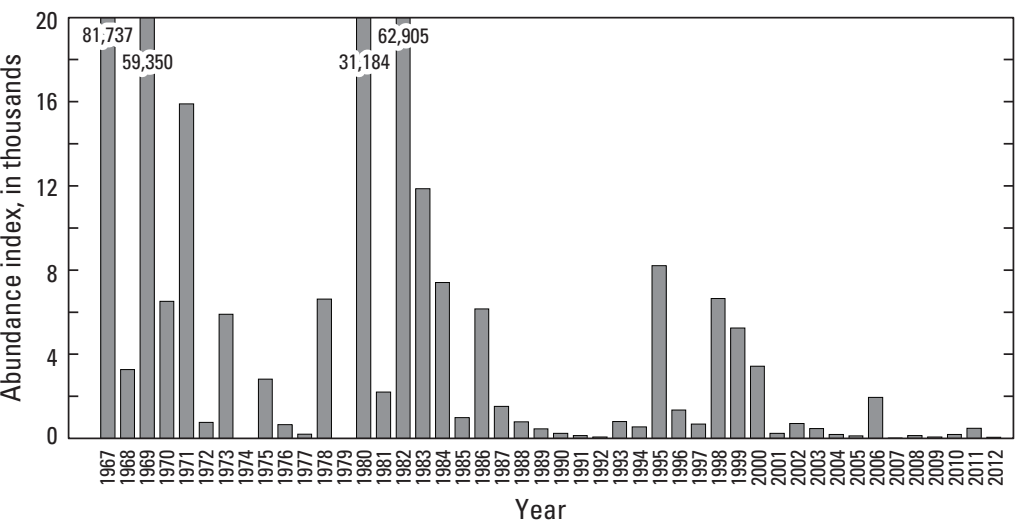

D

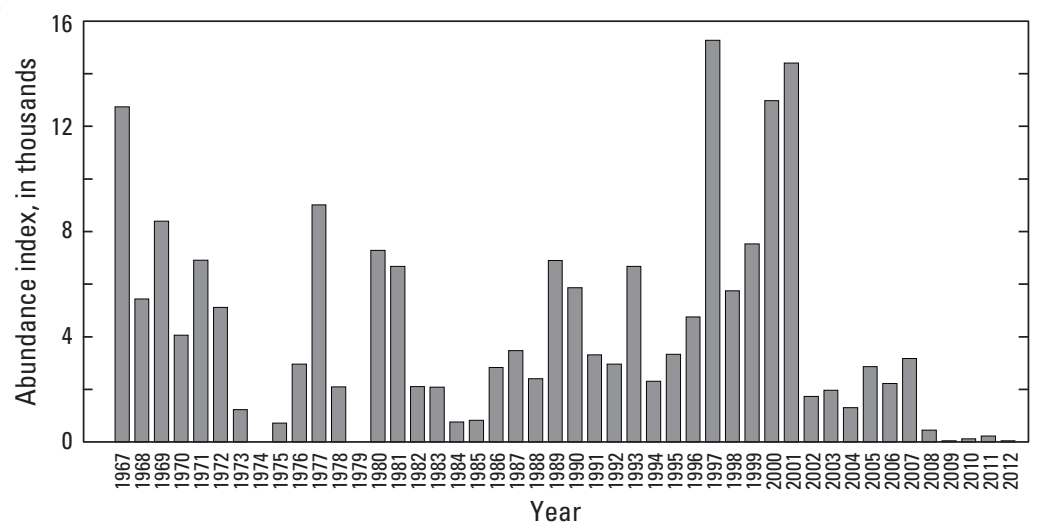

Figure 5. Trends in abundance indices for four pelagic fishes from 1967 to 2012 based on the fall midwater-trawl survey, a California Department of Fish and Wildlife survey that samples the upper San Francisco Estuary for $A$, striped bass; $B$, delta smelt; $C$, longfin smelt; and $D$, threadfin shad (appendix 4). There was no sampling in 1974 or 1979. Note that the $y$-axis for longfin smelt represents only the lower 25 percent of its abundance range to more clearly portray the lower abundance range. 


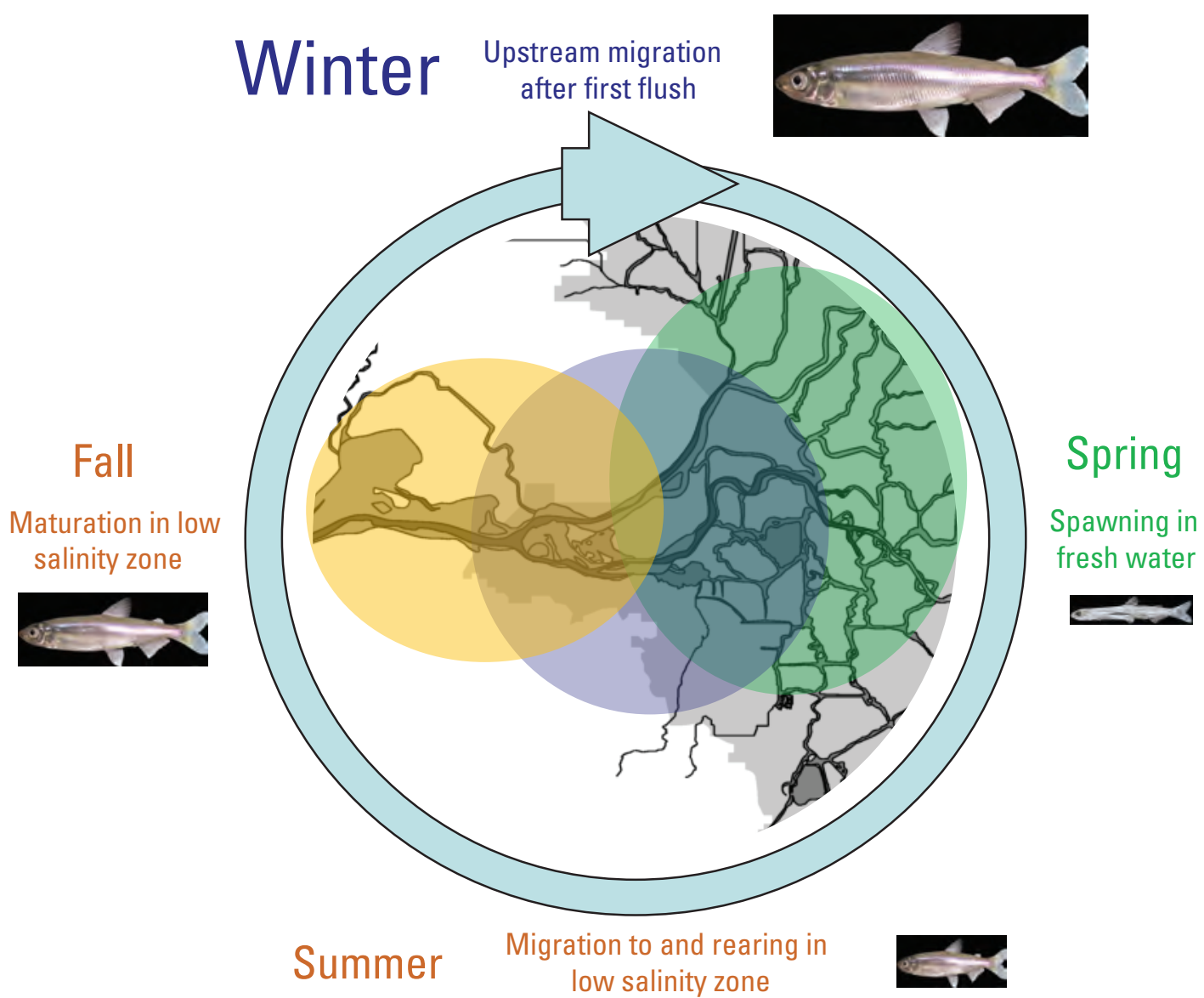

Figure 6. Simple conceptual diagram of the delta smelt annual life cycle (modified from Bennett, 2005).
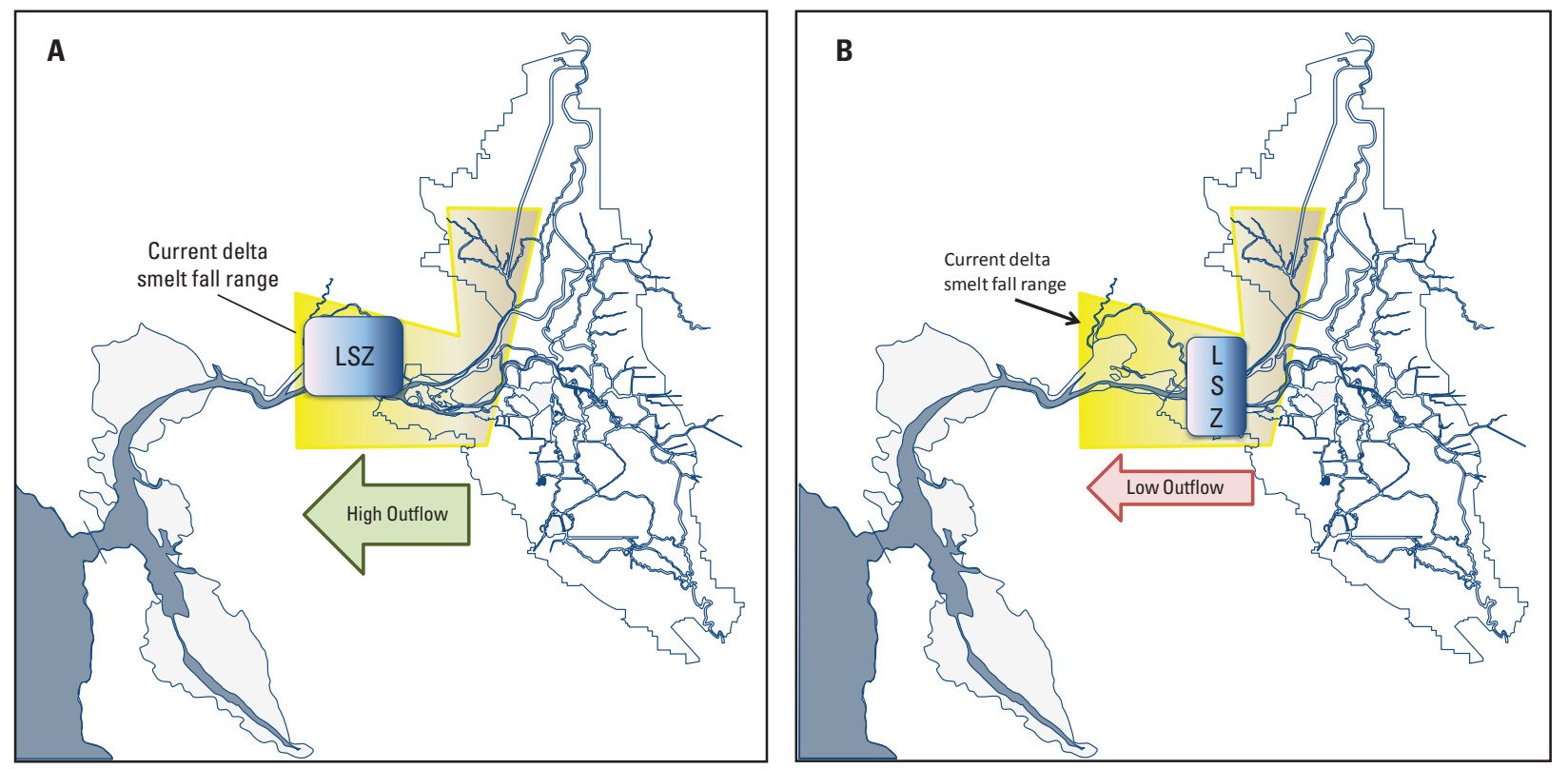

Figure 7. Location of the fall low-salinity zone (LSZ), where most delta smelt are found: $A$, under high outflow conditions, when the LSZ overlaps the Suisun region, and $B$, under low outflow conditions, when the LSZ overlaps the river confluence (from U.S. Bureau of Reclamation, 2012). 
Although abundance of delta smelt has been highly variable, there is a demonstrable long-term decline in abundance (fig. 4; Manly and Chotkowski, 2006; Sommer and others, 2007; U.S. Fish and Wildlife Service, 2008; Thomson and others, 2010). The decline spans the entire period of survey records from the completion of the major reservoirs in the Central Valley through the POD (Baxter and others, 2010). Statistical analyses confirm that a step decline in pelagic fish abundance marks the transition to the POD period (Manly and Chotkowski, 2006; Moyle and Bennett, 2008; Mac Nally and others, 2010; Moyle and others, 2010; Thomson and others, 2010) and could signal a rapid ecological regime shift in the upper estuary (Baxter and others, 2010; Moyle and others, 2010). The decline of delta smelt has been intensively studied as part of an IEP effort to understand the POD (Sommer and others, 2007; Baxter and others, 2010). The POD investigators have concluded that the decline has likely been caused by the interactive effects of several causes, including both changes in physical habitat (for example, salinity and turbidity fields) and the biotic habitat (that is, food web). This conclusion was generally supported by a recent independent review panel (National Research Council, 2012).

\section{Conceptual Models}

Conceptual models are formalized versions of mental models that are communicated to others verbally and graphically. Ecologists use them to tell stories of "how ecosystems work" and to explore how human actions and other drivers change ecosystems. They usually consist of a combination of narrative text and graphical illustrations about ecosystem components and the relationships among them that summarize hypotheses about ecosystem processes and outcomes. There have been a number of conceptual models applied to the SFE over time. In this section, we review some of the more recent conceptual models and how those models have evolved and contributed to the conceptual model in the AMP (U.S. Bureau of Reclamation, 2012), which serves as the basis for the FLaSH studies and predictions evaluated in this report. Results from monitoring activities and FLaSH studies in 2011 will inform conceptual-model refinement for future years. We acknowledge that the conceptual models presented in this report are not exhaustive, and other conceptual models are certainly possible. For example, Glibert and others (2011) stress the importance of nutrients and nutrient ratios to phytoplankton, and of the bottom-up effects of phytoplankton composition and production on upper trophic levels. Miller and others (2012) suggest a hierarchical conceptual model for consideration of factors with direct and indirect effects on delta smelt.

Adaptive management calls for the use of quantitative models when available. A wide variety of statistical approaches have been applied to studies of delta smelt in the SFE. Various forms of regression- and multiple-regression models have been widely applied (for example, Manly and
Chotkowski, 2006; Feyrer and others, 2010; Miller and others, 2012). General additive models have been used to identify important abiotic habitat factors (Feyrer and other, 2007; Nobriga and others, 2008). Additional models include Bayesian change-point models (Thomson and others, 2010) and a Bayesian-based multivariate autoregressive model of delta smelt fall abundance (Mac Nally and others, 2010). Importantly, these studies differed widely in methodology and objectives and rarely evaluated the same environmental factors. As a result, they often reached different conclusions about the direct or indirect importance of the same environmental factor on the species.

Life-cycle models that quantify and integrate many aspects of the conceptual models are currently under development and are expected to eventually provide results that will help guide fall-outflow management and other management actions in the coming years. Maunder and Deriso (2011) developed a statistical state-space multistage life-cycle model to evaluate the importance of various factors on different life stages of delta smelt. Another life-cycle model, currently under development, has a state-space structure similar to Maunder and Deriso (2011). It differs in three critical ways: (1) the model is spatially explicit, so that management actions thought to have particular local effects can be assessed; (2) the temporal resolution is finer, a monthly time step; and (3) data from more fish surveys are being used to fit the model (Ken Newman, U.S. Fish and Wildlife Service, written commun., 2012). A numerical simulation model has also been developed by a group led by Kenneth Rose (Louisiana State University) and Wim Kimmerer (California State University, San Francisco) (Rose and others, 2013a, 2013b). These three models could be useful for evaluating hypothesized associations in conceptual models as the FLaSH AMP proceeds.

Kimmerer (2004) summarized many of the earlier conceptual models on the physical aspects of the SFE and how they were believed to affect the movement and ecology of fishes. Simply stated, the earliest conceptual models of the estuary assumed unidirectional riverine flow with a classical estuarine entrapment zone, which supported high levels of biological production. The early models of fish populations emphasized delta outflow and diversions as driving factors (Stevens, 1977; Stevens and Miller, 1983).

As knowledge of the upper SFE increased, it was recognized that the interactions of tides, bathymetry, river flow, channel configuration, and diversions were important to generating the physical conditions that affect fishes at different life stages. Ecologically, continued invasions of non-indigenous species into the SFE were shown to have important effects on the food web. The effects of the invasive clam Potamocorbula amurensis were particularly important because its high rate of filter feeding (grazing rate) and tolerance of brackish water enabled it to remove a large proportion of phytoplankton biomass and early life stages of zooplankton from the water column in and near the LSZ (Alpine and Cloern, 1992; Kimmerer and others, 1994; Kimmerer and Orsi, 1996). 
This growing body of knowledge provided the backdrop for the next major conceptual model based on X2. The intent of using X2 as an index was to develop an easily measured, policy-relevant indicator with ecological significance for multiple species and processes (Jassby and others, 1995). In this context, the position of the LSZ as indexed by $\mathrm{X} 2$ is more easily measured than delta outflow. Relative abundance indices of many estuarine resources do show statistically significant linear relationships with spring X2, but not delta smelt (Kimmerer, 2002a, 2002b).

The recognition of the decline of four pelagic fish populations, commonly referred to as the POD, resulted in the development of a new set of conceptual models. These models evolved into the AMP model that provided the basis for the FLaSH investigation (U.S. Bureau of Reclamation, 2012). Each of these models is briefly summarized in the following sections.

\section{Basic POD model}

The basic POD conceptual model (fig. 8), introduced in Sommer and others (2007), focuses on the four POD fish species (delta smelt, longfin smelt, age-0 striped bass, and threadfin shad) and contains four major components: (1) prior fish abundance (that is, stock-recruitment effects), which assumes that abundance history affects subsequent recruitment; (2) habitat, which assumes that the volume or surface area of aquatic habitat suitable for a species depends on characteristics of the aquatic habitat, such as estuarine water-quality variables, presence of pathogens, and toxic algal blooms; (3) top-down effects, which assume that predation and water-project entrainment affect mortality rates; and (4) bottom-up effects, which assume that consumable resources and food-web interactions affect growth and thereby survival and reproduction. Each model component contains one or more potential drivers affecting the POD fishes. It is important to emphasize several points about the POD conceptual model. The habitat box is shown to overlap the top-down and bottom-up boxes (fig. 8). This is intended to show that changes in habitat not only affect the species of interest but also affect their predators and prey. The conceptual model was at least partially designed to provide a simple vehicle for communicating information to a wide variety of stakeholders. The traditional "box and arrow" model was too complex for such general use. The text of the two recent POD reports (Baxter and others, 2008, 2010) represents the increasing knowledge about the SFE ecosystem and recognizes that habitat features could affect each of the other categories of drivers additively, antagonistically, or synergistically and, thereby, produce outcomes that are not always easily predictable.

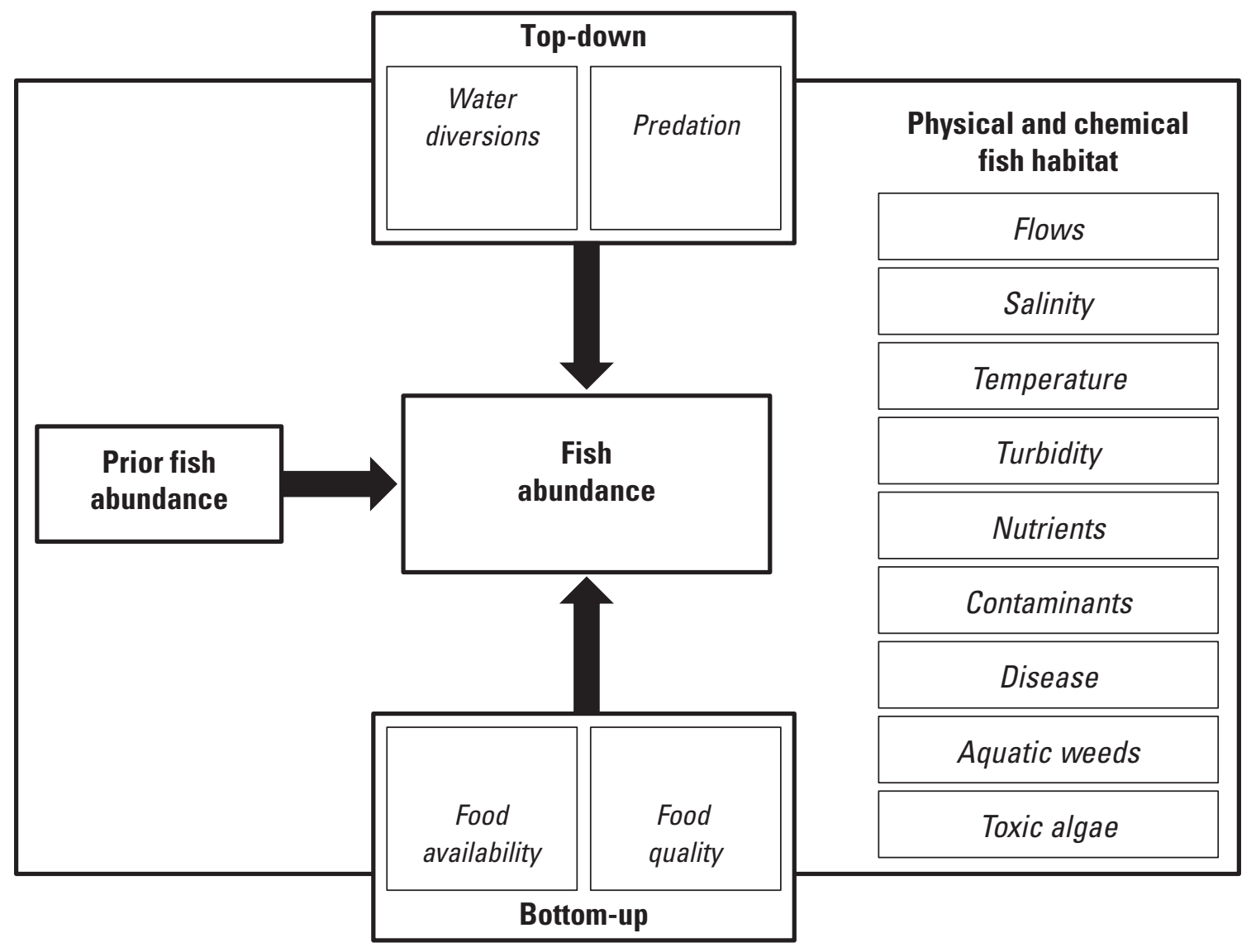

Figure 8. The basic conceptual model for the pelagic organism decline (adapted from Baxter and others, 2010). 


\section{Delta Smelt Species Model}

Because of the graphical simplicity of the basic POD model, Baxter and others (2010) also developed species-specific models for each of the POD species. These models were able to communicate differences in factors hypothesized to affect different life stages of the four POD species. The model identifies key seasonal drivers, as well as proximal causes and effects. Several concepts in the delta smelt conceptual model (fig. 9) are important to the FLaSH studies. The reduced size of spawning adults along with reduced fecundity in smaller fish affects egg supply; this was thought to be at least partially associated with warm water temperatures and reduced food in the LSZ during the summer. These conditions require that more energy goes to basic metabolic demands, instead of the growth and production of gametes. In fall, reduced habitat area was posited to affect the population through continued reduced growth and restricted egg supply rather than direct mortality (Baxter and others, 2010). Therefore, fall effects can manifest as potential limits on subsequent abundance, where the outcome depends on a variety of other seasonal factors (for example, outflow, exports, and water temperature).

\section{Regime-Shift Model}

The idea that the POD was a manifestation of a rapid and comprehensive ecological regime shift that followed a longerterm erosion of ecological resilience in the estuary was first addressed in detail by Moyle and Bennett (2008). This concept was accepted by many researchers of the SFE because it integrated various observations about changes in habitats and species in addition to changes in the pelagic habitat and the POD species (Baxter and others, 2010; Mac Nally and others, 2010; Moyle and others, 2010; Thomson and others, 2010). In other words, the conceptual model represents an ecosystem approach, which recognizes that multiple factors can have interactive effects on any individual species or process.

The conceptual model adopted by Baxter and others (2010; fig. 10) was presented as a working hypothesis for future ecosystem investigations. Changes in outflow, salinity, and turbidity are considered among the key "slow" environmental drivers in this conceptual model. In this context, outflow and salinity are viewed with respect to long-term climatic variability. Turbidity, primarily related to suspended-sediment concentration in the SFE (Ganju and others, 2007), is also

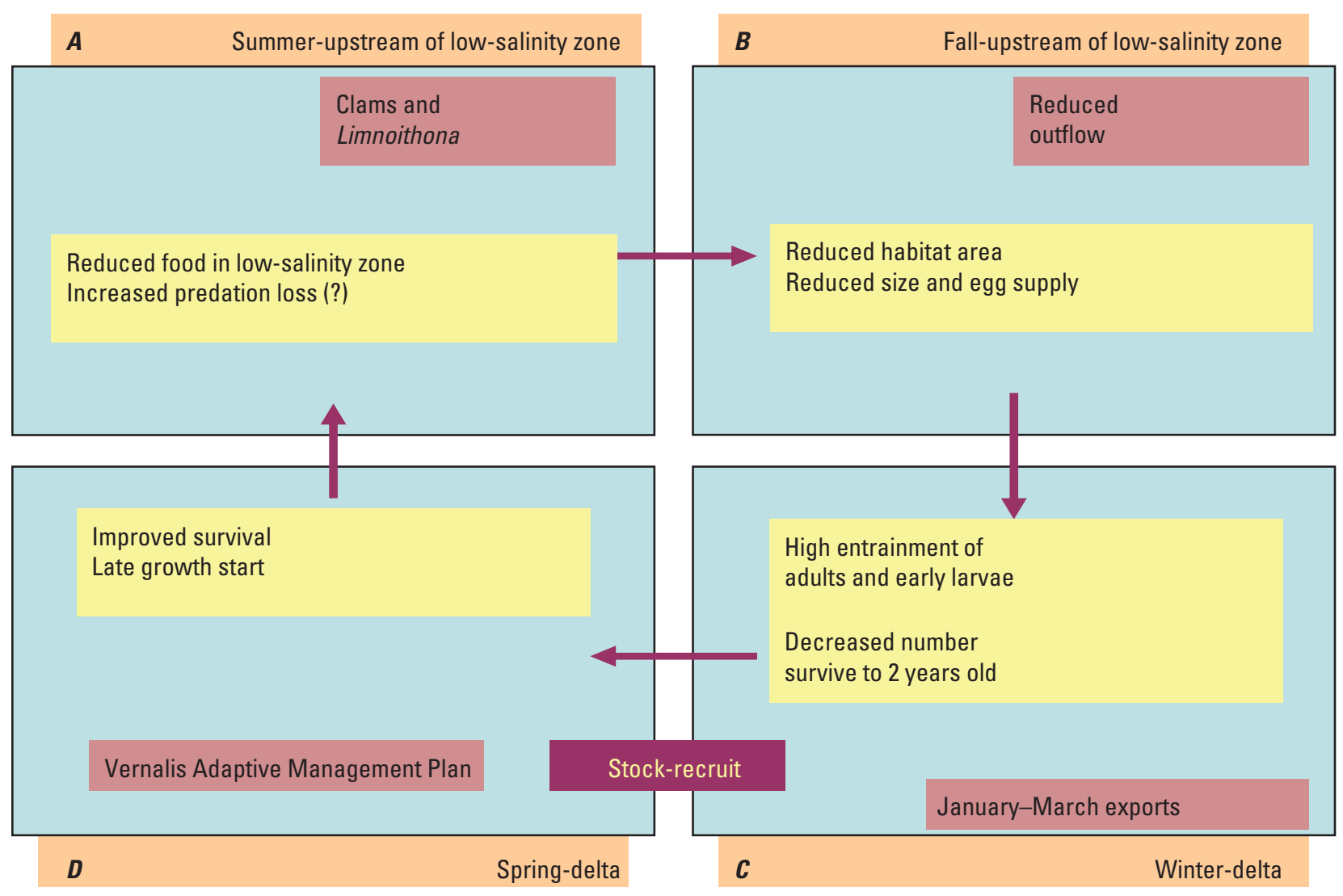

Figure 9. Delta smelt species-specific model (adapted from Baxter and others, 2010): $A$, summer conditions; $B$, fall conditions; $C$, winter conditions; and $D$, spring conditions. The model identifies key seasonal drivers in red, with proximal causes and effects in yellow. 
$\boldsymbol{A}$

\begin{tabular}{|c|c|c|}
\hline Old regime & Environmental drivers & New regime \\
\hline Variable, high & Outflow & Variable, lower \\
\hline To the west, variable & Salinity gradient & To the east, constricted \\
\hline Complex, variable & Landscape & Simplified, rigid \\
\hline Low, variable & Temperature & High, uniform \\
\hline High, variable & Turbidity & Low, less variable \\
\hline High P, low N & Nutrients & Low P, high $\mathrm{N}_{\left(\mathrm{NH}_{4}{ }^{+}\right)}$ \\
\hline Few, low & Contaminants & Many, high \\
\hline Predation, fishing & "Harvest" & Predation and entrainment \\
\hline
\end{tabular}

$B$

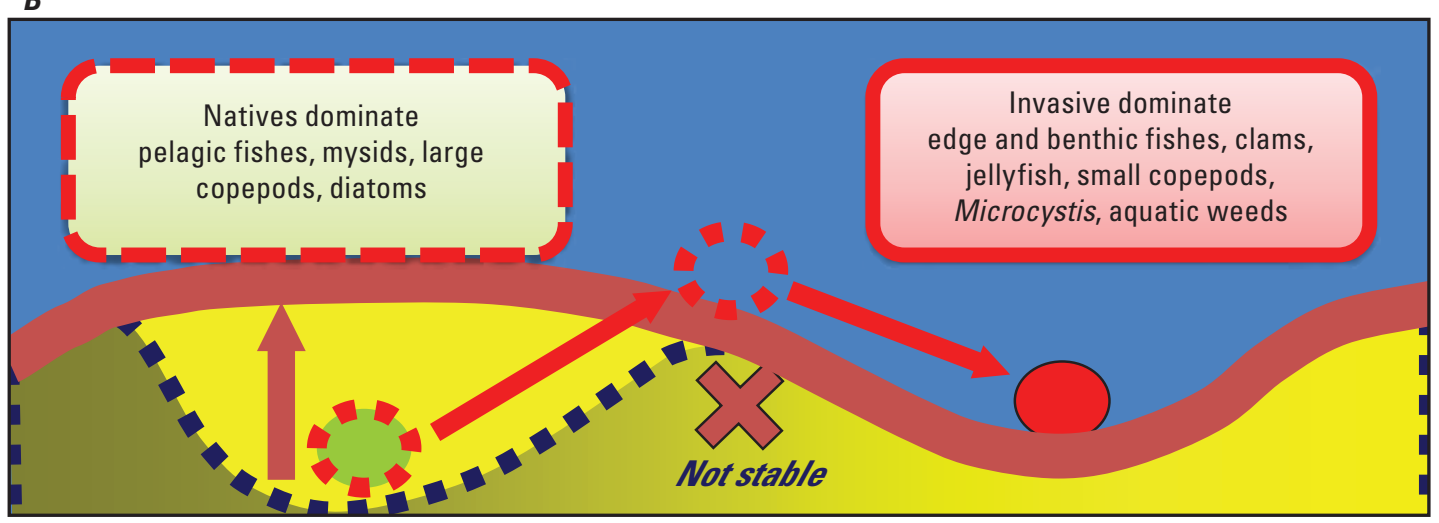

Figure 10. Regime-shift model from Baxter and others (2010). The model assumes that ecological regime shift in the Delta results from $A$, changes in environmental drivers that lead to $B$, profoundly altered biological communities. The dotted lines show the ecosystem (green ball with red dotted line) before the regime shift. The environment changes (dotted blue line moves up to solid red line) pushing the ecosystem through an unstable threshold region (red X) before the new relatively stable ecosystem (red ball) regime is established. Nutrients are $\mathrm{P}$, phosphorus; $\mathrm{N}$, nitrogen; and $\mathrm{NH}_{4}{ }^{+}$, ammonium. The background colors are for contrast only and have no particular meaning.

viewed in this longer-term climatic context. The conceptual model indicates that changes in these fundamental physical drivers, as well as the other five drivers (fig. 10), shifted the system to a state that no longer favored native species. Introduction of invasive species is also an important process in the shift.

The model indicates that a more westward (toward Suisun region) and variable (annually and seasonally) salinity gradient favors native species (such as delta smelt), while a more eastward (near the confluence region), constricted, and stable salinity gradient favors non-native and nuisance species (such as invasive clams and submerged aquatic vegetation and its associated fishes). In this context, the fall low-salinity habitat component of the RPA tends to move the LSZ to a more westward position in wetter years and to increase seasonal and interannual variability in salinity to provide improved conditions for native fishes. This conceptual model also recognizes that turbidity in Suisun Bay showed a step decline after the sediment-flushing outflow event associated with the 1997-1998 El Niño (Schoellhamer, 2011). Along with persistent high fall salinity in Suisun Bay during the POD period, this sudden clearing also could have contributed to the POD regime shift and affected delta smelt fall habitat (Baxter and others, 2010). It is important to realize that the establishment of multiple invasive species, new invasions, and ongoing human needs for resources make it difficult for the SFE ecosystem to ever fully return to its previous conditions (Moyle and Bennett, 2008; Baxter and others, 2010; Lund and others, 2010). The goal of the RPA is to improve conditions within the current regime (U.S. Bureau of Reclamation, 2012) such that conditions for delta smelt are improved, presumably with positive effects for other desirable species. Another goal is to reduce uncertainties about the fall low-salinity habitat component of the RPA through the FLaSH AMP and study. Lund and others (2010) explored some more comprehensive approaches to managing the Delta to improve the ecosystem, while maintaining human uses. 


\section{Habitat Study Group Model}

In a precursor to the FLaSH AMP, the 2010 Habitat Study Group (HSG) adaptive management plan (U.S. Fish and Wildlife Service, 2010a) adapted the POD models to address key processes associated with habitat quality and quantity for delta smelt in the fall. The position and extent of LSH, as indexed by fall X2, is envisioned as a "filter" modifying the drivers and subsequent delta smelt responses. This model represents the importance of physical habitat and its effects on delta smelt abundance, distribution, and health (fig. 11). Bottom-up and top-down drivers are included, but the exact processes involved and responses of those processes to changes in LSH are unknown, as indicated by the question marks in figure 11 . The model indicates that most of the potential effects of fall outflow are expected to involve the processes that affect the growth and survival of juvenile and fecundity of adult delta smelt. The HSG conceptual model was not developed further, although several areas of research identified during the development of the model were subsequently pursued. The HSG AMP was integrated into the FLaSH AMP when the decision was made to implement the RPA.

\section{Estuarine Habitats Model}

The estuarine habitats conceptual model (fig. 12) was an important element in developing the new conceptual model to guide the FLaSH AMP. The general model, developed by Peterson (2003), established a theoretical framework for many of the ideas included in earlier conceptual models related to the position of the LSZ in the estuary and the interactions of the LSZ with delta smelt and other organisms. The Peterson (2003) model proposed an ecosystem-based view of estuarine habitats. A modified version of this conceptual framework was presented by the Environmental Flows Group (Moyle and others, 2010) to the State Water Resources Control Board (SWRCB) in the SWRCB proceedings to develop flow recommendations for the Delta. This group included regional technical experts, including several members of the IEP POD team, and their view of estuarine habitats was reflected in the SWRCB's final report (State Water Resources Control Board, 2010). In this framework, the environment of an estuary consists of two integral parts:

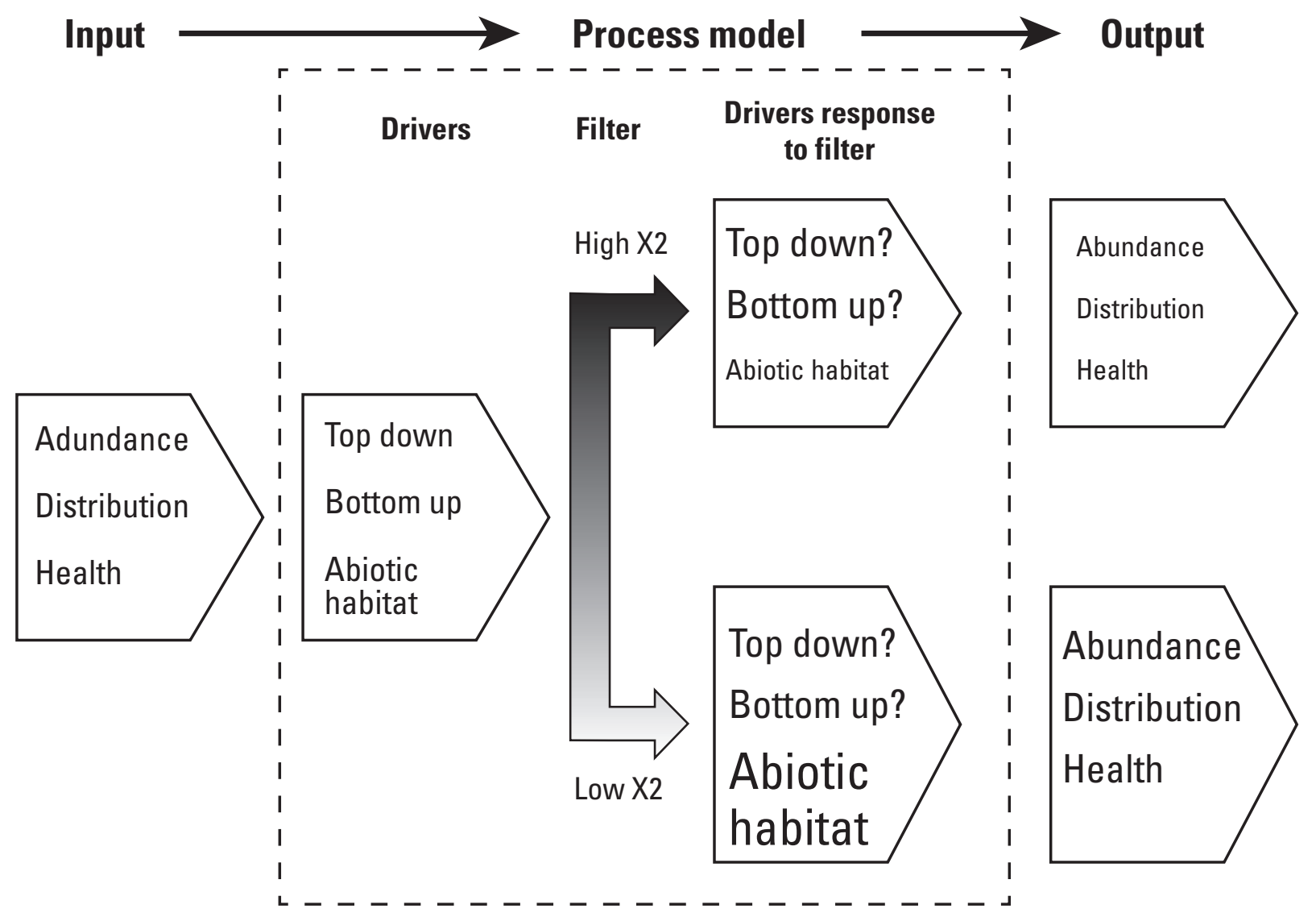

Figure 11. Habitat Study Group model of effects of fall low-salinity habitat position, as indexed by X2 (the horizontal distance in kilometers from the Golden Gate up the axis of the estuary to where tidally averaged near-bottom salinity is 2), on delta smelt through changes in habitat quantity and quality. The position and extent of fall low-salinity habitat affects the expected outcomes for the same drivers either directly or indirectly (from U.S. Bureau of Reclamation, 2012). Different-sized fonts indicate expected qualitative differences between $\mathrm{X} 2$ and expected driver responses and measures of delta smelt population response (abundance, distribution, health). 


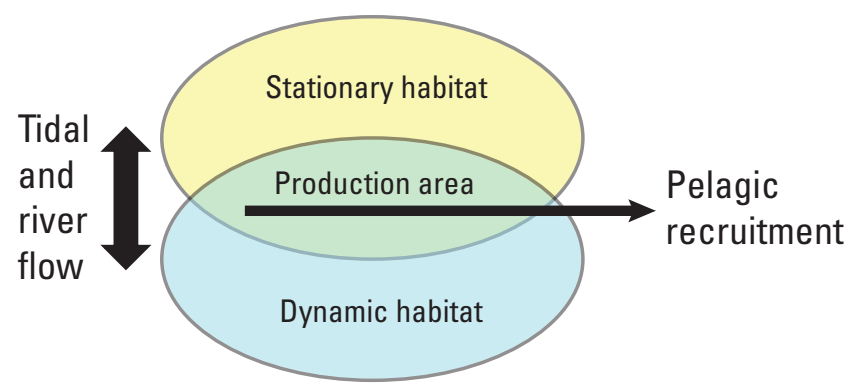

Figure 12. Illustration showing estuarine habitat conceptual model (modified from Peterson, 2003).

- A stationary topography with distinct physical features that produce different levels of support and stress for organisms in the estuary.

- A dynamic regime of flows and salinities where organisms passively transported by flow or actively searching for a suitable salinity are exposed to the different levels of support and stress that are fixed in space in the stationary topography.

Together, these stationary and dynamic habitat features are hypothesized to control the survival, health, growth, fecundity, and, ultimately, the reproductive success of estuarine pelagic species (fig. 12).

For the Delta, this dynamic and interactive view of estuarine ecology captured several important elements. First, the interactions of outflow, and subsequent position of the LSZ (dynamic habitat), with the physical configuration of the Delta (stationary habitat) and anticipated outcomes for estuarine organisms (for example, Jassby and others, 1995; recruitment), are clearly a reflection of concepts from earlier conceptual models. Second, variability in the dynamic habitat in daily, seasonal, annual, and longer time scales produces habitat complexity and variability, which can be important in promoting species diversity. The second idea is consistent with the concepts regarding regime shift.

Moyle and others (2010) highlighted the extensive literature documenting the significant roles of habitat complexity and variability in promoting abundance, diversity, and persistence of species in a wide array of ecosystems. They stressed the importance of both predictable and stochastic physical disturbances, timing and extent of resource availability, as well as the degree of connectivity among habitat patches relative to the abilities of organisms to move between them. Further, they recognized that landscapes are not stable in their configurations through time, and environmental fluctuations generally increase the duration and frequency of connections among patches of different kinds of habitat. The implication of variability is that different processes interact at various scales in space and time, with the result that more species are present than would be in a hypothetical uniform landscape. They concluded that ecological theory strongly supports the idea that an estuarine landscape that is heterogeneous in salinity and geometry (depth, the configuration of flooded islands, tidal sloughs, floodplains, and so on) is most likely to have high overall productivity, high species richness, and high abundances of desired species (Moyle and others, 2010).

\section{A New Conceptual Model for Fall Low-Salinity Habitat}

The new conceptual model, developed by the U.S. Bureau of Reclamation (2012) to guide the FLaSH AMP (fig. 13), and thus the FLaSH studies, combines and highlights aspects of previous models pertaining to the effects of falloutflow management on delta smelt with the estuarine habitat conceptual model (fig. 12). The new conceptual model offers a way to describe existing knowledge and to identify what is known and what remains uncertain about abiotic and biotic components of delta smelt fall habitat under different outflow scenarios. The model includes interacting dynamic and stationary (geographically fixed) abiotic habitat components that determine the characteristics of LSH. These conditions interact with dynamic biotic habitat components of food and predators. The combined abiotic and biotic habitats determine the quantity and quality of fall LSH for delta smelt, which are expressed through delta smelt population responses. In the AMP and this report, we use the new conceptual model in the context of understanding delta smelt, their predators, and their food resources in the river channels of the western Delta and in the Suisun region in the fall. The new conceptual model could be applied to other species to evaluate whether actions to improve habitat for delta smelt could have unanticipated consequences for other species. The basic approach could also be applied to other seasons to address all life stages of delta smelt and other species of interest.

The stationary abiotic habitat components (fig. 13) are associated with the physical orientation and connections of the component waterbodies and the bathymetry of those waterbodies. The dynamic abiotic habitat components are associated with hydrodynamic conditions and position of the salinity gradient associated with fall outflow. The interactions of stationary and dynamic abiotic habitat components determine the position and characteristics of LSH available for delta smelt (fig. 13). With respect to the RPA, interest is focused on two generalized flow regimes within the remaining fall range of delta smelt. In the "low outflow" regime, LSH is located near the confluence of the Sacramento and San Joaquin Rivers (referred to as the "river confluence" in this report). In the "high outflow" regime, LSH is located in the Suisun region, which extends seaward from the river confluence to the west and includes Suisun Bay, Grizzly Bay, Honker Bay, and Suisun Marsh (fig. 13). 


\begin{tabular}{|c|c|c|}
\hline Suisun region & Stationary abiotic habitat components & River confluence \\
\hline Higher & Bathymetric complexity & Lower \\
\hline Higher & Erodible Sediment supply & Lower \\
\hline Many in south, fewer in north & Contaminant sources & Many \\
\hline Fewer & Entrainment sites & More \\
\hline Variable fall outflow regime & Dynamic abiotic habitat components & Static fall outflow regime \\
\hline Higher after wet springs & Net Total Delta Fall Outflow & Always low \\
\hline Higher after wet springs & San Joaquin river contribution to fall outflow & Always low \\
\hline $\begin{array}{l}\text { After wet springs, broad fall LSZ } \\
\text { overlaps Suisun region }\end{array}$ & 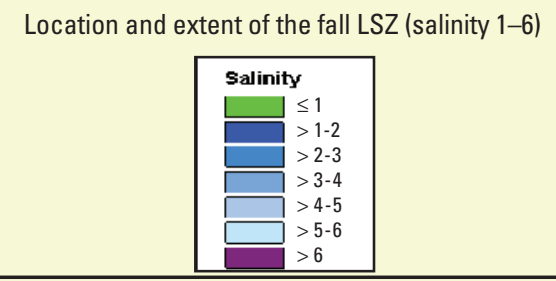 & $\begin{array}{l}\text { Narrow fall LSZ in river channels, } \\
\text { Never overlaps suisun region }\end{array}$ \\
\hline Higher after wet springs & Hydrodynamic complexity in the fall LSZ & Always lower \\
\hline Higher after wet springs & Wind speed in the Fall LSZ & Always lower \\
\hline More variable, higher after wet springs & Turbidity in the Fall LSZ & Always less variable, lower \\
\hline More variable, maybe lower after wet springs & Contaminant concentrations in the Fall LSZ & Less variable, maybe higher \\
\hline LSZ overlaps Suisun region & Dynamic biotic habitat components & LSZ overlaps river confluence \\
\hline Higher & Food availability and quality & Lower \\
\hline Variable & Predator abundance & Higher \\
\hline LSZ overlaps Suisun region & Delta smelt responses & LSZ overlaps river confluence \\
\hline Broad, westward & Distribution & Constricted, eastward \\
\hline Higher & Growth, survival, fecundity & Lower \\
\hline Better & Health and condition & Worse \\
\hline May be higher & Recruitment in the next spring & Lower \\
\hline
\end{tabular}

Figure 13. Spatially explicit conceptual model for the western reach of the modern delta smelt range in the fall: interacting stationary and dynamic habitat features drive delta smelt responses. The location of the low-salinity zone (LSZ) is related to the value of X2, which is the horizontal distance in kilometers $(\mathrm{km})$ from the Golden Gate up the axis of the estuary to where tidally averaged near-bottom salinity is 2 . Symbols: $\leq$, less than or equal to; and $>$, greater than. 
In the FLaSH conceptual model, the LSZ represents the abiotic portion of the production area (fig. 12), which is the dynamic outcome of the interaction between stationary and dynamic habitat components. The LSZ can be considered a dynamic, abiotic habitat component (fig. 13) because its extent (for example, surface area) and location vary with net freshwater outflow from the Delta. Delta smelt and other organisms that seek salinity levels within the LSZ range, or are transported by flow into the area, likely respond differently to the dynamic and stationary habitat features of the fall high- and low-outflow regimes. In other words, conditions for the different outflow regimes potentially do or do not correspond to those necessary for successful recruitment. The concept that the LSZ represents the optimal region for delta smelt production is central to the FLaSH conceptual model. After describing the conceptual model in some detail, delta smelt habitat in the northern Delta is considered.

The new conceptual model provides the framework for accomplishing the main objectives of this report, including presentation of the results of studies and monitoring during fall 2011 and a synthesis of the available information assessing whether the data support predictions made in the FLaSH AMP (U.S. Bureau of Reclamation, 2012) . Detailed justifications for the various assumptions made in the new conceptual model are not repeated here. Justifications for each element of the conceptual model, based on available data, are presented in the FLaSH AMP (U.S. Bureau of Reclamation, 2012). In this report, each element of the new conceptual model is briefly reviewed so that readers are familiar with the basis for each of the predictions to be evaluated. It is important to understand that it is not the purpose of this report to revise or provide support for the new conceptual model developed by the U.S. Bureau of Reclamation (2012). The conceptual model is reviewed in this report so that readers understand the basis of the predictions that are assessed in this report. Revisions to the conceptual model are more appropriate as part of a revision of the AMP.

\section{Stationary Abiotic Habitat Components}

The POD and HSG models indicate four key stationary habitat components that differ between the river confluence and Suisun regions, and that could affect habitat quality and availability for delta smelt. It is important to note that these features differ between the two regions but also vary within each region, and all change over time in response to dynamic drivers, albeit much more slowly than the dynamic habitat components. For example, bathymetry and erodible sediment supply can change as more sediment is transported into the region and is deposited or eroded and flushed out to the ocean. Contaminant sources and entrainment sites are added or eliminated with changes in land and water use. The four stationary habitat components in the river confluence and Suisun region are as follows (fig. 13):
- Bathymetric complexity: Differences in bathymetry and spatial configuration between the Suisun region and the river confluence affect nearly all other habitat features and interact strongly with the prevailing dynamic tidal and river flows to produce regionally distinct hydrodynamics. Overall, the Suisun region is more bathymetrically complex than the river confluence (U.S. Bureau of Reclamation 2012). Extensive shallow, shoal areas in the Suisun region are considered particularly important.

- Erodible Sediment Supply: The amount and composition of the erodible sediment supply is an important factor in the regulation of dynamic suspendedsediment concentrations and turbidity levels in the water column. Suisun Bay features extensive shallow water areas, such as Grizzly and Honker bays, that are subject to wind waves that resuspend bottom sediment and increase turbidity relative to the confluence (Ruhl and Schoellhamer, 2004). The contribution and role of organic material to the erodible sediment supply in the Suisun region and the river confluence are uncertain.

- Contaminant Sources: The large urban areas surrounding the estuary in concert with the intensive agricultural land use in the Central Valley watershed and the Delta have resulted in pollution of the estuary by many chemical contaminants (Johnson and others, 2010; Brooks and others, 2012). Many of these pollutants (for example, heavy metals and pesticides) can be toxic to aquatic organisms. The largest wastewater-treatment plant in the Delta, the Sacramento Regional Wastewater Treatment Plant (SRWTP), discharges effluent with large amounts of ammonium, pesticides, and other pollutants into the Sacramento River near the northern Delta border (Jassby, 2008; Weston and Leidy, 2010; Parker and others, 2012). The Contra Costa wastewater-treatment plant also discharges substantial amounts of ammonium into the western Suisun Bay near Carquinez Strait (Jassby, 2008). Ammonium has been found to suppress nitrate uptake and growth of phytoplankton in the Delta and Suisun Bay (Dugdale and others, 2007). In addition, blooms of the toxic cyanobacteria Microcystis aeruginosa have become a common summer occurrence in the central and southern parts of the Delta, including the river confluence and the eastern edge of the Suisun region (Lehman and others, 2008, 2010). Because Microcystis can produce potentially toxic microcystins and is considered poor food for secondary consumers, the conceptual model considered it a biological contaminant. 
- Entrainment sites: Entrainment sites include agricultural water diversions and urban water intakes throughout the Delta and Suisun regions of the estuary, the SWP and CVP water project pumps in the southern Delta (fig. 3), and two power-plant cooling-water intakes in the Suisun region (in Pittsburg and Antioch). Entrainment can cause direct mortality in fish screens, pumps, or pipes (Grimaldo and others, 2009; Castillo and others, 2012), and it can cause indirect mortality due to enhanced predation or unsuitable water quality associated with diversion structures and operations (Arthur and others, 1996; Feyrer and others, 2007; Moyle and others, 2010). Direct entrainment of delta smelt in the fall months is likely to be rare; however, fall hydrodynamic conditions could influence where delta smelt stage in anticipation of the winter migration (Sommer and others, 2011b). A more eastward starting location can increase entrainment risk of delta smelt at the SWP and CVP when diversions cause flows in Old and Middle River (OMR) to move toward the projects (known as negative OMR flows) rather than seaward during smelt upstream migration periods (Grimaldo and others, 2009); however, this effect is only important when turbidity exceeds about 12 Nephelometric Turbidity Units (NTU) in the region between the staging area and the SWP and CVP because delta smelt tend not to move into clear water (Grimaldo and others, 2009). Current management strategies are in place to reduce exports during the first large storms of the season, usually in late fall (known as "first flush"), when turbidities increase above 12 NTU throughout large regions of the Delta and upstream movement of delta smelt is expected (U.S. Fish and Wildlife Service, 2008).

\section{Dynamic Abiotic Habitat Components}

The POD and HSG models also indicate a number of dynamic components that change in magnitude and spatial configuration at daily, tidal, seasonal, and annual time scales. Their interactions with each other and with stationary habitat components determine the extent and location of production areas for estuarine species. The major dynamic abiotic habitat components follow (U.S. Bureau of Reclamation, 2012):

- Total Delta outflow and San Joaquin River contribution to outflow in the fall: The interaction of ocean tides with inflows from tributary rivers is the main dynamic driving force in estuaries and determines outflow to the ocean. The SFE experiences twice-daily ebb and flood tides and strong fortnightly spring and neap tidal cycles. The estuary is located in a Mediterranean climate zone with highly variable precipitation and river flow patterns (Dettinger, 2011). Winters are generally wet, and summers are dry, but there is large interannual variability, and California water managers distinguish among five different water-year types (wet, above-normal, below-normal, dry, and critically dry). A water year begins on October 1 of the preceding year and ends on 30 September. Water-year types for the Sacramento and San Joaquin River watersheds are based on calculation of an index incorporating unimpaired runoff during the current and previous water year (State Water Resources Control Board, 1995). For the Sacramento River, index values greater than or equal to 9.2 million acre feet (MAF) denote a wet year, and values greater than 7.8 MAF and less than 9.2 MAF denote an above-normal year. For the San Joaquin River, index values greater than or equal to 3.8 MAF denote a wet year, and values greater than 3.1 MAF and less than 3.8 MAF denote an abovenormal year (historical water-year types are available at http://cdec.water.ca.gov/cgi-progs/iodir/WSIHIST). On an annual basis, San Joaquin River flows are less than Sacramento River flows and are reduced to a much greater extent by storage and diversions compared to Sacramento River flows. Only a small amount of San Joaquin River water is actually discharged to the ocean in all but the wettest years. This is especially true in the fall months, when only a very small fraction of Delta outflow is contributed by water from the San Joaquin River.

- Location and extent of the fall LSZ: Under the static, fall-outflow regime that has been typical for the POD period, outflows during much of the fall are always low, and salinity intrudes far to the east (X2 greater than $80 \mathrm{~km}$ ), causing the LSZ to be constricted to the confluence of the deep Sacramento and San Joaquin river channels (fig. 14). When X2 is more seaward, the LSZ includes more of the Suisun region (figs. 15 and 16).

- Hydrodynamic complexity in the fall LSZ: The term "hydrodynamic complexity" is meant to convey the idea of habitat heterogeneity within the LSZ. The U.S. Bureau of Reclamation (2012) hypothesized that when the LSZ is located in Suisun Bay, there is more shoal habitat available, connections with Suisun Marsh are possible, and there is greater likelihood of gyres and eddies forming. Conceptually, this provides a greater array of habitat types for delta smelt to utilize for resting, feeding, and other activities. Hydrodynamics are primarily driven by the interaction of dynamic river flows and ocean tides with stationary bathymetry and spatial configuration of channels. With respect to the movement of water masses through the estuary, hydrodynamics in the estuary are generally understood and have been modeled with a variety of tools 

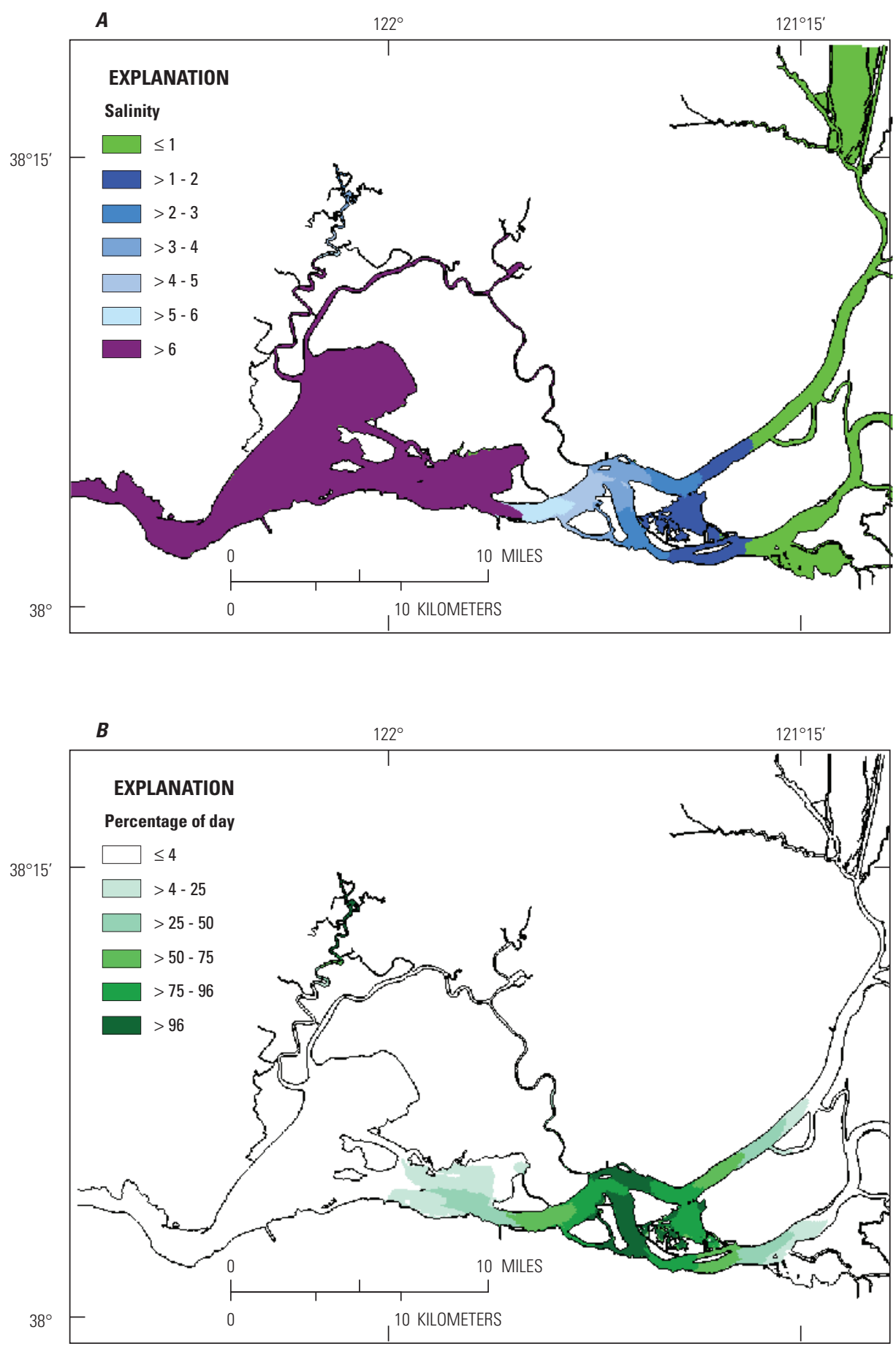

Figure 14. Maps showing $A$, Location of the low-salinity zone (salinity 1-6) when X2 is at 85 kilometers; connections to Suisun Bay and Suisun Marsh are minimal. $B$, Percentage of day that the low-salinity zone occupies different areas (appendix 2). X2 is the horizontal distance in kilometers from the Golden Gate up the axis of the estuary to where tidally averaged near-bottom salinity is 2 . Symbols: $\leq$, less than or equal to; and $>$, greater than. 

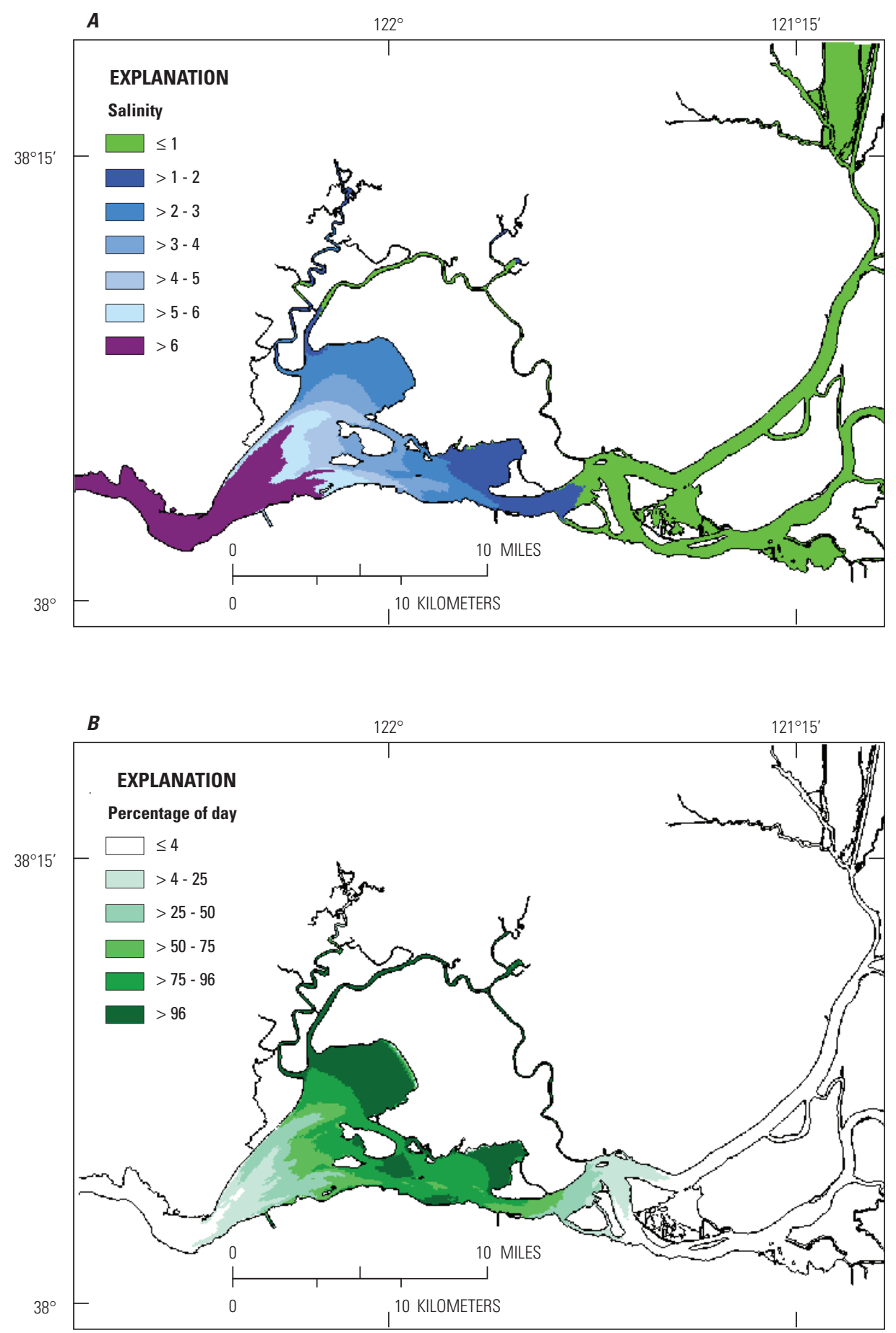

Figure 15. Maps showing $A$, Location of the low-salinity zone (salinity 1-6) when $\mathrm{X} 2$ is at 74 kilometers; connections to Suisun Bay and Suisun Marsh are extensive. $B$, Percentage of day that the low-salinity zone occupies different areas (appendix 2). X2 is the horizontal distance in kilometers from the Golden Gate up the axis of the estuary to where tidally averaged near-bottom salinity is 2 . Symbols: $\leq$, less than or equal to; and >, greater than. 

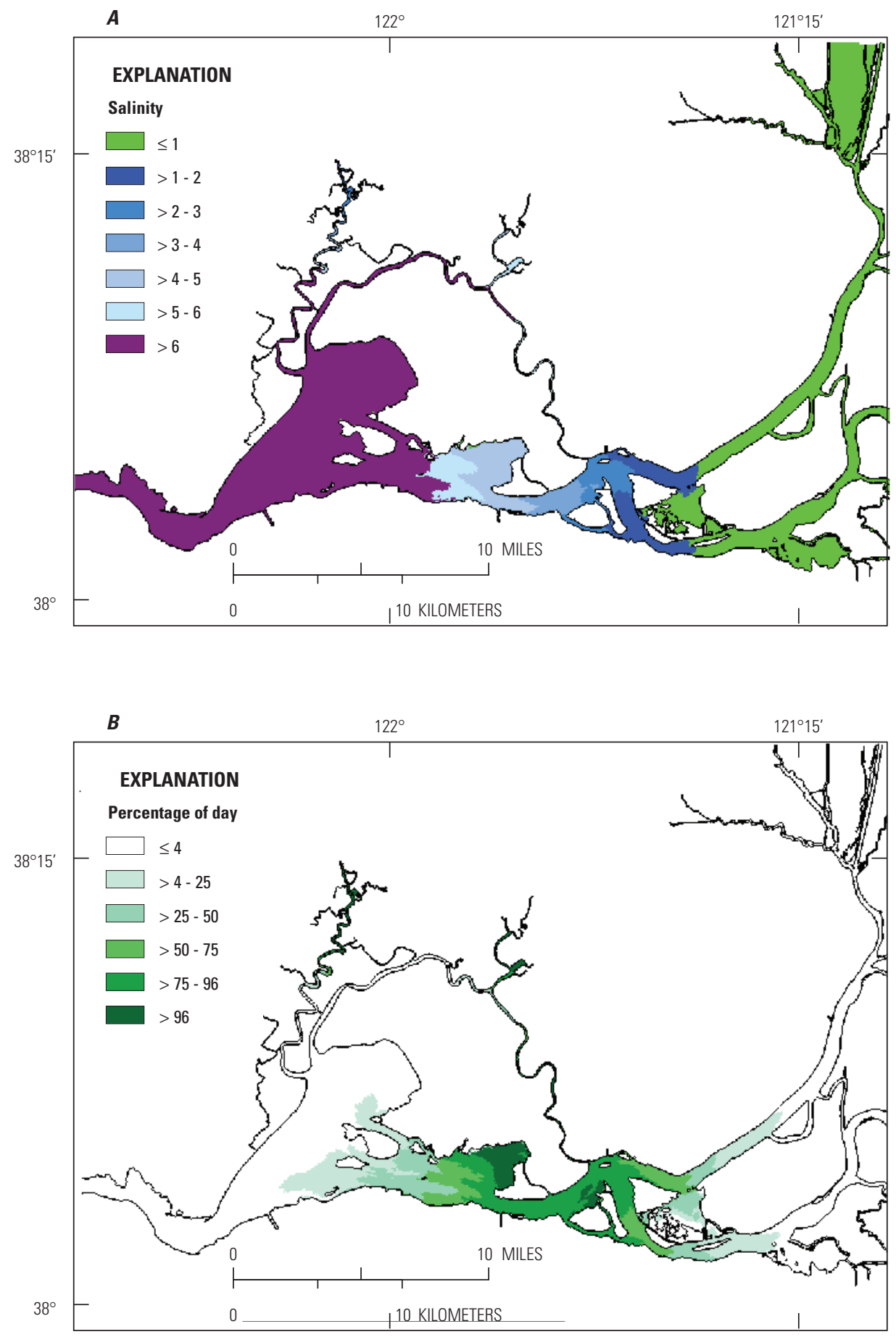

Figure 16. Maps showing $A$, Location of the low-salinity zone (salinity 1-6) when X2 is at 81 kilometers; the low-salinity zone (LSZ) is connected to Suisun Bay, but not Suisun Marsh. B, Percentage of day that the LSZ occupies different areas (appendix 2). X2 is the horizontal distance in kilometers from the Golden Gate up the axis of the estuary to where tidally averaged near-bottom salinity is 2. Symbols: $\leq$, less than or equal to; and $>$, greater than. 
(see, for example, Delta Simulation Model II; Close and others, 2003; California Department of Water Resources, 2005; California Department of Water Resources, 2008). There remains much uncertainty, however, about the interaction of hydrodynamics with the stationary habitat components in the Suisun and river confluence regions and their combined effects on other dynamic habitat components including turbidity, contaminants, and biota. The diverse configurations of shoals, channels, and connections to Suisun Marsh produce complex hydrodynamic features, such as floodtide pulses in Grizzly Bay (Warner and others, 2004), tidal asymmetry (Stacey and others, 2010), lateral density fronts in Suisun cutoff (Lacy and others, 2003), and multiple null zones and turbidity maxima (Schoellhamer and Burau, 1998; Schoellhamer, 2001). In contrast, the river confluence area has simpler bathymetry that lacks extensive shallow embayments. Large, shallow freshwater embayments (flooded islands) exist in the central and northern Delta, but are outside of the region overlain by the LSZ.

- Wind speed in the fall LSZ: Strong winds from the north and west are characteristic of the Suisun and river confluence regions of the SFE. On average, wind speeds are high during most of the year, including early fall, but lower in mid to late fall. The interaction of wind with river and tidal flows and the erodible sediment supply drives the resuspension of erodible bed sediments in shallow water. Wind-wave resuspension is substantial in the shallow bays of the Suisun region and helps maintain generally high suspended-sediment concentrations and turbidity levels in these areas (Ruhl and Schoellhamer, 2004). In contrast, wind likely plays a less important role in suspending sediments in the deep channels of the river confluence.

- Turbidity in the fall LSZ: Turbidity, often measured as Secchi depth in the Delta, has been found to be an important explanatory factor in delta smelt occurrence during the summer (Nobriga and others, 2008) and fall (Feyrer and others, 2007). Secchi depth is the depth at which the pattern on a Secchi disk is no longer visible from the surface. Turbidity during the winter also appears to be important as a cue for the upstream spawning migration (Grimaldo and others, 2009; Sommer and others, 2011b). Turbidity is assumed to reduce predation risk for delta smelt, as it does for other fishes, but no direct experiments or observations exist to support this hypothesis. In the SFE, turbidity is largely determined by the amount of suspended, inorganic sediment in the water (Cloern, 1987; Ganju and others, 2007; Schoellhamer and others, 2012), although organic components could also play a role (U.S. Geological Survey, 2008). Sediment particles are constantly deposited, eroded, and resuspended and are transported into, within, and out of the estuary. The amount of sediment that is suspended in the water column depends on the available hydrodynamic energy, which determines transport capacity, and on the supply of erodible sediment. Strong turbulent hydrodynamics in the Suisun region caused by strongly interacting tidal and riverine flows, bathymetric complexity, and high wind speeds constantly resuspend large amounts of the remaining erodible sediment in the large and open shallow bays of the Suisun region. The Suisun region thus remains one of the most turbid regions of the estuary. Turbidity dynamics in the deep channels of the river confluence are driven primarily by riverine and tidal processes, while high wind and associated sediment resuspension have little, if any, effect (Ruhl and Schoellhamer, 2004). In the fall, fine, erodible sediment has been somewhat winnowed from the bed, and wind speed is less than in spring and summer, so wind-wave resuspension and suspended-sediment concentrations typically are low compared to other seasons. In the fall, usually there is less turbidity in the river confluence than in the Suisun region. This difference is also consistent with preliminary analyses by W. Kimmerer (San Francisco State University, written commun.), which indicate that turbidity in the LSZ is higher when fall X2 is further downstream and the LSZ overlaps the Suisun region.

- Contaminant Concentrations in the fall LSZ: Chemical contaminants from agricultural and urban sources that are present in the estuary include pyrethroid pesticides, endocrine disruptors, and many traditional contaminants of concern (Kuivila and Hladik, 2008; Johnson and others, 2010; Brooks and others, 2012). Some regions of the upper estuary are also enriched with the nutrient ammonium (Johnson and others, 2010; Brooks and others, 2012). In the late summer and early fall, blooms of the cyanobacteria Microcystis aeruginosa can release toxic microcystins (Lehman and others, 2010). Agricultural contaminants are delivered into the LSZ from winter to summer in storm-water runoff, rice field discharge, and irrigation-return water (Kuivila and Hladik, 2008). The amount and types of agricultural contaminants that reach the LSZ vary seasonally, with more inputs from winter to summer than during the fall (Kuivila and Hladik, 2008). Urban and industrial pollution from wastewater-treatment plants and industrial discharges is more constant throughout the year, although the amount of contaminant-containing urban storm-water run-off is greatest during winter and spring. In the fall, pollutant loading from stormwater is generally negligible, and lower river flows mobilize fewer sediment-bound contaminants than during other seasons (U.S. Bureau of Reclamation, 2012). 


\section{Dynamic Biotic Habitat Components:}

Estuarine fishes seek areas with a combination of dynamic and stationary habitat components that are well suited to their particular life histories. In addition to abiotic habitat components, fish habitat also includes dynamic biological components, such as food availability and quality and predator abundance.

- Food availability and quality: Food production in estuaries is a dynamic process that involves light, nutrients, algae, microbes, and aquatic plants at the base of the food web and transfers to intermediate and higher trophic levels, including invertebrates, such as zooplankton, benthic invertebrates, and vertebrates such as fishes and water birds. As in many other estuaries, higher trophic-level production in the open waters of the Delta and Suisun regions is fueled by phytoplankton production (Sobczak and others, 2002). In contrast to many other estuaries, however, the SFE has low phytoplankton production and biomass overall (Cloern and Jassby, 2008). Phytoplankton production in the estuary is highly variable on a seasonal and interannual basis (Jassby and others, 2002; Cloern and Jassby, 2010). The SFE also has a large amount of spatial variability in food production and food web dynamics. Estuaries and rivers often have dynamic food and biogeochemical "hot spots" (Winemiller and others, 2010) that persist in one location for some time or move with river and tidal flows. There also are usually areas with low food production and biomass. The temporal and spatial variability of food production, quality, and biomass in estuaries is the result of the interaction of dynamic drivers, such as biomass and nutrient inputs from upstream, estuarine hydrodynamics, salinity, turbidity, and trophic interactions with stationary habitat components, such as the bathymetric complexity and spatial configuration of a particular geographic area. Food resources for delta smelt in the fall LSZ vary considerably on many spatial and temporal scales. Microcystis became abundant in the estuary in the early 2000s, coincident with the POD (Lehman and others, 2005). The neurotoxic microcystins found in this cyanobacterium have been found in many components of the food web (Lehman and others, 2010). Although Microcystis tends to be restricted to freshwater in the Delta, blooms can extend down into the LSZ. In relation to delta smelt, concern over Microcystis is currently focused on possible food-web effects, particularly negative effects on populations of calanoid copepods (Ger and others, 2009, 2010a, 2010b), which are an important food source for delta smelt. If blooms expand in scope and duration, there could be more concern regarding direct effects. Many uncertainties remain about the dynamics of food resources that ultimately contribute to delta smelt survival, growth, and health in the fall, particularly at the small scales important to individual delta smelt. Uncertainties also remain regarding the relative importance of food subsidies from upstream regions and food produced in the LSZ. When flows are sufficient to transport biomass downstream, subsidies of biomass from the San Joaquin River have been hypothesized to be important to the LSZ. Species invasions associated with extreme salinity intrusions during droughts have greatly altered the composition of the invertebrate community in the LSZ, with uncertain effects on pelagic food sources and, ultimately, on delta smelt. Overall, food quantity and quality could be greater for delta smelt if the fall LSZ is in Suisun Bay, rather than the river confluence, but many uncertainties remain (U.S. Bureau of Reclamation, 2012).

- Predator composition and abundance: Predators are a natural biological component of ecosystems, and most organisms are exposed to predation during some part of their lives. In general, a reduction in extent of habitat for a population of prey organisms can cause the prey density to increase in the remaining habitat, which results in an increased probability of predatorprey encounters. In the SFE, the fall distribution of piscivorous juvenile striped bass overlaps the fall distribution of delta smelt. Striped bass are in both the confluence and the Suisun region (Nobriga and others, 2005; Sommer and others, 2011a). Greater turbidity in the Suisun region could, however, reduce predation risk for delta smelt in these areas compared to the river confluence, where turbidity is generally less. Largemouth bass are increasingly abundant in the central and northern Delta (Brown and Michniuk, 2007) and could potentially exert significant predation pressure on delta smelt in the river confluence region, although this has not yet been documented. Sacramento pikeminnow, Ptychocheilus grandis, a native predator, occurs in both regions. Mississippi silversides, another introduced species, appear to prey on larval delta smelt in the spring (Baerwald and others, 2012), but are too small to prey on juvenile and sub-adult delta smelt in the fall. High predator abundance has been documented in the river confluence at the release sites for fishes salvaged in the CVP and SWP fish facilities (Miranda and Padilla, 2010). Overall, predator abundance and associated predation risk for delta smelt generally could be high in the river confluence, but variable in the Suisun region (U.S. Bureau of Reclamation, 2012). Much uncertainty remains, however, about the role and magnitude of predation in these regions. 


\section{Delta Smelt Responses}

The POD and HSG models indicate that delta smelt respond in several ways to outflow-related habitat changes in the fall. Specifically, access to areas of greater bathymetric complexity, such as those found in the Suisun region, could offer multiple advantages to delta smelt, although many uncertainties regarding the mechanisms that link delta smelt responses to outflow conditions and the position of the LSZ remain. Note also that the responses of delta smelt could be muted, depending on the status of the population. For example, severely low adult abundance is likely to generate relatively low recruitment regardless of habitat quality. At the extreme end of low abundance, the delta smelt population could be subject to Allee effects, which cause a downward spiral that can be difficult to reverse (Baxter and others, 2008). However, the increase in the 2011 delta smelt abundance index compared to years in the 2000s (fig. 4) indicates that the delta smelt population is still resilient and able to respond to favorable conditions, reducing the risk of Allee effects (but see Fisch and others, 2011).

- Distribution: Prior to their upstream spawning migration in the winter, delta smelt are commonly found in the LSZ (Feyrer and others, 2007; Sommer and others, 2011b). Older life stages of delta smelt potentially do not require the same high-turbidity levels that larval delta smelt need to successfully feed, but are most likely able to discriminate degrees and types of turbidity (and salinity) to find waters that contain appropriate prey resources and that will provide some protection against predation (U.S. Bureau of Reclamation, 2012). A westward LSZ (fig. 15) ensures delta smelt access to a larger habitat area that overlaps with the more bathymetrically complex Suisun region with its deep channels; large, shallow shoal areas; and connectivity with Suisun Marsh sloughs.

- Growth, survival, and fecundity: Distribution across a larger area with more turbidity and more food, when the LSZ overlaps the Suisun region, could help delta smelt avoid predators and increase survival and growth. Distance from entrainment sites and locations where predators can congregate (artificial physical structures, scour holes in river channels, and Egeria beds) could also help increase survival. Higher phytoplankton production in shallow areas of the Suisun could provide more zooplankton (U.S. Bureau of Reclamation, 2012) and, thus, better food resources for delta smelt compared to the deep river confluence during high outflow years when the deep water and short residence time could limit phytoplankton growth rate (Lucas and Thompson, 2012). Increased growth could result in greater size of adult delta smelt and greater fecundity of females, since the number of eggs is related to length (Bennett, 2005).
- Health and condition: The same mechanisms listed for growth, survival, and fecundity can affect health and condition. Improved health and condition at the beginning of the spawning period could increase the likelihood of repeat spawning by females. In addition, a larger habitat area could help delta smelt avoid areas with high concentrations of contaminants.

- Recruitment in the next spring: Ultimately, the factors listed previously could lead to increased distribution, abundance, and reproductive potential (that is, total egg production) of the delta smelt population. However, adult delta smelt need to successfully spawn, and larvae must find suitable rearing conditions to produce increased numbers of young fish in the spring. In addition to preceding summer and fall habitat conditions, successful spring recruitment, thus, requires suitable winter and spring conditions for migration, gamete maturation, spawning, and larval rearing. These habitat conditions depend on the interplay of a different set of stationary and changing dynamic habitat features. Only if habitat conditions are met year-round will delta smelt be able to successfully maintain their life history and genetic diversity.

\section{Delta Smelt in the Northern Delta}

While the center of the delta smelt distribution in the fall is the LSZ, delta smelt also are observed year-round in the northern Delta (Sommer and others, 2011b; Merz and others, 2011); therefore, this region also constitutes delta smelt fall habitat. It is important to note, however, that habitat quality and resulting delta smelt survival, health, growth, fecundity, and recruitment contribution to the total population could differ between this region and the LSZ. The 2011 FLaSH studies included a comparison of dynamic and stationary habitat features to delta smelt responses in the LSZ and northern Delta habitats.

The northern Delta range of delta smelt in the fall includes the SRDWSC and the Cache Slough complex with its dead-end sloughs and the large, flooded Liberty Island (fig. 3; Sommer and others, 2011b). There is a slight salinity gradient from freshwater in the mainstem Sacramento River to about salinity 0.5 in the SRDWSC and the smaller sloughs. Stationary habitat features in the northern Delta have a number of similarities with those of the Suisun region. The northern Delta is bathymetrically complex, turbid, productive, has low entrainment risk, and variable risk of toxin exposure and predation. Dynamic habitat features include strong tidal exchanges with the Sacramento River and variable contributions of productive tributary waters. 
Although the salinity and temperature ranges potentially are not physiologically optimal in the northern Delta, other factors, such as differences in food availability or predation rates, could offset any physiological stress associated with living in freshwater. Because the northern Delta serves as a delta smelt spawning area (Sommer and others, 2011b), fish rearing in the area could avoid negative factors associated with downstream dispersal followed by an upstream spawning migration. Thus, the northern Delta could represent a secondary production area for delta smelt. As noted earlier, delta smelt in this region are not genetically distinct from delta smelt from other regions (Fisch and others, 2011); however, groups of individuals (contingents) within the population can exhibit different migration patterns (Sommer and others, 2011b).

\section{Hypotheses and Predictions}

A key to the adaptive approach described in the FLaSH AMP is that the alternative fall-outflow scenarios within the fall low-salinity habitat component of the RPA lead to a suite of expected responses based on the hypotheses, which constitute the conceptual model. Such expected responses range from changes in dynamic habitat drivers to changes in biological responses at multiple levels of the ecosystem. Those expectations about dynamic habitat drivers and biological responses are presented in the form of quantitative and qualitative predictions in table 1 . The science plan detailed in the FLaSH AMP is designed to test these predictions. In this report, we use data from ongoing monitoring and research programs to determine if the predictions are supported.

Table 1. Predicted qualitative and quantitative outcomes of the fall low-salinity habitat component of the Reasonable and Prudent Alternative based on three levels of X2 (modified from U.S. Bureau of Reclamation, 2012). In wet years, the target is X2 at $74 \mathrm{~km}$, and in above normal years, the target is $\mathrm{X} 2$ at $81 \mathrm{~km}$.

[X2 is the horizontal distance in kilometers from the Golden Gate up the axis of the estuary to where tidally averaged near-bottom salinity is 2. Abbreviations: cfs, cubic feet per second; CVP, Central Valley Project; DS, delta smelt; ha, hectare; LSZ, low salinity zone (salinity 1-6); SWP, State Water Project; $\sim$, approximately]

\begin{tabular}{|c|c|c|c|}
\hline \multirow{2}{*}{ Variable (September-October) } & \multicolumn{3}{|c|}{ Predictions for $\mathrm{X} 2$ scenarios } \\
\hline & 85 km & 81 km & 74 km \\
\hline \multicolumn{4}{|c|}{ Dynamic abiotic habitat components } \\
\hline Average daily net delta outflow & $\sim 5,000 \mathrm{cfs}$ & $\sim 8,000 \mathrm{cfs}$ & 11,400 \\
\hline Surface area of the fall LSZ & $\sim 4,000$ ha & $\sim 5,000$ ha & $\sim 9,000$ ha \\
\hline Delta smelt abiotic habitat index & 3,523 & 4,835 & 7,261 \\
\hline Average wind speed in the LSZ & Lower & Moderate & Higher \\
\hline Average turbidity in the LSZ & Lower & Moderate & Higher \\
\hline Average Secchi depth in the LSZ & Higher & Moderate & Lower \\
\hline Average ammonium concentration in the LSZ & Higher & Moderate & Lower \\
\hline Average nitrate concentration in the LSZ & Moderate & Moderate & Higher \\
\hline \multicolumn{4}{|c|}{ Dynamic biotic habitat components } \\
\hline Average floating Microcystis density in the LSZ & Higher & Moderate & Lower \\
\hline Phytoplankton biomass variability across LSZ & Lower & Moderate & Higher \\
\hline Calanoid copepod biomass in the LSZ & Lower & Moderate & Higher \\
\hline Cyclopoid copepod biomass in the LSZ & Lower & Moderate & Moderate \\
\hline Copepod biomass variability across LSZ & Lower & Moderate & Higher \\
\hline Potamocorbula biomass in the LSZ & Higher & Moderate & Lower \\
\hline Predator abundance in the LSZ & Lower & Moderate & Higher \\
\hline Predation rates in the LSZ & Lower & Moderate & Higher \\
\hline \multicolumn{4}{|c|}{ Delta smelt responses } \\
\hline DS caught at Suisun power plants & 0 & 0 & Some \\
\hline
\end{tabular}


Several important dynamic response variables are indicated by the conceptual model, but not yet incorporated into table 1 because the available data are insufficient to support qualitative or quantitative predictions. These include contaminant concentrations and effects, jellyfish dynamics, microbial dynamics, and delta smelt population responses in seasons other than the fall. The "81-km" and "74-km" columns in table 1 correspond to X2 targets for "above-normal" and "wet" water years and the high-outflow variant of the variable outflow scenario described in the new conceptual model (left side of fig. 13). The $85-\mathrm{km}$ column in table 1 represents the static low-fall outflow scenario (right side of fig. 13).

\section{Methodology}

The general approach in this report is to evaluate the predictions in the AMP. For each prediction in table 1, we reviewed the available information and made a judgment about whether the prediction was supported by the available data. For the purposes of this report, we defined fall as the months of the fall midwater-trawl (FMWT) survey, which generally begins in September and ends by mid-December. Within fall, we recognized two important periods. The RPA requires water management to maintain X2 at a designated value in September and October, which is the first period of interest. November through mid-December constitute the second period of interest. Our evaluation of predictions relied largely on agency collected monitoring data (table 2) because those were the data available at the time, but this does not reflect any preference for those data. Note that data can include actual measurements, calculations from measurements, or the output of models (table 2 and appendixes 1-8). Chlorophyll- $\alpha$ concentrations were measured by chemical analysis of pigments, unless noted otherwise.

We included analyses of data from other years besides 2011 because our approach is comparative. We included 2006 because it is the most recent wet year preceding 2011. As already noted, we recognize that preceding habitat conditions can have important implications for the outcomes of the fall low-salinity habitat component of the RPA during any particular year; therefore, we also considered data from 2005 and 2010. Coincidentally, during fall 2010, X2 averaged $85 \mathrm{~km}$ (table 3), which provided a good comparison with 2011 because X2 was very close to the minimum and maximum referenced in table 1. In 2005 and 2006, fall X2 averaged 83 and $82 \mathrm{~km}$, respectively. While these values do not correspond exactly to the $81-\mathrm{km}$ condition in table 1 , they do provide contrasting data for years where X2 was between 75 and $85 \mathrm{~km}$.

The data analyses focused on calendar years rather than water years. A water year begins on October 1 of the preceding year and ends on 30 September. Thus, for analysis of a selected calendar year, we included data from January 1 to September 30, which is the overlap of water year and calendar year, plus the first 3 months of the following water year, October 1 to December 31. All 4 years of interest were during the
Table 2. Data sources with references to appendixes 1-8, where more detailed methods can be found.

[X2 is the horizontal distance in kilometers from the Golden Gate up the axis of the estuary to where tidally averaged near-bottom salinity is 2. Abbreviations: CDFW, California Department of Fish and Wildlife; DWR, Department of Water Resources; LSZ, low salinity zone (salinity 1-6); QWEST, the calculated net outflow from the San Joaquin River; UCD, University of California at Davis; USGS, U.S. Geological Survey; + , plus; - , not available]

\begin{tabular}{lclc}
\hline \multicolumn{1}{c}{ Type of data } & $\begin{array}{c}\text { Responsible } \\
\text { agency }\end{array}$ & $\begin{array}{c}\text { Data } \\
\text { type }\end{array}$ & Appendix \\
\hline \multicolumn{4}{c}{ DayFlow data } \\
\hline Delta average daily outflow & DWR & Calculation \\
QWEST & DWR & Calculation & 1 \\
X2 & DWR & Calculation & 1 \\
\hline \multicolumn{4}{c}{ Delta Modeling Associates data } \\
\hline Surface area of LSZ & Delta & Model output \\
\multicolumn{4}{c}{ Modeling } \\
Associates \\
Maps of LSZ \\
\multicolumn{4}{c}{ Delta } \\
\end{tabular}

\begin{tabular}{|c|c|c|c|}
\hline \multicolumn{4}{|c|}{ U.S. Bureau of Reclamation data } \\
\hline Delta smelt habitat index & Reclama & Model output & 3 \\
\hline \multicolumn{4}{|c|}{ Fall midwater trawl data } \\
\hline Delta smelt abundance index & CDFW & Calculation & 4 \\
\hline Water temperature & CDFW & Measurement & 4 \\
\hline Specific conductance & $\mathrm{CDFW}$ & Measurement & 4 \\
\hline Secchi depth & CDFW & Measurement & 4 \\
\hline Turbidity & $\mathrm{CDFW}$ & Measurement & 4 \\
\hline Microcystis occurrence & $\mathrm{CDFW}$ & Measurement & 4 \\
\hline Diet data & CDFW & Measurement & 4 \\
\hline Center of distribution & CDFW & Calculation & 4 \\
\hline Ammonium & UCD & Measurement & 4 \\
\hline Nitrate & $\mathrm{UCD}$ & Measurement & 4 \\
\hline Chlorophyll- $\alpha$ & $\mathrm{UCD}$ & Measurement & 4 \\
\hline \multicolumn{4}{|c|}{ USGS sediment monitoring data } \\
\hline $\begin{array}{l}\text { Analyses of turbidity and } \\
\text { suspended sediment }\end{array}$ & USGS & Calculation & 5 \\
\hline \multicolumn{4}{|c|}{ Environmental Monitoring Program data } \\
\hline Ammonium & DWR & Measurement & \\
\hline Nitrite + nitrate & DWR & Measurement & 6 \\
\hline Chlorophyll- $\alpha$ & DWR & Measurement & 6 \\
\hline Zooplankton abundance & DWR & Measurement & 6 \\
\hline \multicolumn{4}{|c|}{ USGS water quality monitoring data } \\
\hline Ammonium & USGS & Measurement & 7 \\
\hline Nitrite + nitrate & USGS & Measurement & 7 \\
\hline Chlorophyll- $\alpha$ & USGS & Measurement & 7 \\
\hline \multicolumn{4}{|c|}{ CDFW fish sampling data } \\
\hline $\begin{array}{l}\text { Spring kodiak trawl delta } \\
\text { smelt abundance index }\end{array}$ & CDFW & Calculation & 8 \\
\hline $\begin{array}{l}\text { 20-mm survey delta smelt } \\
\text { abundance index }\end{array}$ & CDFW & Calculation & 8 \\
\hline $\begin{array}{l}\text { Summer townet survey delta } \\
\text { smelt abundance index }\end{array}$ & CDFW & Calculation & 8 \\
\hline
\end{tabular}


Table 3. Mean and standard deviation (SD) for X2, delta outflow, surface area of low salinity zone and the delta smelt habitat index (Feyrer and others, 2010). Values for X2 (appendix 1), delta outflow (appendix 1), surface area of low salinity zone (appendix 2) are for September-October and values for the habitat index (appendix 3) are for September-December.

[Abbreviations: LSZ, low salinity zone (salinity 1-6); SD, standard deviation; X2, the horizontal distance in kilometers from the Golden Gate up the axis of the estuary to where tidally averaged near-bottom salinity is 2]

\begin{tabular}{|c|c|c|c|c|c|c|c|c|}
\hline \multirow[t]{2}{*}{ Year } & \multicolumn{2}{|c|}{$\begin{array}{c}\text { X2 } \\
\text { (kilometers) }\end{array}$} & \multicolumn{2}{|c|}{$\begin{array}{c}\text { Outflow } \\
\text { (cubic feet } \\
\text { per second) }\end{array}$} & \multicolumn{2}{|c|}{$\begin{array}{c}\text { Surface area } \\
\text { LSZ } \\
\text { (hectares) }\end{array}$} & \multicolumn{2}{|c|}{ Habitat index } \\
\hline & Mean & SD & Mean & SD & Mean & SD & Mean & SD \\
\hline 2005 & 83 & 2 & 5,654 & 1,745 & 4,889 & 252 & 4,294 & 600 \\
\hline 2006 & 82 & 3 & 5,451 & 2,020 & 4,978 & 320 & 4,481 & 823 \\
\hline 2010 & 85 & 2 & 5,677 & 2,709 & 4,635 & 226 & 3,517 & 346 \\
\hline 2011 & 75 & 1 & 12,204 & 3,646 & 8,366 & 133 & 7,095 & 332 \\
\hline
\end{tabular}

POD period that started when fish abundances of delta smelt and three other pelagic species in the SFE suddenly dropped in about 2002 and then remained very low for multiple years (fig. 4; Baxter and others, 2010; Thomson and others, 2010).

Analyses were generally stratified by salinity. Specifically, data were divided into salinity categories of less than 1 , 1-6, and greater than 6. The Cache Slough complex and SRDWSC were treated as a separate category because delta smelt are known to occupy the area for the entire year even though salinities are less than 1 . Thus, this area was of special interest and warranted separate treatment from other freshwater areas. Sources of data are summarized in table 2. Additional details on data collection, measurement, methods of calculation, and analysis are available in appendixes.

Results from other ongoing research efforts were included as appropriate. When such data were not yet available from publicly available interim or final reports, the data were included in the appendix. Much of the data collected as part of the FLaSH studies were not yet available because sample analysis, data processing, data analysis, and data interpretation are ongoing. This information will be incorporated into the next FLaSH report.

Although fall conditions during the years selected for data analysis roughly correspond to values of $\mathrm{X} 2$ designated in the AMP (compare values in tables 1 and 3), this report cannot be considered a rigorous test of the predictions. In many cases, the predictions (table 1) were qualitative rather than quantitative, where the parameter values for X2 at $74 \mathrm{~km}$ were expected to be greater or less than values for X2 at $85 \mathrm{~km}$, and values were expected to be intermediate for X2 at $81 \mathrm{~km}$. For these reasons, we generally limited analyses to qualitative assessment of graphical and tabular summaries of data. Some predictions could not be evaluated because data were not yet available or the needed data were not collected. These situations are identified and science-based approaches are offered for resolving the situation.
Most data are presented as boxplots. The center horizontal line in each box represents the median of the data. The upper and lower ends of the box represent the upper and lower quartiles of the data. These are also known as "hinges." The "whiskers" are the lines extending above and below the box. The whiskers show the range of values when all values are within one and a half times the inter-quartile distance from the nearest hinge; otherwise, it denotes one and a half times the inter-quartile distance from the nearest hinge. Values outside this range are shown as individual symbols. Other types of plots are explained in the figure captions.

\section{Evaluation of Predictions}

Operations during September-October 2011 and the preceding months resulted in an average $\mathrm{X} 2$ similar to that prescribed for a wet-year in the fall low-salinity habitat component of the RPA (table 3, fig. 17). In addition, during September-October 2010, X2 was at $85 \mathrm{~km}$ - the maximum X2 scenario considered. During fall 2005, X2 was at $83 \mathrm{~km}$, somewhat below the $85-\mathrm{km}$ scenario. During fall 2006, X2 was very close to the $81-\mathrm{km} \mathrm{X2}$ scenario for an above-normal year (table 3), even though it was a wet water year (see http://cdec.water.ca.gov/cgi-progs/iodir/wsihist for specific definitions of water-year types; table 3 ). The first four predictions in table 1 are not predictions in the usual sense. We know that Delta outflow, X2, the size of low-salinity habitat, and the delta smelt habitat index are related, and calculations of the latter three values are dependent on the value of the first (see appendixes 1,2, and 3). These predictions are more properly considered tests of our understanding of the system and the methods available for visualizing the LSZ and the habitat it represents.

As described earlier, 2006 was the most recent wet year prior to 2011, and fall outflow, fall X2, the surface area of the LSZ, and the delta smelt habitat index differed between the 2 years (table 3, figs. 17-20). Although plots of the LSZ were not available for the exact X2 values observed, figures 14-16 likely provide a good approximation of the differences in LSZ extent and position during the years of interest.

\section{Predictions for Dynamic Abiotic Habitat Components}

Variation in average September-October daily net Delta outflow during the 4 years of interest was high (fig. 18). Antecedent conditions during the summer also varied (fig. 18). In 2005 and 2006, September flows were similar to flows in the preceding month. In both years, there was a rapid decline in October flows. In 2010, there was an increase in outflow in September-October compared to earlier months. Similarly, in 2011, there was an increase in September-October compared to late-summer flows, as well as higher late-summer flows 

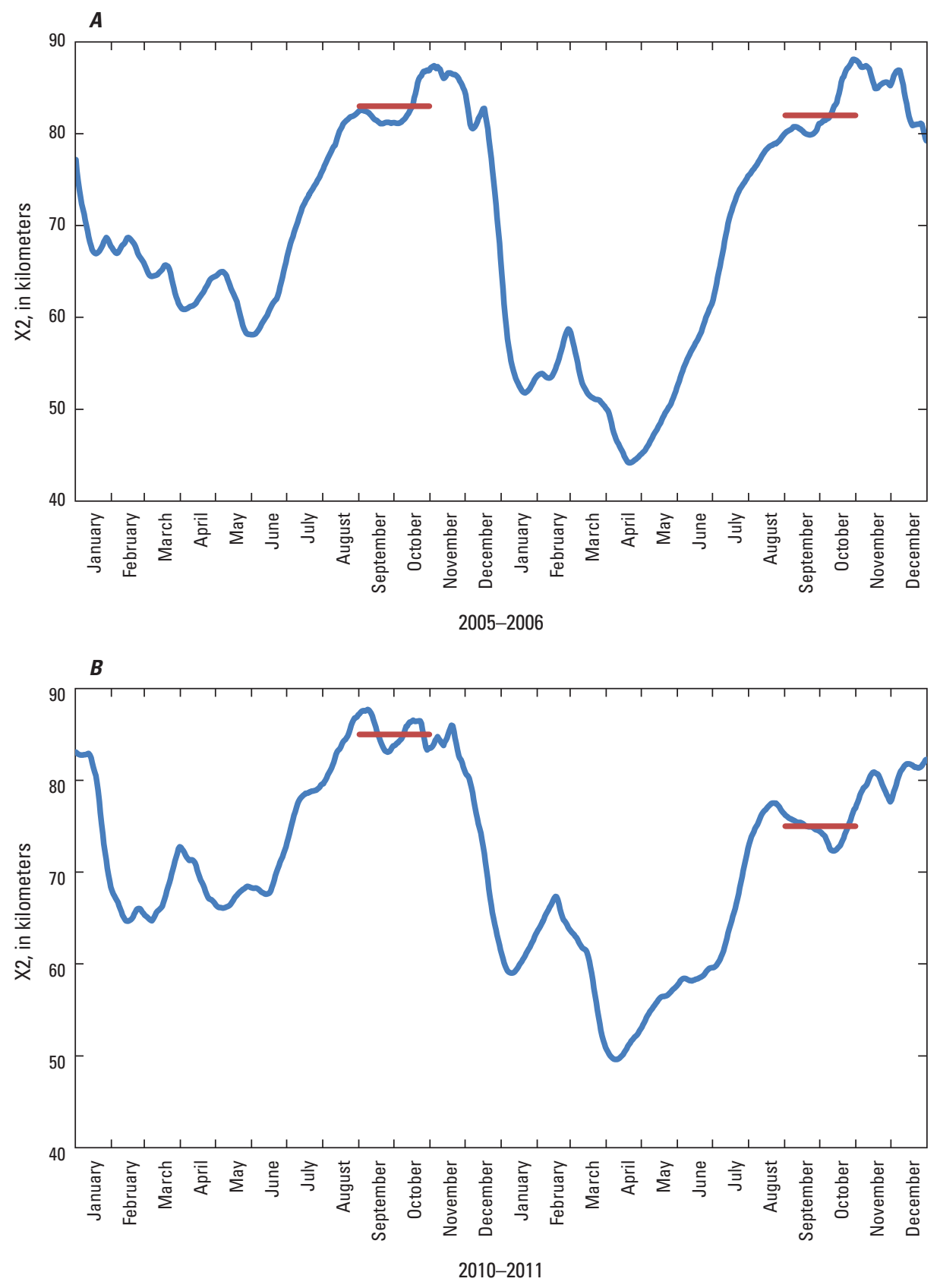

Figure 17. Daily X2 for $A, 2005-2006$ and $B, 2010-2011$. Mean daily X2 for each year during September to October is shown by the horizontal bar (see appendix 1 for data source). X2 is the horizontal distance in kilometers from the Golden Gate up the axis of the estuary to where tidally averaged near-bottom salinity is 2 . 

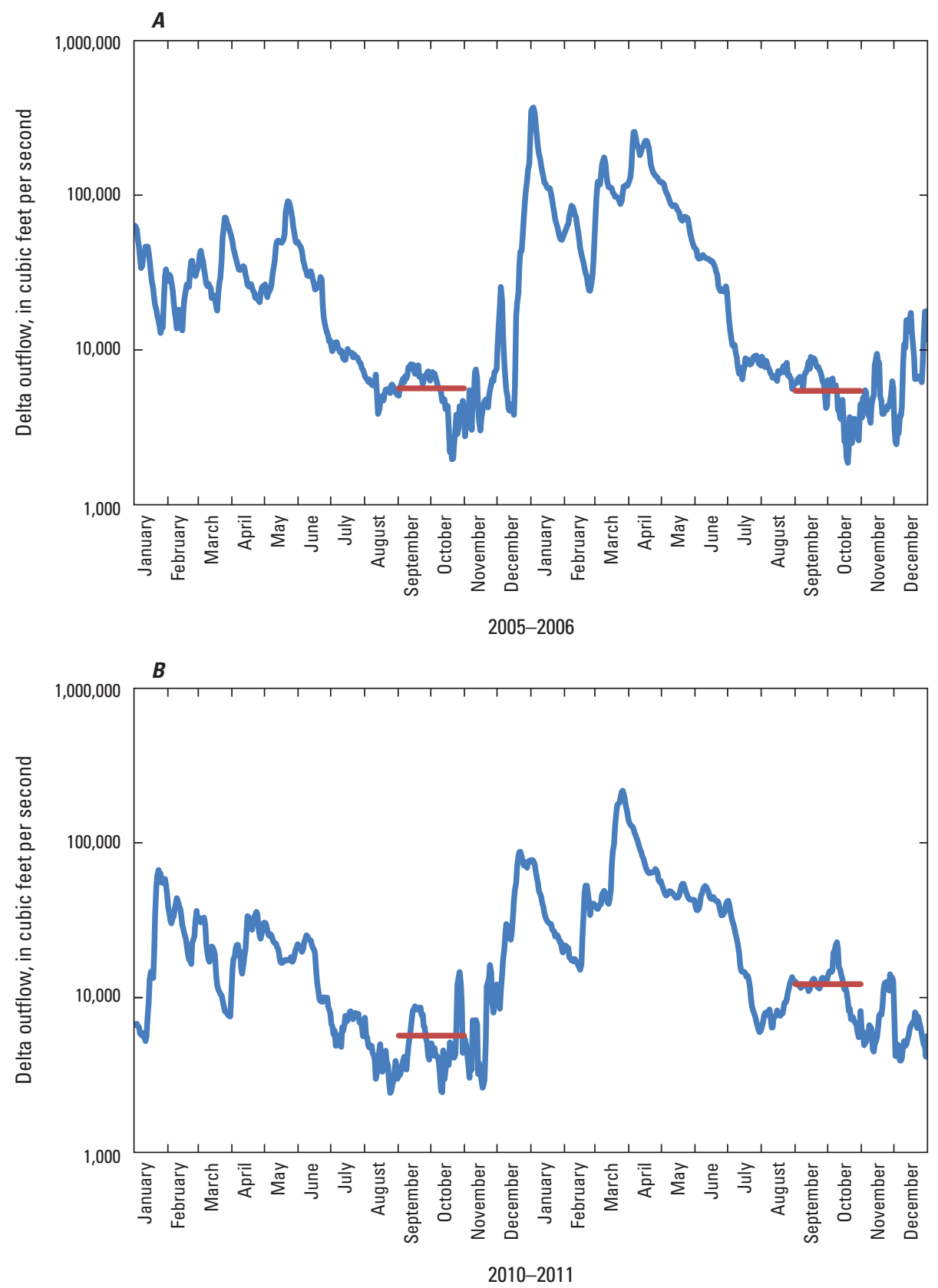

Figure 18. Daily Delta outflow for $A, 2005-2006$ and B, 2010-2011. Mean daily outflow during September to 0 ctober are shown by the horizontal bar (see appendix 1 for data source). 
than in comparison years. Outflows, during fall 2011, were relatively constant or increased compared to the other years; however, there was still a rapid decline in October (fig. 18). Increased flows in September-October are often influenced by water-management actions for migrating salmonids and to reduce reservoir volumes in anticipation of winter-stormflows for flood control.

Observed mean values of outflow (table 3 ) were somewhat similar to those predicted for scenarios with a similar $\mathrm{X} 2$ value (table 1). Predicted outflow with X2 at $74 \mathrm{~km}$ was 11,400 cubic feet per second (cfs) compared to the observed outflow of 12,710 $\pm 3,679 \mathrm{cfs}$ (mean \pm standard deviation; table 3) for X2 at $75 \mathrm{~km}$. There was uncertainty associated with the predictions of outflows for all the X2 scenarios (table 1) because X2 changes more slowly than outflow and depends on the preceding position of the LSZ as well as daily changes in outflow (Jassby and others, 1995). The observed values for outflow showed few differences for X2 varying between 82 and $85 \mathrm{~km}$ (table 3). This indicates that control of outflow to produce relatively fine-scale differences in X2 will be difficult. The prediction of daily Delta outflow associated with an X2 appeared to be correct within a standard deviation of the prediction. The observed values for X2 at $75 \mathrm{~km}$ in fall 2011 indicated that the predicted value was somewhat low to produce an X2 of $74 \mathrm{~km}$; however, variability in the observed values was large, making an exact conclusion impossible. More consistent outflows during a managed action, if possible, could provide for a more definitive conclusion.

Not surprisingly, the daily surface area of the depthaveraged low-salinity zone (fig. 19) showed patterns similar to those of daily outflow (fig. 18). As noted earlier, outflow determines X2 and the location and size of the LSZ in the estuary. The areal size of the LSZ showed less variability than daily outflow (table 3 ). This is likely the case because outflow can be changed relatively quickly by changes in operations; however, the translation of changes in outflows to changes in the location of the LSZ depends on complex hydrodynamic processes that take place over a more extended period, which results in salinity changing in a more gradual and complex manner (Monismith and others, 2002).

There are some notable features of the general pattern of changes in surface area of the LSZ (fig. 19). First, the largest surface areas - above about 9,000 hectares - corresponded to outflows and X2 values that move the LSZ through Carquinez Strait and out into San Pablo Bay. These high flows occurred during the springs of wet years. Low spring $\mathrm{X} 2$ values for extended periods are not always associated with high production of delta smelt (Jassby and others, 1995; Kimmerer, 2002a, 2002b). The other notable result is that in late summer and September-October 2011, there was an extended period where the surface area of the LSZ was large and relatively constant compared to other years (fig. 19). In the other 3 years, the surface area of the LSZ decreased during the preceding summer months, then remained relatively small through the fall and early winter until the first rains.
The predicted surface areas of the LSZ (table 1) were approximately the same as those calculated (table 3 ). The prediction of about 9,000 hectares for the LSZ when X2 is at $74 \mathrm{~km}$ compares favorably with the 8,366 hectares estimated from the data. This is not surprising because both values were calculated from the same model (appendix 2). The difference is that, in fall 2011, average X2 was $75 \mathrm{~km}$, and there was variability in the position of $\mathrm{X} 2$ through the fall. The estimated surface areas for X2 at $82-85 \mathrm{~km}$ were also similar to predicted values (table 3) - between 4,500 and 5,000 hectares. The surface area of the LSZ was expected to decrease when $\mathrm{X} 2$ ranged from 81 to $85 \mathrm{~km}$, and the mean estimated surface area did decrease, as expected, but the standard deviations were approximately equal to the differences between the means (table 3). Given the variability in the values, no firm conclusions are justified concerning the surface area of the $\mathrm{LSZ}$ at the greater values for X2. The prediction that the surface area of low-salinity habitat increases with decreasing X2 values appears to be true when comparing an $\mathrm{X} 2$ of $75 \mathrm{~km}$ to the greater values considered; however, over the shorter range of X2 values, from 82 to $85 \mathrm{~km}$, it is unclear if daily variability in X2 can be operationally controlled sufficiently, such that statistically different areal sizes of LSZ can be provided. Additional work is needed to better understand the operational limits of X2 location control.

The delta smelt abiotic habitat index was greater in September-October 2011 compared to the other years (table 3; fig. 20). The abiotic habitat index was lowest in SeptemberOctober 2010; however, except for September-October 2011, differences between means were relatively small compared to standard deviations, particularly in 2005 and 2006. As for the other measures, this variability makes it difficult to reach any firm conclusions regarding values of the habitat index at X2s in the 81 to $85 \mathrm{~km}$ range. Note that the habitat-index model was developed specifically for the period of the FMWT survey (September-December), so the abiotic habitat index was not calculated for other months.

Generally, there appeared to be little contribution of San Joaquin River flow to Delta outflow through the confluence region and into the LSZ (fig. 21) as measured by the calculated net outflow from the San Joaquin River (QWEST). In 2005 and 2006, QWEST was never positive during September-October. In September-October 2010, 6 days of positive QWEST were observed. In September 2011, 11 days of positive QWEST were observed. QWEST data for October were not available for this report. Although the prediction for San Joaquin River contribution was qualitative, the available data indicated a very low contribution to total outflow even when $\mathrm{X} 2$ is at $74 \mathrm{~km}$; however, 11 days of positive flow in September 2011 was indicative of a greater contribution to flow from the San Joaquin River. The outcome of this prediction could be better determined when water-year 2012 data are finalized. 


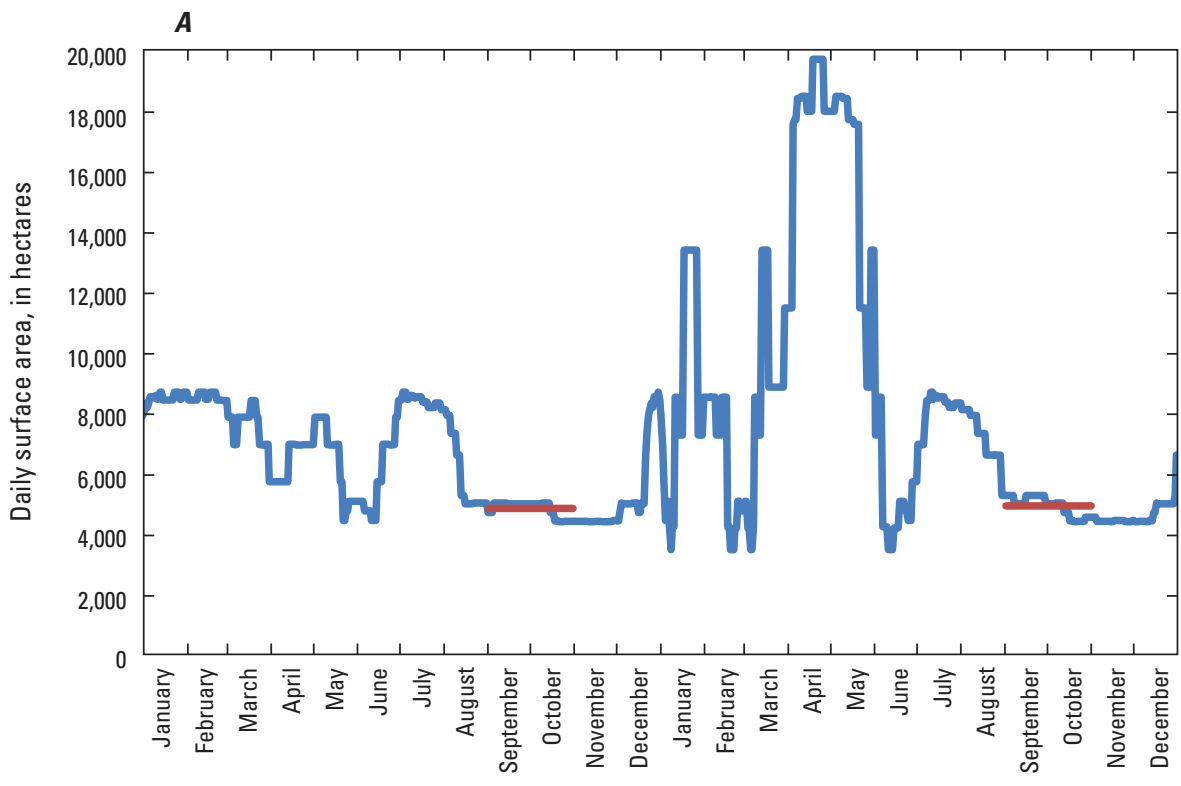

2005-2006

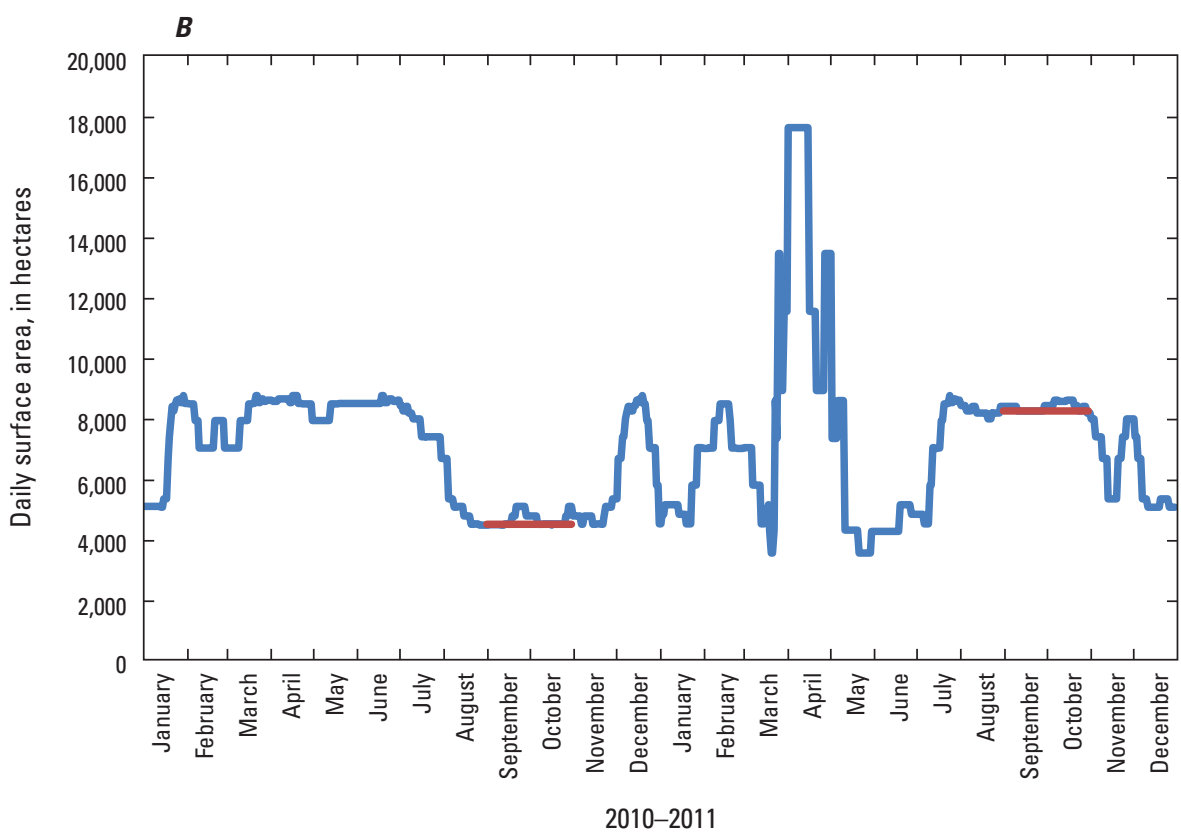

Figure 19. Daily surface area of the depth-averaged low-salinity zone (salinity 1-6) for A, 2005-2006 and B, 2010-2011 (data from table 2.1). Mean daily surface areas during September to October are shown by the horizontal bar. 


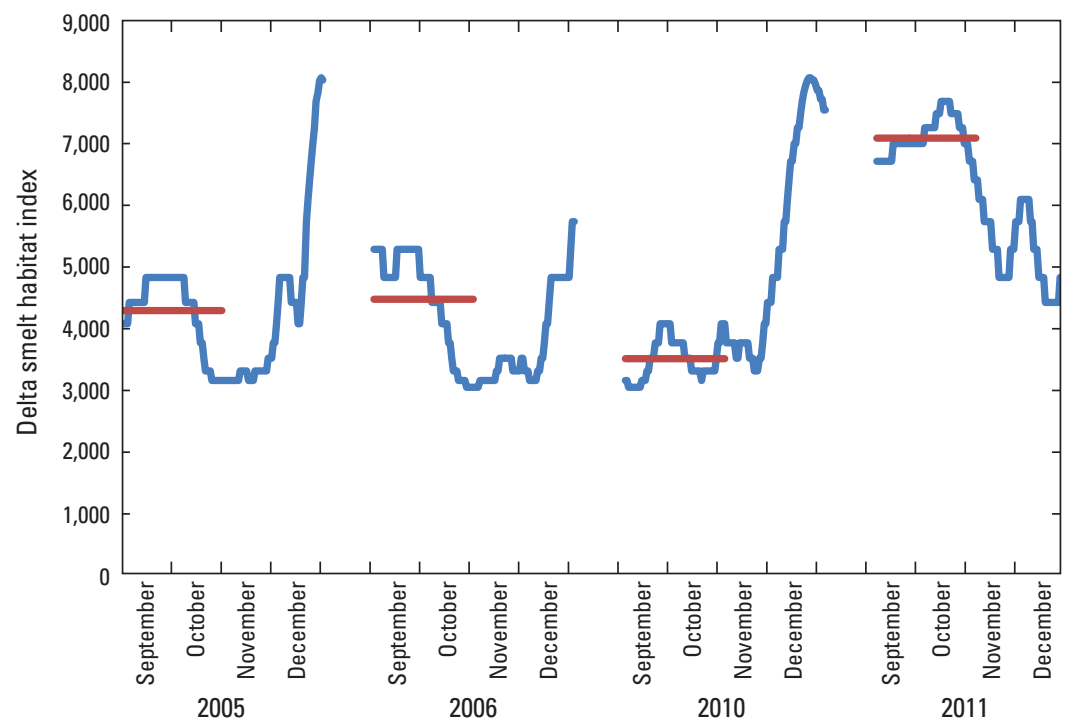

Figure 20. Daily delta smelt habitat index for the fall (September-December) for 2005, 2006, 2010, and 2011 (appendix 3). Mean daily delta smelt habitat index during September to October is shown by the horizontal bar.
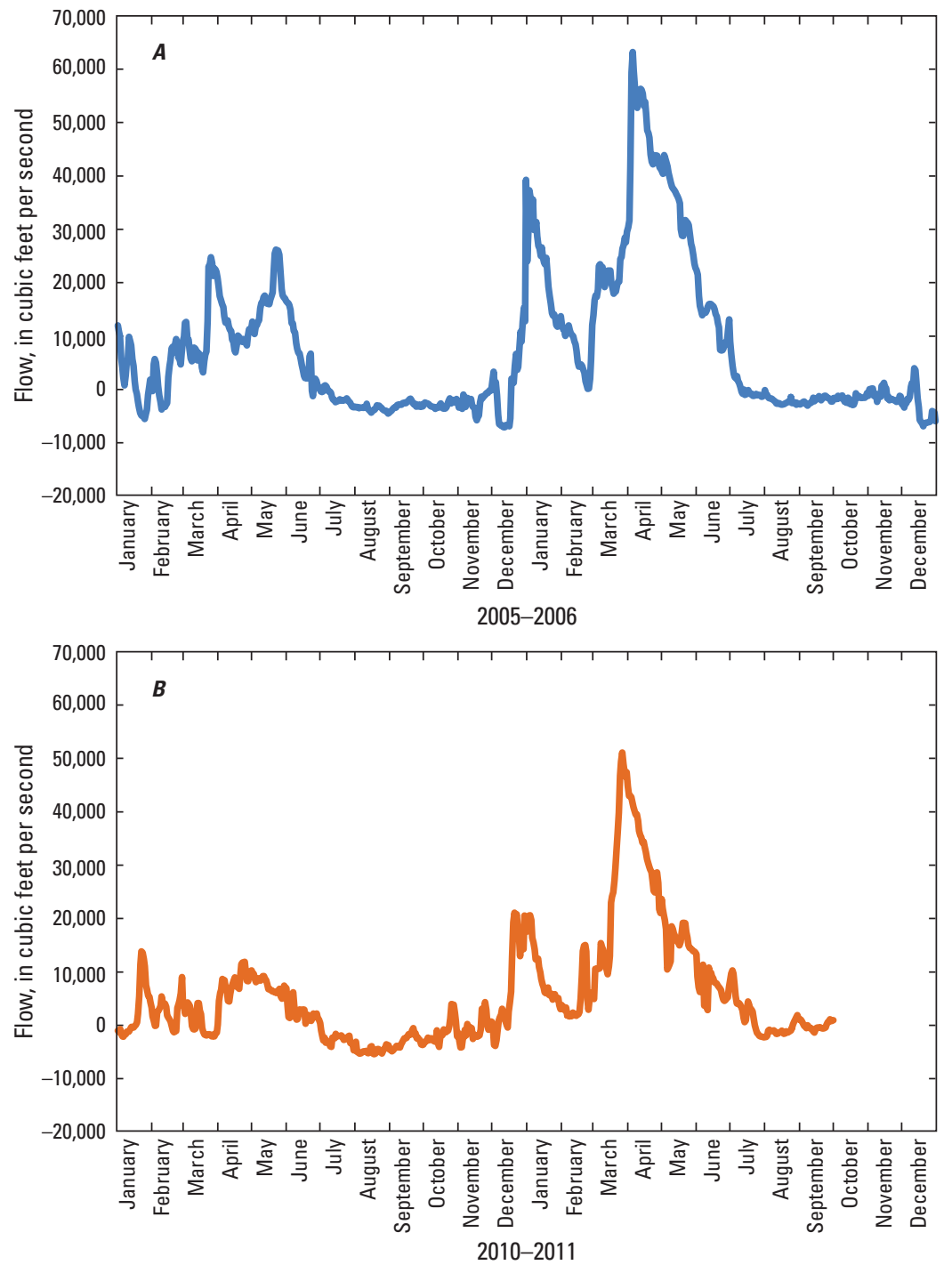

Figure 21. Daily net flow past Jersey Point on the San Joaquin River for $A, 2005-2006$ and B, 2010-2011 (appendix 1). 
The prediction of little to no contribution to fall outflow from San Joaquin River flow with the greatest contribution when $\mathrm{X} 2$ is at $74 \mathrm{~km}$ appeared to be qualitatively correct over the range of X2 considered. The QWEST data are a relatively coarse test of this prediction, and hydrodynamic modeling might provide a more quantitative test.

The prediction about San Joaquin River flow (table 1) is potentially important to delta smelt because of the hypothesized relation between San Joaquin River flow and downstream productivity. The hypothesis is that small "seed" populations transported downstream to the LSZ provide the initial populations for phytoplankton blooms and increased populations of calanoid copepods; however, there are no published data to evaluate this hypothesis. Although, SeptemberOctober total daily Delta outflow (fig. 18) is 10-fold greater than the observed QWEST flows (fig. 21), we cannot rule out the possibility that even modest contributions of San Joaquin River flow could have a biological effect. In 2005, 2006, and 2010, QWEST flows were negative during the preceding months, generally July and August. In contrast, in 2011, positive QWEST flows persisted through most of July. The greater persistence of San Joaquin River contribution into the summer could have effects on productivity that could carry over into the fall.

The prediction regarding increased hydrodynamic complexity at lesser X2 (table 1) could not be evaluated. The FLaSH AMP did not link the prediction with a specific metric to quantify hydrodynamic complexity. Hydrodynamic modeling of SFE could allow for calculation and mapping of hydrodynamic qualities, such as velocity vectors, that could be useful in describing hydrodynamic complexity in a quantitative and easily explainable manner. Deployment of instrument packages, including current profilers, along with existing monitoring stations is likely to provide useful data for calibrating models and directly evaluating hydrodynamic conditions. Some combination of modeling and data collection is necessary to objectively evaluate this hypothesis as the FLaSH AMP continues.

The prediction that wind speed would be higher when $\mathrm{X} 2$ was at $74 \mathrm{~km}$ and lower for X2 at $85 \mathrm{~km}$ could not be evaluated because of lack of data. There are climate monitoring stations in the confluence and Suisun regions; however, they are land-based stations, and it is unclear how the data collected relate to winds across the open waters of the LSZ. This prediction is directly related to predictions regarding turbidity and Secchi depth through the process of wind wave resuspension of fine sediments; however, suspended-sediment concentration also depends on other factors, such as sediment deposition and transport. Wind is also determined by climatic factors independent of the position of the LSZ. Measurements of turbidity seem a more direct connection to factors influencing delta smelt. If there is continued interest in evaluating this prediction, developing a model for wind velocity seems to be a useful approach.
Because the predictions regarding Secchi depth and turbidity are both related to water clarity, we present those results together. The prediction is that turbidity will be greater and Secchi depth lesser at greater X2 (table 1). We first present results from data collected during the FMWT (appendix 4) and then results from detailed analyses of data from fixed sites (appendix 5). We also present additional analyses from fixed sites that are important to understanding the other results.

Secchi depth has a longer data record than turbidity in the FMWT and has been collected since the beginning of the program. In the LSZ, Secchi depth in September-October was lowest in the LSZ in 2011 and highest in 2010 (fig. 22). Overall, September-October Secchi depth was comparable across years and regions, except water clarity tended to be greater in freshwater. Another exception was Cache Slough and the SRDWSC, which had particularly shallow Secchi depth in 2005. The prediction that Secchi depth would be higher when $\mathrm{X} 2$ was at $85 \mathrm{~km}$, and lower when it was at $74 \mathrm{~km}$ was supported for the LSZ.

Turbidity data were only available for the FMWT for 2010 and 2011 (fig. 23). Not surprisingly, differences in turbidity were similar to those for Secchi depth for the available data. Turbidity was greater in the LSZ during SeptemberOctober 2011 compared to 2010. The freshwater region tended to be clearer than the other regions during September-October, although differences from the greater than salinity 6 region were small, especially in 2011. Turbidity in Cache Slough and SRDWSC tended to be greater than in the freshwater and greater than salinity 6 regions, but not as great as in the salinity 1-6 region. Except for the LSZ, turbidities were similar for 2010 and 2011.

The turbidity results were similar to those for Secchi depth for the LSZ in November-December 2011 (figs. 22 and 23). Measurements indicated the LSZ was more turbid in November-December 2011 compared to NovemberDecember 2010. The Secchi depth data had the same trend, but there was more variability in Secchi depth measurements. The prediction that water clarity of the LSZ would decrease (Secchi depth lesser and greater turbidity) with decreasing $\mathrm{X} 2$ values appeared to be true within the range of $\mathrm{X} 2$ values considered $(75-85 \mathrm{~km})$.

Continuous data from fixed sites supported the idea that Suisun Bay was more turbid than the confluence in the fall of 2011 (fig. 24). However, this regional difference in turbidity was independent of any direct influence of X2 or of salinity (appendix 5). The association of water clarity with the LSZ mainly depends on the location of the LSZ with regard to Suisun Bay and the confluence and the water clarity conditions in those areas at any particular time. The pattern observed indicates that in September and the first part of October, Suisun Bay was more turbid than the confluence. In late October and November, the confluence was generally more turbid than Suisun Bay. In December, there was no clear pattern (fig. 24). 


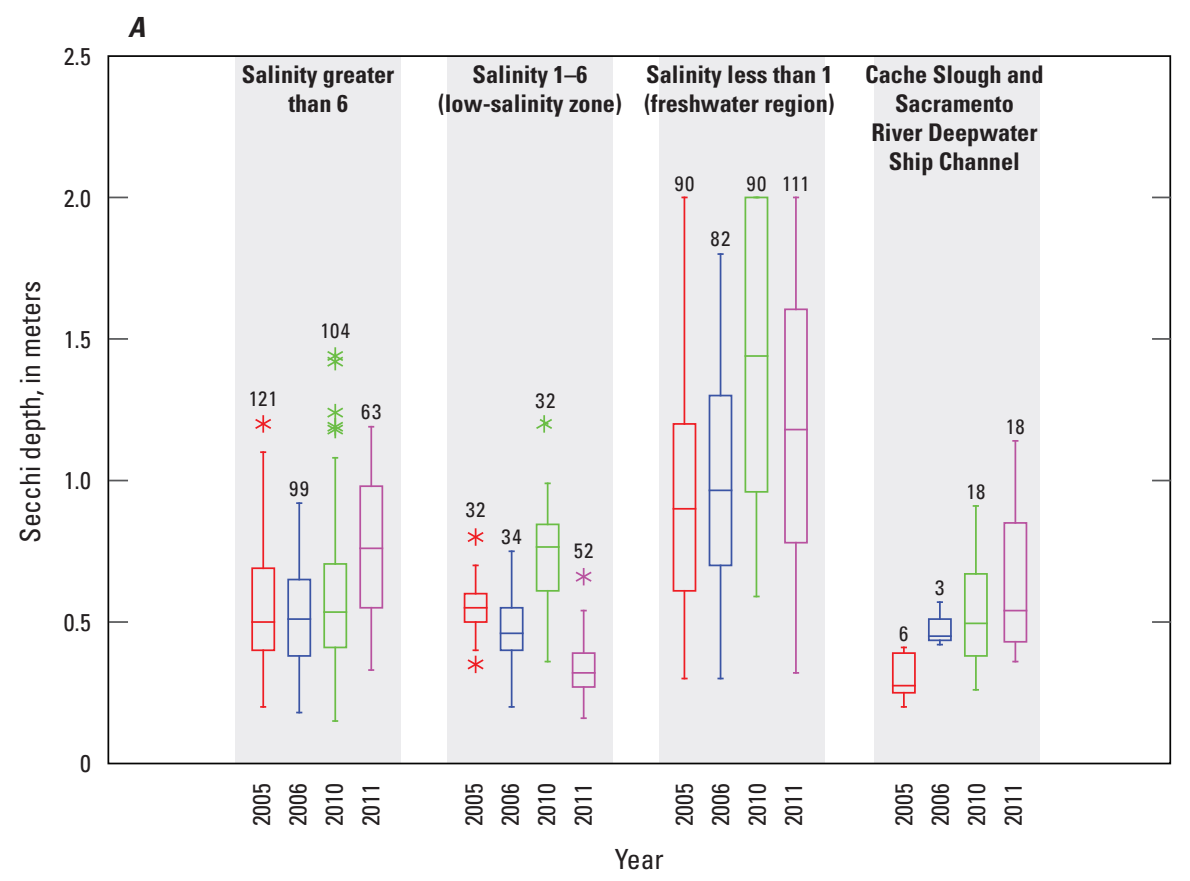

\section{EXPLANATION}

3 Sample size

* Values greater than 1.5 times the interquartile distance from the 75th percentile

Range of values falling within 1.5 times the interquartile distance from the 75th percentile

75th percentile

Median

25th percentile

Range of values falling within 1.5 times the interquartile distance from the 25th percentile

* Values less than 1.5 times the interquartile distance from the 75th percentile

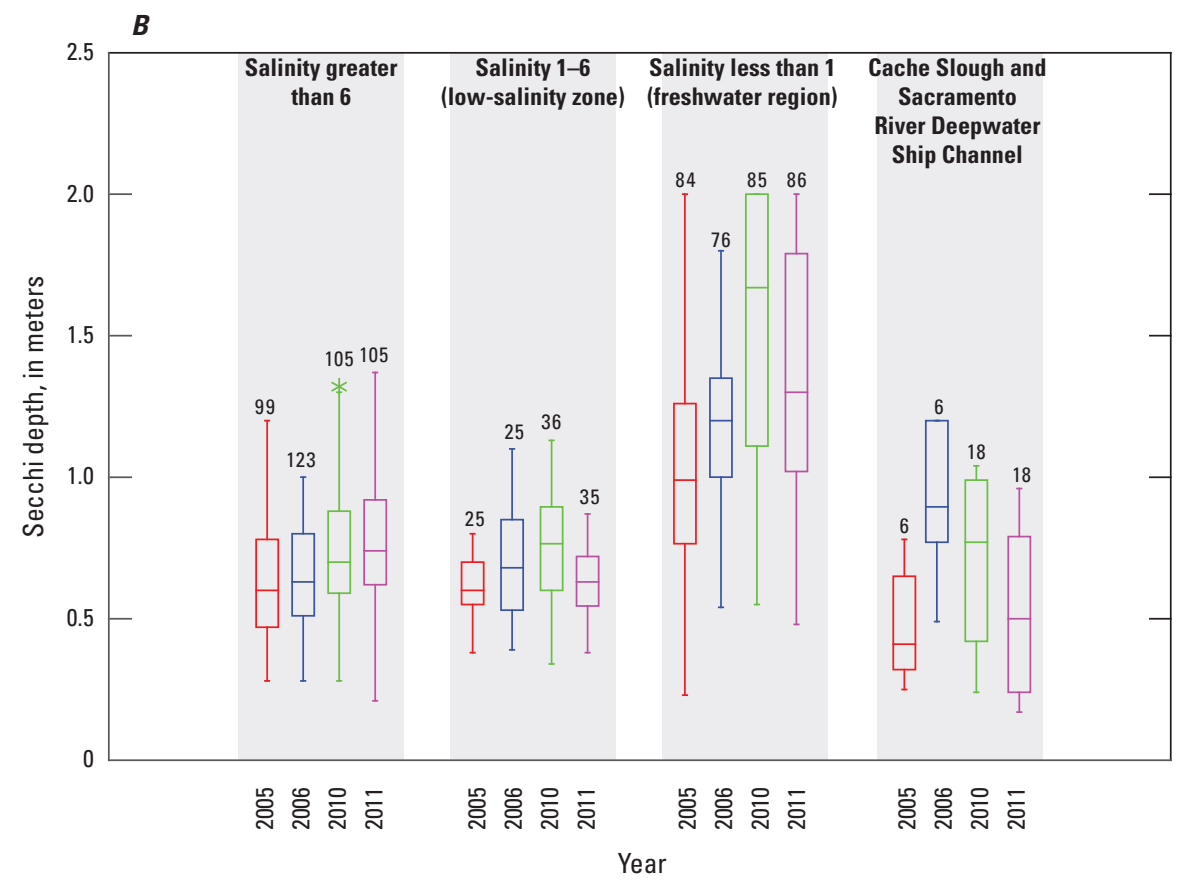

Figure 22. Graphs showing Secchi depth data collected during the fall midwater-trawl survey: $A$, September-0ctober; and $B$, November-December (appendix 4). 


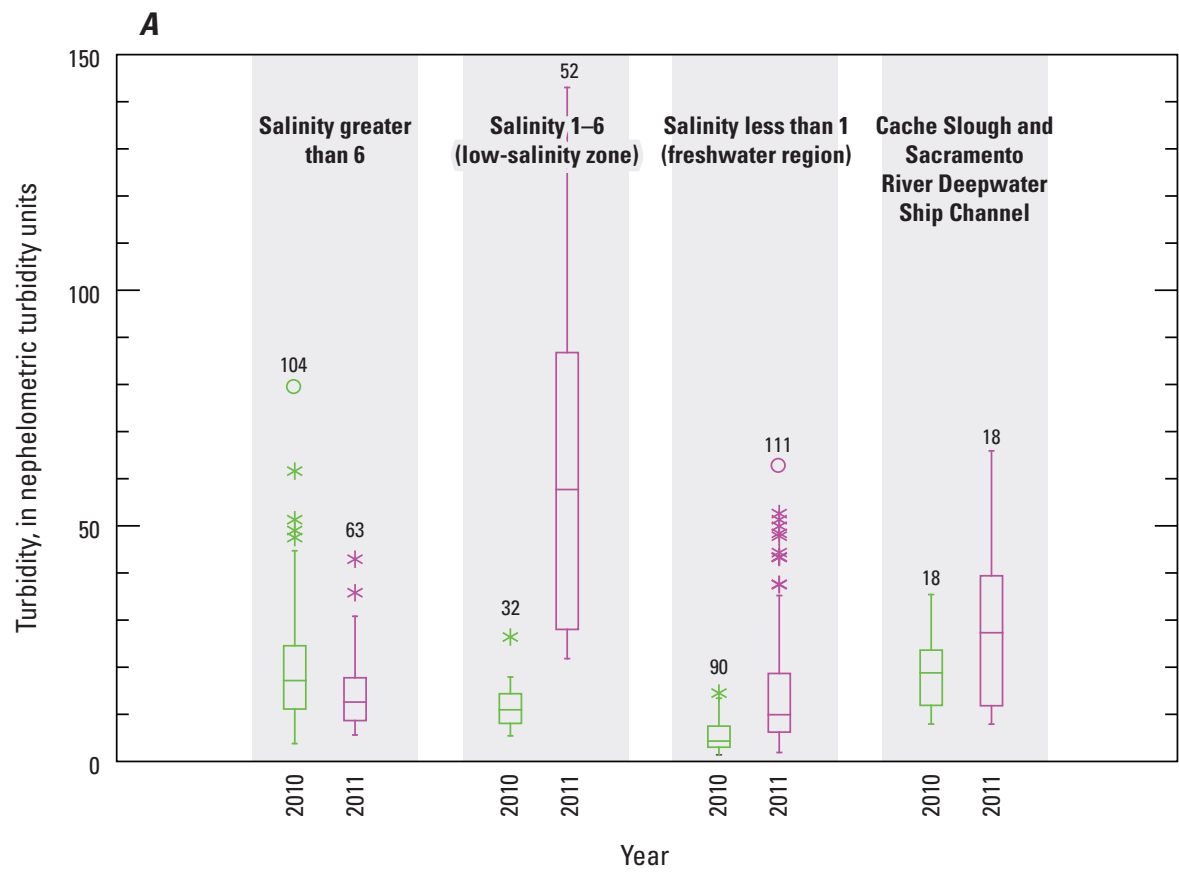

\section{EXPLANATION}

18 Sample size

* Values greater than 1.5 times the interquartile distance from the 75th percentile

Range of values falling within 1.5 times the interquartile distance from the 75th percentile

75th percentile

Median

25th percentile

Range of values falling within 1.5 times the interquartile distance from the 25th percentile

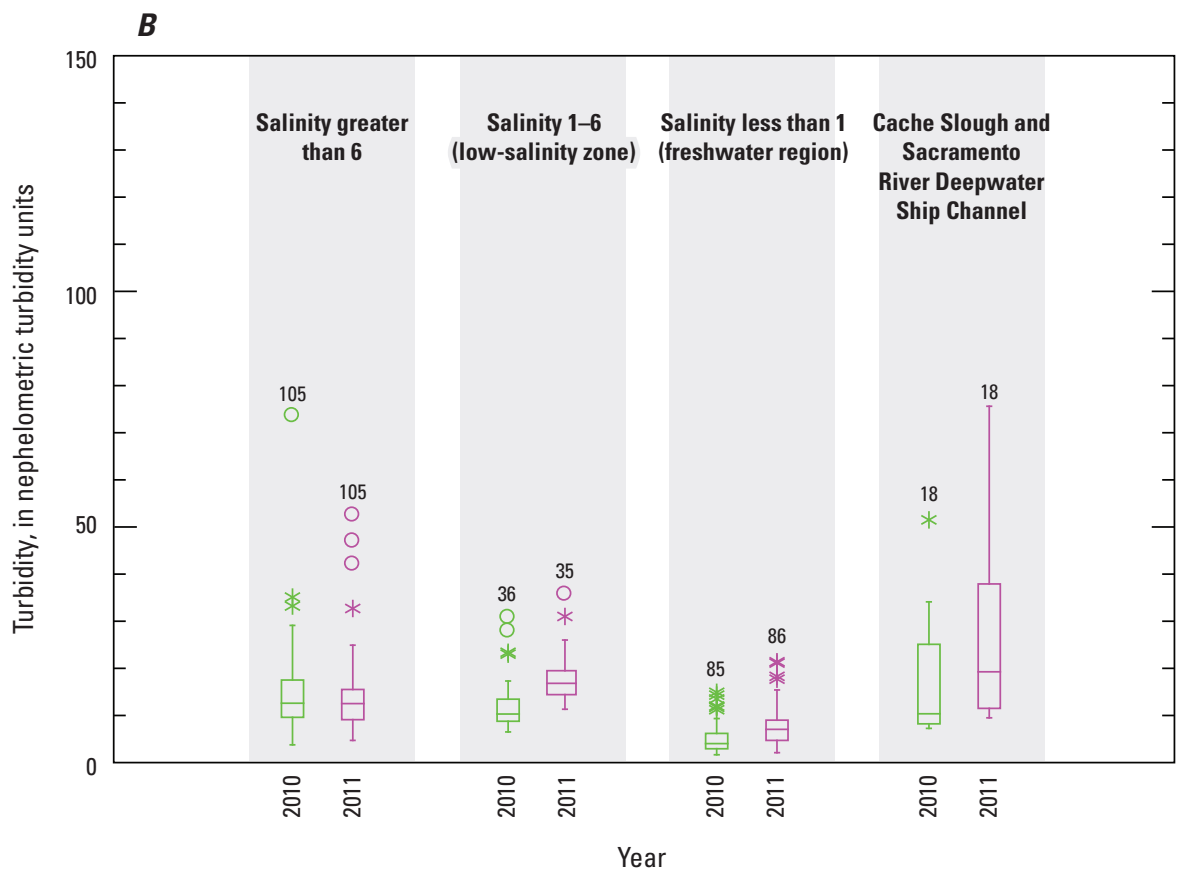

Figure 23. Turbidity data collected during the fall midwater-trawl survey: $A$, September-0ctober; and $B$, November-December (appendix 4). These data were not collected in 2005 and 2006. 


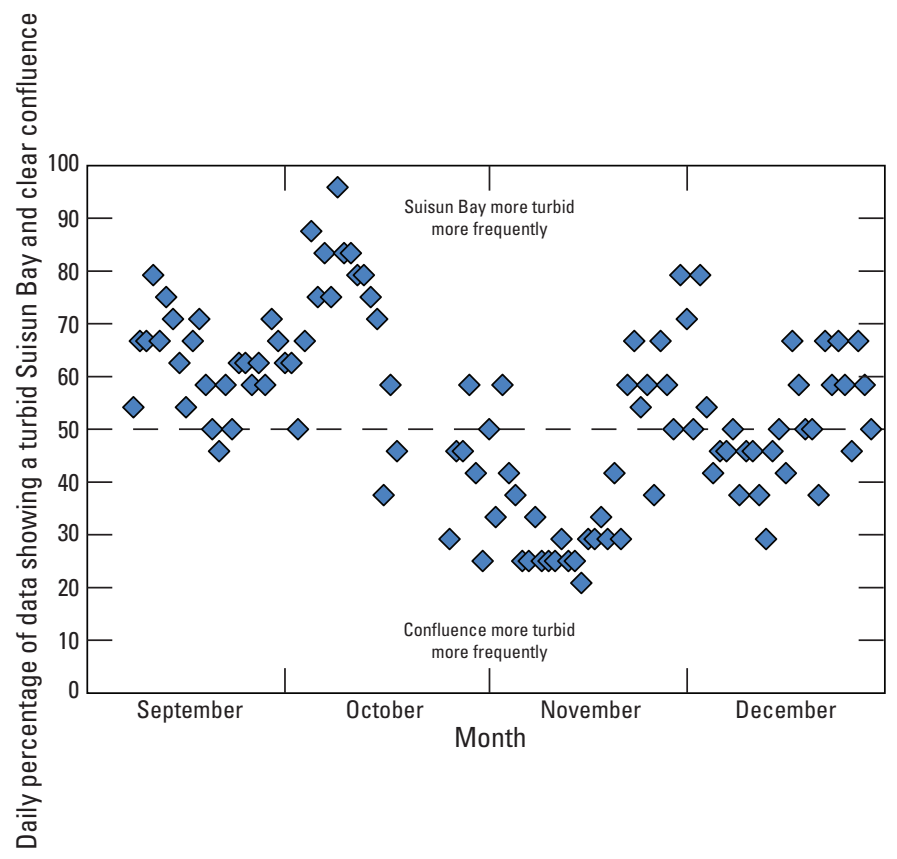

Figure 24. Percentage of data showing a turbid bay and clear confluence, September-December 2011, calculated from the product of hourly deviations of specific conductance and suspended-sediment concentration (SSC) from tidally averaged values. Values greater than 50 percent indicate specific conductance and SSC are either both positive (relatively turbid bay water) or negative (relatively clear confluence water). Values less than 50 percent indicate that deviations of conductance and SSC have opposite signs (relatively clear bay or relatively turbid confluence). See appendix 5 for details.

Although the prediction for turbidity did not include the Cache Slough area, continuous fixed-site data also indicated that Suisun Bay was usually more turbid than the Cache Slough complex in fall 2011 and that turbidity at Mallard Island (confluence region) was greater in fall 2011 than fall 2010. In the Cache Slough complex, however, the opposite was observed; turbidity was greater in fall 2010 than in 2011. Differences in turbidity between Mallard Island and the Cache Slough complex were not consistent between years (appendix 5).

Although the prediction that $\mathrm{X} 2$ at $74 \mathrm{~km}$ was associated with a more turbid LSZ was supported by the data, analysis of long-term trends indicate caution should be applied in assuming that actual turbidity levels will remain consistent over time. Fall suspended-sediment concentration (SSC) at Mallard Island, in the confluence region, decreased by about one-half from 1994 to 2011 (fig. 25; appendix 5). This is consistent with a 50 percent decrease in total suspended-solids concentration (equivalent to SSC in this estuary) in the Delta from 1975 to 1995 (Jassby and others, 2002). In 1999, there was a 36 percent step decrease in SSC in San Francisco Bay when the threshold from transport to supply regulation was crossed because an anthropogenic erodible sediment pool was depleted (Schoellhamer, 2011). Thus, the decrease shown at Mallard Island is consistent with other observations in the estuary and reflects increased water clarity in the SFE as a whole.

Although there was no specific prediction regarding water temperature, it can be an important explanatory variable through its effects on fish growth and physiology and other biological and physical processes. There was relatively little interannual variability in water temperature within a salinity region for any particular month (fig. 26). The freshwater regions tended to be warmer than the LSZ and the greater than salinity 6 region in September, but not in the other months. Water temperatures in 2011 were generally cooler than water temperatures in 2010, except for September.

The major sources of ammonium in the system include point sources of treated wastewater, with the large treatment plant servicing Sacramento and discharging into the Sacramento River constituting a major source (Jassby, 2008). The prediction that ammonium concentrations will be greater when $\mathrm{X} 2$ is at $85 \mathrm{~km}$ compared to $74 \mathrm{~km}$ in table 1 is based on simple dilution. It is expected that the higher flows associated with maintaining X2 at $74 \mathrm{~km}$ will result in lower concentrations of ammonium in the LSZ. On the basis of the Environmental Monitoring Program (EMP) data, concentrations in September-October did not show consistent patterns within or among years (fig. 27). In the LSZ, ammonium concentrations were higher in 2011 compared to 2010. Concentrations of ammonium were generally less than 0.1 milligrams per liter $(\mathrm{mg} / \mathrm{L})$ during September-October in all years. The EMP data indicated that there was little difference in ammonium concentrations for 2006, 2010, and 2011 in the LSZ during November-December (fig. 27). Ammonium concentrations appeared higher in 2005 compared to other years in the LSZ and greater than salinity 6 region. The prediction of lower concentrations of ammonium in the LSZ with lesser values for $\mathrm{X} 2$ was not supported by the EMP data.

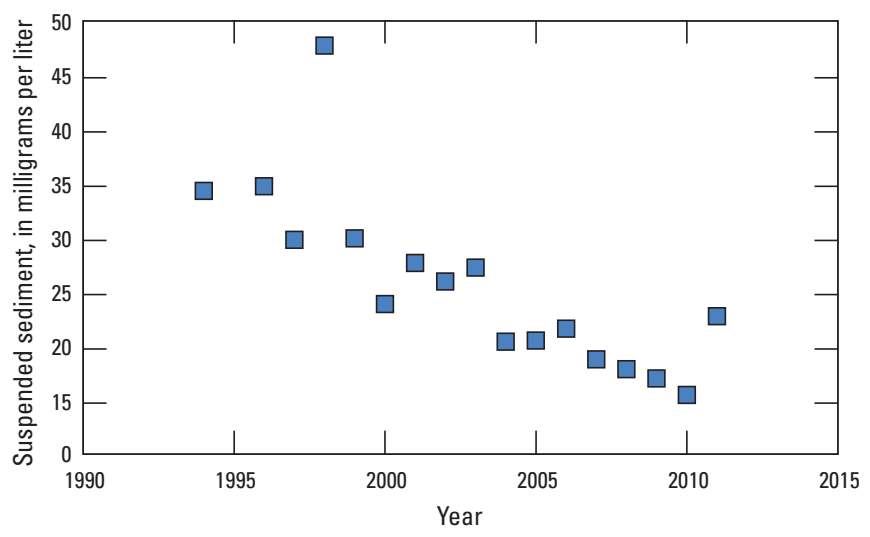

Figure 25. Near-surface suspended-sediment concentration (SSC) at Mallard Island, September-0ctober mean values, 1994-2011. Measurements from 1995 are not included because there were insufficient SSC data. See appendix 5 for more detail on methods and data sources. 
A
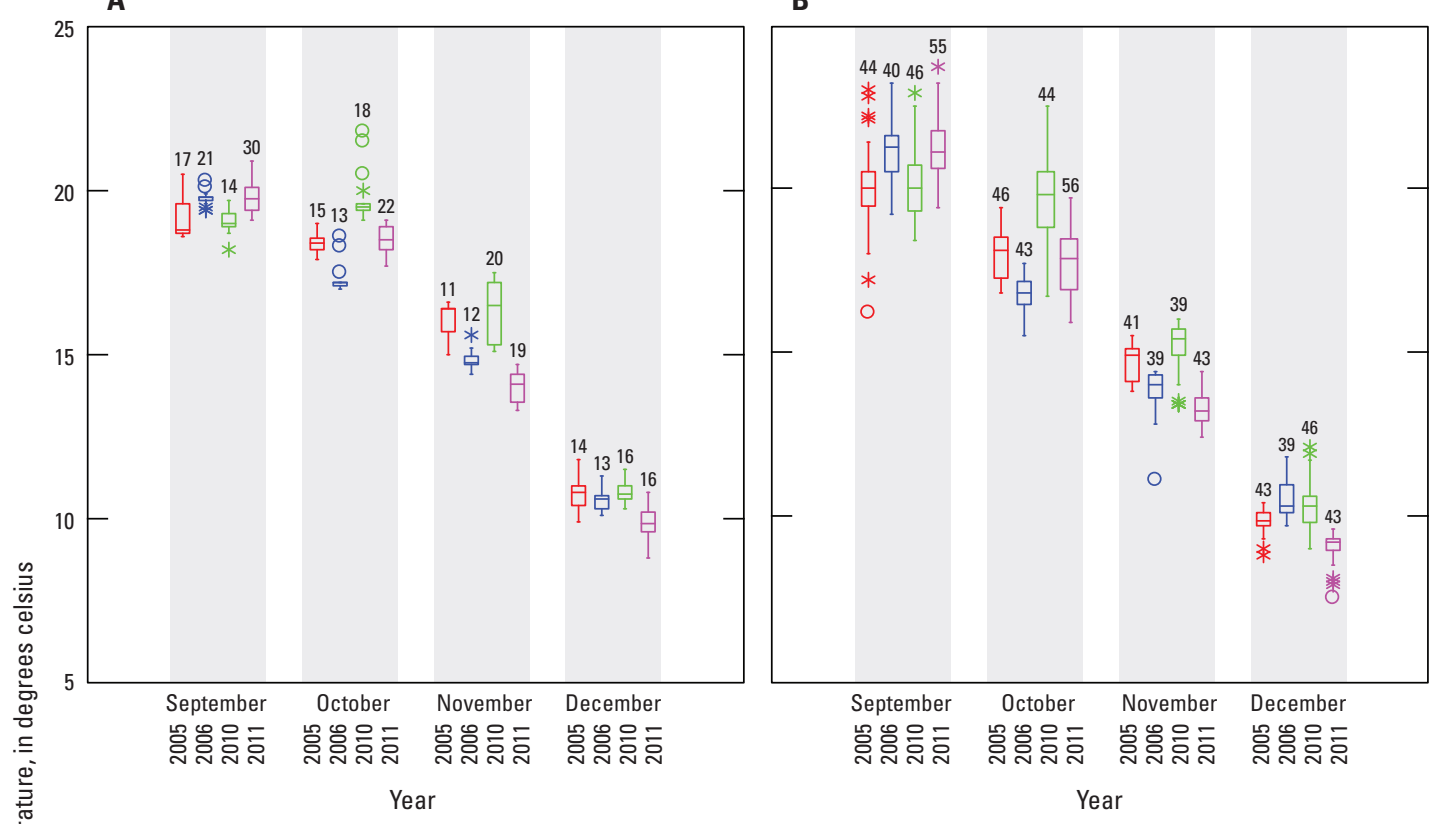

D

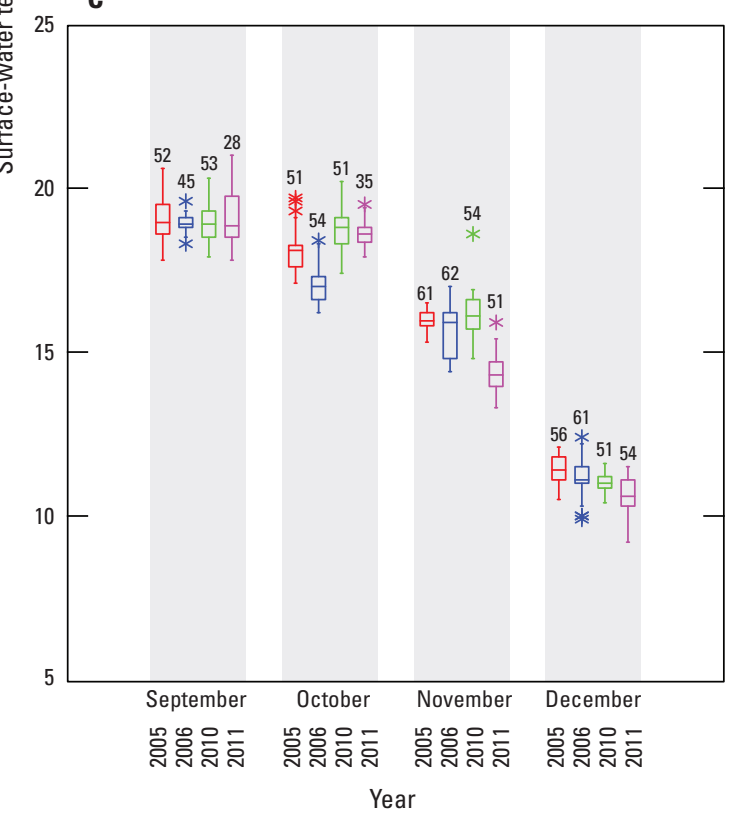

EXPLANATION

3 Sample size

* Values greater than 1.5 times the interquartile distance from the 75th percentile

Range of values falling within 1.5 times the interquartile distance from the 75th percentile

75th percentile

Median

25th percentile

Range of values falling within 1.5 times the interquartile distance from the 25th percentile

* Values less than 1.5 times the interquartile distance from the 75th percentile

Figure 26. Surface-water temperature at fall midwater-trawl sampling sites during monthly sampling for the $A$, salinity 1-6, low-salinity zone; $B$, salinity less than 1 , freshwater region; $C$, salinity greater than 6; and $D$, Cache Slough and Sacramento River Deep Water Ship Channel (see appendix 4 for data sources). 


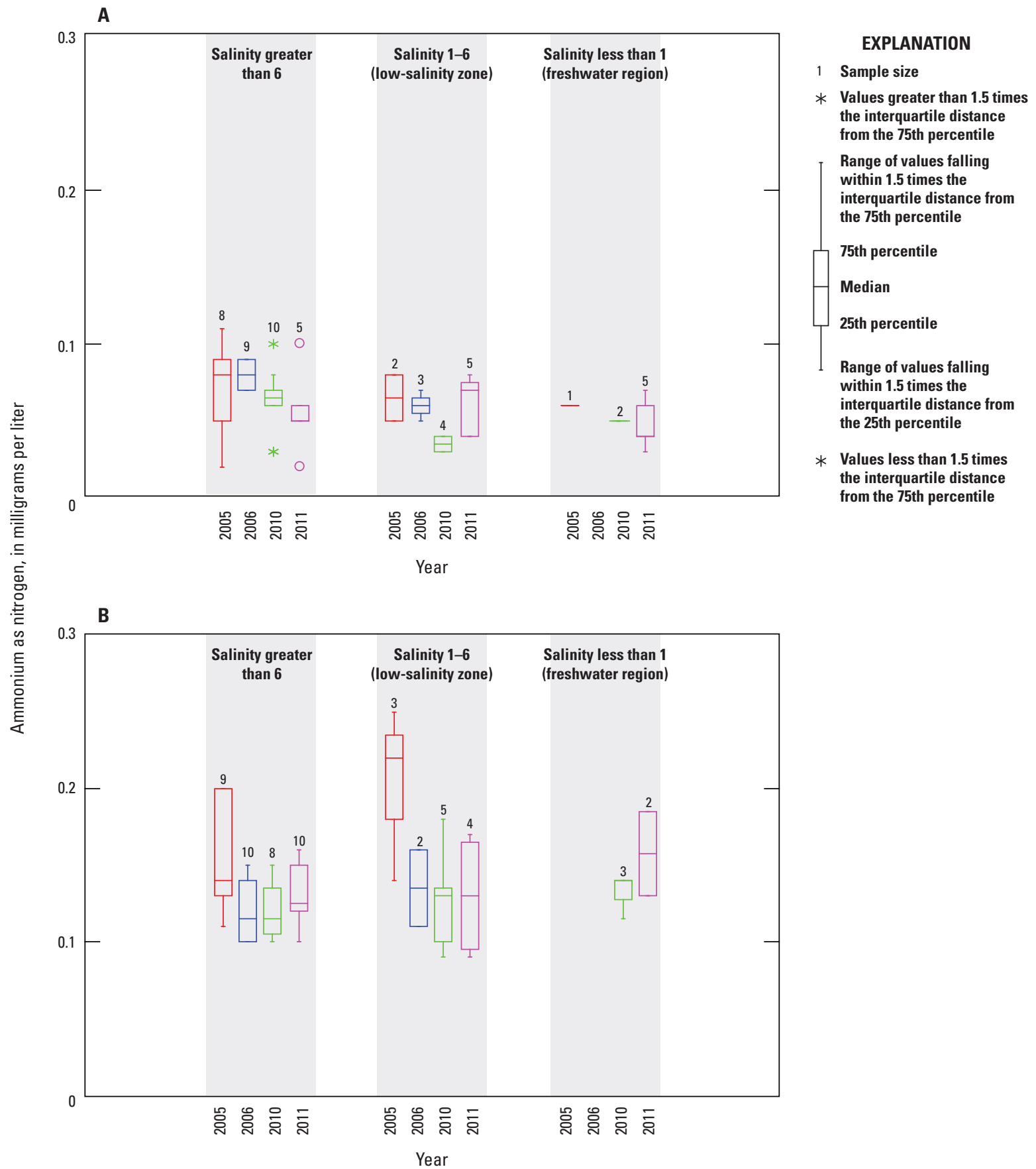

Figure 27. Ammonium concentrations as nitrogen from the Environmental Monitoring Program: $A$, September-0ctober; and $B$, November-December (see appendix 6 for data sources). 
Ammonium data collected during U.S. Geological Survey (USGS) Polaris cruises (fig. 28) differed somewhat from the EMP data (fig. 27). In September-October, the LSZ showed no clear trend among years. Median values in the LSZ and greater than salinity 6 region were near or less than $0.1 \mathrm{mg} / \mathrm{L}$ in both data sets. The USGS data tended to show higher concentrations in freshwater compared to the EMP data, but the USGS sampling program included more stations in the freshwaters of the Sacramento River compared to the EMP data set (appendixes 6 and 7). Similar to the EMP data, the USGS data showed higher concentrations of ammonium in November-December compared to September-October. As with the EMP data, the USGS data did not support the prediction of reduced ammonium concentrations for X2 at $74 \mathrm{~km}$ compared to $85 \mathrm{~km}$.

Ammonium concentrations were measured at FMWT stations concurrent with fish sampling for the first time in 2011 (fig. 29). Unfortunately, time-series data are not yet available for comparison. The concentrations measured during FMWT were generally similar to those measured by the EMP and by the USGS. In September-October 2011, there were some relatively high and low concentrations measured in freshwater compared to the LSZ and greater than salinity 6 region. The interquartile range of the less than salinity 1 region contained the entire range of ammonium concentrations measured in the LSZ and greater than salinity 6 region. During November-December, ammonium concentrations in freshwater were higher than those measured in the LSZ and greater than salinity 6 region, except for one value (fig. 29). These results were similar to the USGS data (fig. 28). The EMP data also showed a slightly higher median value for the freshwater region in November-December 2011 (fig. 27), but the difference in values was not as great as in the other two data sets.

The EMP and USGS data that were used to assess the predictions in table 1 were from monthly sampling at fixed locations in the estuary. Studies of nitrogen cycling generally require shorter sampling intervals than monthly. Such studies were included in the FLaSH investigation, but those data were not available for inclusion in this report. It is somewhat unclear if the research being done as part of FLaSH actually addresses the prediction as stated because nutrient cycling involves many processes other than the simple dilution that is the basis for the prediction. The differences among the EMP, USGS, and FMWT results in 2011 could be due to many factors, including differences in analytical techniques, spatial variability in ammonium concentrations, and changes in ammonium concentrations over time. The relations of ammonium to $\mathrm{X} 2$ values and the LSZ require further research, including analysis of already collected data and continued data collection.

In the EMP data set, nitrite plus nitrate concentrations were generally between 0.2 and $0.4 \mathrm{mg} / \mathrm{L}$ during September-October across all regions in all years (fig. 30). In the LSZ, concentrations in 2011 were similar to 2010 and lower than 2005 and 2006. Overall, 2011 tended to have the lowest concentrations in all years and in all salinity regions.
The EMP data did not support the prediction (table 1) of higher LSZ nitrate concentrations when X2 is at $74 \mathrm{~km}$ compared to $85 \mathrm{~km}$. The prediction was based on the assumption that at higher outflows, more nitrate would be contributed to the LSZ from the nitrate-rich smaller sloughs of the Cache Slough region, the San Joaquin River, or both.

Nitrite plus nitrate concentrations for September-October were generally between 0.2 and $0.4 \mathrm{mg} / \mathrm{L}$ and were similar in the USGS data set (fig. 31) and the EMP data set (fig. 30) with little difference across years and regions. In the LSZ, concentrations were generally lower during September-October 2011 than in other years. There was more variability among years in November-December; however, concentrations in 2011 were always similar to or lower than other years within each region. As with the EMP data, the USGS data did not support the prediction that nitrite plus nitrate concentrations would be higher when X2 was at $74 \mathrm{~km}$ compared to greater values of X2.

Similar to the ammonium measurements, 2011 was the first year that nitrite plus nitrate concentrations were determined during FMWT sampling. Concentrations during FMWT in September-October were lower in freshwater than in the LSZ or greater than salinity 6 region (fig. 32). The lowest concentrations were observed in the Cache Slough region. There was little difference among regions in November-December; however, there was a greater range of nitrite plus nitrate concentrations in the Cache Slough region (fig. 32).

\section{Predictions for Dynamic Biotic Habitat Components}

The concentration of chlorophyll- $\alpha$ is a common surrogate for phytoplankton biomass. The average concentration of chlorophyll- $\alpha$ in the LSZ was predicted to increase in response to $\mathrm{X} 2$ at $74 \mathrm{~km}$ compared to $\mathrm{X} 2$ at greater distances (phytoplankton biomass prediction; table 1) for several reasons, but this prediction does not include Microcystis, which is addressed in a separate section. If the assumed inhibitory effect of ammonium on diatom growth is lessened in the LSZ as a result of higher flows, production of diatoms would be expected to increase, as indicated by increased concentrations of chlorophyll- $\alpha$. Increased nitrate concentrations in the LSZ would also tend to increase the biomass if the initial or subsequent production of phytoplankton was limited by available nitrate. Also, the location of the LSZ could influence the interaction between phytoplankton and grazers, including clams and zooplankton. The prediction that biomass of Potamocorbula, a major grazer of phytoplankton, would be lower when X2 is at $74 \mathrm{~km}$ compared to greater distances is based on this interaction. The hypotheses concerning phytoplankton and Potamocorbula biomass are relatively simplistic for several reasons. For example, nutrient concentrations are likely to depend on chemical processes (that is, nutrient cycling) other than simple dilution and transport. Also, it is assumed that chlorophyll- $\alpha$, the selected indicator of biomass, provides an indication of primary production in the system. 


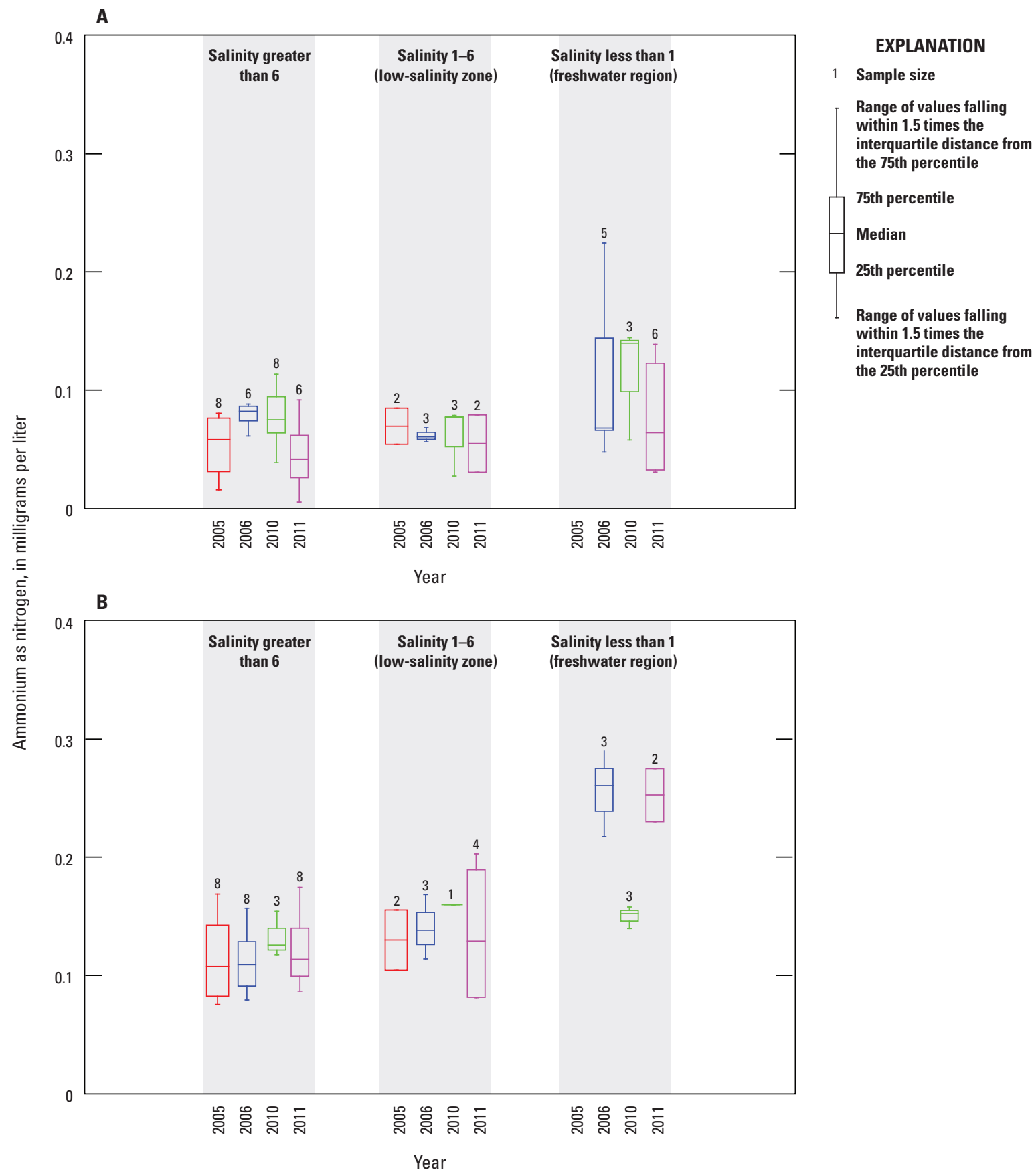

Figure 28. Ammonium as nitrogen data from U.S. Geological Survey monthly sampling cruises: $A$, September-0ctober; and $B$, November-December (see appendix 7 for data sources). 


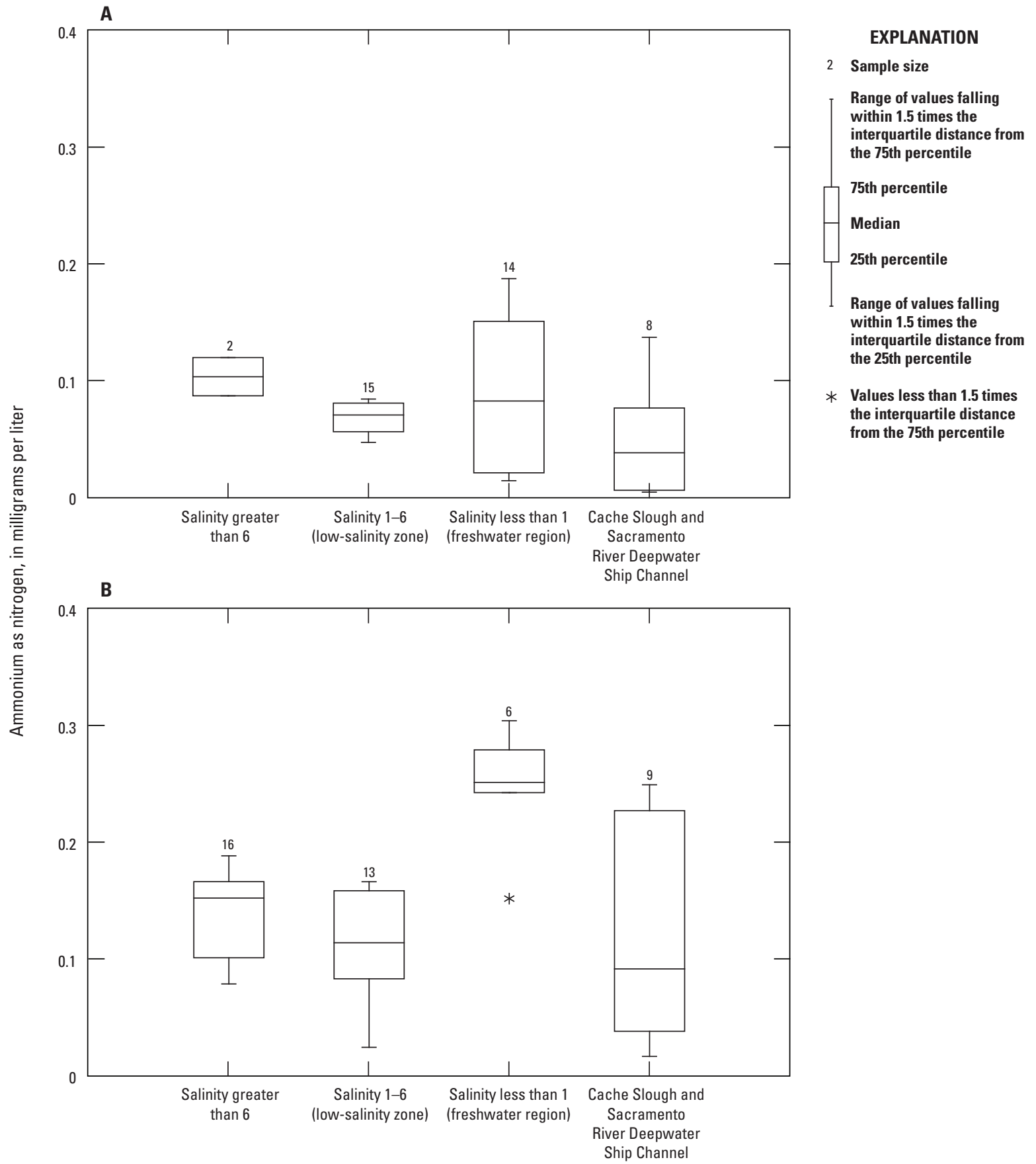

Figure 29. Ammonium as nitrogen concentrations in fall 2011 from samples collected during the fall midwater-trawl survey: $A$, September-October; and B, November-December (see appendix 4). 


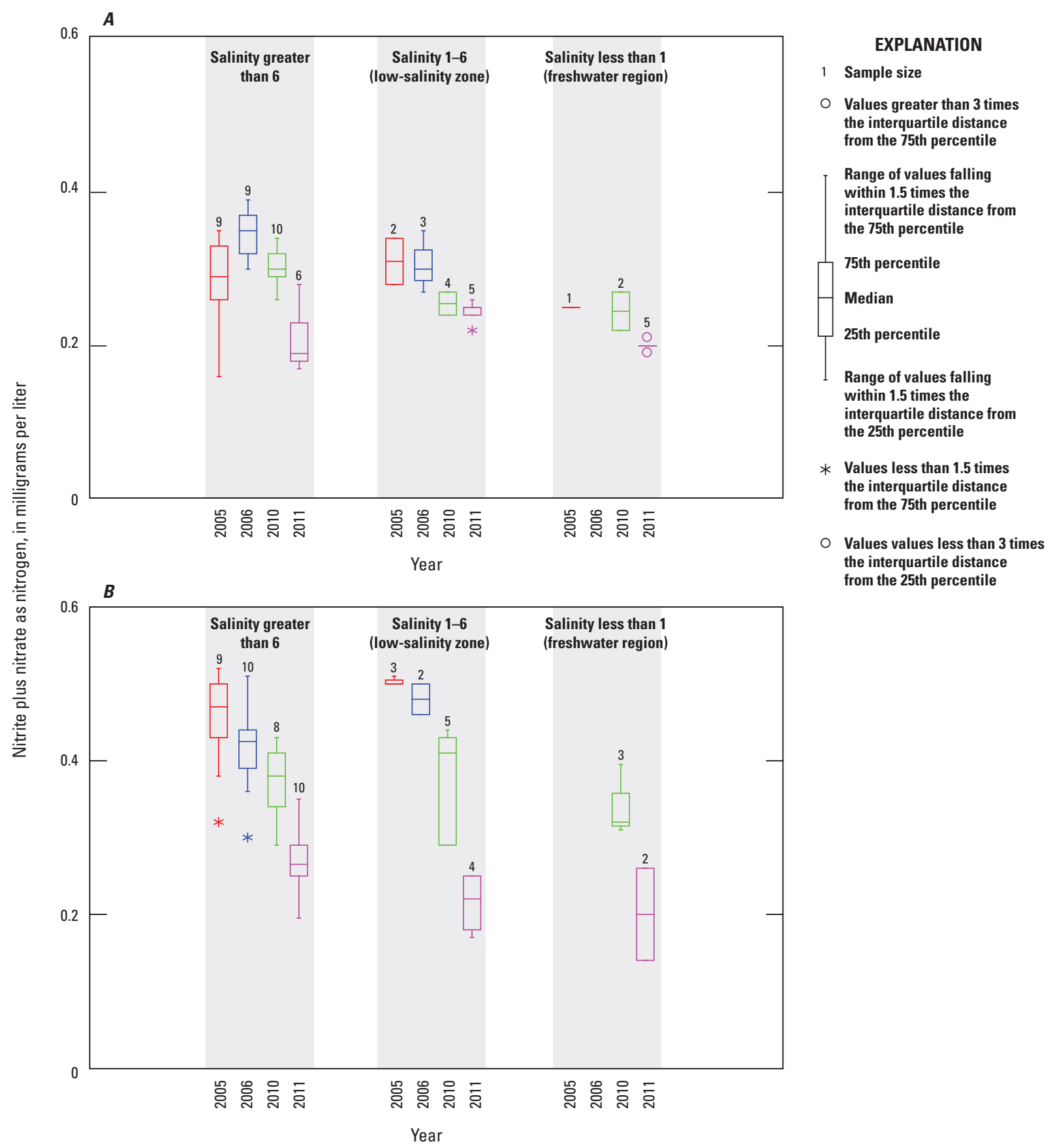

Figure 30. Nitrite plus nitrate as nitrogen concentrations in September-October and November-December from the Environmental Monitoring Program: $A$, September-0ctober; and $B$, November-December (see appendix 6 for data sources). 


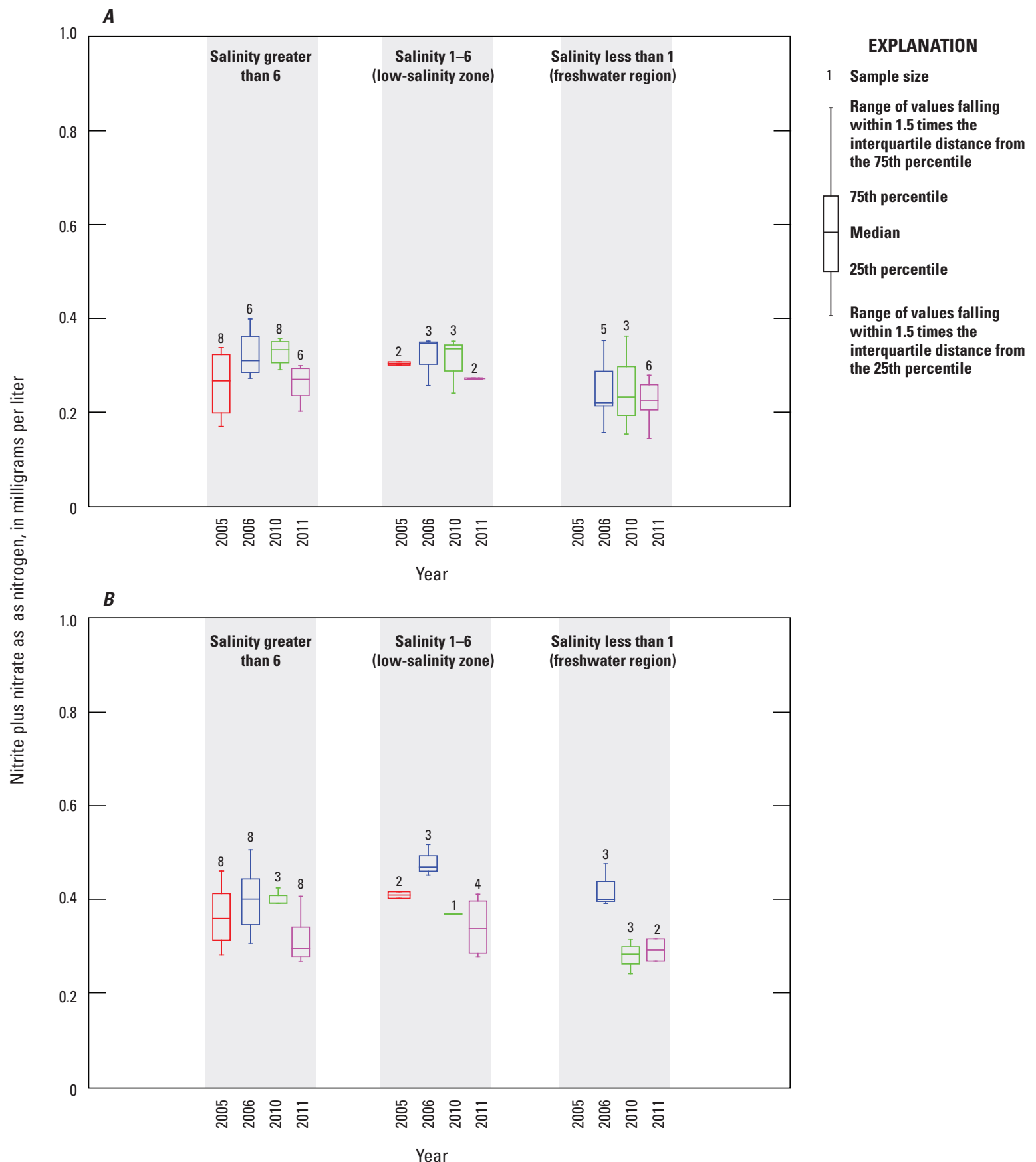

Figure 31. Nitrite plus nitrate as nitrogen concentrations from samples collected during monthly U.S. Geological Survey cruises: $A$, September-0ctober; and $B$, November-December (see appendix 7 for data sources). Original concentrations of nitrite plus nitrate were measured in micromoles. 


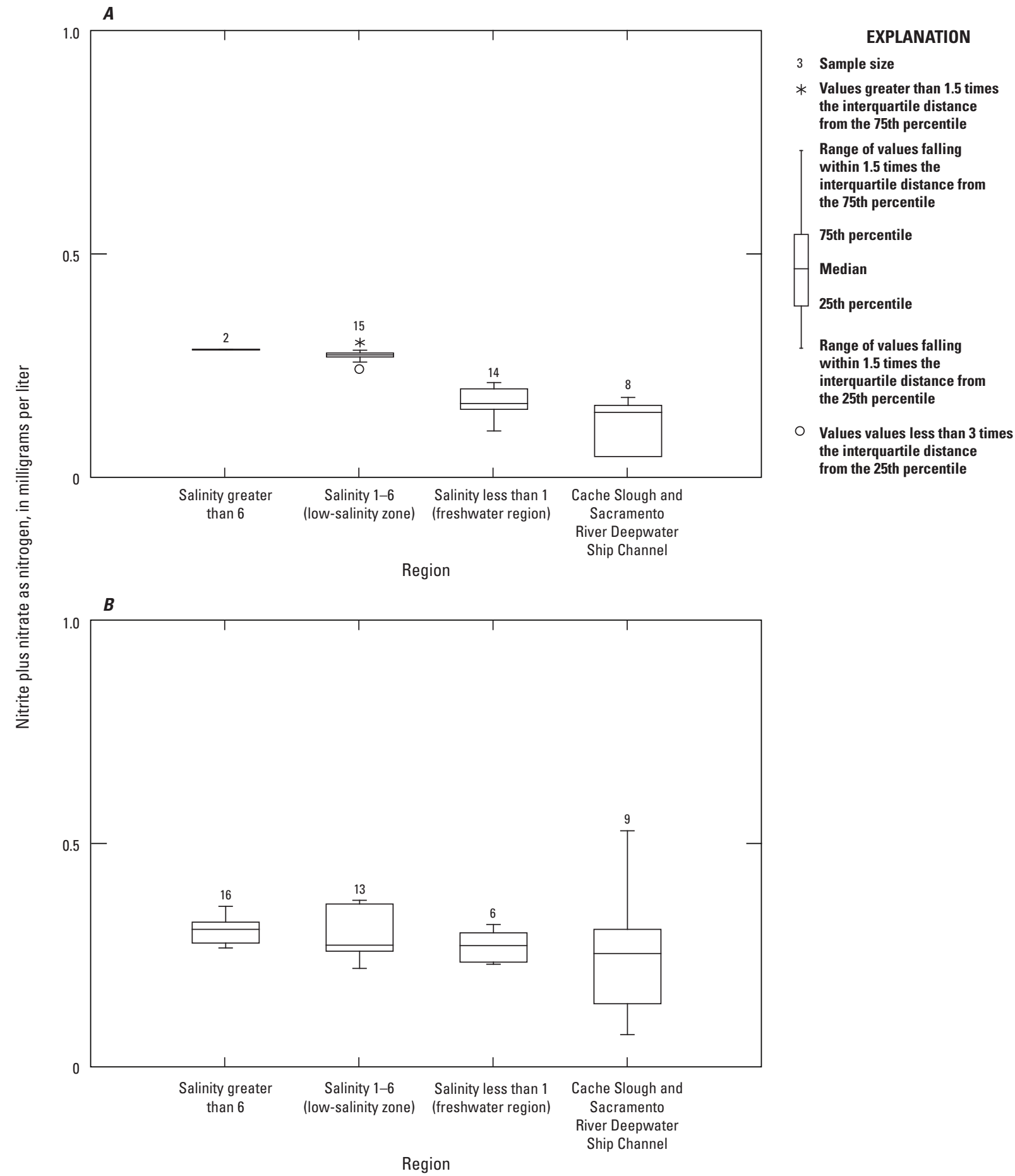

Figure 32. Nitrite plus nitrate as nitrogen concentrations in fall 2011 from the samples collected during the fall midwater-trawl survey: $A$, September-October; and $B$, November-December (see appendix 4 for data sources). 
While production is certainly proportional to biomass, it also depends on the growth rate of the phytoplankton population. The population growth rate of phytoplankton can depend on nutrient concentrations, depth of the photic zone, and circulation of phytoplankton into and out of the photic zone. Furthermore, phytoplankton biomass can depend on complex interactions of factors affecting grazing, such as density of grazers, water temperature, channel characteristics (for example, depth), and hydrodynamics (Lucas and others, 2002; Lopez and others, 2006; Cloern, 2007; Lucas and Thompson, 2012). The basic hypothesis from which these individual predictions about phytoplankton responses were derived is that LSZ primary production (total carbon produced) increases when the LSZ is located in the shoals of the Suisun region (that is, X2 is at $74 \mathrm{~km}$ ), mostly because of increased volume of the photic zone. Increased primary production might support organisms that are eaten by Delta Smelt and other organisms. We address each of the predictions in the AMP individually and on their own merits. We also recognize that the predictions concern a variable (biomass) that is relatively easy to measure, while rates of biological and chemical processes can be very difficult to measure. We expect that the predictions and hypotheses will become more sophisticated as the adaptive management cycle proceeds and the conceptual model is revised in response to research and monitoring results.

Chlorophyll- $\alpha$ concentrations were not particularly high in the LSZ in September-October 2011 based on EMP monthly sampling (fig. 33). In September-October 2011, concentrations were lowest in the LSZ and higher in the greater than salinity 6 and freshwater regions. One high observation in the greater than salinity 6 region could be indicative of a bloom. Median chlorophyll- $\alpha$ concentrations during September-October in the LSZ were generally low, but were higher in 2010 compared to 2011, and concentrations were lowest in 2005 and 2006. The EMP data did not support the hypothesis of greater average phytoplankton biomass as measured by chlorophyll- $\alpha$ at lower X2 values. The other predictions regarding diatoms and other algae in the phytoplankton could not be evaluated because relative biomasses were not available for different algal groups or the characteristics of hydrodynamic complexity have not been defined and so could not be applied to the available data.

In contrast to the EMP data, the data from USGS monthly cruises appeared to support the prediction of more LSZ phytoplankton biomass at lower X2 near $74 \mathrm{~km}$ (fig. 34). Chlorophyll- $\alpha$ concentrations were greatest in SeptemberOctober 2011 when X2 was $75 \mathrm{~km}$ compared to other years across all salinity regions, when $\mathrm{X} 2$ was greater. High chlorophyll- $\alpha$ concentrations continued in the LSZ during November-December 2011. In the other salinity regions, chlorophyll- $\alpha$ concentrations were similar across the years.
Water samples collected during the 2011 FMWT were analyzed for chlorophyll- $\alpha$ (fig. 35). The FMWT samples showed a general trend toward higher concentrations of chlorophyll- $\alpha$ in freshwater habitats, particularly in the Cache Slough complex, in September-October and NovemberDecember 2011, although concentrations were higher in September-October. In the EMP data, the highest concentrations of chlorophyll- $\alpha$ were also found in freshwater (fig. 33). The USGS data showed similar median concentrations of chlorophyll- $\alpha$ across salinity groups (fig. 34). Thus, there is some disagreement among the three surveys about the distribution of phytoplankton biomass among salinity regions in 2011. This could be due to spatial patchiness of phytoplankton and the different sampling dates of the three surveys, among other factors. The most interesting feature of the FMWT data is the high chlorophyll- $\alpha$ concentrations in the Cache Slough region (fig. 35).

Because the EMP and USGS data differed, we evaluated additional data for fall 2011, when X2 was $75 \mathrm{~km}$. In particular, we looked at continuous fluorescence data, a method of estimating chlorophyll- $\alpha$ concentration in the water column, from EMP water-quality stations at Rio Vista and Mallard Island (fig. 36). The data discussed earlier were from chemical analyses of chlorophyll- $\alpha$ in water samples. Rio Vista represents freshwater conditions, and Mallard Island is between the confluence and Suisun Bay region (fig. 3). These data indicate that a bloom in freshwater was advected into the LSZ. Transport from freshwater could account for at least some of the chlorophyll- $\alpha$ observed in the LSZ. Given the conflict between the EMP and USGS data and the evidence for at least some contribution from a freshwater bloom, the prediction about chlorophyll- $\alpha$ production could not be evaluated with certainty.

Because the cyanobacteria Microcystis forms floating colonies that are difficult to quantify with standard sampling techniques, there was not a good long-term dataset on abundance of Microcystis. A semi-quantitative (ranking scale) estimate of abundance has been made during FMWT sampling since 2007, so the data did not include 2005-2006 (see appendix 4). In 2010 and 2011, the Microcystis ranking rarely exceeded the lowest rank for affirmative collections, so we compared the frequency of presence between years. In 2010, the most occurrences were in freshwater (fig. 37). In 2011, the results were similar, except for a high percentage of occurrences in the LSZ in September. Although occurrence data do not directly address the prediction that density is greater when $\mathrm{X} 2$ is at $85 \mathrm{~km}$ compared to $74 \mathrm{~km}$, the prediction is neither supported nor rejected. The average occurrences of Microcystis in September-October of 2010 and 2011 were not particularly different, and there was high variability in 2011. 


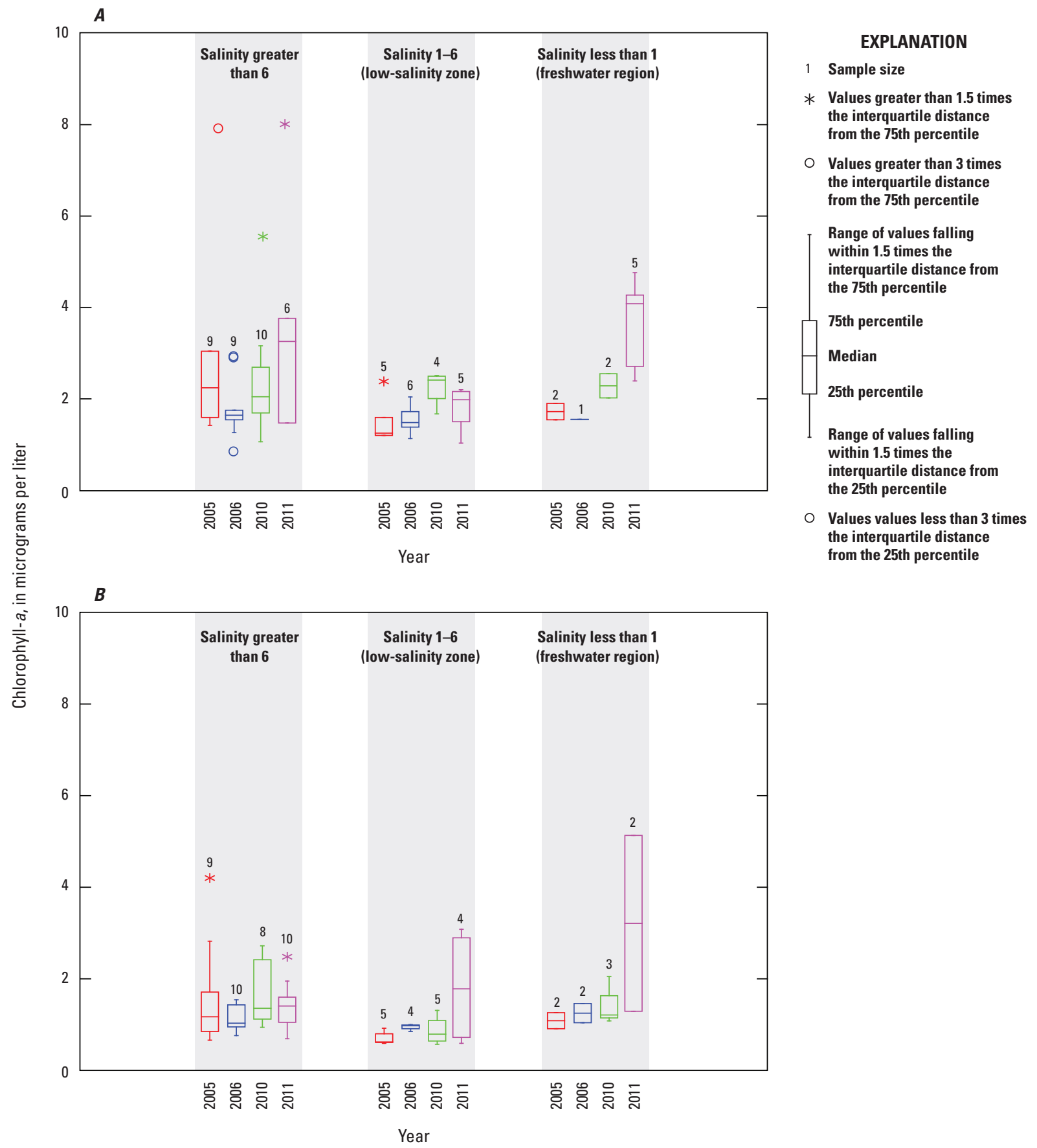

Figure 33. Chlorophyll- $\alpha$ concentrations from the Environmental Monitoring Program: $A$, September-October; and $B$, NovemberDecember (see appendix 6). 


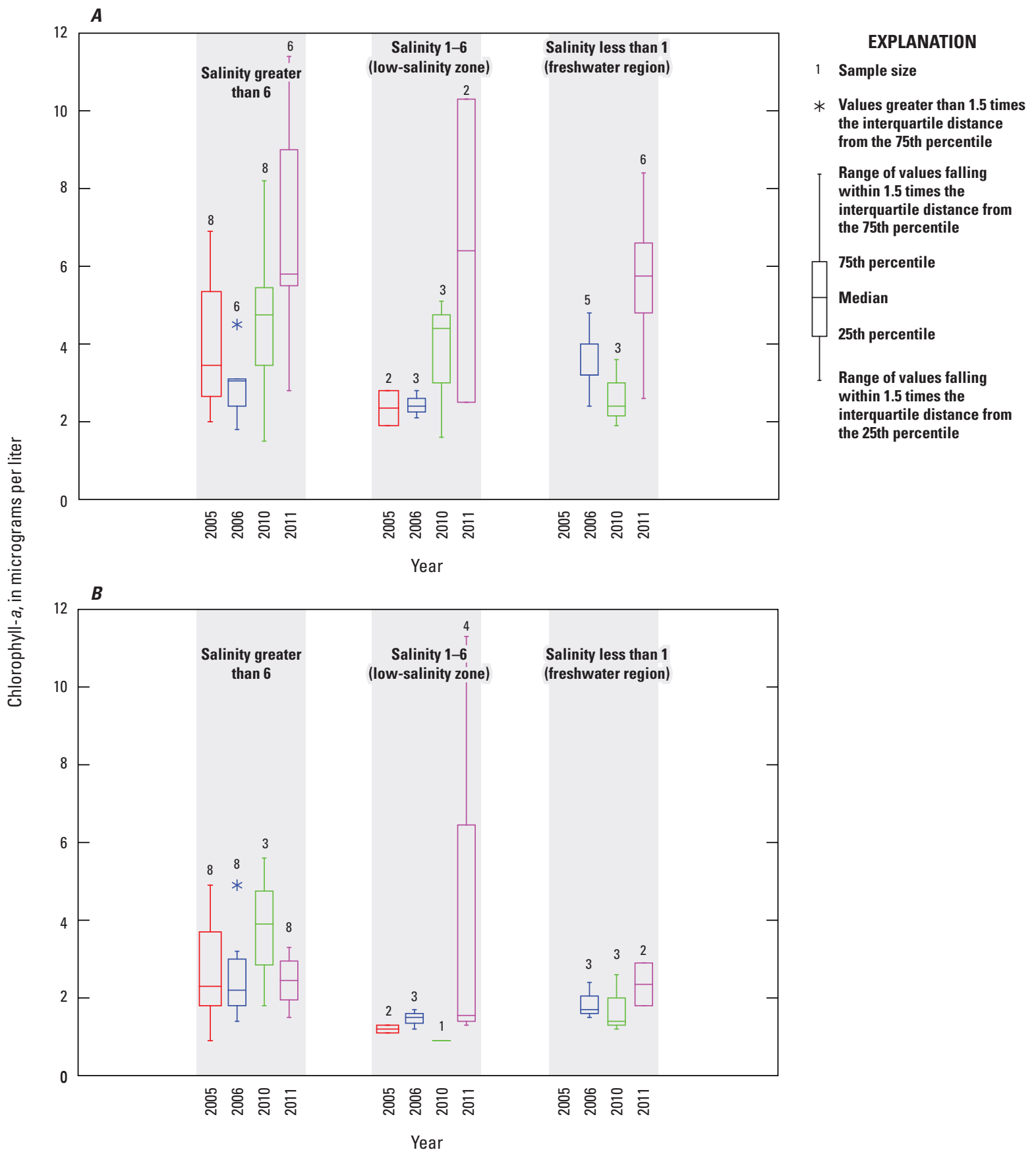

Figure 34. Chlorophyll- $\alpha$ concentrations from samples collected during monthly U.S. Geological Survey cruises: $A$, SeptemberOctober; and B, November-December (see appendix 7). 


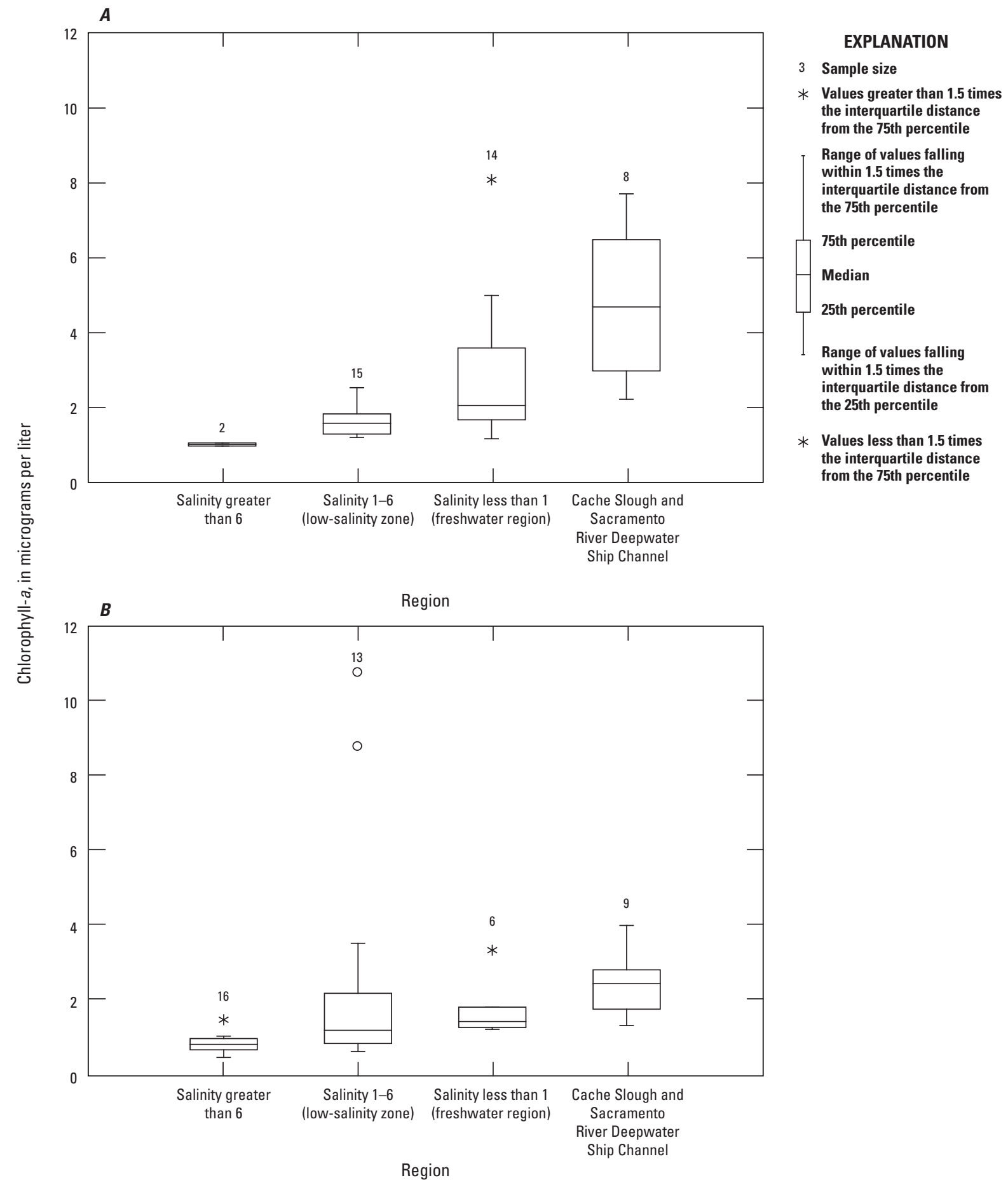

Figure 35. Chlorophyll- $\alpha$ concentration in 2011 from samples collected during the fall midwater-trawl: $A$, September-0ctober; and $B$, November-December (see appendix 4). 


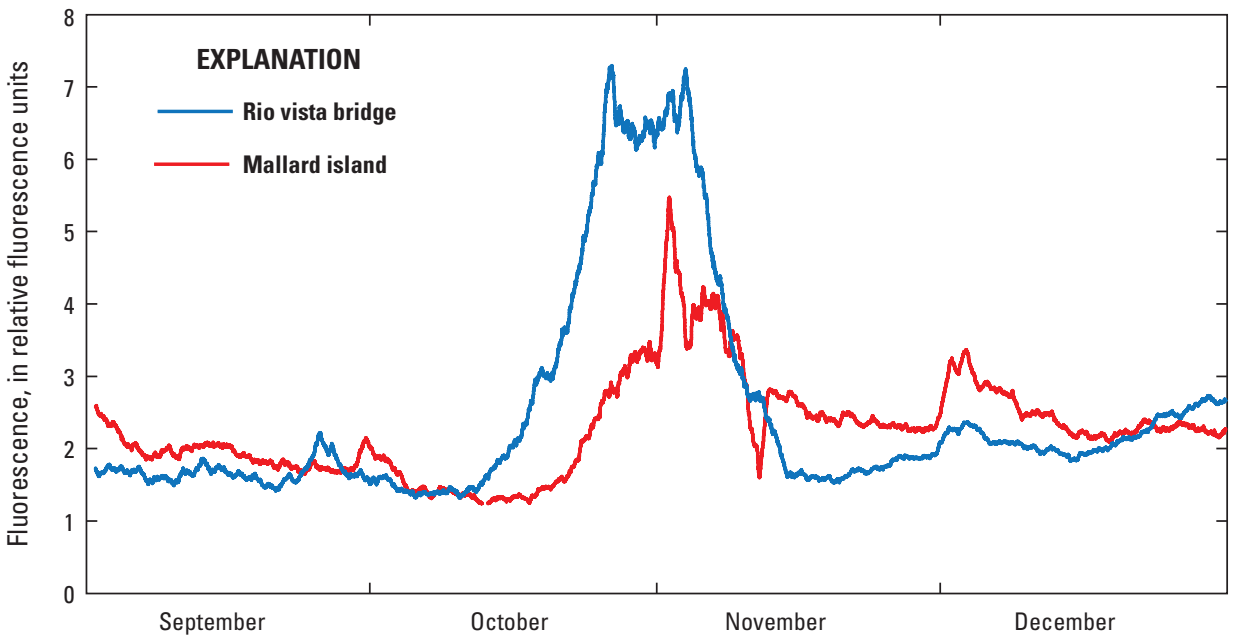

Figure 36. Continuous in-situ fluorescence measurements (a method to estimate chlorophyll- $\alpha$ concentrations) from September to December 2011 for Rio Vista Bridge and Mallard Island (appendix 6). The lines represent 24-hour running averages of data collected at 15-minute intervals.

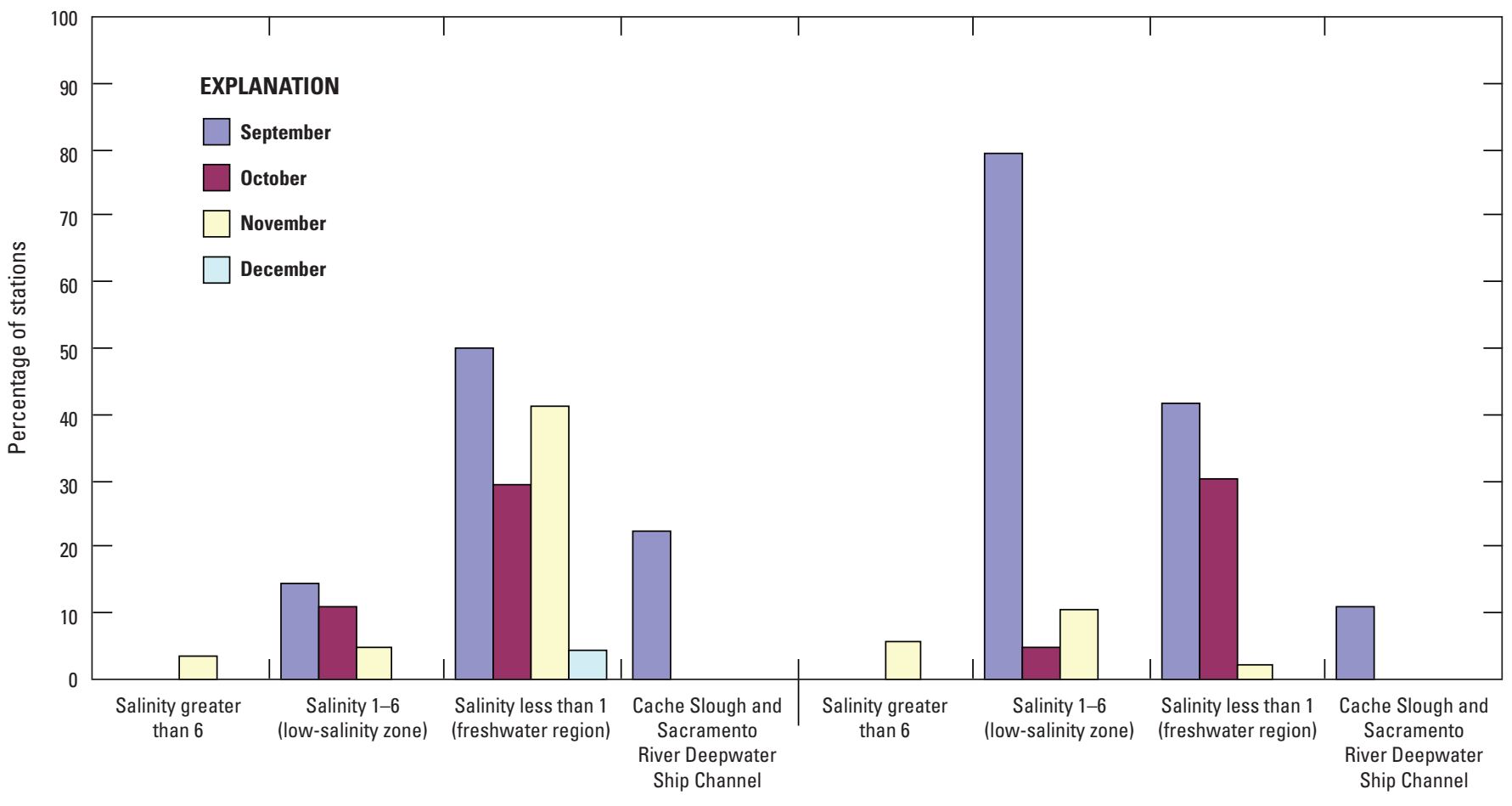

2010

2011

Figure 37. Occurrence of floating Microcystis at fall midwater-trawl sampling stations for September to December 2010 and 2011 (appendix 4 shows sampling locations). 
Several predictions (table 1) concern copepods, a major food source of delta smelt. Calanoid copepods, particularly Pseudodiaptomus forbesi, Eurytemora affinis, and Acartiella sinensis, are generally recognized as important prey for delta smelt. Calanoid copepod biomass per unit effort (BPUE, in micrograms of carbon per cubic meter) tended to be slightly greater in September and October 2011 compared to other years in the LSZ and greater than salinity 6 region; however, standard deviations were large relative to the differences in means (fig. 38). This was not the case in freshwater, where September and October 2011 were similar to September and October of 2005 and 2010. In general, calanoid copepod BPUE tended to be greater in freshwater than in the other salinity regions, mostly because of greater densities of copepodids (juvenile copepods) in freshwater. The greater BPUE in freshwater during September and October was not apparent in November and December. Instead, BPUE was low and similar across all salinity groups in November and December. There was a tendency for November and December BPUE to be slightly greater in the LSZ during the wet years of 2006 and 2011, although standard deviations were large relative to the differences in means. The prediction was that calanoid copepod biomass would be greater in the LSZ at a low X2 value, and the data did show that trend; however, given the high variability in the data, a definite conclusion was not warranted.

Cyclopoid copepods, mainly represented numerically by Limnoithona tetraspina, can also be consumed by delta smelt; however, when calanoids are available, the delta smelt diet usually includes more of the larger calanoid copepods than the smaller cyclopoid copepods. Because of their smaller size, Limnoithona tetraspina are usually only consumed by small delta smelt. Because of the small size of Limnoithona tetraspina, cyclopoid copepods account for only about a tenth of the biomass of calanoid copepods in zooplankton samples (compare figs. 38 and 39). There was a great deal of monthly variability in the BPUE of cyclopoid copepods, based on large standard deviations relative to the mean (fig. 39). In September and October 2011, the BPUE of cyclopoid copepods was both the greatest and the least during 2011. The BPUE of cyclopoid copepods was generally greater in November and December compared to September and October across years (fig. 38), except in freshwater. The prediction that cyclopoid biomass in the LSZ would be less when X2 was at $85 \mathrm{~km}$ is difficult to interpret because both $\mathrm{X} 2$ at $81 \mathrm{~km}$ and $\mathrm{X} 2$ at $74 \mathrm{~km}$ were expected to be moderate. The data indicated that when X2 was at $74 \mathrm{~km}$, the BPUE of cyclopoid copepods could be greater than predicted in comparison to the other conditions, which is not consistent with the prediction; however, as with calanoid copepods, the differences in the mean values are small relative to the standard deviations. Thus, the data did not support the prediction as stated in table 1 , and we defer making a definitive judgment.
Although there was not an explicit prediction for the food that delta smelt might actually consume, we compiled the available data on delta smelt diet to better understand the significance of the copepod data. In general, calanoid copepods dominated the diet, as expected, except during November in the LSZ, when a large cyclopoid copepod, Acanthocyclops sp., was a major prey item (fig. 40). This consumption corresponded to the greatest BPUE of cyclopoid copepds in the LSZ (fig. 39), presumably due to high abundance of this large species. In some months, a large proportion of the diet consisted of other organisms (fig. 41), in particular, mysids and amphipods. The mysids were mainly Hyperacanthomysis longirostris. Amphipods included Americorophium spinicorne and Corophium alienense in the LSZ and Cache Slough and SRDWSC region and included Gammarus daiberi in the Cache Slough and SRDWSC region. The amphipods are epibenthic, and they are not sampled well by the methods used to sample zooplankton. Mysids, which are effectively sampled by EMP nets, contributed large proportions to the diet in some months (fig. 41), but never contributed large proportions to total zooplankton biomass (fig. 42). Individual mysids are larger than copepods and could be selected by delta smelt when available.

To represent total zooplankton available to delta smelt as food, we compiled data on total zooplankton, including mysids and cladocerans in addition to calanoid and cyclopoid copepods. The patterns in mean values of total zooplankton (fig. 42) were almost identical to the patterns apparent in the mean values of calanoid copepods (fig. 38). Zooplankton biomass tended to be higher in freshwater, but standard deviations were large relative to differences in means, making a firm conclusion unwarranted. There was no specific prediction for total zooplankton.

The prediction that Potamocorbula biomass would increase when X2 is at $85 \mathrm{~km}$ and decrease when X2 is at $74 \mathrm{~km}$ (table 1) is related to grazing rates on phytoplankton and zooplankton in the LSZ, which would channel primary and secondary production to clams rather than fishes and other consumers, such as delta smelt. The U.S. Bureau of Reclamation (2012) hypothesized that lower X2 values in wet years could result in decreased fall populations of Potamocorbula in the LSZ because of large shifts in the distribution of salinity in the estuary and subsequent effects on the recruitment and physiology of Potamocorbula. The prediction does not incorporate biomass of Corbicula fluminea, a freshwater invasive clam living on the freshwater side of the LSZ. Corbicula can also exert substantial grazing pressure on phytoplankton (Lucas and others, 2002; Lopez and others, 2006). For this reason, this prediction was addressed in terms of total biomass of Potamocorbula and Corbicula, with the percentage attributed to Potamocorbula identified and a measure of total grazing rate for both species (Thompson and others, 2012). We 


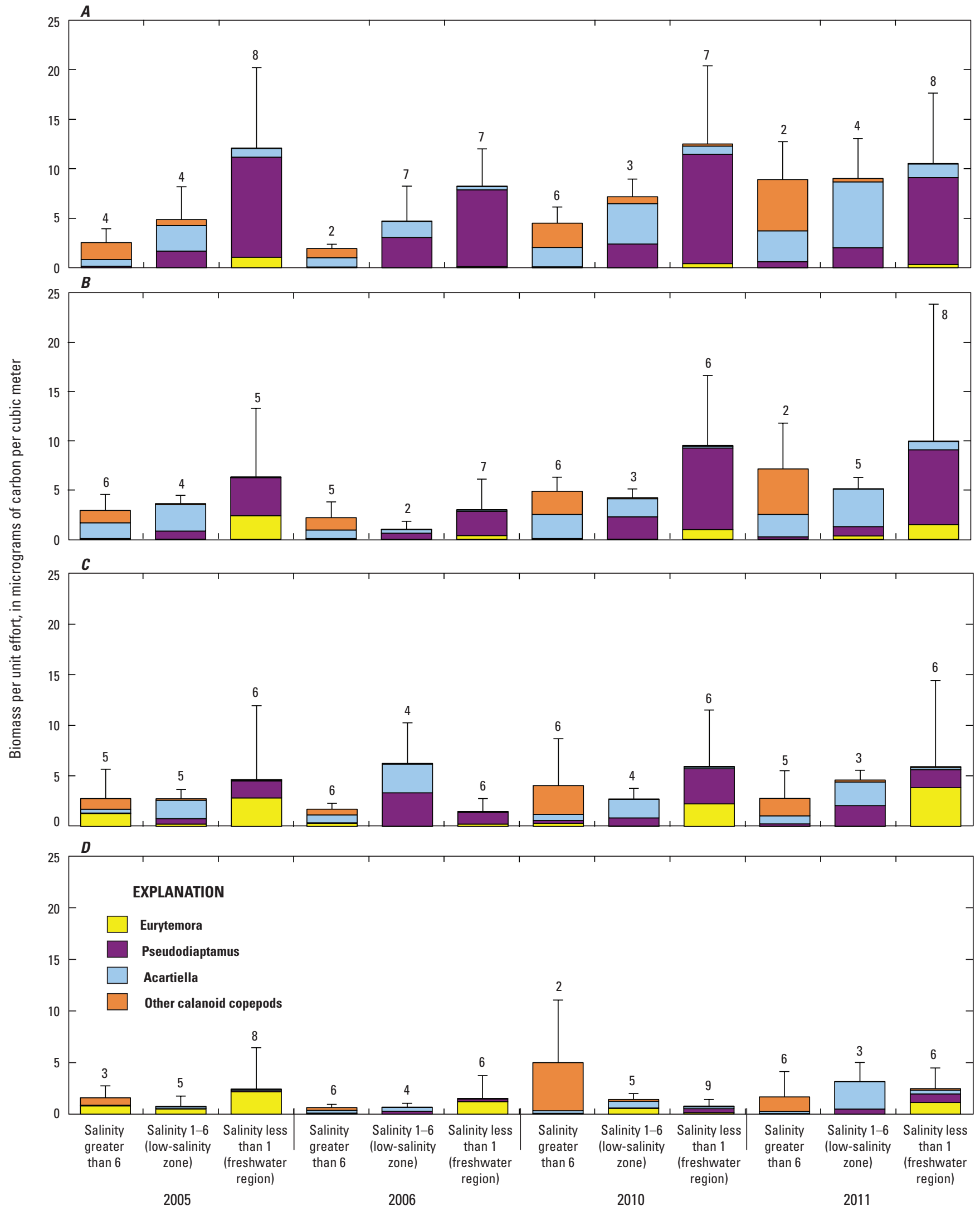

Figure 38. Mean biomass per unit effort of juvenile and adult calanoid copepods for Environmental Monitoring Program samples for: $A$, September; $B, 0$ ctober; $C$, November; $D$, December (see appendix 6 for data sources). Vertical lines represent 1 standard deviation; numbers represent sample sizes for the associated bars. 

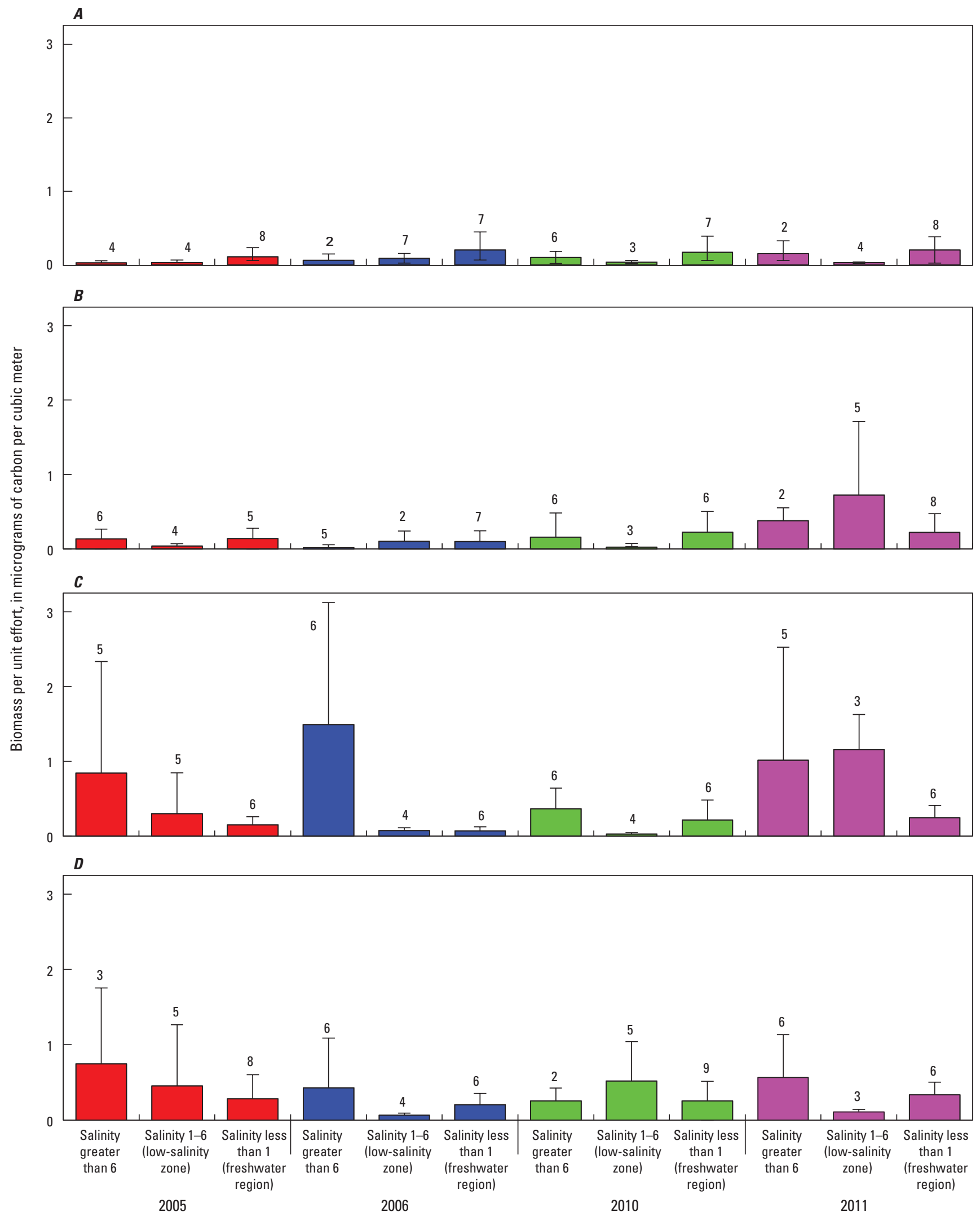

Figure 39. Mean biomass per unit effort of juvenile and adult cyclopoid copepods for Environmental Monitoring Program samples for: A, September; B, October; C, November; D, December (appendix 6). Vertical lines represent 1 standard deviation; numbers represent sample sizes for the associated bars. 

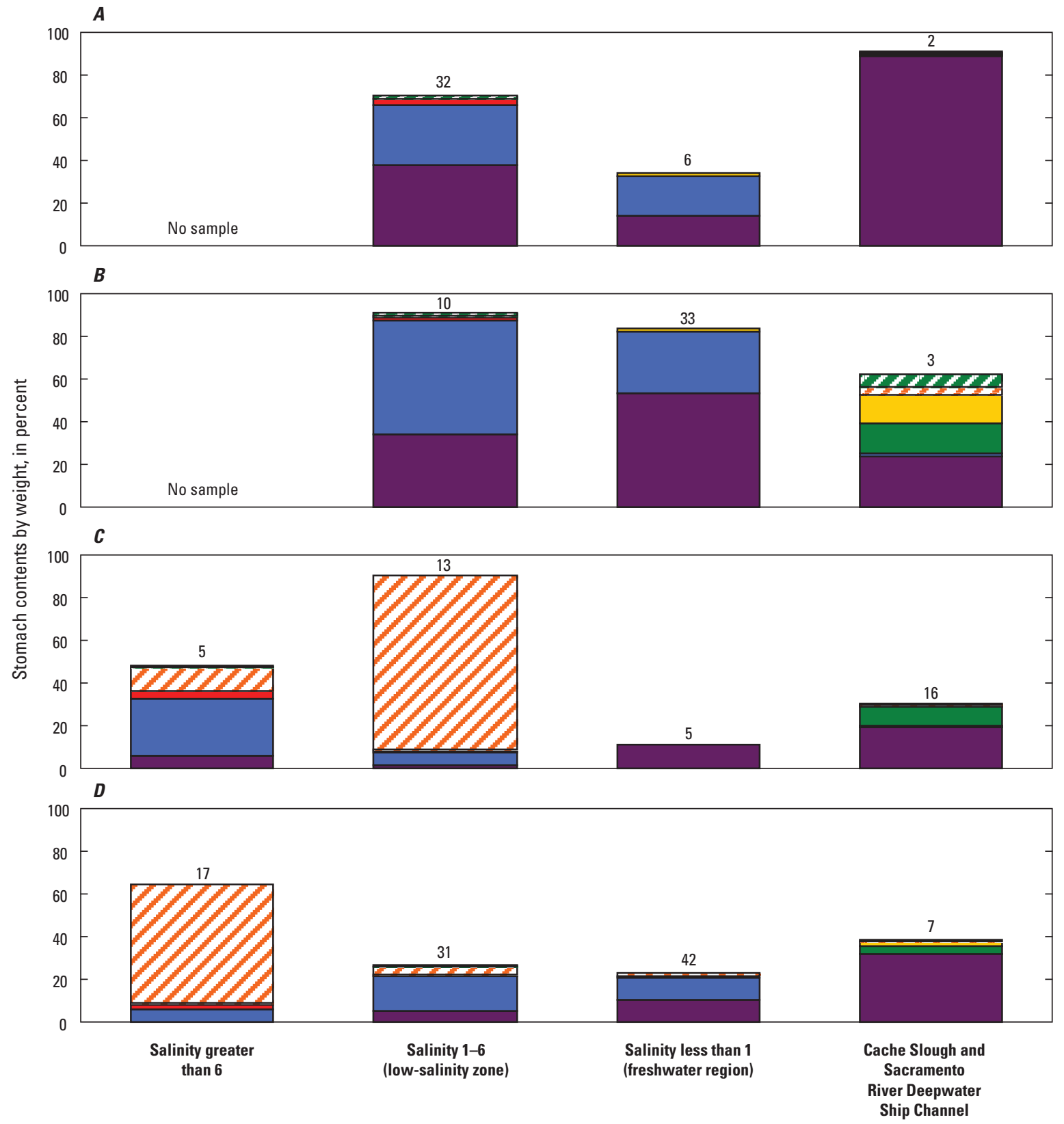

EXPLANATION

Pseudodiaptomus spp.

Acartiella spp.

Other calanoid copepods

Other cyclopoid copepods

Sinocalanus spp.

Tortanus spp.

Figure 40. Stomach contents of delta smelt captured in the fall midwater-trawl survey in 2011 containing calanoid and cyclopoid copepods for: $A$, September; $B, 0$ ctober; $C$, November; $D$, December (see appendix 4 for methods). The composition of the remaining portion of the diet is shown in figure 41. Numbers represent the number of delta smelt stomachs examined to generate the associated bars. Bars indicate means, and lines show 1 standard deviation. 


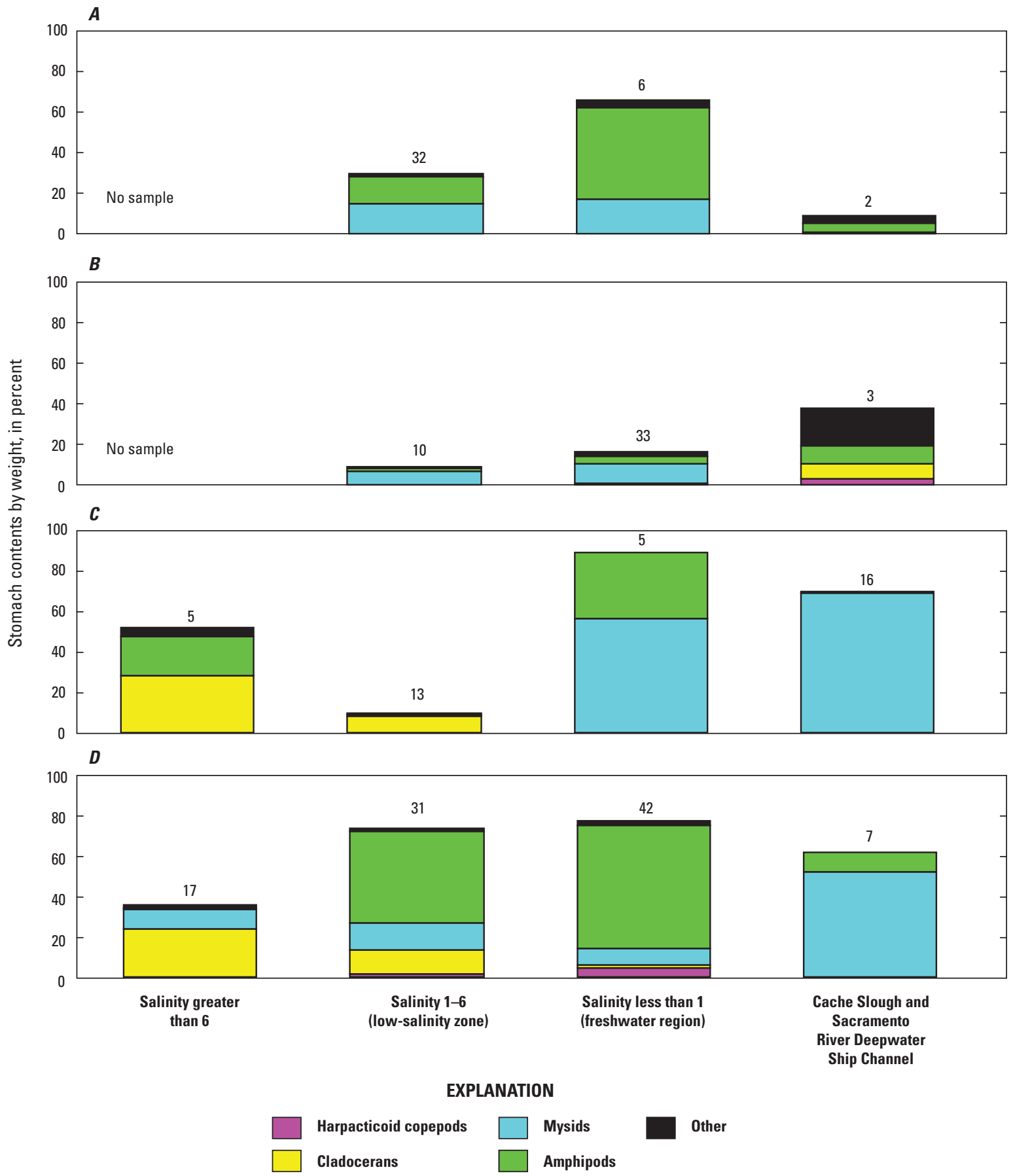

Figure 41. Stomach contents of delta smelt captured in the fall midwater-trawl survey in 2011 containing harpacticoid copepods, cladocerans, mysids, amphipods, and other prey for: $A$, September; $B, 0$ ctober; $C$, November; $D$, December (see appendix 4 for methods). Numbers represent the number of delta smelt stomachs examined to generate the associated bars. Bars indicate means, and lines show 1 standard deviation. 

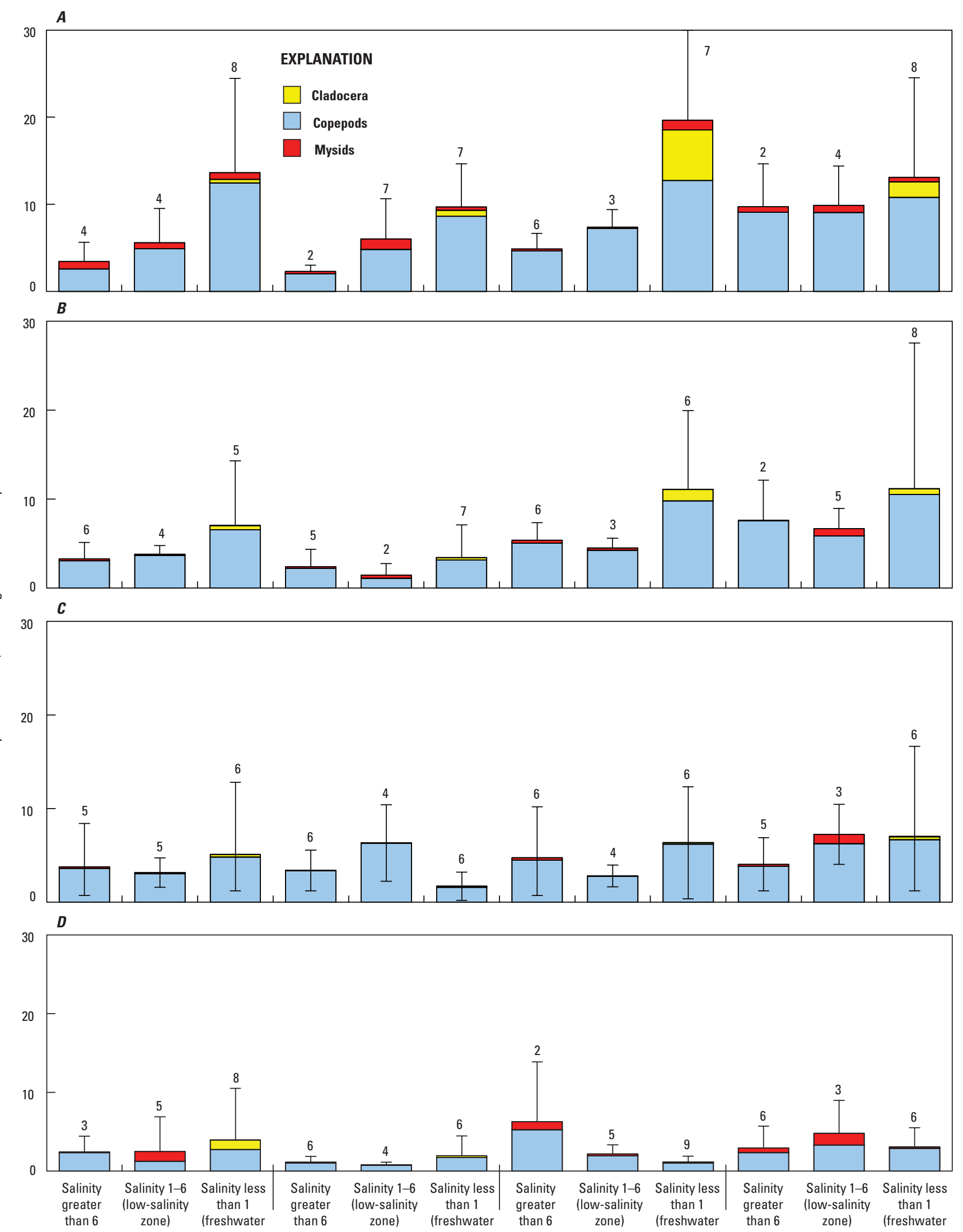

Figure 42. Mean biomass per unit effort of juvenile and adult calanoid copepods, cyclopoid copepods, cladocerans, and mysids for Environmental Monitoring Program samples (see appendix 6 for methods and data sources). Vertical lines represent 1 standard deviation; numbers represent sample sizes for the associated bars. 
only address total grazing rate because the loss to the benthic food web is the important process, rather than which benthic species benefits most, and a specific prediction restricted to Potamocorbula was not made for this process. After young clams settle to the bottom and begin their sedentary, benthic existence, they do not move with the LSZ on tidal or seasonal time scales, as swimming organisms like delta smelt are capable of doing. Therefore, they were considered geographically. Grizzly and Honker Bays (Grizzly/Honker Bays), western Suisun Marsh, the confluence, and several flooded islands (Franks Tract, Big Break, and Sherman Lake) were areas considered by Thompson and others (2012). The first three areas are within the range of Potamocorbula and, in general, are most subject to movements of the LSZ and salinity gradient that results from tides and intra- and interannual flow conditions. The flooded islands are primarily fresh and dominated by Corbicula. Data were only available for October 2009, 2010, and 2011.

In October 2011, the Potamocorbula filtration rate, the volume of water filtered per day, was lower through much of its range compared to 2009 and 2010, except for two stations in the main channel of Suisun Bay (fig. 43). In 2011, X2 was seaward of Grizzly/Honker Bay and western Suisun Marsh for at least some of the time, indicating that those areas were fresher than in 2009 and 2010. In 2009 and 2010, X2 was mainly landward of these areas during the previous 6 months, so water was more brackish in those areas, which favors settlement and growth of Potamocorbula. Based on biomass, Potamocorbula were less abundant in Grizzly/Honker Bay and western Suisun Marsh during October 2011 compared to 2009 and 2010 (fig. 44); however, the hypothesis concerning Potamocorbula is based on the position and extent of the LSZ. In 2010, the LSZ was located in the confluence area on the basis of X2 at $85 \mathrm{~km}$ (fig. 16). In 2011, the LSZ was located in the Grizzly/Suisun Bay and western Suisun Marsh area on the basis of X2 at $74 \mathrm{~km}$ (fig. 14). In 2010, median biomass in the confluence region was about $5 \mathrm{~g}$ ash free dry mass per square meter (AFDM $\left./ \mathrm{m}^{2}\right)$, with 4 percent of biomass accounted for by Potamocorbula. Thus, median biomass of Potamocorbula was only about $0.2 \mathrm{~g} \mathrm{AFDM} / \mathrm{m}^{2}$. In 2011, median biomass in the Grizzly/Honker Bay and Western Suisun Marsh regions was about 2 and $5 \mathrm{~g} \mathrm{AFDM} / \mathrm{m}^{2}$, respectively, with 97 percent and 91 percent of biomass accounted for by Potamocorbula, respectively. Thus, the median biomass contribution of Potamocorbula for the two areas combined was greater than $2 \mathrm{~g} \mathrm{AFDM} / \mathrm{m}^{2}$, and the median biomass of Potamocorbula in the LSZ was greater in 2011 compared to 2010. The prediction that Potamocorbula biomass would be greater when $\mathrm{X} 2$ was at $85 \mathrm{~km}$ compared to $74 \mathrm{~km}$ (table 1) was not supported by the data.

Because clam grazing on phytoplankton is the ecological process underlying the prediction concerning Potamocorbula biomass (table 1), we also considered grazing rates, in terms of turnover rate. In these calculations, grazing rate is different from filtration rate (above) because it assumes food in the water column is depleted by feeding, forming a boundary layer. Thus grazing rates are lower than filtration rates. The turnover rate normalizes the grazing rates to the depth of the water column (fig. 45) and is the proportion of the water column a population of clams filters in a day In all years, the turnover rate in the confluence was relatively low because of the greater depth of many of the confluence channels compared to the shoals of the bays and the greater biomass contribution of Corbicula, which has slower grazing rates than Potamocorbula. The high variability can be attributed to faster turnover rates in some shallower sample locations (fig. 45). Also, in all years, turnover rates were faster in Grizzly/ Honker Bay and western Suisun Marsh, as compared to the confluence. These results are counter to the prediction (table 1) if the hypothesis about Potamocorbula biomass is considered in terms of total grazing pressure on the phytoplankton population; however, high variability made it difficult to draw definite conclusions.

In addition to species of grazer and depth, hydrodynamics, in terms of transport time and circulation of water and associated phytoplankton, can have important effects on grazing rates (Lucas and others, 2002; Lopez and others, 2006; Cloern, 2007; Lucas and Thompson, 2012). For example, tidal exchange between the confluence and flooded islands, which have different total biomasses of clams, and thus, different turnover rates (figs. 44 and 45), could have important effects on phytoplankton biomass that would not be obvious from a simple examination of conditions in specific geographic areas or the LSZ. Because of these uncertainties, we conclude the prediction that Potamocorbula biomass would be greater when $\mathrm{X} 2$ was at $85 \mathrm{~km}$ and less when it was at $74 \mathrm{~km}$ (table 1) was not supported and that the hypothesis was likely too simple to address the underlying process of interest, which was the effect of clam grazing on phytoplankton production. This prediction and the underlying hypotheses could be revisited and revised in an updated AMP.

The predictions about predator abundances and predation rates (table 1) could not be evaluated. There is currently no sampling program targeted at understanding predator abundance and predation rates in the channel and shoal areas occupied by delta smelt in the fall. Addressing these predictions requires new sampling programs.

\section{Predictions for Delta Smelt Responses}

The prediction (table 1) of some delta smelt captured at the Suisun region power plants when X2 was at $74 \mathrm{~km}$ and no delta smelt captured when $\mathrm{X} 2$ values were greater than $74 \mathrm{~km}$ could not be directly assessed because no fish counts were available; however, the power plants only operated at about one-third of capacity for a limited number of days in September and October of 2011. The assumption behind this prediction is that capturing delta smelt near the power plants while they are in operation would indicate that entrainment was likely. At the plant near Pittsburgh, one or two of three generation units operated for 9 days from September 

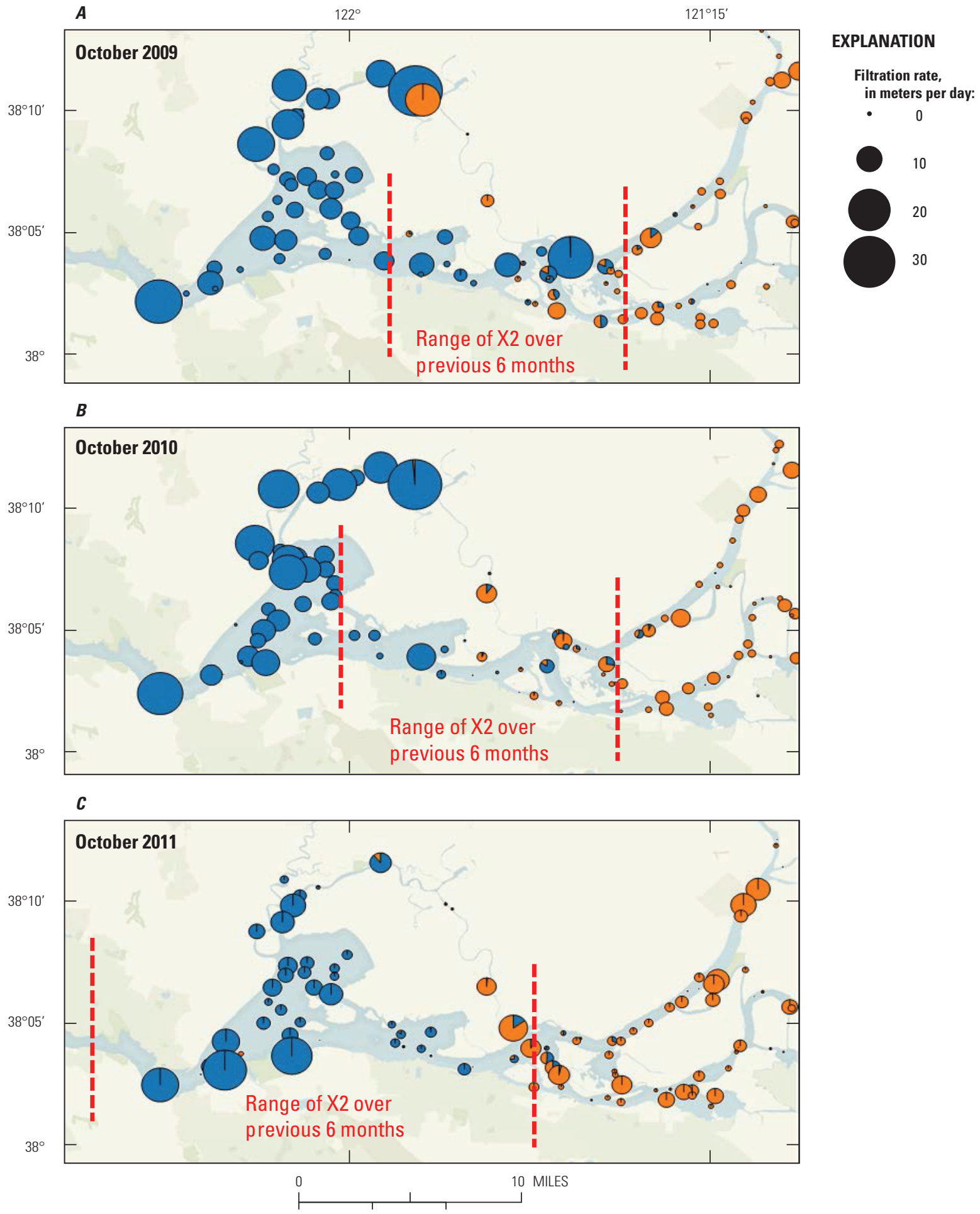

Figure 43. Filtration rates (a function of biomass and temperature) for Potamocorbula amurensis (blue) and Corbicula fluminea (orange) in $A$, October 2009; $B$, October 2010; and $C, 0$ ctober 2011. Range of X2 during previous 6 months shown on map as range where bivalves were expected to overlap. Figure modified from Thompson and others (2012). X2 is the horizontal distance in kilometers from the Golden Gate up the axis of the estuary to where tidally averaged near-bottom salinity is 2. 

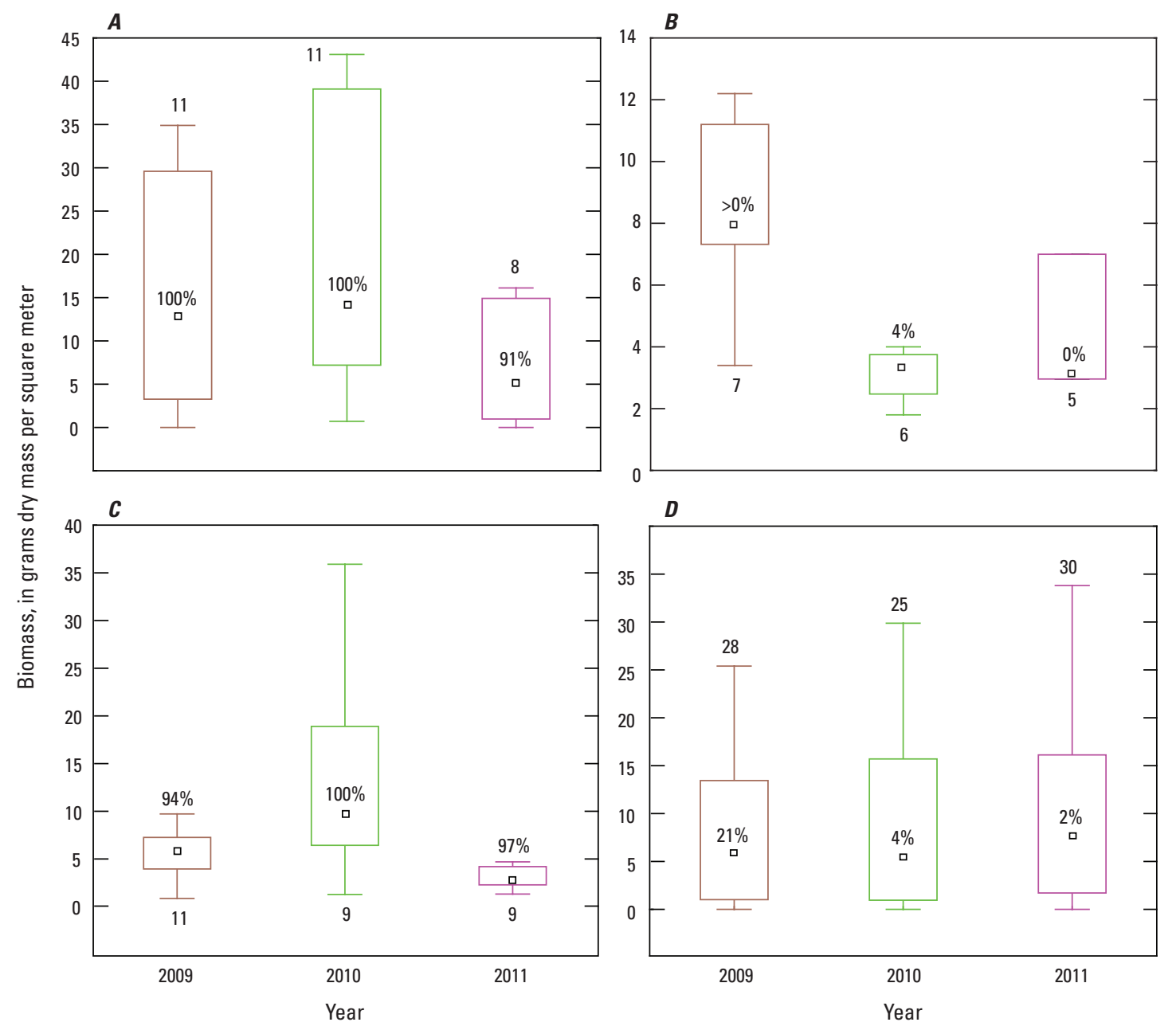

EXPLANATION

8 Sample size

Range of values falling

within 1.5 times the

interquartile distance from

the 75th percentile

75th percentile

Median

25th percentile

Range of values falling within 1.5 times the

interquartile distance from

the 25th percentile

$>$ greater than

$\%$ percentage

Figure 44. Biomass for Potamocorbula amurensis and Corbicula fluminea combined during the October sampling periods in $A$, western Suisun Marsh; $B$, the flooded islands; $C$, Grizzly/Honker Bay shallows; and $D$, the confluence region. Percentages (\%) show proportion of biomass contributed by Potamocorbula amurensis. Figure modified from Thompson and others (2012). 

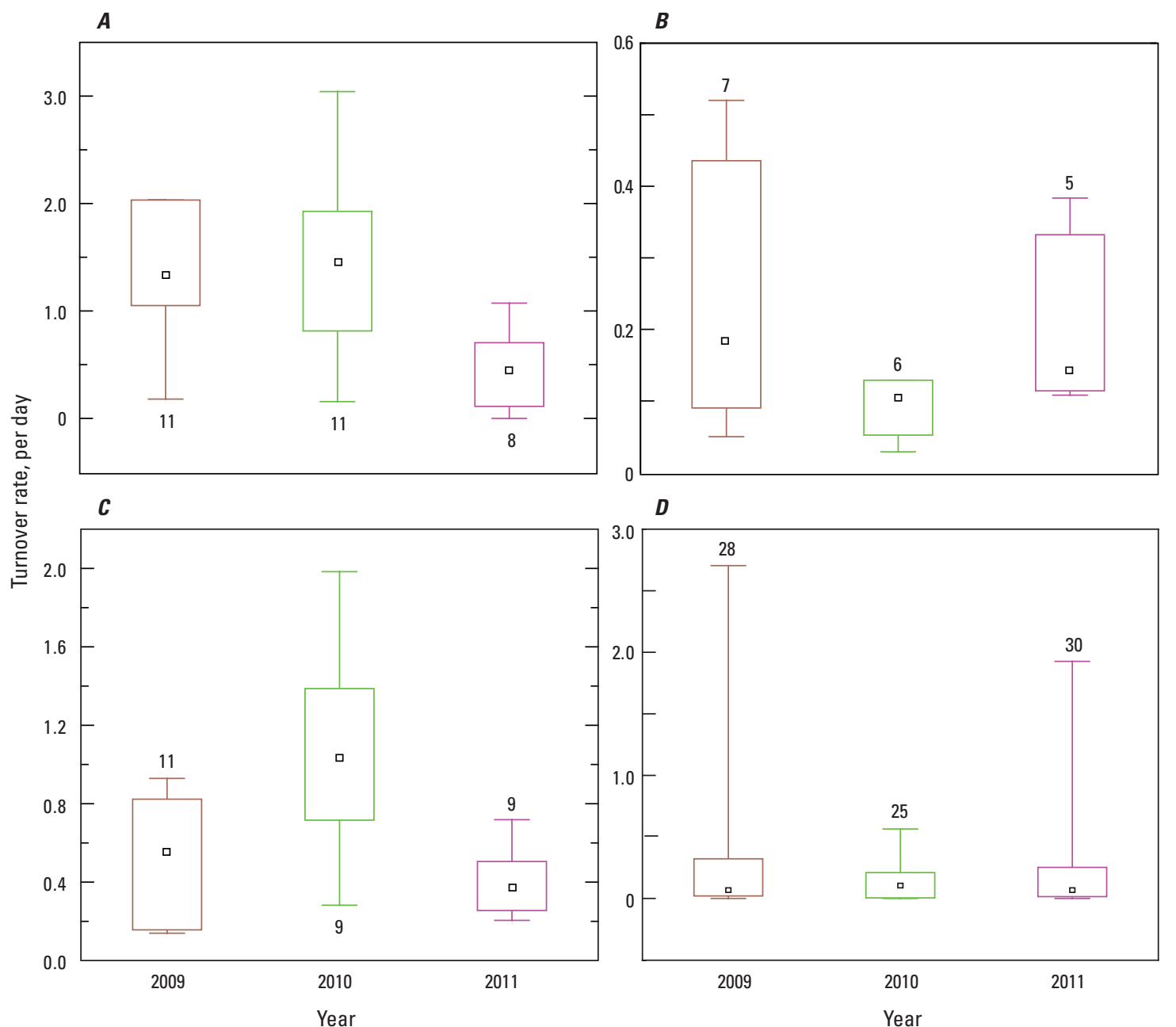

EXPLANATION

5 Sample size

Range of values falling within 1.5 times the interquartile distance from

the 75th percentile

75th percentile

Median

25th percentile

Range of values falling within 1.5 times the interquartile distance from the 25th percentile

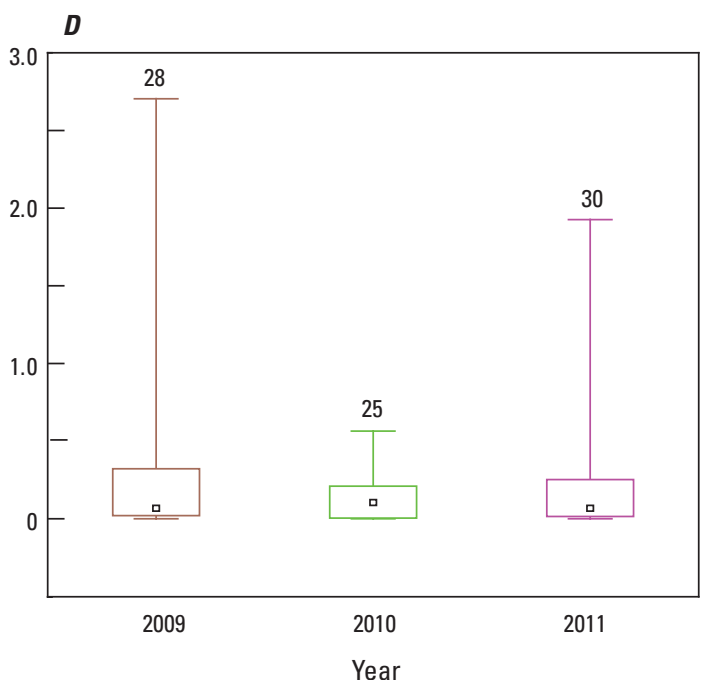

Figure 45. Turnover rates for Potamocorbula amurensis and Corbicula fluminea combined during the October in $A$, western Suisun Marsh; $B$, the flooded islands; $C$, Grizzly/Honker Bay shallows; and $D$, the confluence region. In western Suisun Marsh, turnover rates were not significantly different between 2009 and 2010, but were significantly different between 2010 and 2011 (Kruskal-Wallis test, P less than 0.05, Thompson and others, 2012). In Grizzly/Honker Bay shallows, turnover rates were not significantly different between 2009 and 2011, but the turnover rate in 2010 was significantly different than in 2009 and 2011 (Kruskal-Wallis test, P less than 0.05, Thompson and others, 2012). Figure modified from Thompson and others (2012). 
to October. At the other plant, one of two generation units operated for 18 days, and both units operated for 4 days from September to October. It seems likely that entrainment was nil or very low; however, a definitive conclusion is not possible without fish counts. No delta smelt were salvaged at the CVP or SWP pumping plants from September to October in any of the years considered (ftp://ftp.delta.dfg.ca.gov/salvage/). Fish salvage is determined at fish collection facilities associated with each pumping plant where fish are removed from the diverted water, counted, and subsequently trucked to release points within the Delta. The prediction that there would be no delta smelt in the fall SWP and CVP salvage when X2 was at 74 or $81 \mathrm{~km}$ was supported by data; however, few, if any, delta smelt were expected to be salvaged even at greater values of X2 (table 1).

The center of distribution of delta smelt (median) appeared to be within the predicted range of X2 values (fig. 46) in September-October 2011 (table 1), although it was toward the lower end of the predicted range and many individuals were found farther seaward. The results for the medians of other years also tended to meet predictions, with individual fish often found more seaward in September and October. The number of fish captured was small in all years except 2011. The available data appeared to support the prediction that the center of delta smelt distribution would approximate X2; however, the sparse data for years other than 2011 limited the strength of comparisons.

Preliminary data on delta smelt growth rates determined from otoliths were available for 2011 (Teh, 2012; table 4). The data indicate declining growth from August through December of 2011 in each of the salinity regions, as is expected with seasonally decreasing temperatures and a shift from growth in length to development of gonads. Growth in November and December was similar. Similar otolith-based growth data have been gathered as part of other studies in other years. These data need to be aggregated and the results compared among years before the prediction of greater growth when X2 is at $74 \mathrm{~km}$ compared to $85 \mathrm{~km}$ (table 1) can be evaluated.

Delta smelt survival was not calculated directly because only population abundance indices (fig. 47) rather than population estimates are available; however, some information can be inferred from ratios calculated from the summer townet survey (TNS) and FMWT abundance indices (fig. 48). The ratio of the FMWT to the TNS can be used as an indicator of survival
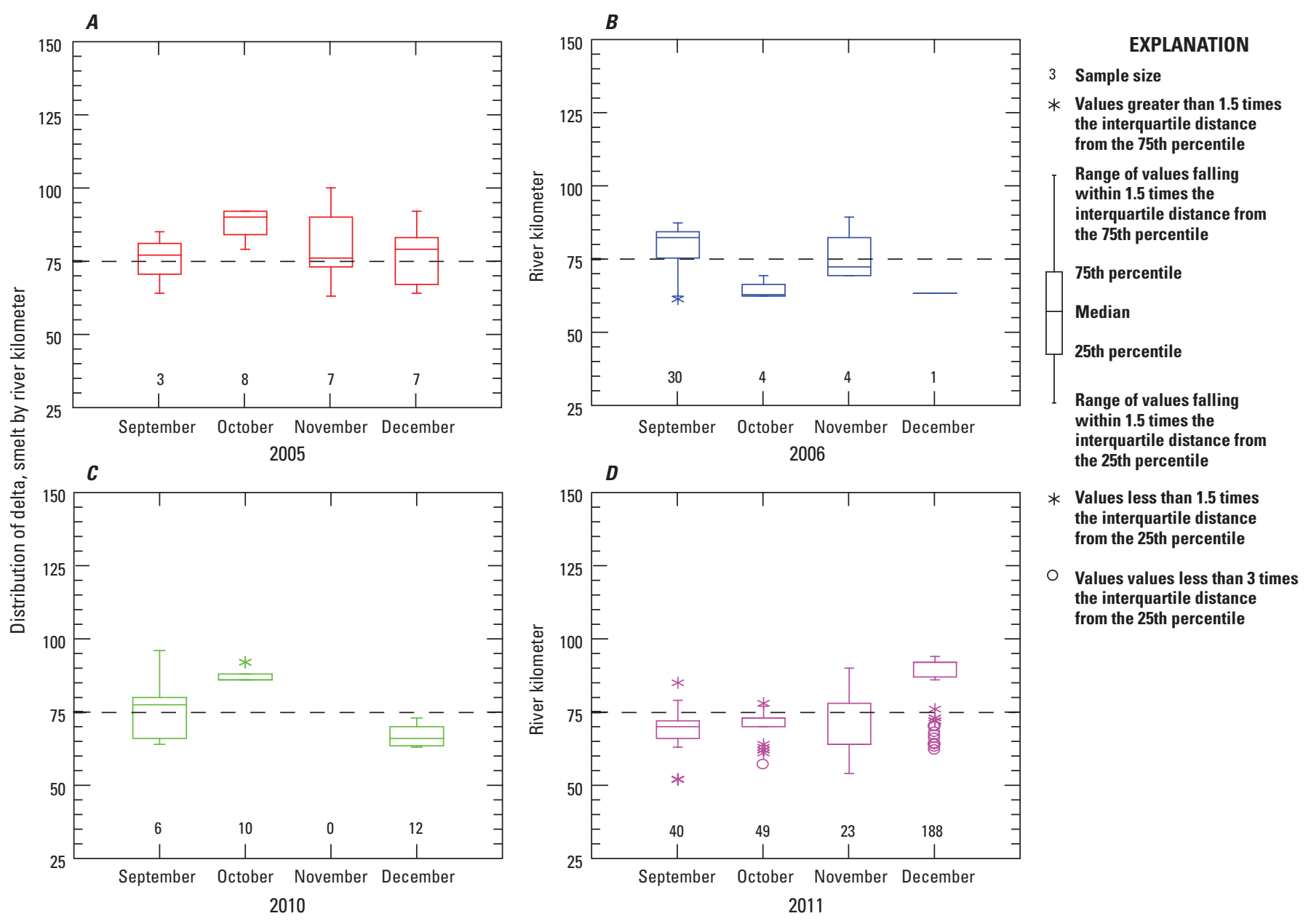

Figure 46. Distribution of delta smelt captured in the fall midwater-trawl survey for: $A, 2005 ; B, 2006 ; C, 2010 ; D$, 2011. The distance from the Golden Gate of each site where delta smelt were captured was weighted by the number of delta smelt caught. The number of delta smelt captured each month are shown. The dotted line indicates 75 kilometers for reference. 
Table 4. Estimated mean and standard deviation of growth rates of delta smelt from August to December 2011 based on otolith analysis from four regions of the San Francisco Estuary: salinity less than 1, salinity 1-6, salinity greater than 6, and Cache Slough/Sacramento River Deepwater Ship Channel (SRDWSC; modified from Teh, 2012).

[Abbreviation: mm/day, millimeter per day]

\begin{tabular}{|c|c|c|c|c|}
\hline \multirow{2}{*}{ Region } & \multirow{2}{*}{ Month } & \multirow{2}{*}{$\begin{array}{c}\text { Number } \\
\text { aged }\end{array}$} & \multicolumn{2}{|c|}{$\begin{array}{c}\text { Growth rate } \\
\text { (mm/day) }\end{array}$} \\
\hline & & & Mean & Standard deviation \\
\hline Cache Slough/SRDWSC & September & 2 & 0.39 & 0.05 \\
\hline Cache Slough/SRDWSC & October & 3 & 0.29 & 0.01 \\
\hline Cache Slough/SRDWSC & November & 16 & 0.28 & 0.01 \\
\hline Salinity less than 1 & September & 5 & 0.42 & 0.04 \\
\hline Salinity less than 1 & October & 32 & 0.36 & 0.04 \\
\hline Salinity less than 1 & November & 1 & 0.27 & No data \\
\hline Salinity less than 1 & December & 69 & 0.29 & 0.02 \\
\hline Salinity $1-6$ & August & 24 & 0.46 & 0.05 \\
\hline Salinity greater than 6 & August & 4 & 0.44 & 0.04 \\
\hline Salinity greater than 6 & September & 5 & 0.41 & 0.02 \\
\hline Salinity greater than 6 & October & 2 & 0.37 & 0.01 \\
\hline Salinity greater than 6 & November & 3 & 0.28 & 0.01 \\
\hline Salinity greater than 6 & December & 31 & 0.28 & 0.02 \\
\hline
\end{tabular}



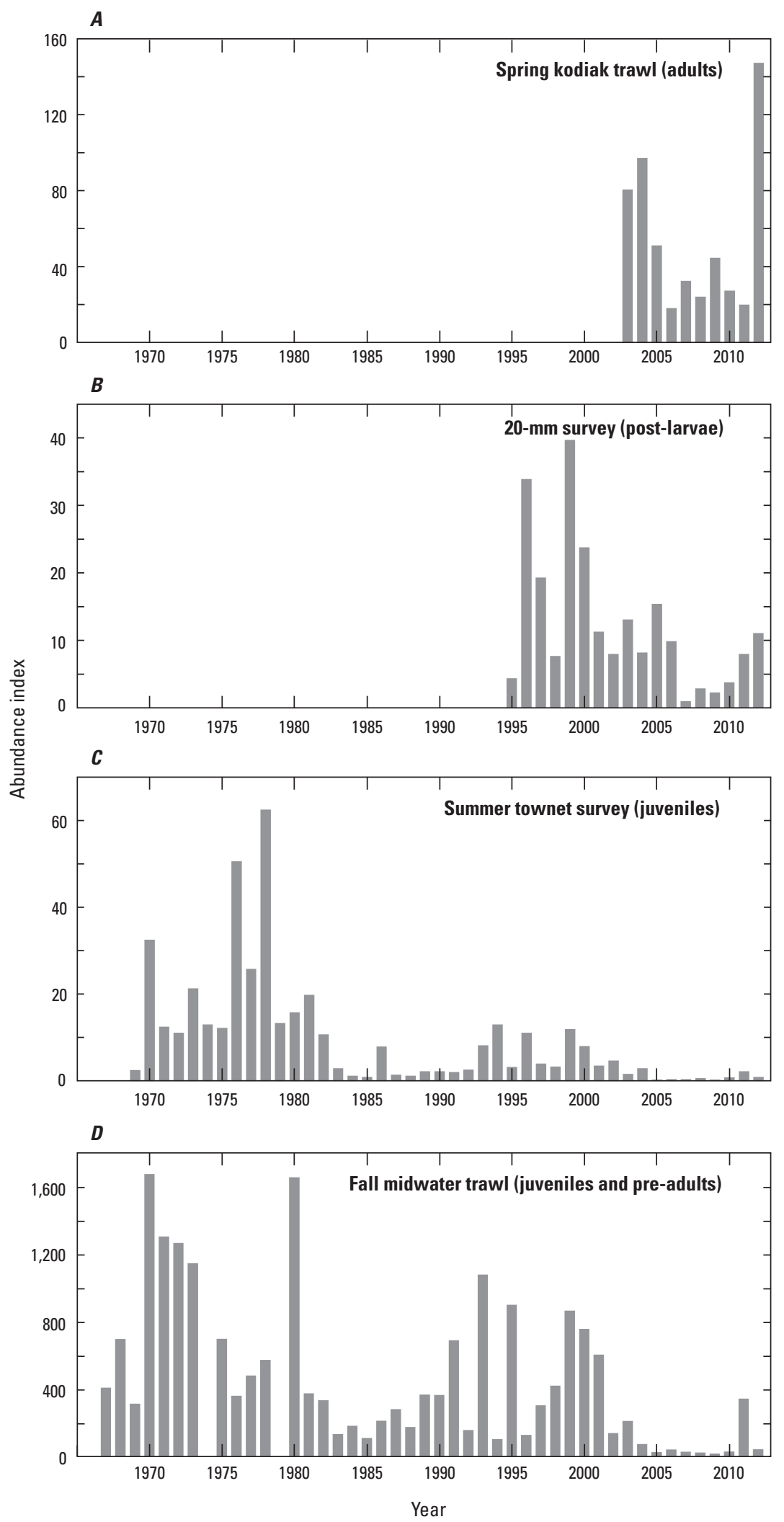

Figure 47. Plots of delta smelt abundance indices by year for $A$, the spring Kodiak-trawl survey (appendix table 8-1); $B$, 20-millimeter $(\mathrm{mm})$ survey (appendix table 8-1); $C$, summer townet survey (appendix table 8-1); and $D$, fall midwater-trawl survey (appendix table 8-1). The fall midwater-trawl survey was not done in 1974 or 1979. The summer townet survey was not done from 1966 to 1968 , and data from 1959 to 1965 are not shown. 

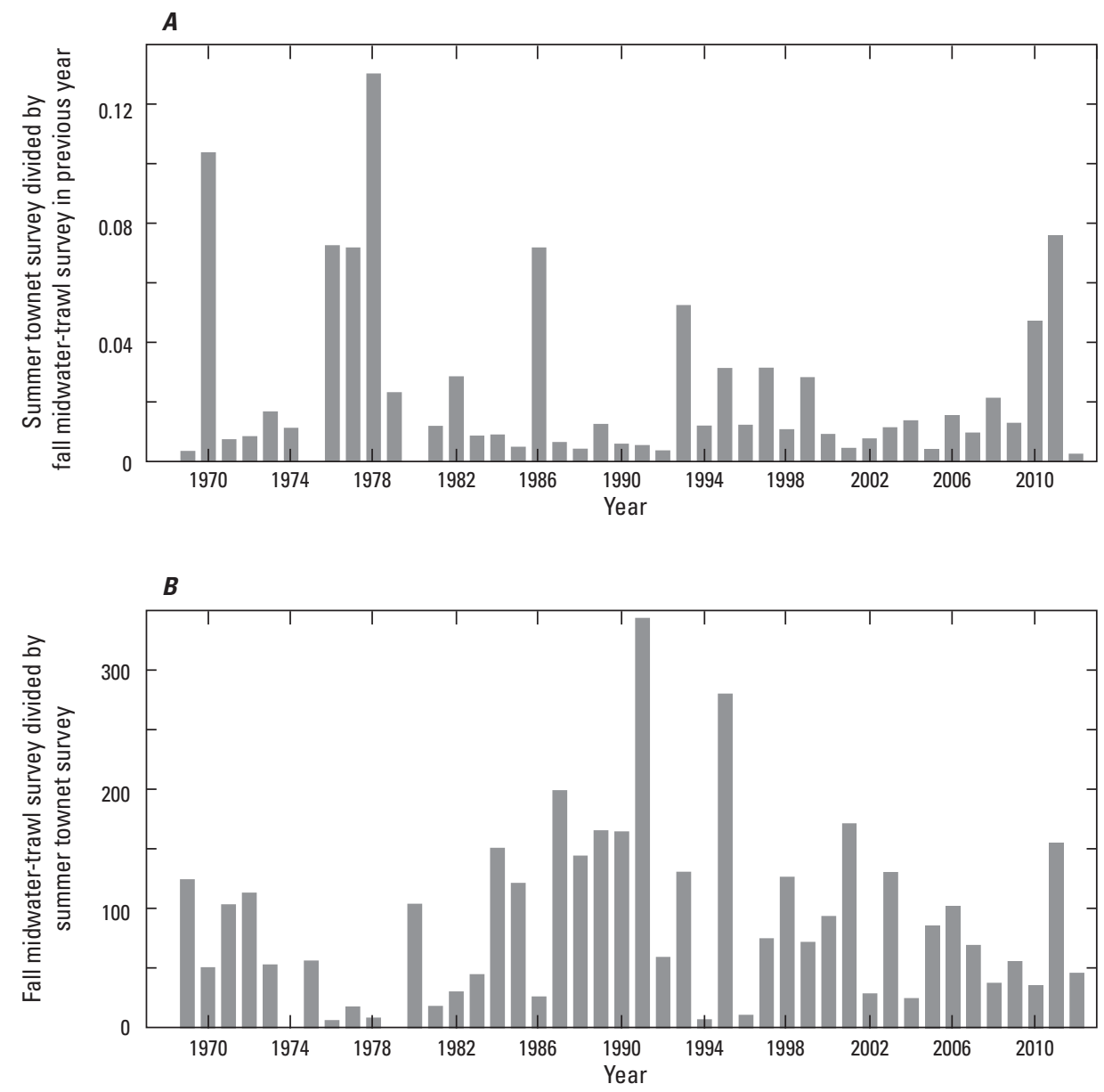

Figure 48. Ratios of delta smelt abundance indices used as indicators of survival by year for $A$, summer townet survey divided by fall midwater-trawl survey in previous year; and B, fall midwater-trawl survey divided by summer townet survey. 
of delta smelt present in the summer (July-August) into the fall (fig. 48B). This ratio was well above the median (74.2) in 2011; however, this could be partially the result of favorable summer conditions and subsequent high survival rates, rather than only favorable fall conditions and survival. The ratio of TNS to the FMWT of the previous year (fig. 48A) can be used as an indicator of successful recruitment of juveniles from the maturing adults sampled by the FMWT. This ratio indicates that juvenile recruitment was high in 2010 and 2011 compared to the long-term median (0.012). The ratio in 2010 was the eighth highest on record, and in 2011, it was among the six highest values on record. This indicates that the increase in FMWT population index in 2011 resulted from a combination of favorable factors in the winter, spring, and summer preceding the fall of 2011. The data indicated that survival in fall 2011, the preceding summer months, or both, was likely greater than in other years, which supports the prediction that delta smelt survival would be greater when X2 was at $74 \mathrm{~km}$ compared to greater values of X2 (table 1). The prediction about fecundity could not be addressed because samples were still being processed and, even if 2011 data were available, there are few data from preceding years for comparison.

The prediction that recruitment in the following year would be greater when X2 was at $74 \mathrm{~km}$ compared to $85 \mathrm{~km}$ can also be assessed by using values of abundance indices and ratios of abundance indices. For recruitment, in addition to the FMWT and TNS abundance indices, we used abundance indices from the spring Kodiak-trawl survey (SKT), which samples mature and spawning adults, and the $20-\mathrm{mm}$ survey (20-mm), which samples post-larval to juvenile delta smelt (fig. 47). Recruitment from the fall into the next year includes two processes. Fish present in the fall must survive into the winter and spring of the following year $\left(\mathrm{SKT}_{\mathrm{FMWT}} \mathrm{FMar-}_{\mathrm{r}}\right)$ and then reproduce. The resulting eggs and larvae must then survive. We assessed recruitment at two stages. We compared values from the 20-mm, TNS, and FMWT in 2012 to values in other years. We also assessed the contribution of spawning adults to recruitment by using ratios. Conceptually, this is equivalent to looking at recruits produced per spawning adult. The ratio of the 20-mm to SKT assesses recruitment to the larval stage from spawning adults. The ratio of the TNS to SKT assesses recruitment to the juvenile stage from spawning adults. In 2012, survival of pre-adults to mature adults was the lowest on record since the SKT began (fig. 49A) and was well below the median ratio of 0.70 . The SKT abundance index in 2012 was the highest ever observed (fig. 47A). Thus, a large population of pre-adults in fall 2011 had proportionately poor survival into 2012, but still produced the largest population of adults since 2003, when these data were first collected.

The 2012 recruitment of post-larval to juvenile delta smelt in the 20-mm survey from the adults surviving after fall 2011 was an improvement from the previous 5 years and was the third greatest observed since the POD began in about 2002 (fig. 47B). The ratio of $20-\mathrm{mm}$ to SKT was the third lowest observed since the SKT began in 2003 (fig. 49B), indicating that the increased recruitment was a result of the large spawning population rather than an increase in survival rate of the young of individual spawning adults. In 2012, recruitment of juveniles from the adults surviving from fall 2011 was less than the previous year and was the fifth greatest observed since the POD began in about 2002 (fig. 47C). The ratio of the TNS to SKT was the second lowest observed since the SKT began in 2003 (fig. 49C), which is consistent with a decrease in survival of the young of individual spawning adults. The 2012 recruitment of pre-adults from the adults surviving from fall 2011 was less than the previous year and was the fifth greatest observed since the POD began in about 2002 (fig. $47 D$ ). The prediction that recruitment the following year would be greater when X2 was at $74 \mathrm{~km}$ in 2011 compared to $85 \mathrm{~km}$ in 2010 was not supported, except at the earliest assessed life stage.

Results for recruitment of post-larval to juvenile delta smelt (20-mm survey) and juveniles (TNS) from the adults surviving from fall 2010 were not always lowest (fig. 47), as predicted for $\mathrm{X} 2$ of $85 \mathrm{~km}$ (table 1), so the prediction that recruitment would be less at greater X2 values was not fully supported. Note that there were no estimates of variability for either the population indices or ratios, so caution is warranted when interpreting these results.

The prediction that fish health would be better when X2 was at $74 \mathrm{~km}$ compared to $85 \mathrm{~km}$ (table 1) cannot be assessed at this time. Assessments of delta smelt health and condition are ongoing, including new measurements that have not been previously performed on delta smelt (Teh, 2012). Analyses include fall growth (otolith daily increments and RNA/DNA ratio), fish condition (condition factor, triglyceride concentration, and histopathology), and indicators of environmental stressors (acetylcholinesterase, sodium-potassium adenosine triphosphatase, histopathology, and pathogens). Preliminary results are available in Teh (2012). Results from fall 2011 will be used as the basis for comparisons with values for future years.

The prediction regarding life history is being addressed with otolith chemistry, specifically, strontium isotope ratios. The major result is a determination of migratory history. A change in strontium isotope ratios in the daily rings of the otolith accompanies migration from the natal habitat (freshwater for delta smelt) to a saltier rearing habitat. In 2011, 231 of 280 delta smelt exhibited the migratory life history (Teh, 2012). Most of the freshwater resident fish were collected in the Cache Slough/SRDWSC. A few fish also showed mixed signatures, indicating movement between different salinity regions through the year. However, there were no comparable data available from other years for assessment of the prediction that life history variability would be greater when X2 was at $74 \mathrm{~km}$ compared to $85 \mathrm{~km}$. 

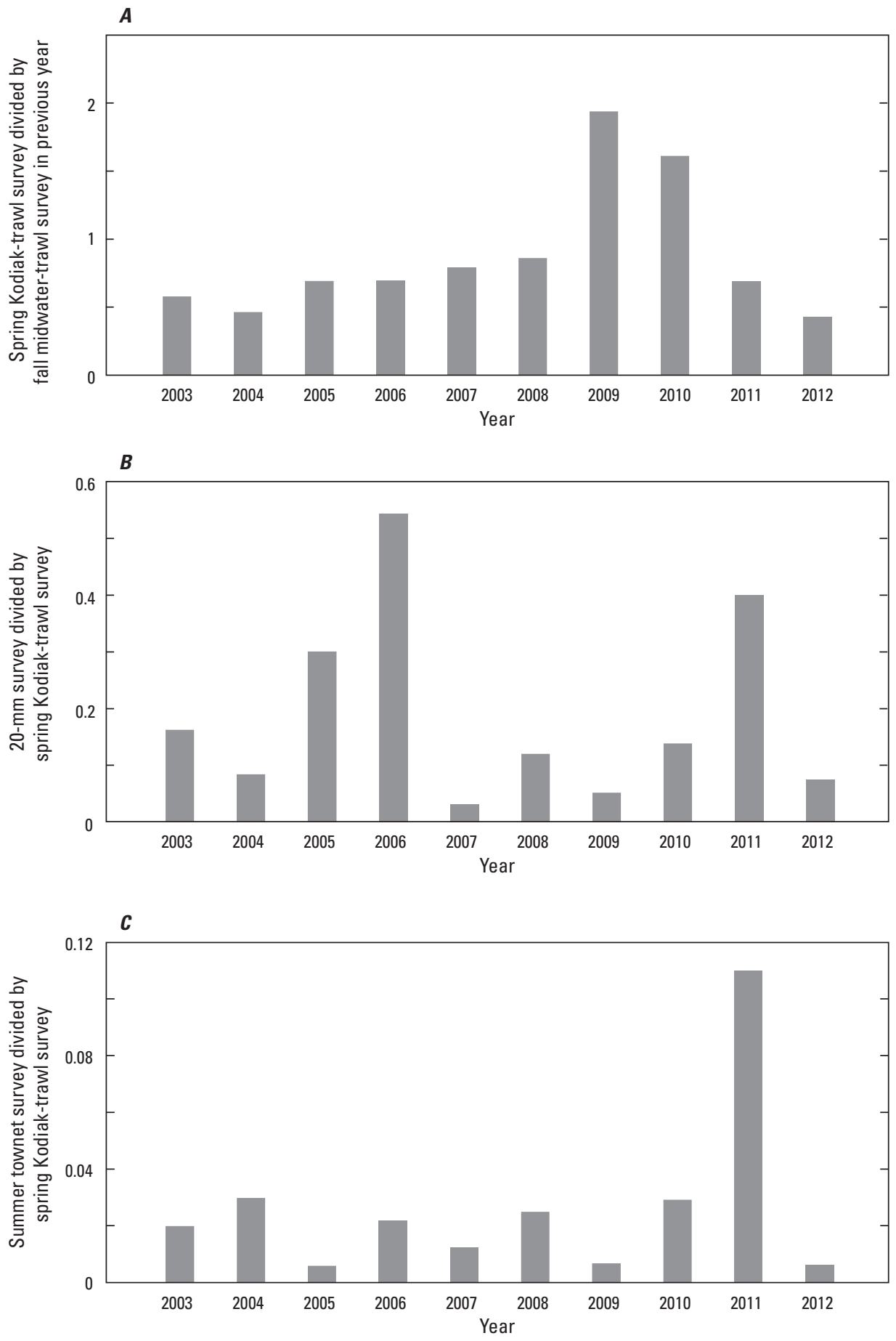

Figure 49. Ratios of delta smelt abundance indices used as indicators of survival and recruitment: $A$, spring Kodiak-trawl survey divided by fall midwater-trawl survey in previous year; $B, 20$-millimeter $(\mathrm{mm})$ survey divided by spring Kodiak-trawl survey; and $C$, summer townet survey divided by spring Kodiak-trawl survey. 


\section{Discussion}

There was an increase in the FMWT abundance index in the wet year of 2011 (fig. 4) when September-October X2 was at $75 \mathrm{~km}$, which is near the objective of X2 at $74 \mathrm{~km}$ identified in the fall low-salinity habitat component of the RPA (U.S. Bureau of Reclamation, 2012). The greater FMWT abundance index in 2011 was followed in early 2012 by the highest winter abundance index for delta smelt since the beginning of the SKT survey in 2003 (fig. 47). The scientific challenge is to understand the degree to which the changes in delta smelt abundances and fall X2 are connected. The conceptual model, developed as part of the FLaSH AMP (fig. 13), formalized the hypotheses associating X2 at $74 \mathrm{~km}$ (or $81 \mathrm{~km}$ ) with improved conditions for delta smelt, which presumably lead to an increase in the population. This conceptual model led directly to the predictions in table 1 . However, the greater numbers of delta smelt present in fall 2011 did not result in more recruitment in the following year, except for post-larvae (fig. 47). High variability in recruitment is not unexpected, particularly in an annual fish. Conditions must be favorable in every season of each year for high survival and recruitment.

Many of the predictions either could not be evaluated with the data available or the needed data were not being collected (table 5). In some cases, the available data were not sufficient to provide a reasonable assessment of the hypothesis at hand. It is unclear if precise water operations can provide the desired mean X2s with sufficiently low variability for assessment of hypotheses related to X2 at 81 and $85 \mathrm{~km}$. Additional data will become available as results from research and monitoring are released. Incorporating these data into future reports, as part of the adaptive management cycle, assuming the FLaSH investigations continue, could provide additional opportunities for improvement of our understanding of the factors affecting delta smelt.

Most of the predictions that could be addressed involved either abiotic habitat components or delta smelt responses (table 5). It is not surprising that abiotic components were relatively easy to assess because many of them are known to be related to X2, particularly daily net Delta outflow, surface area of the LSZ, and the delta smelt habitat index. However, even these measures mainly highlighted differences between conditions when $\mathrm{X} 2$ was at $75 \mathrm{~km}$ and the other $\mathrm{X} 2$ values assessed. Variability in results at X2 between 82 and $85 \mathrm{~km}$ made the finer-scale comparisons difficult. Such variability leaves some question as to whether meaningful comparisons can be made between an X2 at 81 and at $85 \mathrm{~km}$. It is notable that the two abiotic factors where the predictions were not supported concerned the nutrients ammonium and nitrite plus nitrate. These were included in the abiotic factors because they are considered potential contaminants and drivers of phytoplankton productivity and biomass, but they are hardly inert chemicals in the environment. Concentrations of both chemicals in the estuary depend not only on loadings from point and nonpoint sources but also on nutrient cycling and primary production as water passes through the estuary; therefore, it is not surprising that they did not follow a simple conceptual model based only on considerations of sources and transport.

The available data on delta smelt responses were limited to long-term data that were previously analyzed. Salvage data from the SWP and CVP were most recently addressed by Grimaldo and others (2009), and since the POD, managers have been very careful to minimize salvage. The center of distribution for delta smelt was most recently addressed by Sommer and others (2011b). Relationships among the various delta smelt population indices have also been explored (for example, Baxter and others, 2010). Thus, these predictions were based on previous empirical assessments. The data being collected on growth, fecundity, health, and condition in 2011 (Teh, 2012) could not be used to assess the predictions because there were no previous data for comparison; however, these data will be important in the future as a benchmark for a relatively "good" year for delta smelt.

The assessments of predictions concerning biotic habitat components either could not be addressed or the data were inconclusive for all or part of a prediction (table 5). The prediction that biomass of Potamocorbula would be greater in the LSZ at X2 of $85 \mathrm{~km}$ compared to other values was not supported to the extent data were available, and the prediction that average phytoplankton biomass would be greater in the LSZ at X2 of 74 compared to greater values of X2 was partially supported. While there appears to be consensus that food quantity and quality are important factors in the POD (Baxter and others 2008, 2010; Glibert and others, 2011), there is no consensus on the relative importance of such bottom-up factors in relation to other factors or the specific mechanisms driving bottom-up effects. The biotic habitat components are also known to interact with each other and with abiotic components. The prediction for Potamocorbula, which is functionally directed at grazing rates of clams on phytoplankton, does not include Corbicula, a clam which is an important grazer in freshwater. Understanding the effect of clam grazing on phytoplankton available to organisms that delta smelt consume will require modeling of grazing by both clam species in relation to phytoplankton production, hydrodynamics, and channel characteristics (for example, depth; Lucas and others, 2002; Lopez and others, 2006; Cloern, 2007; Lucas and Thompson, 2012). Further, benthic clam distributions do not shift as quickly in response to salinity changes as the distribution of pelagic organisms, and the predictions about clams would be more robust by taking these differences into consideration. Predation on delta smelt could also be a factor, but there are no quantitative data on predation rates to objectively evaluate the importance of predation to the delta smelt population.

In general, the FLaSH investigation of the mechanisms linking X2 and delta smelt abundance has been somewhat inconclusive as of the writing of this report. That is not to be unexpected in the first year of a multi-year adaptive 
Table 5. Assessments of predicted qualitative and quantitative outcomes for September to October of the fall low-salinity habitat component of the Reasonable and Prudent Alternative based on three levels of the action (modified from U.S. Bureau of Reclamation, 2012). The years considered representative of the three levels of action are indicated.

[X2 is the horizontal distance in kilometers from the Golden Gate up the axis of the estuary to where tidally averaged near-bottom salinity is 2 . Green shading means that data supported the prediction; orange shading means the prediction was not supported; gray shading means that data were not yet available to support a conclusion; no shading means there were no data to assess Abbreviations: CVP, Central Valley Project; DS, delta smelt; ha, hectares; km, kilometer; LSZ, low-salinity zone with salinity 1-6; SWP, State Water Project; , approximately]

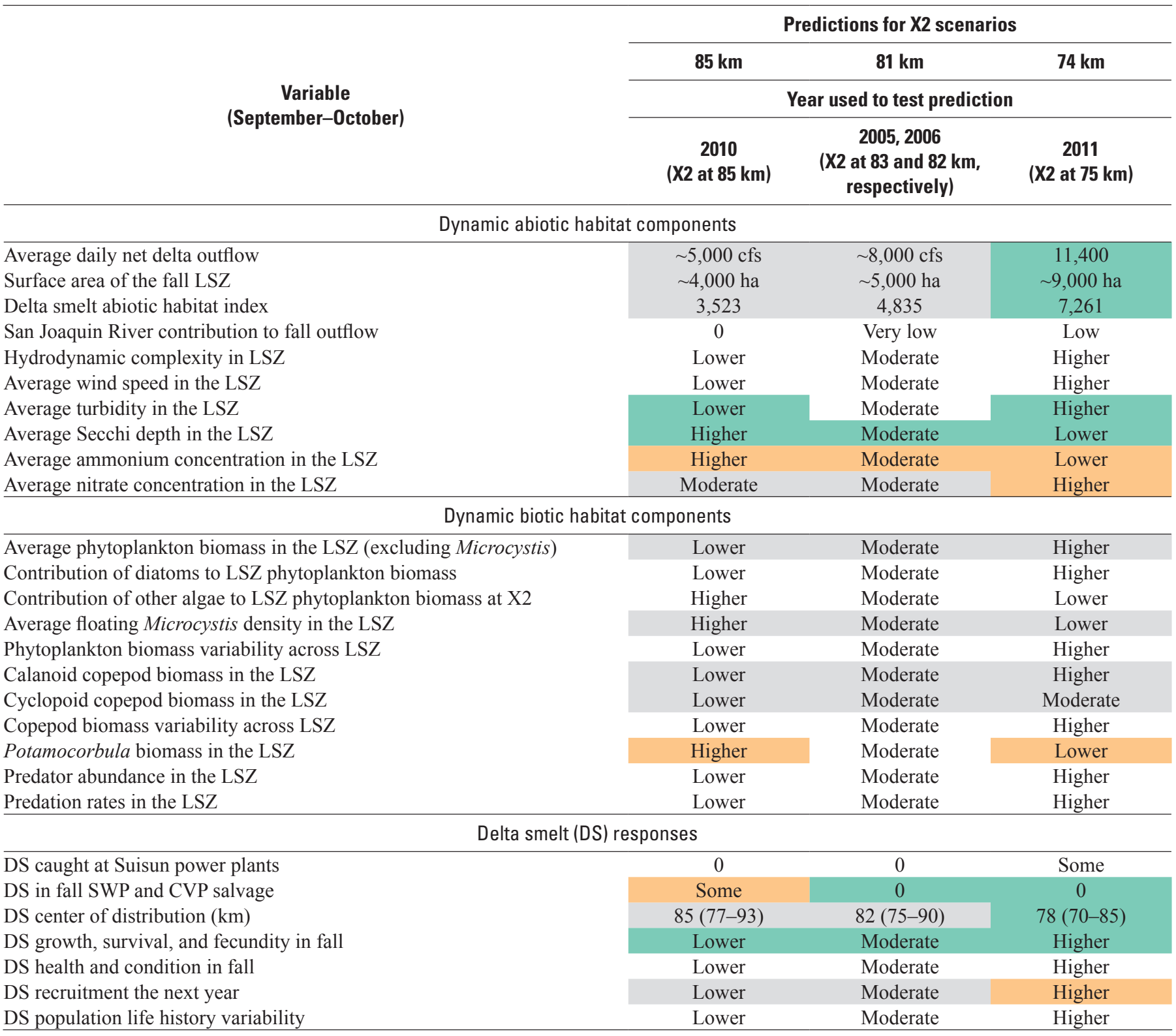


management effort. Substantial knowledge was gained as a result of the work done in fall 2011 and will provide the basis for reassessing some hypotheses that could be too simplistic in the current conceptual model. This report can be viewed as the first chapter of a "living document" to be continually updated as part of the adaptive management cycle. As part of that cycle, the results of this report can be used to revise the conceptual model and predictions based on the conceptual model, perhaps through an annual or biannual update of the adaptive management plan.

The results of this report, especially predictions with insufficient data for evaluation, indicate a number of sciencebased approaches for improving the FLaSH investigations.

- Develop a method of measuring "hydrodynamic complexity." This concept is central to a number of the predictions that could not be evaluated. Accomplishing this will likely require a combination of modeling and empirical studies to identify areas of high and low complexity. Once such areas are identified, additional modeling and empirical studies would be needed to determine if hydrodynamic complexity creates the dynamic, biotic habitat components hypothesized, including variability in phytoplankton and zooplankton biomass, and whether those biotic habitat components contribute to greater abundances of delta smelt.

- Determine if wind speed warrants a stand-alone prediction. The wind-speed prediction is directly related to the turbidity predictions, and wind is only one of several factors important to determining turbidity. If important goals are the understanding of the processes generating turbidity and the ability to predict turbidity, then development of a suspended-sediment and turbidity model that incorporates wind and other important factors is warranted.

- Determine the correct spatial and temporal scales necessary for monitoring, and identify other studies to address the predicted abiotic and biotic responses. Many of the assessments in this report were based on monthly sampling of dynamic habitat components, such as phytoplankton and zooplankton populations, that can change daily.

- Develop a phytoplankton-production model, if feasible. At a minimum, develop a mechanistic conceptual model to support more process-based interpretations of data or the design of new studies, rather than making simple predictions of increase or decrease of nutrient concentrations or the biomass of phytoplankton and grazers. Such a model could include components of nutrient cycling and grazing, which would highlight any needs for additional research and understanding of those processes.
- Refine predictions about delta smelt prey availability and quality by using data on delta smelt diet and other information on delta smelt prey characteristics.

- Determine if studies of predation are feasible in areas occupied by delta smelt.

As noted previously, a major limitation of this report is that many of the key analyses from the FLaSH studies were not completed at the time that this report was prepared. Even when these analyses are completed, rigorous inter-year comparisons will not be possible because there are not other years with comparable levels of effort dedicated to understanding the same features of the LSZ. Such comparisons, therefore, will depend on detailed data collection in future years with a full range of fall-flow conditions, as outlined in the AMP. Moreover, the scope of this report only addressed selected months in selected years to limit the need to incorporate larger data sets in the limited time available to prepare the report and because the FLaSH investigation focuses only on the fall. Future iterations of this report can incorporate additional data as they become available, including data from seasons other than the fall. There are fewer available data from earlier years to compare to recent years because additional types of data have been collected as management of delta smelt became important. Differences in overall habitat conditions and status of delta smelt were greater in earlier years before the POD (Thomson and others, 2010; Baxter and others, 2010). This makes comparisons with earlier years more difficult and less likely to be conclusive. Inclusion of data from all seasons, not just fall, is critical to our understanding of factors affecting delta smelt. It is difficult to evaluate the importance of a single season in isolation from other seasons in the population biology of an organism. For example, a "good" fall could easily have no measurable effect on a population if stressful conditions during the preceding spring affected spawning success of adults and the subsequent survival of larvae. Understanding the relative importance of such events is the basis of life-cycle models, which could be useful tools for managing delta smelt in the future. A broader analysis that incorporates the results of the FLaSH investigation is one of the objectives of the newly formed IEP Management, Analysis, and Synthesis Team. The Management, Analysis, and Synthesis Team is intended to provide a broader analysis of factors affecting delta smelt and could serve as a template for formation of a FLaSH team as part of the AMP that would prepare future versions of this report. 


\section{References Cited}

Alpine, A.E., and Cloern, J.E., 1992, Trophic interactions and direct physical effects control phytoplankton biomass and production in an estuary: Limnology and Oceanography v. 37, p. 946-955.

Arthur, J.F., Ball, M.D., and Baughman, S.Y., 1996, Summary of federal and state water project environmental impacts in the San Francisco Bay-Delta estuary, California, in Hollibaugh, J.T., ed., San Francisco Bay: the ecosystem: San Francisco, California, Pacific Division American Association for the Advancement of Science, p. 445-495.

Baerwald, M.R., Schreier, B.M., Schumer, Greg, and May, Bernie, 2012, Detection of threatened delta smelt in the gut contents of the invasive Mississippi silverside in the San Francisco Estuary using TaqMan Assays: Transactions of the American Fisheries Society, v. 141, p. 1600-1607.

Baxter, Randall, Breuer, Richard, Brown, Larry, Chotkowski, Mike, Feyrer, Frederick, Gingras, Marty, Herbold, Bruce, Mueller-Solger, Anke, Nobriga, Matthew, Sommer, Ted, and Souza, Kelly, 2008, Pelagic organism decline progress report: 2007 synthesis of results: Stockton, Calif., Interagency Ecological Program for the San Francisco Estuary, Technical Report 227, 86 p., http://www.water.ca.gov/iep/ docs/pod/synthesis_report_031408.pdf.

Baxter, Randall, Breuer, Richard, Brown, Larry, Conrad, Louise, Feyrer, Frederick, Fong, Stephanie, Gehrts, Karen, Grimaldo, Lenny, Herbold, Bruce, Hrodey, Pte, MuellerSolger, Anke, Sommer, Ted, and Souza, Kelly, 2010, Interagency Ecological Program 2010 Pelagic Organism Decline work plan and synthesis of results: Stockton, Calif., Interagency Ecological Program for the San Francisco Estuary, 259 p., http://www.water.ca.gov/iep/docs/ FinalPOD2010Workplan12610.pdf.

Bennett, W.A., 2005, Critical assessment of the delta smelt population in the San Francisco Estuary, California: San Francisco Estuary and Watershed Science, v. 3, article 1, 71 p., http://repositories.cdlib.org/jmie/sfews/vol3/iss2/art1.

Bennett, W.A., and Moyle, P.B., 1996, Where have all the fishes gone? Interactive factors producing fish declines in the Sacramento San Joaquin Estuary, in Hollibaugh, J.T., ed., San Francisco Bay: the ecosystem: San Francisco, Calif., Pacific Division American Association for the Advancement of Science, p. 519-542.
Brooks, M.L., Fleishman, Erica, Brown, L.R., Lehman, P.W., Werner, Inge, Scholz, Nathaniel, Mitchelmore, Carys, Lovvorn, J.R., Johnson, M.L., Schlenk, Daniel, van Drunick, Suzanne, Drever, J.I., Stoms, D. M., Parker, A. E., and Dugdale, Richard, 2012, Life histories, salinity zones, and sublethal contributions of contaminants to pelagic fish declines illustrated with a case study of San Francisco Estuary, California, USA: Estuaries and Coasts, v. 35, p. 603-621.

Brown, L.R., and Michniuk, Dennis, 2007, Littoral fish assemblages of the alien-dominated Sacramento-San Joaquin Delta, California, 1980-1983 and 2001-2003: Estuaries and Coasts, v. 30, p. 186-200.

Brown, L.R., and Moyle, P.B., 2005, Native fish communities of the Sacramento-San Joaquin watershed, California: a history of decline: American Fisheries Society Symposium, v. 45 , p. 75-98.

California Department of Water Resources, 2005, Flooded islands pre-feasibility, RMA Delta Model Calibration Report: Fairfield, Calif., Resource Management Associates, report to California Department of Water Resources, 158 p., http://www.water.ca.gov/frankstract/docs/(8)RMACalibration\%20Report.pdf.

California Department of Water Resources, 2008, POD 3-D Particle Tracking Modeling Study, San Francisco BayDelta UnTRIM Model Calibration Report: Sacramento, Calif., report to California Department of Water Resources, 334 p., http://www.water.ca.gov/iep/docs/pod/UnTRIM Calibration_Report.pdf.

California Fish and Game Commission, 2009, Final statement of reasons for regulatory action, Amend Title 14, CCR, Section 670.5, Re: uplisting the delta smelt to endangered species status: Sacramento, Calif., California Fish and Game Commission.11 p., http://www.fgc.ca.gov/ regulations/2009/670_5dsfsor.pdf.

Castillo, Gonzalo, Morinaka, Jerry, Lindberg, Joan, Fujimura, Robert, Baskerville-Bridges, Bradd, Hobbs, James, Tigan, Galen, and Ellison, Luke, 2012, Pre-screen loss and fish facility efficiency for delta smelt at the south Delta's State Water Project, California: San Francisco Estuary and Watershed Science, v. 10, no. 4, p. 1-23, http://www.escholarship. org/uc/item/28m595k4.

Cloern, J.E., 1987, Turbidity as a control on phytoplankton biomass and productivity in estuaries: Continental Shelf Research, v. 7, p. 1367-1381. 
Cloern, J. E., 2007, Habitat connectivity and ecosystem productivity: implications from a simple model: American Naturalist, v. 169, p. E21-E33.

Cloern, J.E., and Jassby, A.D., 2008, Complex seasonal patterns of primary producers at the land-sea interface: Ecology Letters, v. 11, p. 1294-1303.

Cloern, J.E., and Jassby, A.D., 2010, Patterns and scales of phytoplankton variability in estuarine-coastal ecosystems: Estuaries and Coasts, v. 33, p. 230-241.

Close, Andy, Haneman, W.M., Labadie, J.W., Loucks (Chair), D.P., Lund, J.R., McKinney, D.C., and Stedinger, J. R., 2003, A strategic review of CALSIM II and its use for water planning, management, and operations in Central California: Sacramento, Calif., CALFED Science Program Report, 14 p., http://www.waterboards.ca.gov/waterrights/water issues/programs/hearings/daviswoodland/daviswoodland_ cspa_es9.pdf.

Conomos, T.J., ed., 1979, San Francisco Bay: the urbanized estuary. Investigation into the natural history of San Francisco Bay and Delta with reference to the influence of man: San Francisco, California, Pacific Division American Association for the Advancement of Science, 493 p.

Dege, Michael, and Brown, L.R., 2004, Effect of outflow on spring and summertime distribution and abundance of larval and juvenile fishes in the upper San Francisco Estuary: American Fisheries Society Symposium, v. 39, p. 49-65.

Dettinger, M.D., 2011, Climate change, atmospheric rivers and floods in California-A multimodel analysis of storm frequency and magnitude changes: Journal of American Water Resources Association, v. 47, p. 514-523.

Dugdale, R.C., Wilkerson, F.P., Hogue, V.E., and Marchi, Albert, 2007, The role of ammonium and nitrate in spring bloom development in San Francisco Bay: Estuarine, Coastal, and Shelf Science, v. 73, p. 17-29.

Erkkila, L.F., Moffett, J.W., Cope, O.B., Smith, B.R., and Nelson, R.S., 1950, Sacramento-San Joaquin Delta fishery resources: effects of Tracy pumping plant and delta cross channels: Special Scientific Report, Fisheries 56, U.S. Fish and Wildlife Service, 109 p.

Feyrer, Frederick, Brown, L.R., Brown, R.L., and Orsi, J.J., eds., 2004, Early life history of fishes in the San Francisco Estuary and Watershed: American Fisheries Society Symposium 39, Bethesda, Maryland, American Fisheries Society, $296 \mathrm{p}$.

Feyrer, Frederick, Sommer, Ted, and Harrell, William, 2006, Managing floodplain inundation for native fish: production dynamics of age- 0 splittail in California's Yolo Bypass: Hydrobiologia, v. 573, p. 213-226.
Feyrer, Frederick, Nobriga, M.L., and Sommer, T.R., 2007, Multi-decadal trends for three declining fish species: habitat patterns and mechanisms in the San Francisco Estuary, California, USA: Canadian Journal of Fisheries and Aquatic Sciences, v. 64, p. 723-734.

Feyrer, Frederick, Newman, Ken, Nobriga, Matthew, and Sommer, Ted, 2010, Modeling the effects of future freshwater flow on the abiotic habitat of an imperiled estuarine fish: Estuaries and Coasts, v. 34, p. 120-128.

Fisch, K.M., 2011, Conservation genetics of the endangered delta smelt (Hypomesus transpacificus) in the San Francisco Estuary: Davis, Calif., University of California, Davis, $\mathrm{Ph}$. D dissertation, $113 \mathrm{p}$.

Fisch, K.M., Henderson, J.M., Burton, R.S., and May Bernie, 2011, Population genetics and conservation implications for the endangered delta smelt in the San Francisco Bay-Delta: Conservation Genetics, v. 12, p. 1421-1434.

Ganju, N.K., Schoellhamer, D.H., Murrell, M.C., Gartner, J.W., and Wright, S.A., 2007, Constancy of the relation between floc size and density in San Francisco Bay, in Maa, J.P.-Y., Sanford, L.P., and Schoellhamer, D.H., ed., Estuarine and Coastal Fine Sediments Dynamics: Elsevier Science B.V., p. 75-91.

Ger, K.A., Teh, S.J., and Goldman, C.R., 2009, MicrocystinLR toxicity on dominant copepods Eurytemora affinis and Pseudodiaptomus forbesi of the upper San Francisco Estuary: Science of the Total Environment, v. 407, p. 4852-4857.

Ger, K.A., Arneson, Patricia, Goldman, C.R., and Teh, S.J., 2010a, Species specific differences in the ingestion of Microcystis cells by the calanoid copepods Eurytemora affinis and Pseudodiaptomus forbesi: Journal of Plankton Research, v. 32, p. 1479-1484.

Ger, K.A., Teh, S.J., Baxa, D.V., Lesmeister, Sarah and Goldman, C.R., 2010b, The effects of dietary Microcystis aeruginosa and microcystin on the copepods of the upper San Francisco Estuary: Freshwater Biology, v. 55, p. $1548-1559$.

Glibert, P.M., Fullerton, David, Burkholder, J.M., Cornwell, J.C., and Kana, T.M., 2011, Ecological stoichiometry, biogeochemical cycling, invasive species, and aquatic food webs: San Francisco Estuary and comparative systems: Reviews in Fisheries Science, v. 19, p. 358-417.

Grimaldo, L.F., Sommer, Ted, Van Ark, Nick, Jones, Gardner, Holland, Erika, Moyle, P.B., Herbold, Bruce, and Smith, Pete, 2009, Factors affecting fish entrainment into massive water diversions in a tidal freshwater estuary: Can fish losses be managed?: North American Journal of Fisheries Management, v. 29, p. 1253-1270. 
Hollibaugh, J.T., ed., 1996, San Francisco Bay: the ecosystem: San Francisco, California, Pacific Division American Association for the Advancement of Science, $542 \mathrm{p}$.

Jassby, A.D., 2008, Phytoplankton in the upper San Francisco Estuary: recent biomass trends, their causes and their trophic significance: San Francisco Estuary and Watershed Science, v. 6, no. 1, http://www.escholarship.org/uc/ item/71h077rl.

Jassby, A.D., Kimmerer, W.J., Monismith, S.G., Armor, Chuck, Cloern, J.E., Powell, T.M., Schubel, J.R., and Vendlinski, T.J., 1995, Isohaline position as a habitat indicator for estuarine populations: Ecological Applications, v. 5, p. 272-289.

Jassby, A.D., Cloern, J.E., and Cole, B.E., 2002, Annual primary production: patterns and mechanisms of change in a nutrient-rich tidal ecosystem: Limnology and Oceanography, v. 47, p. 698-712.

Johnson, M.L., Werner, Inge, Teh, Swee, and Loge, Frank, 2010, Evaluation of chemical, toxicological, and histopathological data to determine their role in the pelagic organism decline: Davis, California, University of California, Davis, Final report to the California State Water Resources Control Board and Central Valley Regional Water Quality Control Board, 296 p., http://www.swrcb.ca.gov/rwqcb5/water issues/delta_water_quality/comprehensive_monitoring program/contaminant_synthesis_report.pdf.

Kimmerer, W.J., 2002a, Physical, biological, and management responses to variable freshwater flow into the San Francisco Estuary: Estuaries, v. 25, p. 1275-1290.

Kimmerer, W.J., 2002b, Effects of freshwater flow on abundance of estuarine organisms: physical effects or trophic linkages: Marine Ecology Progress Series, v. 243, p. 39-55.

Kimmerer, W.J., 2004, Open-water processes of the San Francisco Estuary: from physical forcing to biological responses: San Francisco Estuary and Watershed Science, v. 2, http://escholarship.org/uc/item/9bp499mv.

Kimmerer, W.J., and Orsi, J.J., 1996, Changes in the zooplankton of the San Francisco Bay Estuary since the introduction of the clam Potamocorbula amurensis, in Hollibaugh, J.T., ed., San Francisco Bay: the ecosystem: San Francisco, California, Pacific Division American Association for the Advancement of Science, p. 403-423.

Kimmerer, W.J., Gartside, Ellen, and Orsi, J.J., 1994, Predation by an introduced clam as the likely cause of substantial declines in zooplankton of San Francisco Bay: Marine Ecology Progress Series, v. 113, p. 81-93.
Kimmerer, W.J., Gross, E.S., and MacWilliams, M.L., 2009, Is the response of estuarine nekton to freshwater flow in the San Francisco Estuary explained by variation in habitat volume?: Estuaries and Coasts, v. 32, p. 375-389.

Komoroske L.M., Connon, R.E., Lindberg. Joan, Cheng, B.S., Castillo, Gonzalo, Hasenbein, Matthias, Fangue, N.A., 2014, Ontogeny influences sensitivity to climate change stressors in an endangered fish: Conservation Physiology, v. 2, doi:10.1093/conphys/cou008.

Kuivila, K.M., and Hladik, M.L., 2008, Understanding the occurrence and transport of current-use pesticide in the San Francisco Estuary Watershed: San Francisco Estuary and Watershed Science, v. 6, no. 3, http://www.escholarship.org/ uc/item/06n8b36k.

Lacy, J.R., Stacey, M.T., Burau, J.R., and Monismith, S.G., 2003, Interaction of lateral baroclinic forcing and turbulence in an estuary: Journal of Geophysical Research, v. 108, no. c3, p. 3089.

Lehman, P.W., Boyer, Greg, Hall, Catherine, Waller, Scott, and Gehrts, Karen, 2005, Distribution and toxicity of a new colonial Microcystis aeruginosa bloom in the San Francisco Bay Estuary, California: Hydrobiologia, v. 541, p. 87-99.

Lehman, P.W., Boyer, Greg, Satchwell, Michael, and Waller, Scott, 2008, The influence of environmental conditions on the seasonal variation of Microcystis cell density and microcystins concentration in San Francisco Estuary: Hydrobiologia, v. 600, p. 187-204.

Lehman, P.W., Teh, S.J., Boyer, G.L., Nobriga, M.L., Bass, Erin, and Hogle, Christopher, 2010, Initial impacts of Microcystis aeruginosa blooms on the aquatic food web in the San Francisco Estuary: Hydrobiologia, v. 637, p. 229-248.

Lopez, C.B., Cloern, J.E., Schraga, T.S., Little, A.J., Lucas, L.V., Thompson, J.K., and Burau, J.R., 2006, Ecological values of shallow-water habitats: Implications for restoration of disturbed ecosystems: Ecosystems, v. 9, p. 422-440.

Lotze, H.K., Lenihan, H.S., Bourque, B.J., Bradbury, R.H., Cooke, R.G., Kay, M.C., Kidwell, S.M., Kirby, M.X., Peterson, C.H., Jackson, J.B.C., 2006, Depletion, degradation, and recovery potential of estuaries and coastal seas: Science, v. 312 p. 1806-1809.

Lucas, L.V., and Thompson, J.K., 2012, Changing restoration rules: Exotic bivalves interact with residence time and depth to control phytoplankton productivity: Ecosphere: v. 3, no. 12, p. 117, available at: $h t t p: / / d x . d o i . o r g / 10.1890 / E S 12-$ 00251.1. 
Lucas, L.V., Cloern, J.E., Thompson, J.K., and Monsen, N.E., 2002, Functional variability of habitats within the Sacramento-San Joaquin Delta: Restoration implications: Ecological Applications, v. 12, p. 1528-1547.

Lund, J.R., Hanak, Ellen, Fleenor, W.E., Bennett, W.A., Howitt, R.E., Mount, J.F., and Moyle, P.B., 2010, Comparing futures for the Sacramento-San Joaquin Delta: Berkeley, California, University of California Press, $256 \mathrm{p}$.

Mac Nally, Ralph, Thompson, J.R., Kimmerer, W.J., Feyrer, Frederick, Newman, K.B., Sih, Andy, Bennett, W.A., Brown, Larry, Fleishman, Erica, Culberson, S.D., Castillo, Gonzalo, 2010, An analysis of pelagic species decline in the upper San Francisco Estuary using multivariate autoregressive modeling (MAR): Ecological Applications, v. 20, p. 1417-1430.

Manly, B.J.F., and Chotkowski, M.A., 2006, Two new methods for regime change analysis: Archiv für Hydrobiologie, v. 167 , p. $593-607$.

Maunder, M.N., and Deriso, R.B., 2011, A state-space multistage life cycle model to evaluate population impacts in the presence of density dependence: illustrated with application to delta smelt (Hyposmesus transpacificus): Canadian Journal of Fisheries and Aquatic Sciences, v. 68, p.1285-1306.

Merz, J.E., Hamilton, Scott, Bergman, P.S., and Cavallo, Bradley, 2011, Spatial perspective for delta smelt: a summary of contemporary survey data: California Fish and Game, v. 97, no. 4, p. 164-189.

Miller, W.J., Manly, B.F.J., Murphy, D.D., Fullerton, David, and Ramey, R.R., 2012, An investigation of factors affecting the decline of delta smelt (Hypomesus transpacificus) in the Sacramento-San Joaquin Estuary: Reviews in Fisheries Science, v. 20, p. 1-19.

Miranda, Javier, and Padilla, Rogelio, 2010, Release site predation study: Sacramento, Calif., Fishery Improvements Section, Bay-Delta Office, California Department of Water Resources, 189 p., http://baydeltaoffice.water.ca.gov/ announcement/Element2FinalReport5-2010.pdf.

Monismith, S.G., Kimmerer, Wim, Burau, J.R., and Stacey, M.T., 2002, Structure and flow-induced variability of the subtidal salinity field in northern San Francisco Bay: Journal of Physical Oceanography, v. 32, p. 3003-3019.

Moyle, P.B., 2002, Inland fishes of California, $2^{\text {nd }}$ edition: Berkeley, Calif., University of California Press,517 p.
Moyle, P.B., and Bennett, W.A., 2008, The future of the Delta ecosystem and its fish, Technical appendix D, in Lund, J., Hanak, E., Fleenor, W., Bennett, W., Howitt, R., Mount, J., and Moyle, P., eds., Comparing Futures for the SacramentoSan Joaquin Delta: San Francisco, California, Public Policy Institute of California, 46 p., http://www.ppic.org/content/ pubs/other/708ehr_appendixd.pdf.

Moyle, P.B., Herbold, Bruce, Stevens, D.E., and Miller L.W., 1992, Life history and status of delta smelt in the Sacramento-San Joaquin Estuary, California: Transactions of the American Fisheries Society, v. 121, p. 67-77.

Moyle, P.B., Bennett, W.A., Fleenor, W.E., and Lund, J.R., 2010, Habitat variability and complexity in the upper San Francisco Estuary: San Francisco Estuary and Watershed Science, v. 8, no. 3, available at http://escholarship.org/uc/ item/0kf0d $32 x$.

National Research Council, 2012, Sustainable water and environmental management in the California Bay-Delta: National Research Council, Washington, D.C., The National Academies Press, 280 p., http://www.nap.edu/catalog. php?record_id $=13394$.

Nobriga, Matthew, Feyrer, Frederick, Baxter, Randall, and Chotkowski, Mike, 2005, Fish community ecology in an altered river delta: spatial patterns in species composition, life history strategies, and biomass: Estuaries, v. 28, p. 776-785.

Nobriga, M.L., Sommer, T.R., Feyrer, Frederick, and Fleming, Kevin, 2008, Long-term trends in summertime habitat suitability for delta smelt, Hypomesus transpacificus: San Francisco Estuary and Watershed Science, v. 6, no. 1, http:// escholarship.org/uc/item/5xd3q8tx.

Parker, A.E., Dugdale, R.C., and Wilkerson, F.P., 2012, Elevated ammonium concentrations from wastewater discharge depress primary productivity in the Sacramento River and the Northern San Francisco Estuary: Marine Pollution Bulletin, v. 64 , no. 3 , p. $574-586$.

Peterson, M.S., 2003, Conceptual view of the environmenthabitat-production linkages in tidal river estuaries: Reviews in Fisheries Science, v. 11, p. 291-313.

Radtke, L.D., 1966, Distribution of smelt, juvenile sturgeon, and starry flounder in the Sacramento-San Joaquin Delta: Sacramento, Calif., California Department of Fish and Game, Fish Bulletin 136, p. 115-129. 
Rose, K.A., Kimmerer, W.J., Edwards, K.P., and Bennett, W.A., 2013, Individual-based modeling of delta smelt population dynamics in the upper San Francisco Estuary: I. Model description and baseline results: Transactions of the American Fisheries Society, v. 142, p. 1238-1259.

Rose, K.A., Kimmerer, W.J., Edwards, K.P., and Bennett, W.A., 2013, Individual-based modeling of delta smelt population dynamics in the upper San Francisco Estuary: II. Alternative baselines and good versus bad years: Transactions of the American Fisheries Society, v. 142, p. 1260-1272.

Ruhl, C.A., and Schoellhamer, D.H., 2004, Spatial and temporal variability of suspended-sediment concentrations in a shallow estuarine environment: San Francisco Estuary and Watershed Science, v. 2, no. 2, http://escholarship.org/uc/ item $/ \lg 1756 d w$.

Schoellhamer, D.H., 2001, Influence of salinity, bottom topography, and tides on locations of estuarine turbidity maxima in northern San Francisco Bay, in McAnally, W.H., and Mehta, A.J., ed., Coastal and estuarine fine sediment transport trocesses: Elsevier Science B.V., p. 343-357, http:// ca.water.usgs.gov/abstract/sfbay/elsevier0102.pdf.

Schoellhamer, D.H., 2011, Sudden clearing of estuarine waters upon crossing the threshold from transport to supply regulation of sediment transport as an erodible sediment pool is depleted: San Francisco Bay, 1999: Estuaries and Coasts, v. 34, p. 885-899.

Schoellhamer, D.H., and Burau, J.R., 1998, Summary of findings about circulation and the estuarine turbidity maximum in Suisun Bay, California: U.S. Geological Survey Fact Sheet FS-047-98, 6 p., http://sfbay.wr.usgs.gov/sediment/ circulation/.

Schoellhamer, D.H., Wright, S.A., and Drexler, J.Z., 2012, Conceptual model of sedimentation in the Sacramento - San Joaquin River Delta: San Francisco Estuary and Watershed Science v. 10, no. 3, http://www.escholarship.org/uc/ item/2652z8sq.

Sobczak, W.V., Cloern, J.E., Jassby, A.D., and Muller-Solger, A.B., 2002, Bioavailability of organic matter in a highly disturbed estuary: The role of detrital and algal resources: Proceedings of the National Academy of Sciences, v. 99, p. 8101-8105.

Sommer, Ted, Nobriga, M. L., Harrell, W.C., Batham, Wendy, and Kimmerer, W.J., 2001, Floodplain rearing of juvenile chinook salmon: evidence of enhanced growth and survival: Canadian Journal of Fisheries and Aquatic Sciences, v. 58, p. 325-333.
Sommer, T.R., Harrell, W.C., Nobriga, M.L., and Kurth, Ryon, 2003, Floodplain as habitat for native fish: Lessons from California's Yolo Bypass, in Faber, P.M., ed., California riparian systems: Processes and floodplain management, ecology, and restoration, 2001 Riparian Habitat and Floodplains Conference Proceedings: Riparian Habitat Joint Venture, Sacramento, California, p. 81-87.

Sommer, T.R., Harrell, W.C., Kurth, Ryon, Feyrer, Frederick., Zeug, S.C., and O’Leary, Gavin, 2004, Ecological patterns of early life stages of fishes in a river-floodplain of the San Francisco Estuary: American Fisheries Society Symposium, v. 39, p. 111-123.

Sommer, Ted, Armor, Chuck, Baxter, Randall, Breuer, Richard, Brown, Larry, Chotkowski, Mike, Culberson, Steve, Feyrer, Frederick, Gingras, Marty, Herbold, Bruce, Kimmerer, Wim, Mueller-Solger, Anke, Nobriga, Matthew, and Souza, Kelly, 2007, The collapse of pelagic fishes in the upper San Francisco Estuary: Fisheries, v. 32, no. 6, p. 270-277.

Sommer, Ted, Mejia, Francine, Hieb, Kathryn, Baxter, Randall, Loboschefsky, Erik., and Loge, Frank, 2011a, Longterm shifts in the lateral distribution of age- 0 striped bass Morone saxatilis in the San Francisco estuary: Transactions of the American Fisheries Society, v. 140, p. 1451-1459.

Sommer, Ted, Mejia, F.H., Nobriga, M.L., Feyrer, Frederick, and Grimaldo, Lenny, 2011b, The spawning migration of delta smelt in the upper San Francisco Estuary: San Francisco Estuary and Watershed Science, v. 9, no. 2, http:// www.escholarship.org/uc/item/86m0g5sz.

Stacey, M.T., Brennan, M.L., Burau, J.R., and Monismith, S.G., 2010, The tidally averaged momentum balance in a partially and periodically stratified estuary: Journal of Physical Oceanography, v. 40, p. 2418-2434.

State Water Resources Control Board, 1995, Water quality control plan for the San Francisco Bay/Sacramento-San Joaquin Delta Estuary: Sacramento, California, State Water Resources Control Board, California Environmental Protection Agency, 55 p., http://www.waterrights.ca.gov/ baydelta/1995WQCPB.pdf.

State Water Resources Control Board, 2010, Development of flow criteria for the Sacramento-San Joaquin Delta ecosystem: Sacramento, California, State Water Resources Control Board, California Environmental Protection Agency, 191 p., http://www.waterboards.ca.gov/waterrights/water_issues/ programs/bay_delta/deltaflow/docs/final_rpt080310.pdf. 
Stevens, D.E., 1977, Striped bass (Morone saxatilis) year class strength in relation to river flow in the Sacramento-San Joaquin Estuary, California: Transactions of the American Fisheries Society, v. 106, p. 34-42.

Stevens, D.E., and Miller, L.W., 1983, Effects of river flow on abundance of young Chinook salmon, American shad, longfin smelt, and delta smelt in the Sacramento-San Joaquin River system: North American Journal of Fisheries Management, v. 3, p. 425-437.

Swanson, Christina, Reid, Turid, Young, P.S., and Cech, J.J., Jr., 2000, Comparative environmental tolerances of threatened delta smelt (Hypomesus transpacificus) and introduced wakasagi (H. nipponensis) in an altered California estuary: Oecologia, v. 123, p. 384-390.

Teh, Swee, 2012, Fall X2 fish health study: contrasts in health indices, growth and reproductive fitness of delta smelt and other pelagic fishes rearing in the low salinity zone and Cache Slough regions: Progress Report to Environmental Restoration Program: Sacramento, Calif., California Department of Fish and Wildlife.

Thomson, J.R., Kimmerer, W.J., Brown, L.R., Newman, K.B., Mac Nally, R., Bennett, W.A., Feyrer, F., and Fleishman, E., 2010, Bayesian change-point analysis of abundance trends for pelagic fishes in the upper San Francisco Estuary: Ecological Applications, v. 20, p. 1431-1448.

Thompson, Janet, Gehrts, Karen, Parchaso, Frances, and Fuller, Heather, 2012, Going with the flow: the distribution, biomass and grazing rate of Potamocorbula and Corbicula with varying freshwater flow (May and October 20092011): Progress Report to U.S. Bureau of Reclamation: Sacramento, Calif., 29 p.

U.S. Bureau of Reclamation, 2012, Adaptive management of fall outflow for delta smelt protection and water supply reliability: U.S. Bureau of Reclamation, Sacramento, Calif., http://deltacouncil.ca.gov/sites/default/files/documents/files/ Revised_fall_X2_Adaptive_MgmtPlan_EVN_06_29_2012_ final.pdf.

U. S. Fish and Wildlife Service, 1993, Endangered and threatened wildlife and plants; determination of threatened status for the delta smelt: Federal Register, v. 58, p. 12854-12864.

U.S. Fish and Wildlife Service, 2008, Formal Endangered Species Act consultation on the proposed coordinated operations of the Central Valley Project and State Water Project: Sacramento, Calif., U.S. Fish and Wildlife Service, 410 p., http://www.fws.gov/sfbaydelta/documents/swp-cvp_ops_ bo_12-15_final_ocr.pdf.
U.S. Fish and Wildlife Service, 2010a, 2008, CVP/SWP coordinated operations delta smelt fall habitat action adaptive management program implementation plan: Sacramento, Calif., U.S. Fish and Wildlife Service, 54 p. http:// deltacouncil.ca.gov/sites/default/files/documents/files/ DRAFT_FHA_AMP_Plan_v2.pdf.

U.S. Fish and Wildlife Service, 2010b, Endangered and threatened wildlife and plants; 12 -month finding on a petition to reclassify the delta smelt from threatened to endangered throughout its range: Federal Register, v. 75, p. $17677-$ 17680 .

U.S. Geological Survey, 2008, Tracking organic matter in Delta drinking water: Sacramento, Calif., CALFED Science Program, Science Action, News from the CALFED Science Program, April 2008, 8p., http://www.science.calwater. ca.gov/pdf/publications/sia/sia_doc_041608.pdf.

Warner, J.C., Schoellhamer, D.H., Ruhl, C.A., and Burau, J.R., 2004, Floodtide pulses after low tides in shallow subembayments adjacent to deep channels: Estuarine, Coastal and Shelf Science, v. 60, no. 2, p. 213-228.

Weston, D.P. and Lydy, M.J., 2010, Urban and agricultural sources of pyrethroid insecticides to the Sacramento-San Joaquin Delta of California: Environmental Science and Technology, v. 44, no. 5, p. 1833-1840.

Whipple, Alison, Grossinger, Robin, Rankin, Daniel, Stanford, Bronwen, and Askevold, Ruth, 2012, Sacramento-San Joaquin Delta historical ecology investigation: Exploring pattern and process: Richmond, Calif., San Francisco Estuary Institute, 225 p., available at: http://www.sfei.org/ DeltaHEStudy.

Williams, B. K., Szaro, R.C., and Shapiro, C.D., 2009, Adaptive management: The U.S. Department of the Interior technical guide: Washington, DC, U.S. Department of the Interior, Adaptive Management Working Group, 86 p., http://www.doi.gov/initiatives/AdaptiveManagement/ TechGuide.pdf.

Winemiller, K.O., Flecker, A.S., and Hoeinghaus, D.J., 2010, Patch dynamics and environmental heterogeneity in lotic ecosystems: Journal of the North American Benthological Society, v. 29, p. 84-99. 
This page intentionally left blank. 


\section{Appendixes}




\section{Appendix 1. Dayflow}

Dayflow was the source for basic flow data used in this report. Full documentation and data for Dayflow are available at http://www.water.ca.gov/dayflow/. The following description is directly from the website with minimal editing.

Dayflow is a computer program designed to estimate daily average Delta outflow. The program uses daily river inflows, water exports, rainfall, and estimates of Delta agriculture depletions to estimate the "net" flow at the confluence of the Sacramento and San Joaquin Rivers, nominally at Chipps Island. It is a key index of the physical, chemical, biological state of the northern reach of the San Francisco Bay estuary.

The Dayflow program also estimates the following flow and parameter values as daily averages:

- Net flow through the Delta Cross Channel and Georgiana Slough (when measured flow is not available).

- Net flow at Jersey Point (also called QWEST).

- Position of X2, the salinity 2 isohaline.

The Dayflow estimate of Delta outflow is referred to as the "net Delta outflow index" (NDOI) because it does not a account for tidal flows, the fortnight lunar fill-drain cycle of the estuary, or barometric pressure changes. It is a quantity that never actually occurs in real time. Rather, it is an estimate of the net difference between ebbing and flooding tidal flows at Chipps Island (about $\pm 150,000 \mathrm{cfs}$ ), aliased to a daily average. Depending on conditions, the actual net Delta outflow for a given day can be much more or less than the Dayflow estimate.
Dayflow is computed for each year following completion of the water year (October 1). At that time, we request official quality assured and controlled data from several sources (table 1-1). Once all input data are received, we compute the Dayflow estimate of Delta outflow. Our goal is to provide data for the previous water year by January 1 .

Over time, some inflow inputs have been lost because stream-flow gages have been abandoned or discontinued because of lack of funding. The input data are further described in the Dayflow program documentation.

In 2000, the software used to perform Dayflow calculations was rewritten in Java. Input data are stored in a HEC-DSS file, and output is written to ASCII, excel, and DSS format files. Data are available for one or more years.

The stations used in Dayflow calculations are shown in figure 1-1. We utilized three calculated outputs from Dayflow. We utilize the net Delta outflow index; however, for simplicity, we refer to it as outflow. Note that this is a calculated, rather than a measured, value. We use daily X2. Dayflow uses the following autoregressive lag model to calculate X2:

$$
\mathrm{X} 2(\mathrm{t})=10.16+0.945 * \mathrm{X} 2(\mathrm{t}-1)-1.487 \log (\mathrm{QOUT}(\mathrm{t}))(1)
$$

where

$\mathrm{t}$ is current day, and

$\mathrm{t}-1$ is previous day.

We also used QWEST, the calculated net flow at Jersey Point in the San Joaquin River, as a measure of the influence of San Joaquin River outflow on total outflow. Note that QWEST is the same as quantity WEST in Dayflow data output files.

Table 1-1. Responsible agencies and data used as input to the Dayflow program.

[X2 is the horizontal distance in kilometers from the Golden Gate up the axis of the estuary to where tidally averaged near-bottom salinity is 2. Abbreviation: ID, Irrigation District]

\section{Responsible}

agency

U.S. Geological Survey

U.S. Army Corps of Engineers

East Bay Municipal Utility District

California Department of Water Resources Operations and Maintenance

California Department of Water Resources Bay-Delta

California Department of Water Resources

Planning and Local Assistance

Reclamation

Solano County Water District
Input data

Flow: Sacramento River at Freeport, Yolo Bypass at Woodland, Cosumnes River at Michigan Bar, San Joaquin River at Vernalis, Delta Cross Channel, Georgiana Slough.

Flow: Calaveras River.

Flow: Mokelumne River at Woodbridge.

Precipitation at Stockton Fire Department, Clifton Court Forebay gate flow, Barker Slough export, Byron Bethany ID depletion, X2 (only when outflow is negative).

Estimated delta island consumptive use.

Sacramento Weir spill, Lisbon Weir flow.

Delta cross-channel gate status, Tracy export, Contra Costa export. Lake Barryessa releases, Lake Solano inflow, Putah Creek. 


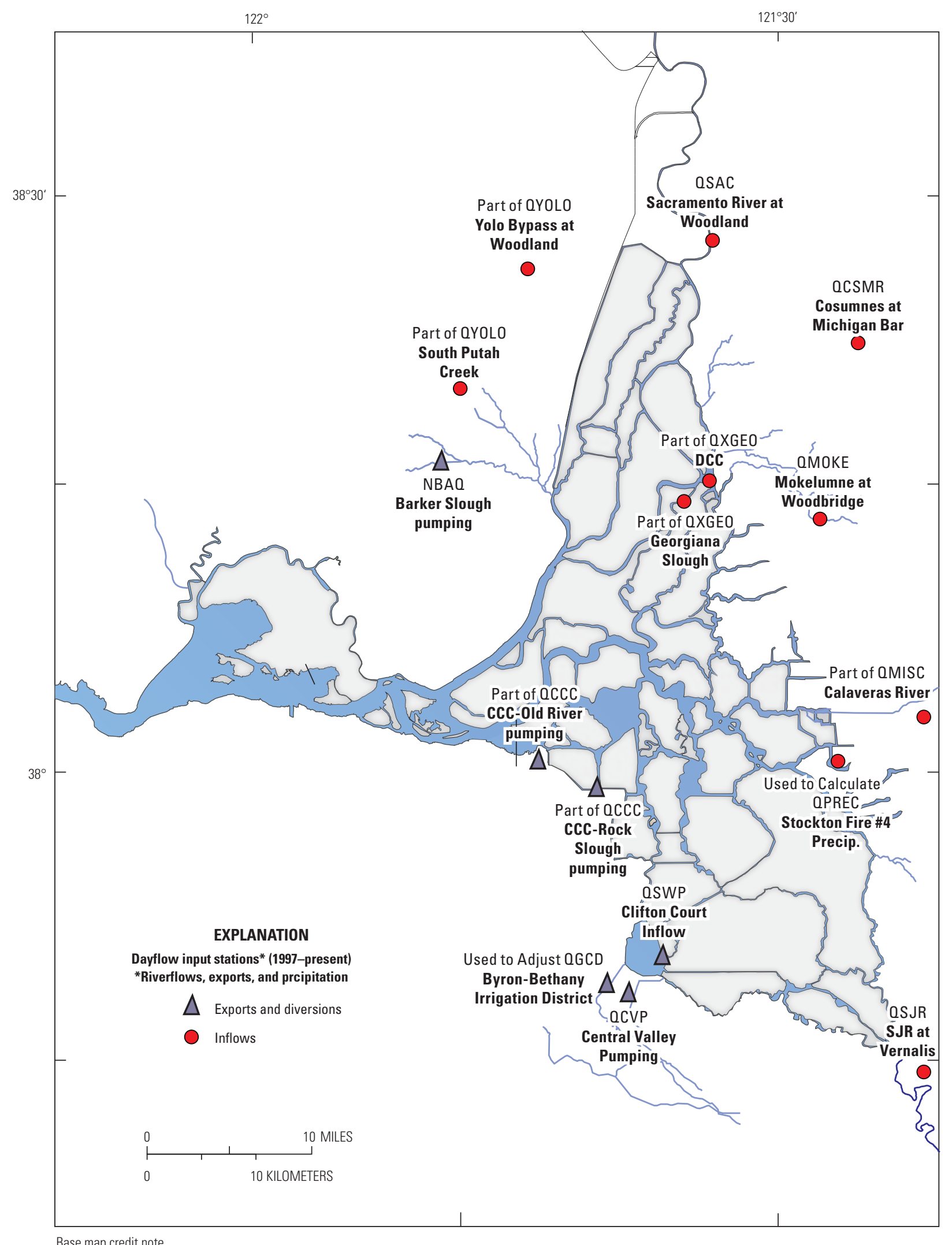

Figure 1-1. Sites used in Dayflow calculations (http://www.water.ca.gov/dayflow/. 


\section{Appendix 2. Surface Area and Maps of the Low-Salinity Zone}

Our calculations of area of the LSZ were based on conversions of X2 (the horizontal distance in kilometers from the Golden Gate up the axis of the estuary to where tidally averaged near-bottom salinity is 2) to area from modeling runs for 1 April 1994 to 1 October 1995. The following methods are from a report provided through the courtesy of Michael MacWilliams, Delta Modeling Associates. The results of the described modeling were used to produce the maps of the salinity gradient shown in figures $14-16$ of the report. The results were also used to create a table (table 2-1) for conversion of X2 to surface area of the LSZ. Dr. MacWilliams cautions that the distribution of salinity in the estuary for the same $\mathrm{X} 2$ can differ depending on whether $\mathrm{X} 2$ is moving seaward or landward and on the exact flow conditions in the year of interest. Therefore, the maps and calculated surface areas are to be considered estimates rather than exact values.

\section{Low-Salinity Zone Area and Depth Analysis}

Figure references have been updated in the following text, dated January 23, 2012, provided by Michael L. MacWilliams, Ph.D. The text has been edited for this appendix.

\section{Introduction}

This document presents an analysis of the low-salinity zone (LSZ) area and depth based on a simulation of historic conditions over an eighteen month period from April 1, 1994, to October 1, 1995. Model validation of predicted salinity for this period will be documented in an upcoming paper in collaboration with Wim Kimmerer and Ed Gross.

In this analysis, the LSZ is defined as the area with a salinity range between 1.0 and 6.0 (similar analyses have used a slightly wider salinity range, from 0.5 to 6.0 ). This analysis focuses specifically on the relationship between X2 and the areal extent and average depth of the LSZ.

\section{LSZ Habitat Area and Depth Calculation Approach}

In this analysis, the LSZ habitat area is calculated by using the predicted depth-averaged daily averaged salinity for the simulation of a historic period from April 1, 1994, to October 1, 1995. For each model time step (90 seconds), the depth-averaged salinity is calculated within each grid cell in the model domain, and then the daily averaged depth-averaged salinity is calculated from the depth-averaged salinity calculated at each of 960 model time steps in each day. The daily averaged LSZ habitat area for each day is then calculated by summing up the total area of the grid cells that has depth-averaged daily averaged salinity between 1 and 6 and is within a specified geographic range. For this analysis, the geographic range extends from San Pablo Bay through the western and central Delta and covers the domain shown in figure 2-1. Area within the salinity range of the LSZ that is not within the model domain is not counted as LSZ habitat in this analysis.

Once the area of the LSZ is defined on a given day, the average depth of the LSZ for that day is calculated on the basis of the daily averaged water level within each cell that is within the LSZ. Water levels are only averaged during periods when the cells are wet, so that the average depth of intertidal cells is calculated on the basis of the average depth during the time each cell was wet during each day.

Table 2-1. Estimates of the area of the low-salinity zone (LSZ) for specified X2.

[X2 is the horizontal distance in kilometers from the Golden Gate up the axis of the estuary to where tidally averaged near-bottom salinity is 2 . Abbreviations: $\mathrm{km}$, kilometers]

\begin{tabular}{|c|c|c|c|}
\hline $\begin{array}{c}\mathrm{X} 2 \\
(\mathrm{~km})\end{array}$ & $\begin{array}{c}\text { Area of LSZ } \\
\text { (hectares) }\end{array}$ & $\begin{array}{c}\mathrm{X} 2 \\
(\mathrm{~km})\end{array}$ & $\begin{array}{c}\text { Area of LSZ } \\
\text { (hectares) }\end{array}$ \\
\hline 30 & 18,324 & 64 & 6,981 \\
\hline 31 & 10,933 & 65 & 6,999 \\
\hline 32 & 9,544 & 66 & 7,912 \\
\hline 33 & 12,675 & 67 & 8,467 \\
\hline 34 & 15,432 & 68 & 8,474 \\
\hline 35 & 11,423 & 69 & 8,743 \\
\hline 36 & 7,413 & 70 & 8,500 \\
\hline 37 & 14,905 & 71 & 8,632 \\
\hline 38 & 20,693 & 72 & 8,539 \\
\hline 39 & 14,154 & 73 & 8,585 \\
\hline 40 & 17,138 & 74 & 8,408 \\
\hline 41 & 19,969 & 75 & 8,231 \\
\hline 42 & 19,421 & 76 & 8,380 \\
\hline 43 & 19,131 & 77 & 8,162 \\
\hline 44 & 21,651 & 78 & 7,959 \\
\hline 45 & 19,746 & 79 & 7,369 \\
\hline 46 & 18,021 & 80 & 6,653 \\
\hline 47 & 18,525 & 81 & 5,313 \\
\hline 48 & 18,450 & 82 & 5,051 \\
\hline 49 & 17,743 & 83 & 5,075 \\
\hline 50 & 17,590 & 84 & 4,753 \\
\hline 51 & 11,525 & 85 & 4,483 \\
\hline 52 & 8,908 & 86 & 4,492 \\
\hline 53 & 13,429 & 87 & 4,456 \\
\hline 54 & 7,313 & 88 & 4,463 \\
\hline 55 & 8,576 & 89 & 4,604 \\
\hline 56 & 4,284 & 90 & 4,635 \\
\hline 57 & 3,530 & 91 & 4,653 \\
\hline 58 & 4,244 & 92 & 4,655 \\
\hline 59 & 5,127 & 93 & 4,953 \\
\hline 60 & 4,813 & 94 & 5,000 \\
\hline 61 & 4,498 & 95 & 5,025 \\
\hline 62 & 5,773 & 96 & 4,996 \\
\hline
\end{tabular}




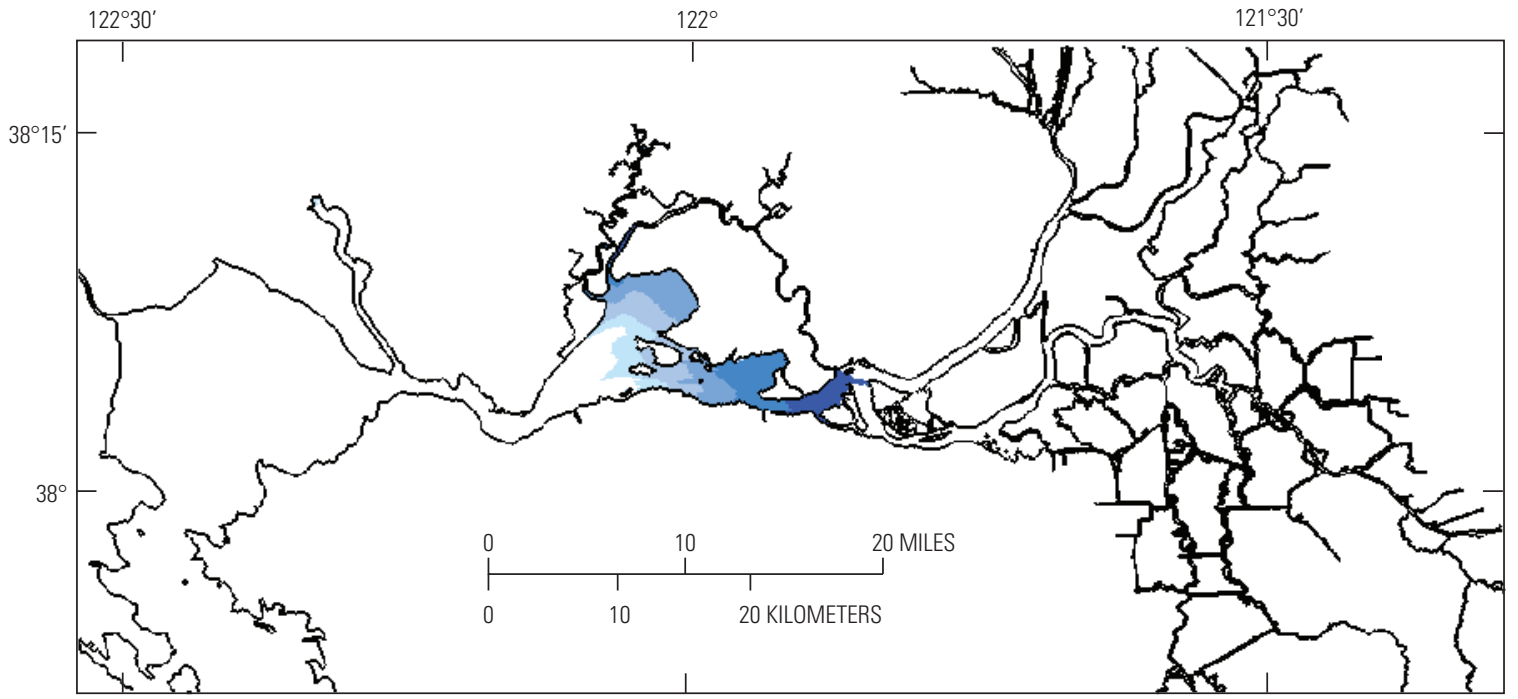

EXPLANATION

Daily average depth-averaged salinity: April 5, 1994
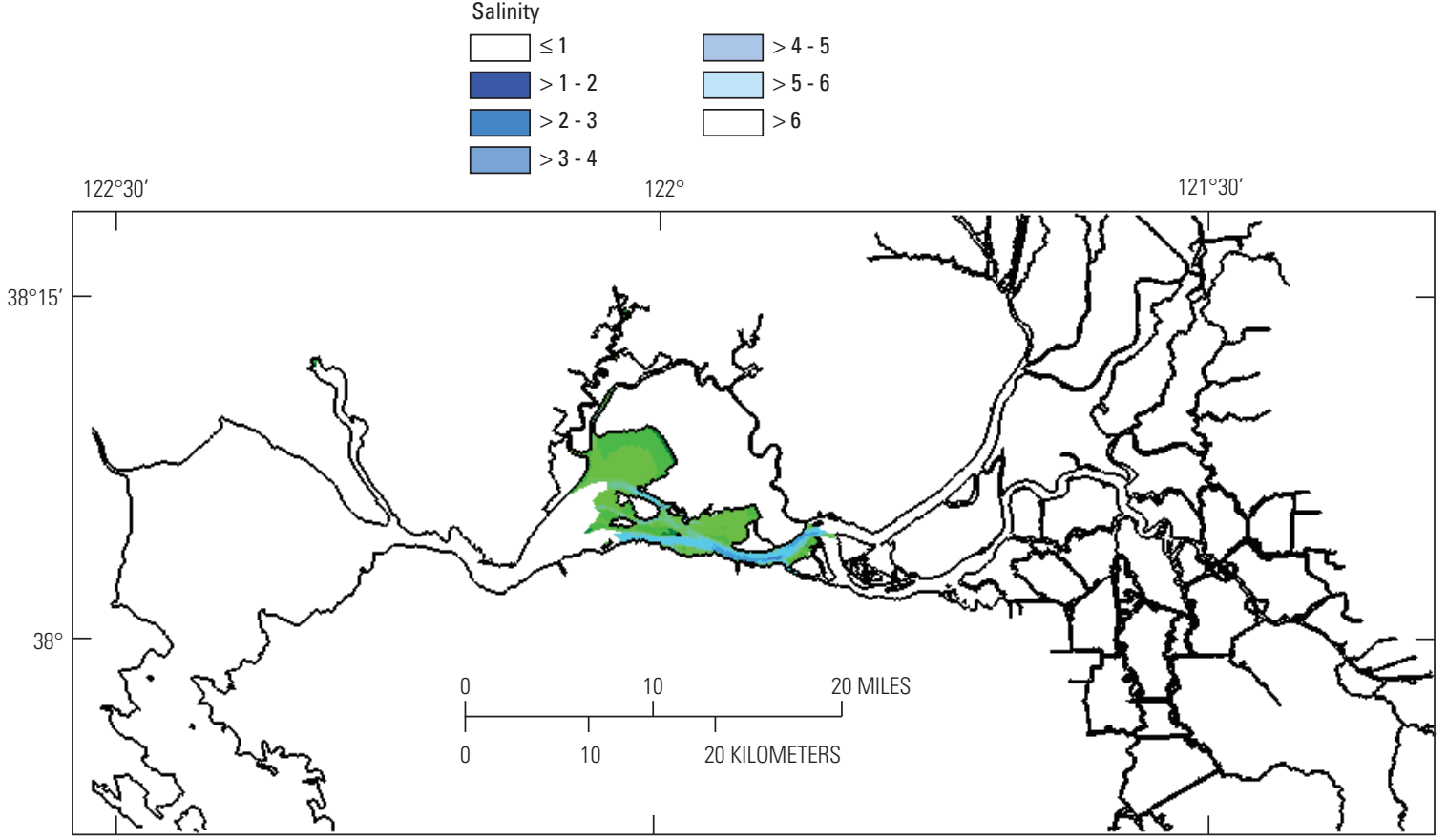

EXPLANATION

Daily-average depth
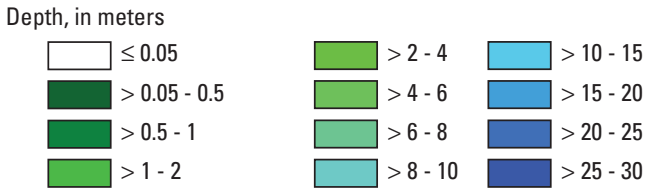

Figure 2-1. Model domain (entire mapped region) showing daily averaged depth-averaged salinity (top) and daily averaged depth (bottom) of the low-salinity zone (salinity 1-6) on April 5, 1994, when X2 was approximately 75. Area not within the LSZ is shown in white. $\mathrm{X} 2$ is the horizontal distance from the Golden Gate up the axis of the estuary to where tidally averaged near-bottom salinity is 2 . Symbols are: , less then or equal to; and $>$, greater than. 


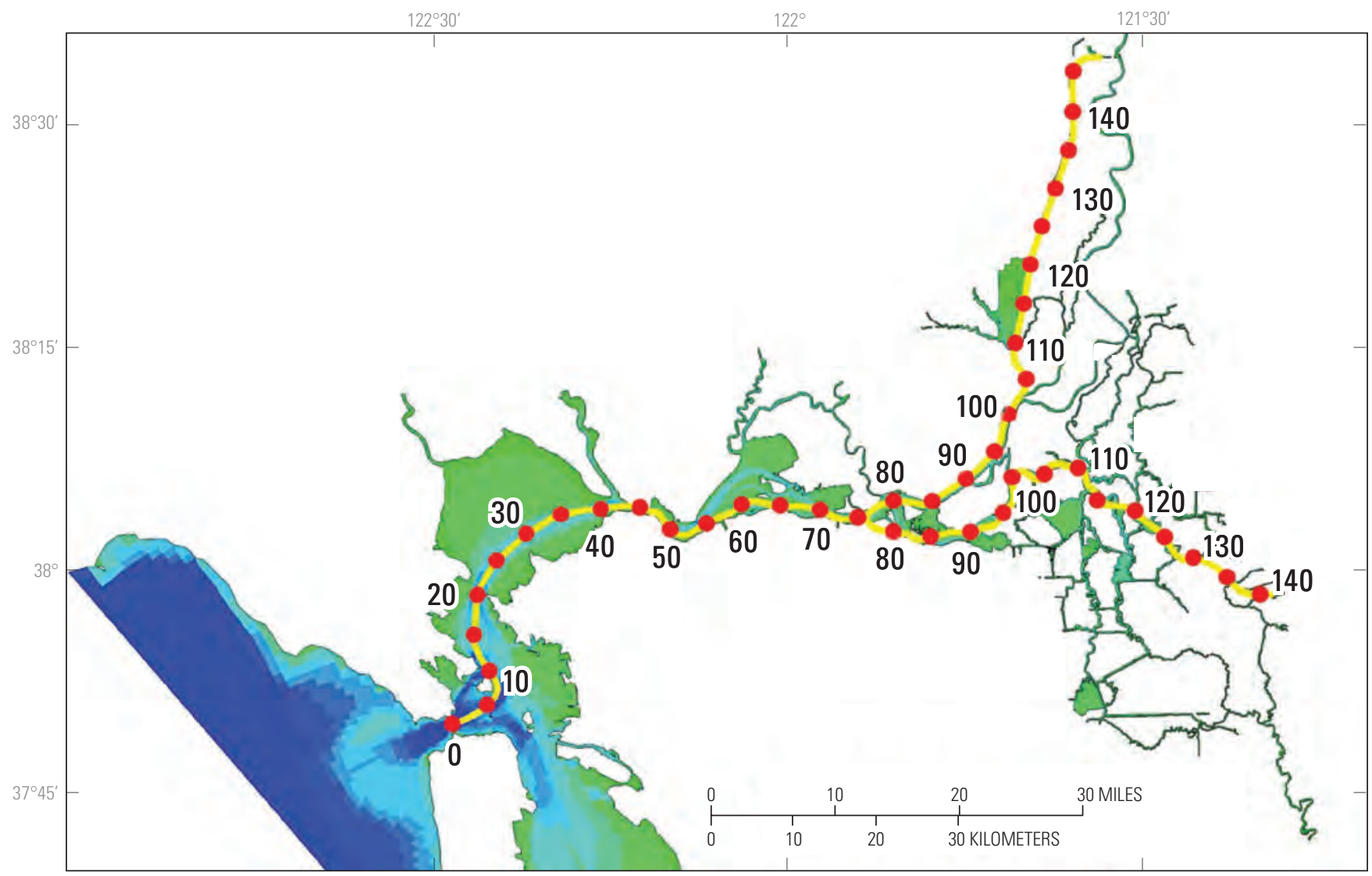

Figure 2-2. Transects along the axis of northern San Francisco Bay used to measure X2 in the UnTRIM Bay-Delta model.

\section{X2 Calculation Approach}

By definition, $\mathrm{X} 2$ is the horizontal distance from the Golden Gate up the axis of the estuary to where tidally averaged near-bottom salinity is 2 . The 1995 Bay-Delta agreement established standards for salinity in the estuary. Specifically, the standards determine the degree to which salinity is allowed to penetrate up-estuary, with salinity to be controlled through Delta outflow (http://www.water.ca.gov/dayflow/ documentation/dayflowDoc.cfm \#Introduction). This regulation is based on observations that the abundance or survival of several estuarine biological populations in the San Francisco Estuary is positively related to freshwater flow (Jassby and others, 1995), although recent studies indicate that some of these relationships have changed (Sommer and others, 2007).

Jassby and others (1995) provide a graphical depiction of X2 (see fig. 2 of report), showing selected values of X2. The inset in the figure shows an X2 of about $75 \mathrm{~km}$ at Chipps Island and $81 \mathrm{~km}$ at Collinsville. In the UnTRIM Bay-Delta model, X2 is calculated along the axis of the estuary at the transects shown in figure 2-2. For X2 greater than $75 \mathrm{~km}$, the distance from the Golden Gate to the location of near-bottom salinity 2 isohaline is measured along both the Sacramento and San Joaquin transects, and the reported predicted "average X2" is the average of the Sacramento and San Joaquin X2 distances. Use of an average over a number of years, within water-year types, could perhaps provide a consistent basis for conversion or modeling future areas.

\section{References Cited}

Jassby, A.D., Kimmerer, W.J., Monismith, S.G., Armor, Chuck, Cloern, J.E., Powell, T.M., Schubel, J.R., and Vendlinski, T.J., 1995, Isohaline position as a habitat indicator for estuarine populations: Ecological Applications, v. 5, p. 272-289.

Sommer, Ted, Armor, Chuck, Baxter, Randall, Breuer, Richard, Brown, Larry, Chotkowski, Mike, Culberson, Steve, Feyrer, Frederick, Gingras, Marty, Herbold, Bruce, Kimmerer, Wim, Mueller-Solger, Anke, Nobriga, Matthew, and Souza, Kelly, 2007, The collapse of pelagic fishes in the upper San Francisco Estuary: Fisheries, v. 32, no. 6, p. 270-277. 
This page intentionally left blank. 


\section{Appendix 3. Delta Smelt Habitat Index}

We used a table (table 3-1) to convert daily X2 (the horizontal distance from the Golden Gate up the axis of the estuary to where tidally averaged near-bottom salinity is 2) to daily estimates of the delta smelt habitat index. The derivation of the habitat index is described in detail in Feyrer and others (2010). In essence, the habitat index weights the probability of occurrence of delta smelt at a fall midwater-trawl (FMWT) station by the surface area associated with that station. The probability of occurrence of delta smelt at a station is based on a general additive model incorporating water temperature, salinity, and turbidity measured at the time fish were sampled. The habitat index was calculated as the average habitat index for the 4 months of the FMWT, September-December. The annual habitat index was then related to mean X2 from September to December by using locally weighted-regression scatterplot smoothing (LOESS regression). The LOESS regression model was then used to generate a predicted habitat-index value for each value of X2 in the table.

\section{References Cited}

Feyrer, Frederick, Newman, Ken, Nobriga, Matthew, and Sommer, Ted, 2010, Modeling the effects of future freshwater flow on the abiotic habitat of an imperiled estuarine fish: Estuaries and Coasts, v. 34, p. 120-128.

Table 3-1. Delta smelt habitat index values for specified X2.

[X2 is the horizontal distance in kilometers from the Golden Gate up the axis of the estuary to where tidally averaged near-bottom salinity is 2 . Abbreviations: $\mathrm{km}$, kilometer]

\begin{tabular}{ccccc}
\hline $\begin{array}{c}\text { X2 } \\
(\mathbf{k m})\end{array}$ & $\begin{array}{c}\text { Predicted } \\
\text { habitat index }\end{array}$ & & $\begin{array}{c}\text { X2 } \\
\mathbf{( k m )}\end{array}$ & $\begin{array}{c}\text { Predicted } \\
\text { habitat index }\end{array}$ \\
\hline 61 & 7,343 & & 78 & 6,099 \\
62 & 7,551 & & 79 & 5,735 \\
63 & 7,724 & & 80 & 5,292 \\
64 & 7,863 & & 81 & 4,835 \\
65 & 7,967 & 82 & 4,430 \\
66 & 8,036 & 83 & 4,081 \\
67 & 8,069 & 84 & 3,777 \\
68 & 8,067 & 85 & 3,523 \\
69 & 8,027 & 86 & 3,314 \\
70 & 7,950 & 87 & 3,160 \\
71 & 7,837 & 88 & 3,054 \\
72 & 7,685 & 89 & 2,996 \\
73 & 7,491 & 90 & 2,987 \\
74 & 7,261 & 91 & 3,028 \\
75 & 7,000 & 92 & 3,116 \\
76 & 6,716 & 93 & 3,252 \\
\cline { 4 - 5 } & 6,414 & &
\end{tabular}

$77 \quad 6,414$


This page intentionally left blank. 


\section{Appendix 4. Fall Midwater-Trawl Survey}

A description of the fall midwater-trawl survey (FMWT) and data for fish abundance indices are available at http:// www.dfg.ca.gov/delta/projects.asp? ProjectID $=F M W T$. The FMWT is carried out by the California Department of Fish and Wildlife under the umbrella of Interagency Ecological Program monitoring activities. For convenience, in this appendix, we present an edited version of the general description of the FWMT sampling and provide additional details. We also include a map (fig. 4-1) and latitude and longitude (table 4-1) of the sampling stations. Values of the FMWT delta smelt abundance index are provided in appendix 8 with abundance indices from other sampling programs.

The fall midwater-trawl survey (FMWT) has been completed annually since its inception in 1967, with the exceptions of 1974 and 1979, when sampling was not performed. The FMWT was initiated to determine the relative abundance and distribution of age- 0 striped bass (Morone saxatilis) in the estuary, but the data have also been used for other upper estuary pelagic species, including delta smelt (Hypomesus transpacificus), longfin smelt (Spirinchus thaleichthys), American shad (Alosa sapidissima), splittail (Pogonichthys macrolepidotus), and threadfin shad (Dorosoma petenense). The FMWT samples 122 stations each month from September to December, and a subset of these data is used to calculate an annual abundance index. The 122 stations are located from San Pablo Bay upstream to Stockton on the San Joaquin River and to Hood on the Sacramento River, including locations in the Sacramento Deep Water Ship Channel. Sampling takes approximately 9 days a month to complete. Historically, FMWT sampling occasionally began as early as July (1972) or August (1968-1973, 1993-1994, 1996-1997) and sometimes continued past December to March (1968-1973, 1978, 1991-2001) or beyond (1992-1995). The consistent JanuaryMarch midwater-trawl sampling performed from 1991-2001 to track movements of mature, adult delta smelt was replaced in 2002 with the more effective spring Kodiak trawl.

The midwater-trawl net has mouth dimensions of $12 \mathrm{ft}$ by $12 \mathrm{ft}$ when stretched taut, but mouth dimensions tend to be smaller when under tension during a tow. Net mesh sizes graduate in nine sections from 8-inch stretch-mesh at the mouth to 0.5 -inch stretch-mesh at the cod-end. All four corners of the net mouth are connected to planing doors, which together counteract the drag on net material and hold the net mouth open when it is towed through the water. At each station, the net is towed for 12 minutes as it is retrieved obliquely through the water column from bottom to surface, after which, all fish, shrimp, and jellyfish are identified and enumerated. In addition, the crew measures water temperature, electrical conductivity (specific conductance), Secchi depth, and turbidity.

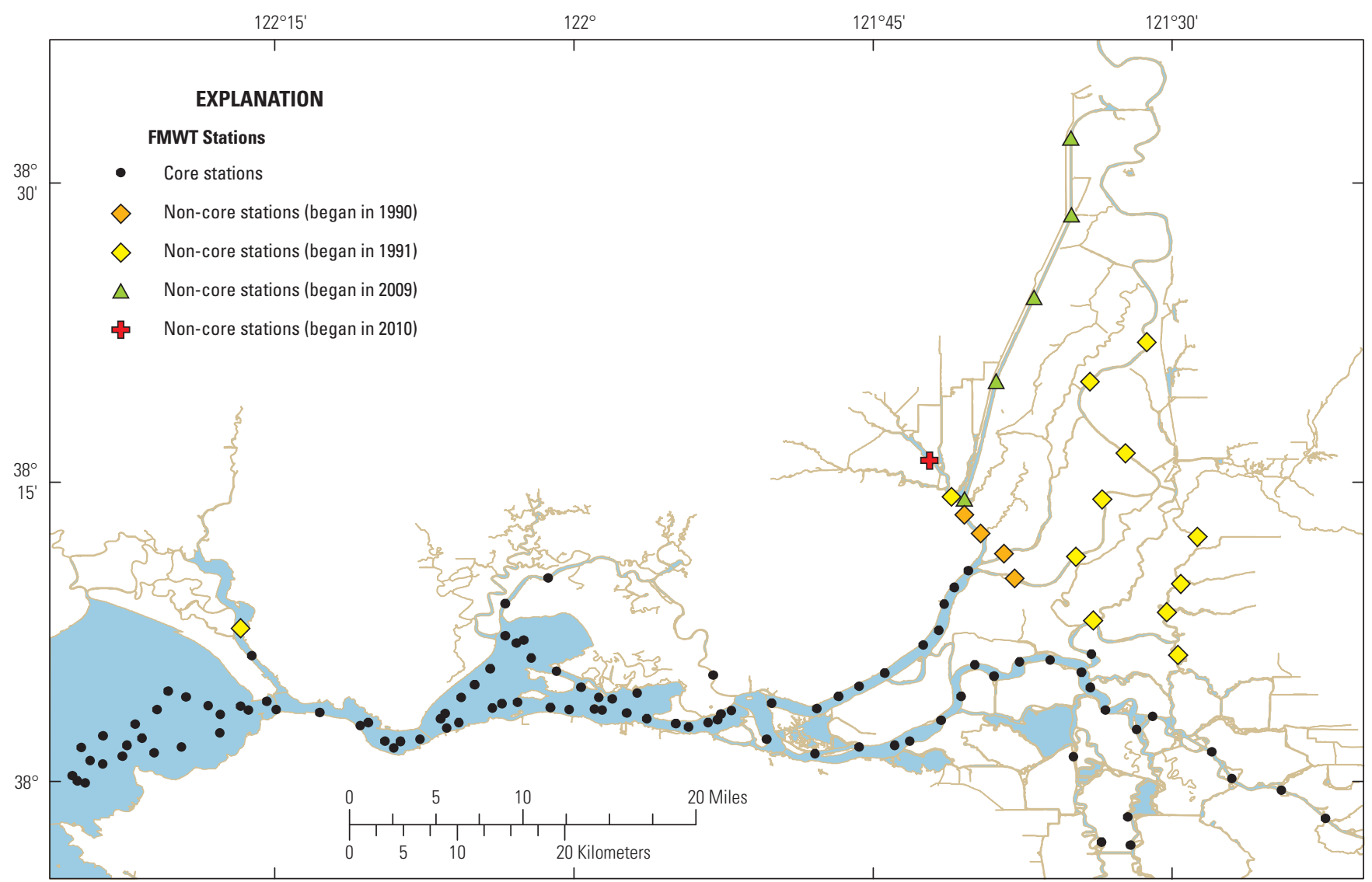

Figure 4-1. Locations of fall midwater-trawl sampling (FMWT) stations in the San Francisco Bay estuary. 

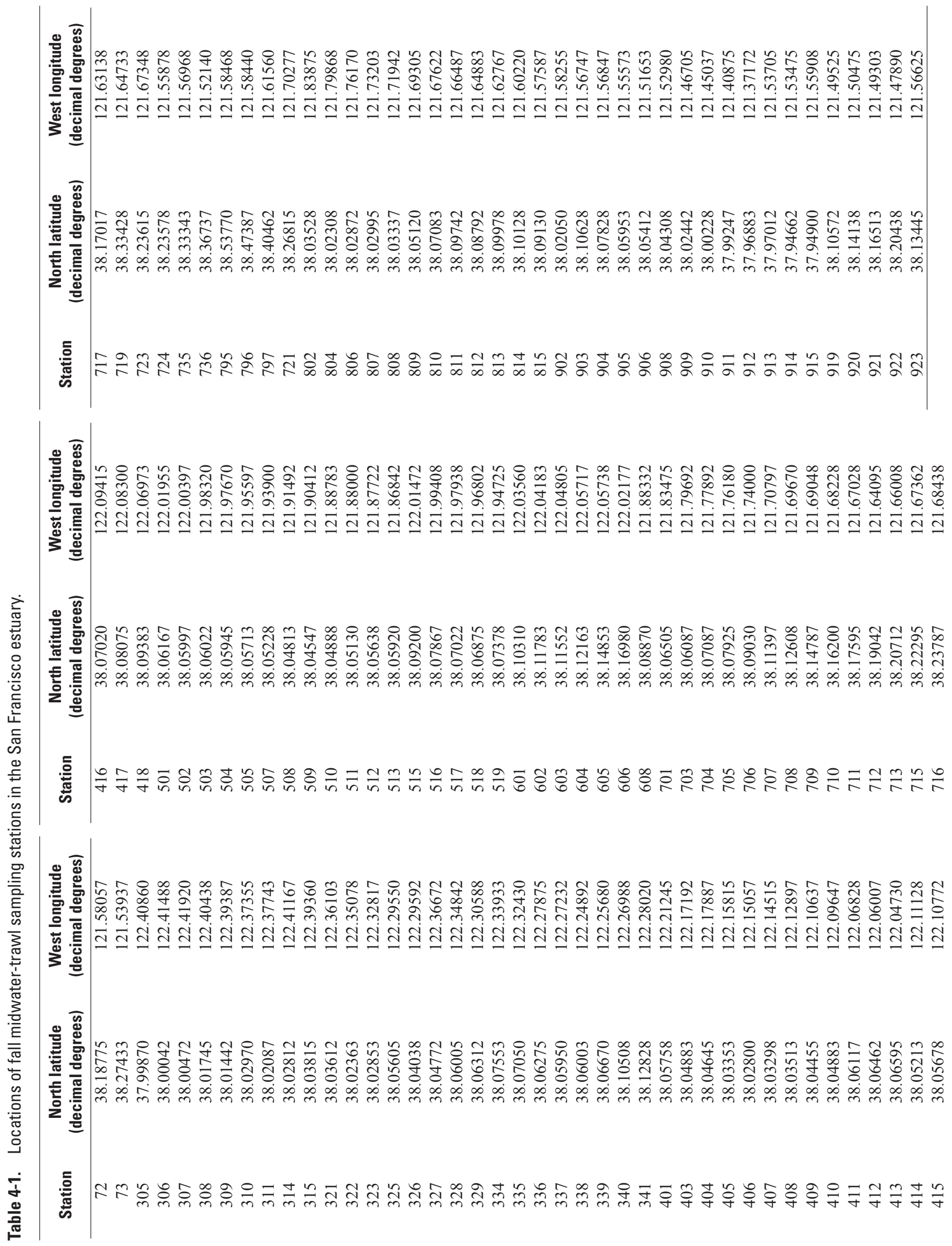
The FMWT equipment and methods have remained consistent since the survey's inception, which allows annual abundance indices to be compared. Monthly and annual abundance indices are calculated by using catch data from 100 "index" stations grouped into 17 regional "areas." Monthly indices are calculated by averaging catch per tow for index stations in each regional area, multiplying these means by their respective weighting factors (that is, a scalar based on water volume) for each area, and summing these products for all 17 areas. Annual abundance indices are the sum of the four (September-December) monthly indices.

The FMWT is mandated by the Delta Smelt Biological Opinion for the coordinated operation of the Central Valley Project and the State Water Project.

In addition to the FMWT delta smelt abundance index, we assessed water-quality data collected during sampling, specifically, water temperature, electrical conductivity (converted to salinity), Secchi depth, and turbidity (table 4-2). Turbidity has only been measured since 2010. Estimates of Microcystis abundance have been made since 2008 by using a visual ranking system (fig. 4-2). Ratings of 4 or 5 were never observed. We analyzed these data as occurrence data. Diet data were collected from delta smelt collected and preserved during the FMWT. Stomachs were dissected and inspected, and prey items were identified to the lowest practical taxon. Data were recorded as number of each prey taxon and weight of each taxon in the diet. We present data as percentage of the weight of all prey items in the diet. The center of distribution of the delta smelt population was determined by weighting the distance (kilometers) of each station from the Golden Gate by the number of fish captured at that station. The data were then plotted, with the median of the data considered to be the center of distribution of the population.

In 2011, water samples were collected from a second boat during the FMWT for the first time. These water samples were analyzed at the University of California Davis under the direction of Dr. Randy Dahlgren. Samples were returned from the field on ice in the evening and processing began the next morning. We used data on chlorophyll- $\alpha$, ammonia as nitrogen, and nitrite plus nitrate as nitrogen (table 4-3).

Algal pigments were determined by using method SM10200-H (Clesceri and others, 1998). Samples were filtered by using a Whatman GF/F glass-fiber filter within 12 hours of delivery, and the filters were frozen prior to extraction. The method was altered by using 90 percent ethanol for extraction instead of 90 percent acetone, and the glass-fiber filters were freeze-dried but not ground (Sartory and Grobbelaar, 1984). Samples were analyzed by fluorometric determination; the limit of detection was generally about $0.5 \mu \mathrm{g} / \mathrm{L}$, but it varied depending on the volume of water filtered (200 to 1,000 mL).

A subsample was filtered through a pre-rinsed 0.45-micrometer polycarbonate membrane (Millipore) for quantification of ammonium as nitrogen $\left(\mathrm{NH}_{4}-\mathrm{N}\right) . \mathrm{NH}_{4}-\mathrm{N}$ was determined spectroscopically with the Berthelot reaction using a salicylate analog of indophenol blue (limit of detection is about 0.010 milligrams per liter; Forster 1995). Analysis of $\mathrm{NH}_{4}-\mathrm{N}$ was completed within 48 hours of sample collection. The vanadium chloride method was used to spectroscopically determine nitrate plus nitrite as nitrogen (limit of detection is 0.01 milligrams per liter).

Laboratory quality assurance/quality control included implementation of Surface Water Ambient Monitoring Program (SWAMP)-compatible standard laboratory procedures including replicates, spikes, reference materials, setting of control limits, criteria for rejection, and data validation methods (Puckett, 2002).

\section{References Cited}

Clesceri, L.S., Greenberg, A.E., and Eaton A.D., eds., 1998, Standard methods for the examination of water and wastewater, 20th ed.: American Public Health Association, American Water Works Association, and Water Environment Association, Washington, DC.

Forster, J.C., 1995, Soil nitrogen, in Alef, K., and Nannipieri, P., eds., Methods in applied soil microbiology and biochemistry: Academic Press, p. 79-87.

Puckett, M., 2002, Quality assurance management plan for the State of California's Surface Water Ambient Monitoring Program ("SWAMP"): California Department of Fish and Game, Monterey, Calif., prepared for the State Water Resources Control Board, Sacramento, Calif., 145 p. plus appendices.

Sartory, D.P., and Grobbelaar, J.U., 1984, Extraction of chlorophyll- $\alpha$ from freshwater phytoplankton for spectrophotometric analysis: Hydrobiologia, v. 114, p. 177-187. 
Table 4-2. Surface-water temperature, Secchi depth, turbidity, and Microcystis rating data collected during the fall midwater-trawl sampling survey in 2005, 2006, 2010, and 2011.

[Latitude and longitude of sampling stations are in table 4-1. Microcystis: see figure 5 for visual rating system. Data were analysed within salinity group. Data were analyzed within salinity groups. Abbreviations: CS, Cache Slough; SDWSC, Sacramento River Deepwater Ship Channel; m, meter; mm/dd/yyyy, month/day/year; NTU, nephelometric turbidity unit; ${ }^{\circ} \mathrm{C}$, degree Celsius; - , missing data; <, less than; >, greater than]

\begin{tabular}{|c|c|c|c|c|c|c|c|c|c|c|c|c|c|}
\hline Station & $\begin{array}{c}\text { Date } \\
\text { (mm/dd/yyyy) }\end{array}$ & $\begin{array}{l}\text { Salinity } \\
\text { group }\end{array}$ & $\begin{array}{c}\text { Surface- } \\
\text { water } \\
\text { temper- } \\
\text { ature } \\
\left({ }^{\circ} \mathrm{C}\right)\end{array}$ & $\begin{array}{c}\text { Secchi } \\
\text { depth } \\
\text { (m) }\end{array}$ & $\begin{array}{c}\text { Turbidity } \\
\text { (NTU) }\end{array}$ & $\begin{array}{c}\text { Micro- } \\
\text { cystis } \\
(0-5)\end{array}$ & Station & $\begin{array}{c}\text { Date } \\
\text { (mm/dd/yyyy) }\end{array}$ & $\begin{array}{c}\text { Salinity } \\
\text { group }\end{array}$ & $\begin{array}{c}\text { Surface- } \\
\text { water } \\
\text { temper- } \\
\text { ature } \\
\left({ }^{\circ} \mathrm{C}\right)\end{array}$ & $\begin{array}{c}\text { Secchi } \\
\text { depth } \\
\text { (m) }\end{array}$ & $\begin{array}{c}\text { Turbidity } \\
\text { (NTU) }\end{array}$ & $\begin{array}{c}\text { Micro- } \\
\text { cystis } \\
(0-5)\end{array}$ \\
\hline 72 & $09 / 19 / 2005$ & $<1$ & 19.0 & 1.05 & - & - & 505 & $09 / 15 / 2005$ & $1-6$ & 18.7 & 0.70 & - & - \\
\hline 73 & 09/19/2005 & $<1$ & 19.2 & 0.90 & - & - & 507 & $09 / 15 / 2005$ & $1-6$ & 18.7 & 0.60 & - & - \\
\hline 307 & $09 / 06 / 2005$ & $>6$ & 18.8 & 0.92 & - & - & 510 & $09 / 15 / 2005$ & $1-6$ & 18.7 & 0.35 & - & - \\
\hline 308 & 09/06/2005 & $>6$ & 18.7 & 0.80 & - & - & 511 & $09 / 15 / 2005$ & $1-6$ & 18.8 & 0.42 & - & - \\
\hline 309 & $09 / 06 / 2005$ & $>6$ & 18.7 & 0.89 & - & - & 512 & $09 / 15 / 2005$ & $1-6$ & 19.0 & 0.45 & - & - \\
\hline 310 & $09 / 06 / 2005$ & $>6$ & 19.0 & 0.94 & - & - & 513 & $09 / 15 / 2005$ & $1-6$ & 18.9 & 0.40 & - & - \\
\hline 311 & $09 / 06 / 2005$ & $>6$ & 18.7 & 0.81 & - & - & 515 & $09 / 08 / 2005$ & $>6$ & 19.2 & 0.45 & - & - \\
\hline 314 & $09 / 06 / 2005$ & $>6$ & 18.8 & 0.45 & - & - & 516 & $09 / 08 / 2005$ & $>6$ & 19.7 & 0.48 & - & - \\
\hline 323 & $09 / 06 / 2005$ & $>6$ & 18.5 & 0.50 & - & - & 601 & 09/08/2005 & $>6$ & 18.8 & 0.30 & - & - \\
\hline 325 & 09/06/2005 & $>6$ & 19.8 & 0.84 & - & - & 602 & $09 / 08 / 2005$ & $>6$ & 19.3 & 0.23 & - & - \\
\hline 326 & $09 / 06 / 2005$ & $>6$ & 19.0 & 0.44 & - & - & 603 & $09 / 08 / 2005$ & $>6$ & 19.1 & 0.35 & - & - \\
\hline 327 & $09 / 06 / 2005$ & $>6$ & 18.7 & 0.39 & - & - & 604 & $09 / 08 / 2005$ & $>6$ & 19.8 & 0.40 & - & - \\
\hline 328 & $09 / 06 / 2005$ & $>6$ & 18.7 & 0.49 & - & - & 605 & $09 / 08 / 2005$ & $>6$ & 20.4 & 0.41 & - & - \\
\hline 329 & $09 / 06 / 2005$ & $>6$ & 17.9 & 0.49 & - & - & 606 & $09 / 08 / 2005$ & $>6$ & 20.6 & 0.39 & - & - \\
\hline 334 & $09 / 06 / 2005$ & $>6$ & 18.9 & 0.35 & - & - & 608 & $09 / 08 / 2005$ & $1-6$ & 20.5 & 0.42 & - & - \\
\hline 335 & $09 / 06 / 2005$ & $>6$ & 18.8 & 0.45 & - & - & 701 & $09 / 12 / 2005$ & $1-6$ & 19.8 & 0.49 & - & - \\
\hline 336 & $09 / 06 / 2005$ & $>6$ & 19.8 & 0.40 & - & - & 703 & $09 / 12 / 2005$ & $<1$ & 19.9 & 0.40 & - & - \\
\hline 337 & 09/06/2005 & $>6$ & 19.8 & 0.50 & - & - & 704 & $09 / 12 / 2005$ & $<1$ & 20.0 & 0.42 & - & - \\
\hline 338 & 09/06/2005 & $>6$ & 19.9 & 0.85 & - & - & 705 & $09 / 12 / 2005$ & $<1$ & 20.1 & 0.30 & - & - \\
\hline 407 & $09 / 08 / 2005$ & $>6$ & 19.3 & 0.72 & - & - & & & SDWSC & & & & \\
\hline 408 & $09 / 08 / 2005$ & $>6$ & 19.3 & 0.50 & - & - & 715 & $09 / 12 / 2005$ & CS/ & 19.3 & 0.41 & - & - \\
\hline 409 & $09 / 15 / 2005$ & $>6$ & 18.5 & 0.50 & - & - & & & SDWSC & & & & \\
\hline 410 & $09 / 15 / 2005$ & $>6$ & 18.5 & 0.60 & - & - & 716 & $09 / 12 / 2005$ & $\mathrm{CS} /$ & 18.9 & 0.30 & - & - \\
\hline 411 & $09 / 15 / 2005$ & $>6$ & 18.4 & 0.50 & - & - & & & SDWSC & & & & \\
\hline 412 & $09 / 15 / 2005$ & $>6$ & 18.4 & 0.50 & - & - & 717 & 09/19/2005 & $<1$ & 19.1 & 0.70 & - & - \\
\hline 413 & $09 / 15 / 2005$ & $>6$ & 18.5 & 0.50 & - & - & 724 & 09/19/2005 & $<1$ & 19.3 & 0.80 & - & - \\
\hline 414 & $09 / 15 / 2005$ & $>6$ & 17.8 & 0.20 & - & - & 735 & $09 / 19 / 2005$ & $<1$ & 19.2 & 0.85 & - & - \\
\hline 415 & $09 / 15 / 2005$ & $>6$ & 18.0 & 0.25 & - & - & 736 & 09/19/2005 & $<1$ & 19.3 & 0.95 & - & - \\
\hline 416 & $09 / 15 / 2005$ & $>6$ & 18.0 & 0.20 & - & - & 802 & 09/19/2005 & $1-6$ & 18.7 & 0.50 & - & - \\
\hline 417 & $09 / 15 / 2005$ & $>6$ & 18.0 & 0.30 & - & - & 804 & $09 / 12 / 2005$ & $1-6$ & 19.9 & 0.60 & - & - \\
\hline 418 & $09 / 15 / 2005$ & $>6$ & 18.0 & 0.30 & - & - & 806 & 09/19/2005 & $<1$ & 20.0 & 0.72 & - & - \\
\hline 501 & $09 / 15 / 2005$ & $1-6$ & 18.6 & 0.65 & - & - & 807 & 09/13/2005 & $<1$ & 20.0 & 0.65 & - & - \\
\hline 502 & $09 / 15 / 2005$ & $1-6$ & 18.6 & 0.55 & - & - & 808 & $09 / 13 / 2005$ & $<1$ & 20.2 & 0.75 & - & - \\
\hline 503 & $09 / 15 / 2005$ & $1-6$ & 18.6 & 0.60 & - & - & 809 & $09 / 13 / 2005$ & $<1$ & 20.1 & 0.80 & - & - \\
\hline 504 & 09/08/2005 & $>6$ & 19.2 & 0.60 & - & - & 810 & $09 / 13 / 2005$ & $<1$ & 20.3 & 0.85 & - & - \\
\hline
\end{tabular}


Table 4-2. Surface-water temperature, Secchi depth, turbidity, and Microcystis rating data collected during the fall midwater-trawl sampling survey in 2005, 2006, 2010, and 2011.-Continued

[Latitude and longitude of sampling stations are in table 4-1. Microcystis: see figure 5 for visual rating system. Data were analysed within salinity group. Data were analyzed within salinity groups. Abbreviations: CS, Cache Slough; SDWSC, Sacramento River Deepwater Ship Channel; m, meter; mm/dd/yyyy, month/day/year; NTU, nephelometric turbidity unit; ${ }^{\circ} \mathrm{C}$, degree Celsius; - , missing data; $<$, less than; >, greater than]

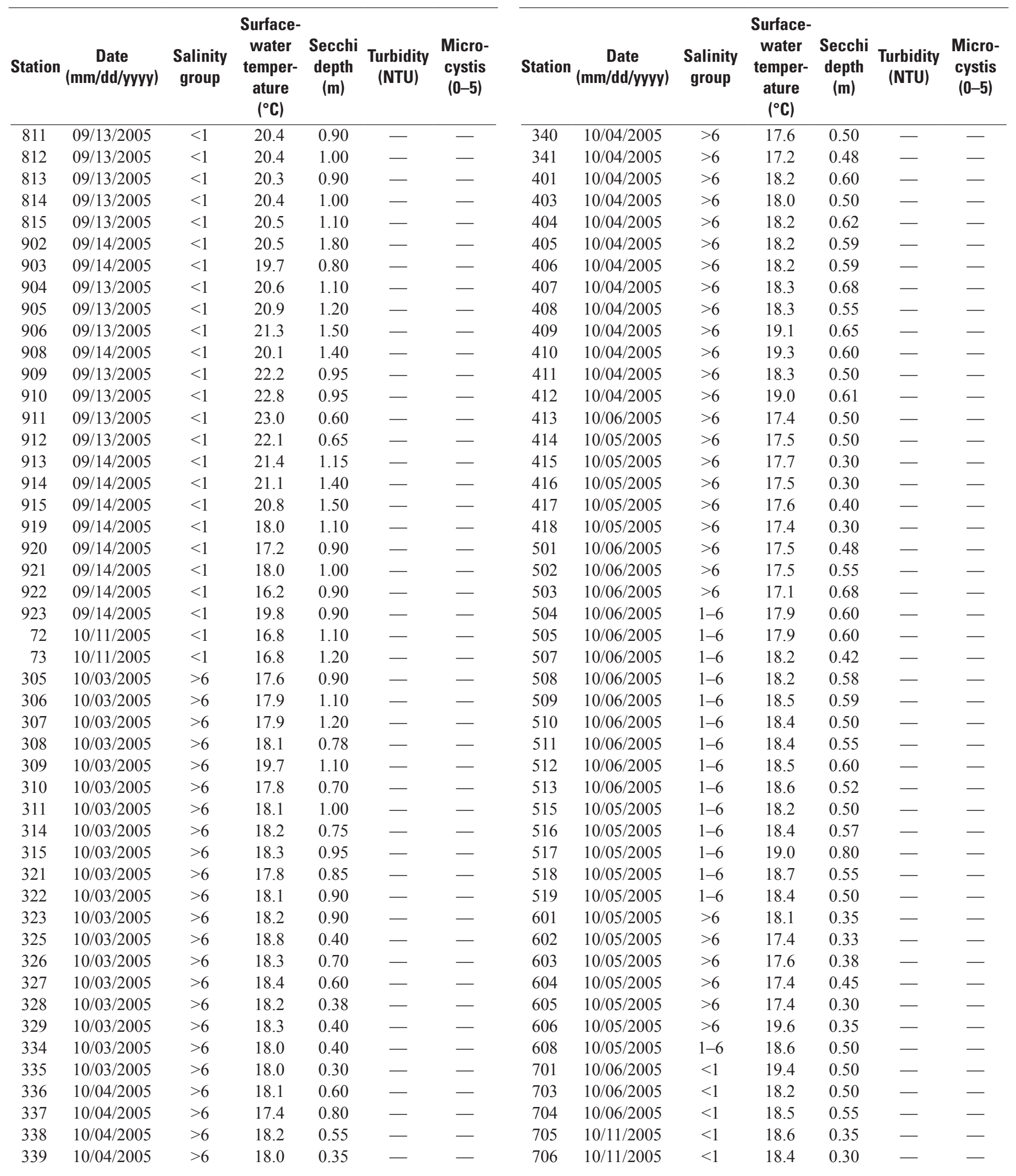


Table 4-2. Surface-water temperature, Secchi depth, turbidity, and Microcystis rating data collected during the fall midwater-trawl sampling survey in 2005, 2006, 2010, and 2011. - Continued

[Latitude and longitude of sampling stations are in table 4-1. Microcystis: see figure 5 for visual rating system. Data were analysed within salinity group. Data were analyzed within salinity groups. Abbreviations: CS, Cache Slough; SDWSC, Sacramento River Deepwater Ship Channel; m, meter; mm/dd/yyyy, month/day/year; NTU, nephelometric turbidity unit; ${ }^{\circ} \mathrm{C}$, degree Celsius; - , missing data; $<$, less than; $>$, greater than]

\begin{tabular}{|c|c|c|c|c|c|c|c|c|c|c|c|c|c|}
\hline Station & $\begin{array}{c}\text { Date } \\
\text { (mm/dd/yyyy) }\end{array}$ & $\begin{array}{c}\text { Salinity } \\
\text { group }\end{array}$ & $\begin{array}{l}\text { Surface- } \\
\text { water } \\
\text { temper- } \\
\text { ature } \\
\left({ }^{\circ} \mathrm{C}\right)\end{array}$ & $\begin{array}{c}\text { Secchi } \\
\text { depth } \\
\text { (m) }\end{array}$ & $\begin{array}{c}\text { Turbidity } \\
\text { (NTU) }\end{array}$ & $\begin{array}{c}\text { Micro- } \\
\text { cystis } \\
(0-5)\end{array}$ & Station & $\begin{array}{c}\text { Date } \\
\text { (mm/dd/yyyy) }\end{array}$ & $\begin{array}{l}\text { Salinity } \\
\text { group }\end{array}$ & $\begin{array}{c}\text { Surface- } \\
\text { water } \\
\text { temper- } \\
\text { ature } \\
\left({ }^{\circ} \mathrm{C}\right)\end{array}$ & $\begin{array}{c}\text { Secchi } \\
\text { depth } \\
\text { (m) }\end{array}$ & $\begin{array}{c}\text { Turbidity } \\
\text { (NTU) }\end{array}$ & $\begin{array}{c}\text { Micro- } \\
\text { cystis } \\
(0-5)\end{array}$ \\
\hline 707 & $10 / 11 / 2005$ & $<1$ & 17.0 & 0.61 & - & - & 306 & $10 / 31 / 2005$ & $>6$ & 15.6 & 1.00 & - & - \\
\hline 708 & $10 / 11 / 2005$ & $<1$ & 17.0 & 0.73 & - & - & 307 & $10 / 31 / 2005$ & $>6$ & 15.6 & 1.20 & - & - \\
\hline 711 & $10 / 11 / 2005$ & $<1$ & 17.2 & 0.50 & - & - & 310 & $10 / 31 / 2005$ & $>6$ & 15.9 & 1.00 & - & - \\
\hline 712 & $10 / 11 / 2005$ & $<1$ & 18.0 & 0.90 & - & - & 311 & $10 / 31 / 2005$ & $>6$ & 16.2 & 0.93 & - & - \\
\hline 713 & $10 / 11 / 2005$ & CS/ & 17.3 & 0.25 & - & - & 314 & $10 / 31 / 2005$ & $>6$ & 15.6 & 0.45 & - & - \\
\hline & & SDWSC & & & & & 315 & $10 / 31 / 2005$ & $>6$ & 15.8 & 1.20 & - & - \\
\hline 715 & $10 / 11 / 2005$ & CS/ & 17.4 & 0.25 & - & - & 321 & $10 / 31 / 2005$ & $>6$ & 15.5 & 1.16 & - & - \\
\hline 724 & $10 / 11 / 2005$ & $<1$ & 17.0 & 1.20 & - & - & 327 & $10 / 31 / 2005$ & $>6$ & 16.1 & 1.20 & - & - \\
\hline 735 & $10 / 11 / 2005$ & $<1$ & 17.0 & 1.35 & - & - & 328 & $10 / 31 / 2005$ & $>6$ & 15.9 & 0.90 & - & - \\
\hline 736 & $10 / 11 / 2005$ & $<1$ & 16.9 & 1.40 & - & - & 329 & $10 / 31 / 2005$ & $>6$ & 15.7 & 0.60 & - & - \\
\hline 802 & $10 / 06 / 2005$ & $<1$ & 18.7 & 0.50 & - & - & 334 & $10 / 31 / 2005$ & $>6$ & 15.9 & 0.70 & - & - \\
\hline 804 & $10 / 12 / 2005$ & $<1$ & 18.6 & 0.40 & - & - & 335 & $10 / 31 / 2005$ & $>6$ & 15.9 & 0.70 & - & - \\
\hline 806 & $10 / 12 / 2005$ & $<1$ & 18.1 & 0.50 & - & - & 336 & $11 / 01 / 2005$ & $>6$ & & 0.65 & - & - \\
\hline 807 & $10 / 12 / 2005$ & $<1$ & 18.6 & 0.80 & - & - & 337 & $11 / 01 / 2005$ & $>6$ & 16.1 & 0.90 & - & - \\
\hline 808 & $10 / 12 / 2005$ & $<1$ & 18.4 & 0.80 & - & - & 338 & $11 / 01 / 2005$ & $>6$ & 16.0 & 1.00 & - & - \\
\hline 809 & $10 / 12 / 2005$ & $<1$ & & 1.00 & - & - & 339 & $11 / 01 / 2005$ & $>6$ & 16.2 & 0.65 & - & - \\
\hline 810 & $10 / 12 / 2005$ & $<1$ & 18.4 & 0.70 & - & - & 340 & $11 / 01 / 2005$ & $>6$ & 16.2 & 0.30 & - & - \\
\hline 811 & $10 / 12 / 2005$ & $<1$ & 18.5 & 1.09 & - & - & 341 & $11 / 01 / 2005$ & $>6$ & 16.4 & 0.39 & - & - \\
\hline 906 & $10 / 17 / 2005$ & $<1$ & 18.4 & 1.88 & - & - & 410 & $11 / 02 / 2005$ & $>6$ & 16.1 & 0.72 & - & - \\
\hline 908 & $10 / 17 / 2005$ & $<1$ & 18.4 & 2.00 & - & - & 411 & $11 / 02 / 2005$ & $>6$ & 16.2 & 0.70 & - & - \\
\hline 909 & $10 / 12 / 2005$ & $<1$ & 18.7 & 0.70 & - & - & 412 & $11 / 02 / 2005$ & $>6$ & 16.1 & 0.81 & - & - \\
\hline 910 & $10 / 12 / 2005$ & $<1$ & 18.6 & 0.70 & - & - & 413 & $11 / 02 / 2005$ & $>6$ & 16.1 & 0.80 & - & - \\
\hline 911 & $10 / 12 / 2005$ & $<1$ & 18.6 & 0.55 & - & - & 414 & $11 / 03 / 2005$ & $>6$ & 15.9 & 0.65 & - & - \\
\hline 912 & $10 / 12 / 2005$ & $<1$ & 18.5 & 0.50 & - & - & 415 & $11 / 03 / 2005$ & $>6$ & 15.7 & 0.50 & - & - \\
\hline 913 & $10 / 17 / 2005$ & $<1$ & 18.5 & 2.00 & - & - & 416 & $11 / 03 / 2005$ & $>6$ & 15.5 & 0.50 & - & - \\
\hline 914 & $10 / 17 / 2005$ & $<1$ & 18.1 & 2.00 & - & - & 417 & $11 / 03 / 2005$ & $>6$ & 15.5 & 0.70 & - & - \\
\hline 915 & $10 / 17 / 2005$ & $<1$ & 17.9 & 1.42 & - & - & 418 & $11 / 03 / 2005$ & $>6$ & 15.5 & 0.50 & - & - \\
\hline 919 & $10 / 17 / 2005$ & $<1$ & 17.4 & 1.53 & - & - & 501 & $11 / 02 / 2005$ & $>6$ & 16.2 & 0.76 & - & - \\
\hline 920 & $10 / 17 / 2005$ & $<1$ & 17.3 & 1.86 & - & - & 502 & $11 / 02 / 2005$ & $>6$ & 16.3 & 0.90 & - & - \\
\hline 921 & $10 / 17 / 2005$ & $<1$ & 17.4 & 1.77 & - & - & 503 & $11 / 02 / 2005$ & $>6$ & 16.3 & 0.65 & - & - \\
\hline 923 & $10 / 17 / 2005$ & $<1$ & 17.6 & 2.00 & - & - & 504 & $11 / 02 / 2005$ & $>6$ & 16.4 & 0.75 & - & - \\
\hline 72 & $11 / 09 / 2005$ & $<1$ & 14.0 & 1.49 & - & - & 505 & $11 / 02 / 2005$ & $>6$ & 16.5 & 0.80 & - & - \\
\hline 73 & $11 / 09 / 2005$ & $<1$ & 14.0 & 0.87 & - & - & 507 & $11 / 02 / 2005$ & $1-6$ & 16.4 & 0.70 & - & - \\
\hline 305 & $10 / 31 / 2005$ & $>6$ & 15.4 & 0.90 & - & - & 508 & $11 / 02 / 2005$ & $1-6$ & 16.4 & 0.75 & - & - \\
\hline
\end{tabular}


Table 4-2. Surface-water temperature, Secchi depth, turbidity, and Microcystis rating data collected during the fall midwater-trawl sampling survey in 2005, 2006, 2010, and 2011.-Continued

[Latitude and longitude of sampling stations are in table 4-1. Microcystis: see figure 5 for visual rating system. Data were analysed within salinity group. Data were analyzed within salinity groups. Abbreviations: CS, Cache Slough; SDWSC, Sacramento River Deepwater Ship Channel; m, meter; mm/dd/yyyy, month/day/year; NTU, nephelometric turbidity unit; ${ }^{\circ} \mathrm{C}$, degree Celsius; —, missing data; <, less than; >, greater than]

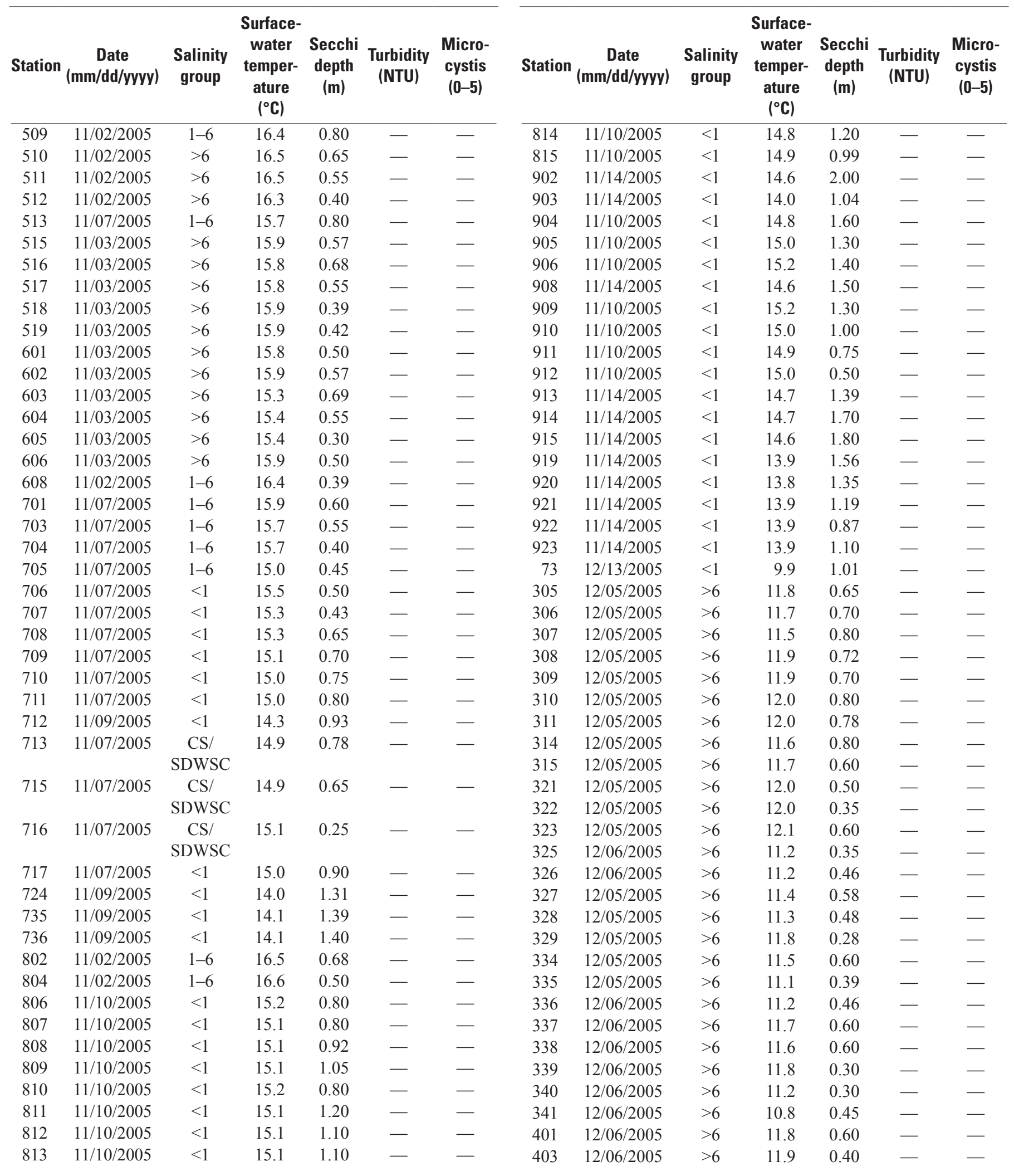


Table 4-2. Surface-water temperature, Secchi depth, turbidity, and Microcystis rating data collected during the fall midwater-trawl sampling survey in 2005, 2006, 2010, and 2011.-Continued

[Latitude and longitude of sampling stations are in table 4-1. Microcystis: see figure 5 for visual rating system. Data were analysed within salinity group. Data were analyzed within salinity groups. Abbreviations: CS, Cache Slough; SDWSC, Sacramento River Deepwater Ship Channel; m, meter; mm/dd/yyyy, month/day/year; NTU, nephelometric turbidity unit; ${ }^{\circ} \mathrm{C}$, degree Celsius; - , missing data; <, less than; >, greater than]

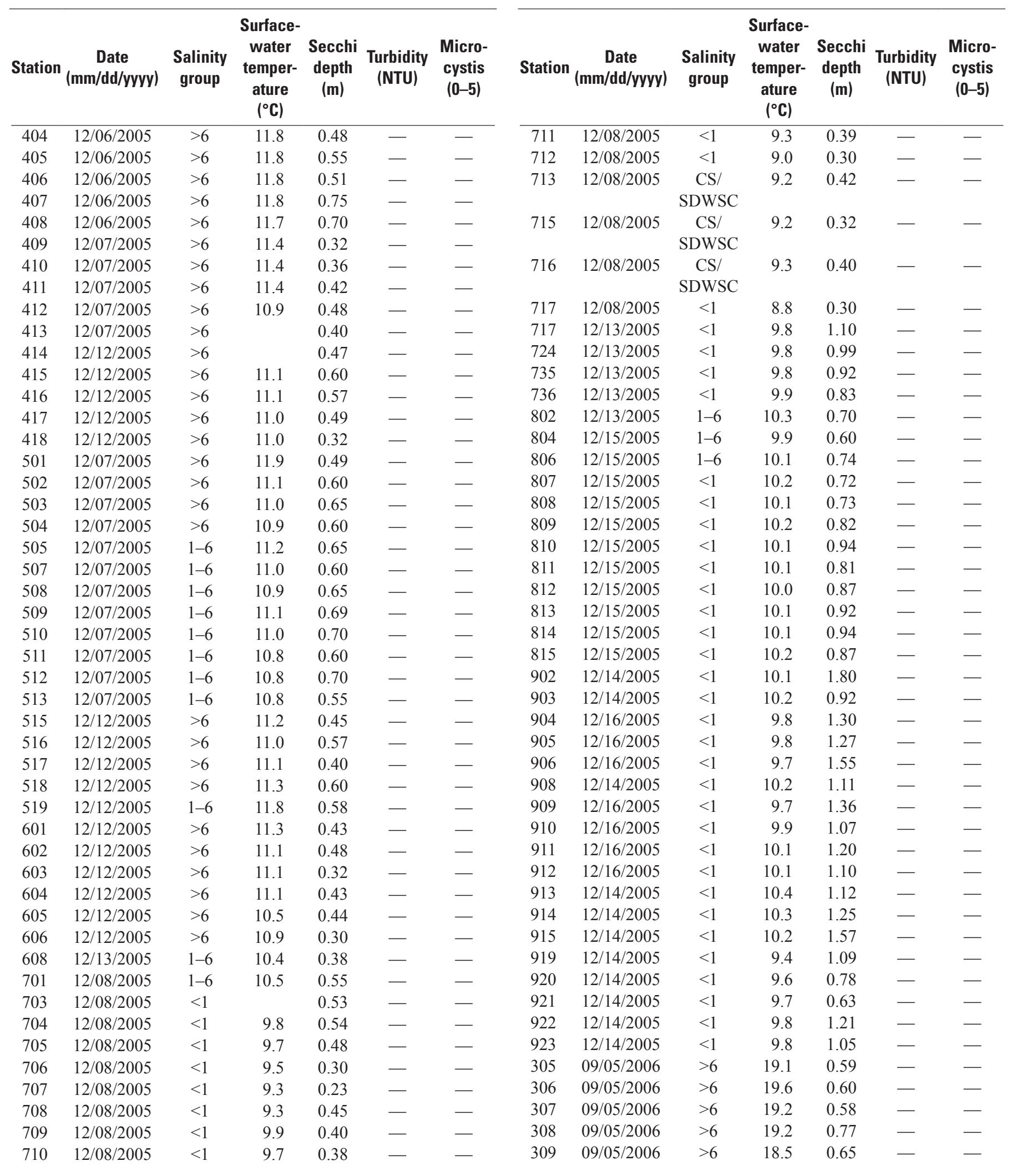


Table 4-2. Surface-water temperature, Secchi depth, turbidity, and Microcystis rating data collected during the fall midwater-trawl sampling survey in 2005, 2006, 2010, and 2011.-Continued

[Latitude and longitude of sampling stations are in table 4-1. Microcystis: see figure 5 for visual rating system. Data were analysed within salinity group. Data were analyzed within salinity groups. Abbreviations: CS, Cache Slough; SDWSC, Sacramento River Deepwater Ship Channel; m, meter; mm/dd/yyyy, month/day/year; NTU, nephelometric turbidity unit; ${ }^{\circ} \mathrm{C}$, degree Celsius; - , missing data; <, less than; >, greater than]

\begin{tabular}{|c|c|c|c|c|c|c|c|c|c|c|c|c|c|}
\hline Station & $\begin{array}{c}\text { Date } \\
\text { (mm/dd/yyyy) }\end{array}$ & $\begin{array}{l}\text { Salinity } \\
\text { group }\end{array}$ & $\begin{array}{c}\text { Surface- } \\
\text { water } \\
\text { temper- } \\
\text { ature } \\
\left({ }^{\circ} \mathrm{C}\right)\end{array}$ & $\begin{array}{c}\text { Secchi } \\
\text { depth } \\
\text { (m) }\end{array}$ & $\begin{array}{c}\text { Turbidity } \\
\text { (NTU) }\end{array}$ & $\begin{array}{c}\text { Micro- } \\
\text { cystis } \\
(0-5)\end{array}$ & Station & $\begin{array}{c}\text { Date } \\
\text { (mm/dd/yyyy) }\end{array}$ & $\begin{array}{l}\text { Salinity } \\
\text { group }\end{array}$ & $\begin{array}{l}\text { Surface- } \\
\text { water } \\
\text { temper- } \\
\text { ature } \\
\left({ }^{\circ} \mathrm{C}\right)\end{array}$ & $\begin{array}{c}\text { Secchi } \\
\text { depth } \\
\text { (m) }\end{array}$ & $\begin{array}{c}\text { Turbidity } \\
\text { (NTU) }\end{array}$ & $\begin{array}{c}\text { Micro- } \\
\text { cystis } \\
(0-5)\end{array}$ \\
\hline 310 & $09 / 05 / 2006$ & $>6$ & 18.5 & 0.70 & - & - & 513 & $09 / 12 / 2006$ & $1-6$ & 19.8 & 0.45 & - & - \\
\hline 311 & $09 / 05 / 2006$ & $>6$ & 18.8 & 0.44 & - & - & 515 & 09/08/2006 & $>6$ & 18.9 & 0.22 & - & - \\
\hline 321 & 09/06/2006 & $>6$ & 19.2 & 0.40 & - & - & 518 & $09 / 11 / 2006$ & $1-6$ & 19.4 & 0.40 & - & - \\
\hline 322 & 09/06/2006 & $>6$ & 18.6 & 0.43 & - & - & 519 & $09 / 11 / 2006$ & $1-6$ & 19.6 & 0.42 & - & - \\
\hline 323 & 09/06/2006 & $>6$ & 18.5 & 0.49 & - & - & 601 & 09/08/2006 & $>6$ & 18.9 & 0.22 & - & - \\
\hline 325 & 09/06/2006 & $>6$ & 18.8 & 0.52 & - & - & 602 & 09/08/2006 & $>6$ & 18.7 & 0.21 & - & - \\
\hline 326 & 09/06/2006 & $>6$ & 18.8 & 0.47 & - & - & 603 & 09/08/2006 & $>6$ & 18.3 & 0.23 & - & - \\
\hline 335 & 09/05/2006 & $>6$ & 18.8 & 0.40 & - & - & 701 & 09/14/2006 & $<1$ & 20.2 & 0.50 & - & - \\
\hline 336 & 09/06/2006 & $>6$ & 18.7 & 0.52 & - & - & 703 & 09/14/2006 & $<1$ & 20.4 & 0.64 & - & - \\
\hline 337 & 09/06/2006 & $>6$ & 18.8 & 0.53 & - & - & 704 & $09 / 14 / 2006$ & $<1$ & 20.4 & 0.46 & - & - \\
\hline 338 & 09/06/2006 & $>6$ & 19.2 & 0.63 & - & - & 705 & $09 / 14 / 2006$ & $<1$ & 20.4 & 0.74 & - & - \\
\hline 339 & 09/06/2006 & $>6$ & 18.8 & 0.62 & - & - & 706 & 09/14/2006 & $<1$ & 20.5 & 0.30 & - & - \\
\hline 340 & 09/06/2006 & $>6$ & 18.8 & 0.47 & - & - & 707 & $09 / 14 / 2006$ & $<1$ & 20.5 & 0.60 & - & - \\
\hline 341 & 09/06/2006 & $>6$ & 19.3 & 0.42 & - & - & 708 & 09/14/2006 & $<1$ & 20.5 & & - & - \\
\hline 401 & 09/06/2006 & $>6$ & 19.2 & 0.66 & - & - & 709 & $09 / 14 / 2006$ & $<1$ & 20.5 & 0.50 & - & - \\
\hline 403 & 09/07/2006 & $>6$ & 18.8 & 0.20 & - & - & 710 & 09/14/2006 & $<1$ & 20.5 & 0.70 & - & - \\
\hline 404 & 09/06/2006 & $>6$ & 19.1 & 0.38 & - & - & 711 & $09 / 14 / 2006$ & $<1$ & 20.5 & 0.85 & - & - \\
\hline 405 & 09/07/2006 & $>6$ & 18.9 & 0.18 & - & - & 802 & $09 / 12 / 2006$ & $<1$ & 20.4 & 0.48 & - & - \\
\hline 414 & 09/08/2006 & $>6$ & 18.9 & 0.35 & - & - & 813 & 09/13/2006 & $<1$ & 21.5 & 1.35 & - & - \\
\hline 415 & 09/08/2006 & $>6$ & 19.0 & 0.27 & - & - & 814 & 09/13/2006 & $<1$ & 21.5 & 0.95 & - & - \\
\hline 416 & 09/08/2006 & $>6$ & 19.0 & 0.35 & - & - & 815 & 09/13/2006 & $<1$ & 21.6 & 1.20 & - & - \\
\hline 417 & 09/08/2006 & $>6$ & 18.9 & 0.25 & - & - & 902 & $09 / 15 / 2006$ & $<1$ & 21.4 & 1.60 & - & - \\
\hline 418 & 09/08/2006 & $>6$ & 19.0 & 0.24 & - & - & 903 & 09/18/2006 & $<1$ & 19.2 & 1.18 & - & - \\
\hline 501 & 09/07/2006 & $1-6$ & 19.7 & 0.50 & - & - & 904 & 09/13/2006 & $<1$ & 21.6 & 1.06 & - & - \\
\hline 502 & 09/07/2006 & $1-6$ & 19.8 & 0.48 & - & - & 905 & 09/13/2006 & $<1$ & 21.9 & 0.94 & - & - \\
\hline 503 & 09/07/2006 & $1-6$ & 19.8 & 0.46 & - & - & 906 & 09/13/2006 & $<1$ & 22.4 & 0.97 & - & - \\
\hline 504 & 09/07/2006 & $1-6$ & 19.8 & 0.46 & - & - & 908 & $09 / 15 / 2006$ & $<1$ & 21.4 & 1.00 & - & - \\
\hline 505 & $09 / 11 / 2006$ & $1-6$ & 19.8 & 0.42 & - & - & 909 & 09/13/2006 & $<1$ & 22.9 & 0.96 & - & - \\
\hline 507 & $09 / 11 / 2006$ & $1-6$ & 19.5 & 0.36 & - & - & 910 & 09/13/2006 & $<1$ & 23.2 & 0.66 & - & - \\
\hline 508 & $09 / 11 / 2006$ & $1-6$ & 19.9 & 0.45 & - & - & 911 & 09/13/2006 & $<1$ & 23.0 & 0.75 & - & - \\
\hline 509 & $09 / 12 / 2006$ & $1-6$ & 19.8 & 0.48 & - & - & 912 & 09/13/2006 & $<1$ & 20.9 & 0.56 & - & - \\
\hline 510 & $09 / 12 / 2006$ & $1-6$ & 19.7 & 0.41 & - & - & 913 & $09 / 15 / 2006$ & $<1$ & 21.6 & 1.20 & - & - \\
\hline 511 & $09 / 12 / 2006$ & $1-6$ & 19.8 & 0.45 & - & - & 914 & $09 / 15 / 2006$ & $<1$ & 21.6 & 1.00 & - & - \\
\hline 512 & $09 / 12 / 2006$ & $1-6$ & 19.8 & 0.40 & - & - & 915 & $09 / 15 / 2006$ & $<1$ & 21.4 & 1.60 & - & - \\
\hline
\end{tabular}


Table 4-2. Surface-water temperature, Secchi depth, turbidity, and Microcystis rating data collected during the fall midwater-trawl sampling survey in 2005, 2006, 2010, and 2011. - Continued

[Latitude and longitude of sampling stations are in table 4-1. Microcystis: see figure 5 for visual rating system. Data were analysed within salinity group. Data were analyzed within salinity groups. Abbreviations: CS, Cache Slough; SDWSC, Sacramento River Deepwater Ship Channel; m, meter; mm/dd/yyyy, month/day/year; NTU, nephelometric turbidity unit; ${ }^{\circ} \mathrm{C}$, degree Celsius; - , missing data; $<$, less than; $>$, greater than]

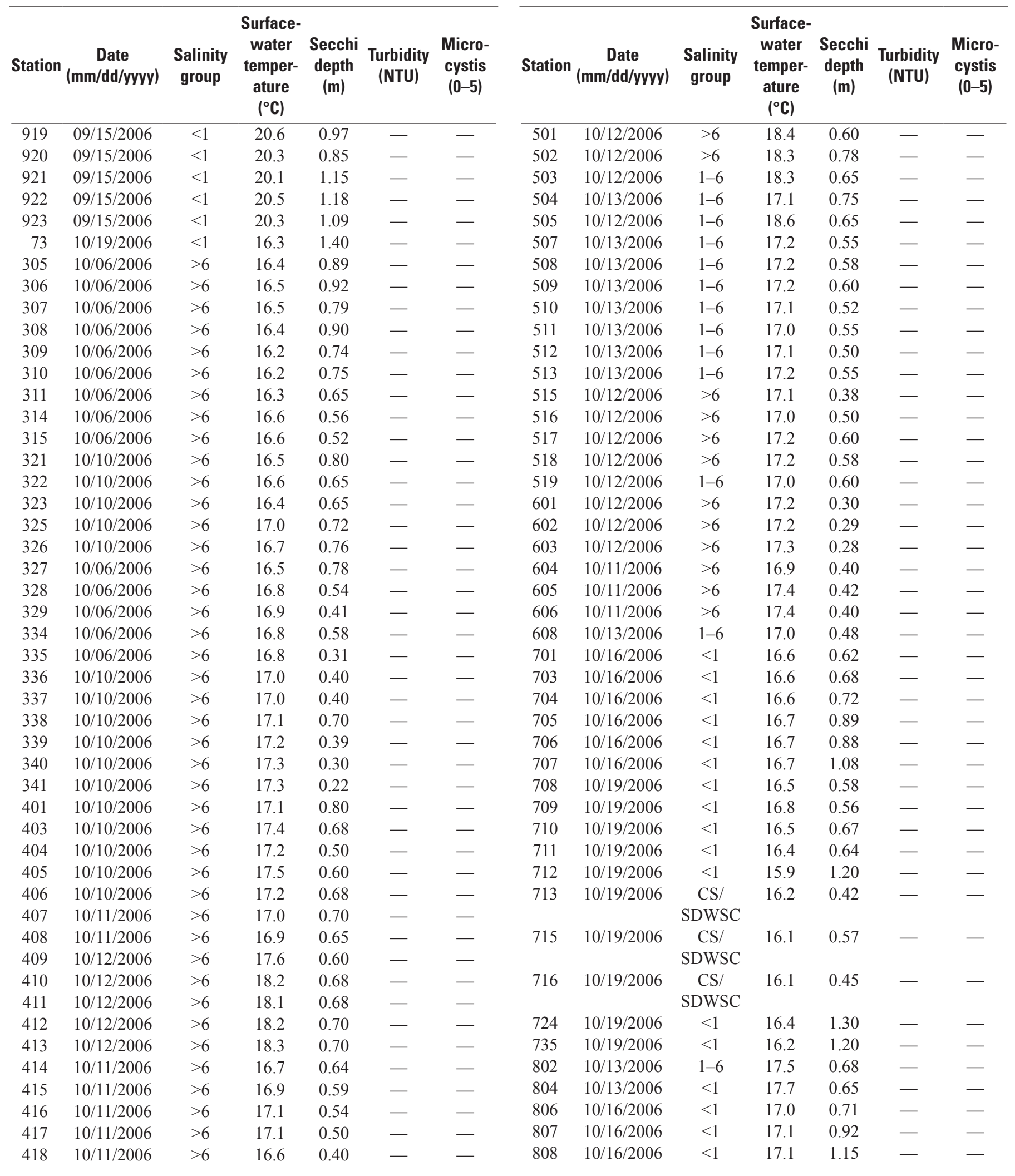


Table 4-2. Surface-water temperature, Secchi depth, turbidity, and Microcystis rating data collected during the fall midwater-trawl sampling survey in 2005, 2006, 2010, and 2011.-Continued

[Latitude and longitude of sampling stations are in table 4-1. Microcystis: see figure 5 for visual rating system. Data were analysed within salinity group. Data were analyzed within salinity groups. Abbreviations: CS, Cache Slough; SDWSC, Sacramento River Deepwater Ship Channel; m, meter; mm/dd/yyyy, month/day/year; NTU, nephelometric turbidity unit; ${ }^{\circ} \mathrm{C}$, degree Celsius; - , missing data; $<$, less than; >, greater than]

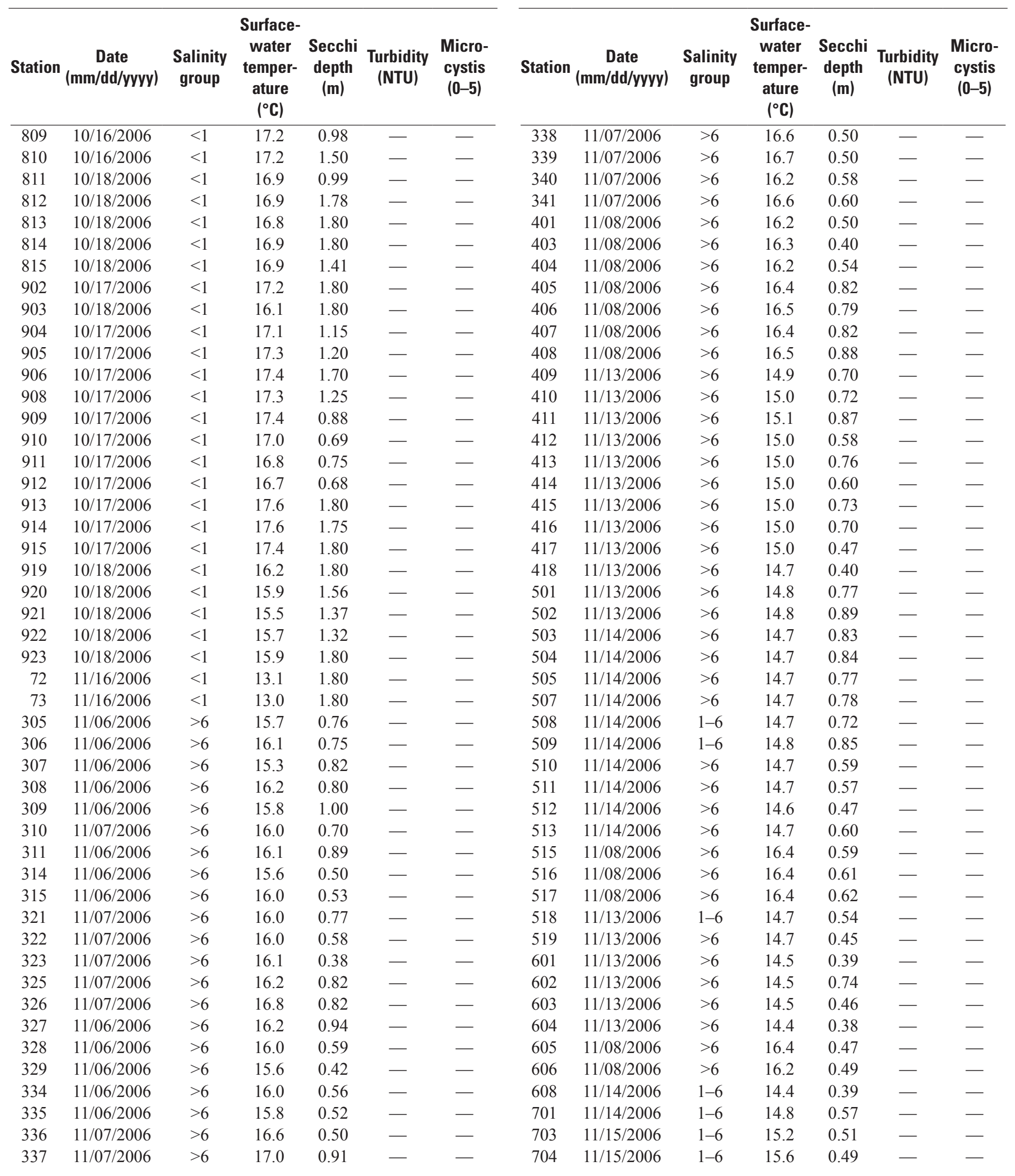


Table 4-2. Surface-water temperature, Secchi depth, turbidity, and Microcystis rating data collected during the fall midwater-trawl sampling survey in 2005, 2006, 2010, and 2011. - Continued

[Latitude and longitude of sampling stations are in table 4-1. Microcystis: see figure 5 for visual rating system. Data were analysed within salinity group. Data were analyzed within salinity groups. Abbreviations: CS, Cache Slough; SDWSC, Sacramento River Deepwater Ship Channel; m, meter; mm/dd/yyyy, month/day/year; NTU, nephelometric turbidity unit; ${ }^{\circ} \mathrm{C}$, degree Celsius; - , missing data; $<$, less than; $>$, greater than]

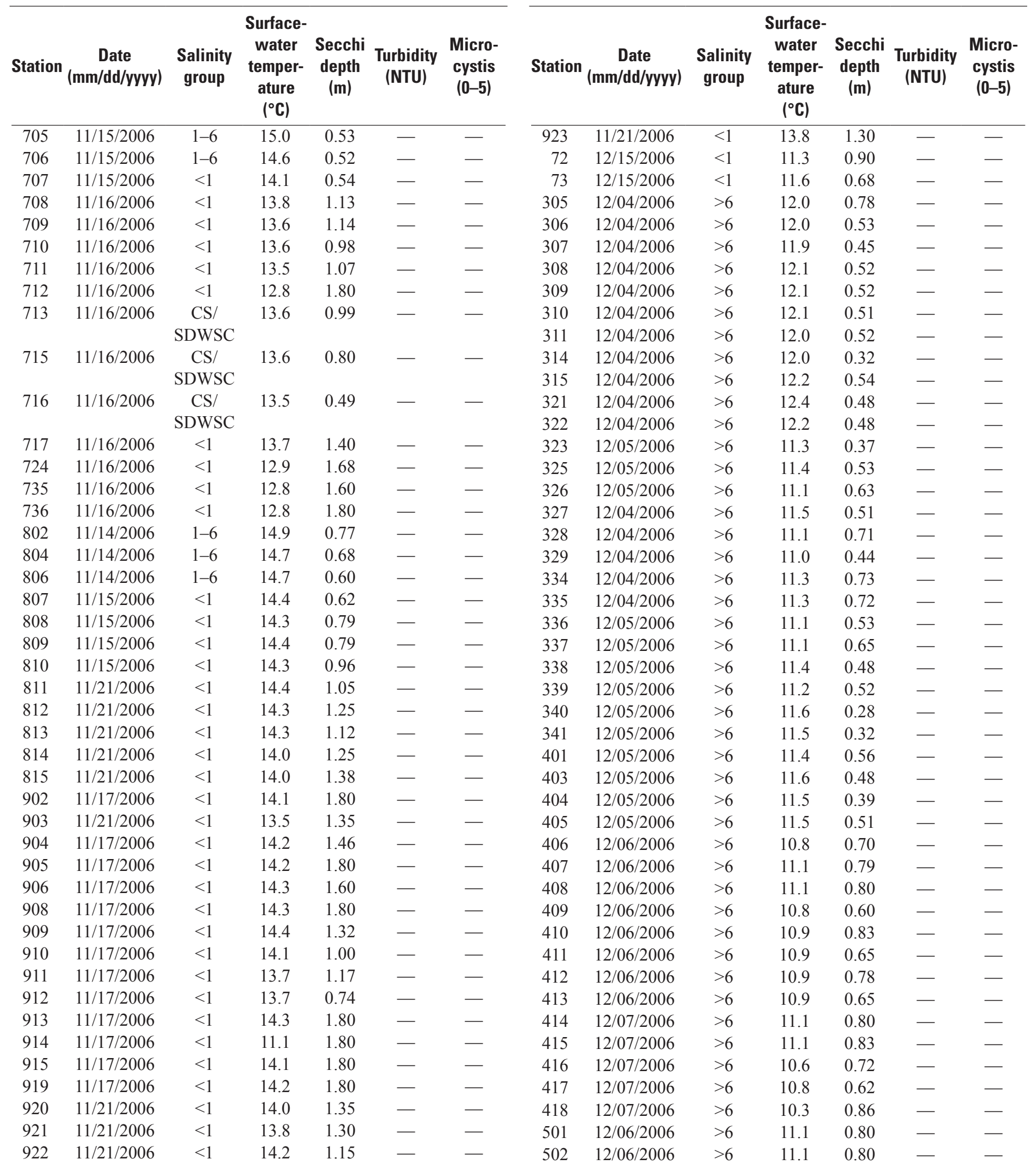


Table 4-2. Surface-water temperature, Secchi depth, turbidity, and Microcystis rating data collected during the fall midwater-trawl sampling survey in 2005, 2006, 2010, and 2011.-Continued

[Latitude and longitude of sampling stations are in table 4-1. Microcystis: see figure 5 for visual rating system. Data were analysed within salinity group. Data were analyzed within salinity groups. Abbreviations: CS, Cache Slough; SDWSC, Sacramento River Deepwater Ship Channel; m, meter; mm/dd/yyyy, month/day/year; NTU, nephelometric turbidity unit; ${ }^{\circ} \mathrm{C}$, degree Celsius; - , missing data; $<$, less than; >, greater than]

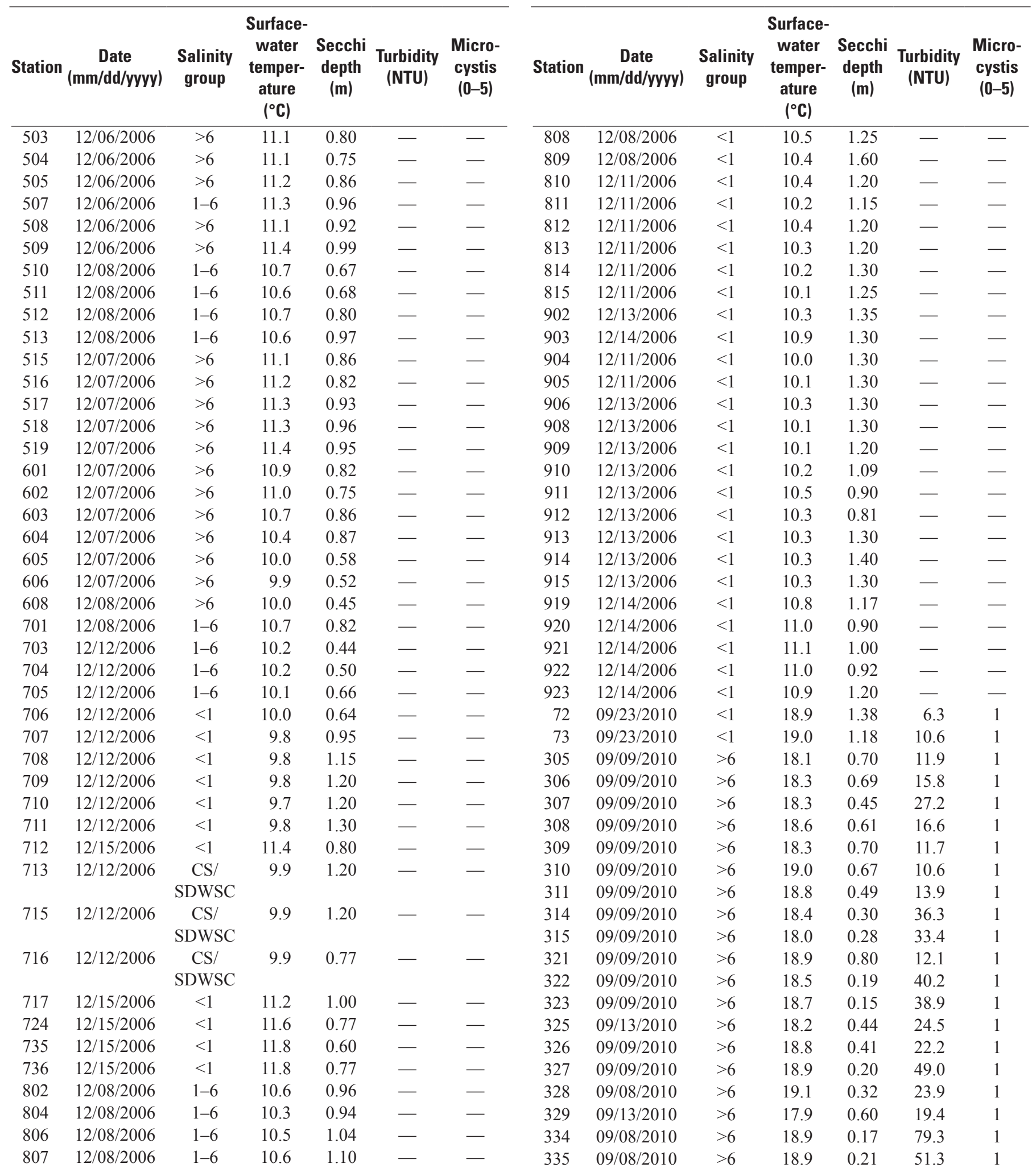


Table 4-2. Surface-water temperature, Secchi depth, turbidity, and Microcystis rating data collected during the fall midwater-trawl sampling survey in 2005, 2006, 2010, and 2011. - Continued

[Latitude and longitude of sampling stations are in table 4-1. Microcystis: see figure 5 for visual rating system. Data were analysed within salinity group. Data were analyzed within salinity groups. Abbreviations: CS, Cache Slough; SDWSC, Sacramento River Deepwater Ship Channel; m, meter; mm/dd/yyyy, month/day/year; NTU, nephelometric turbidity unit; ${ }^{\circ} \mathrm{C}$, degree Celsius; - , missing data; $<$, less than; $>$, greater than]

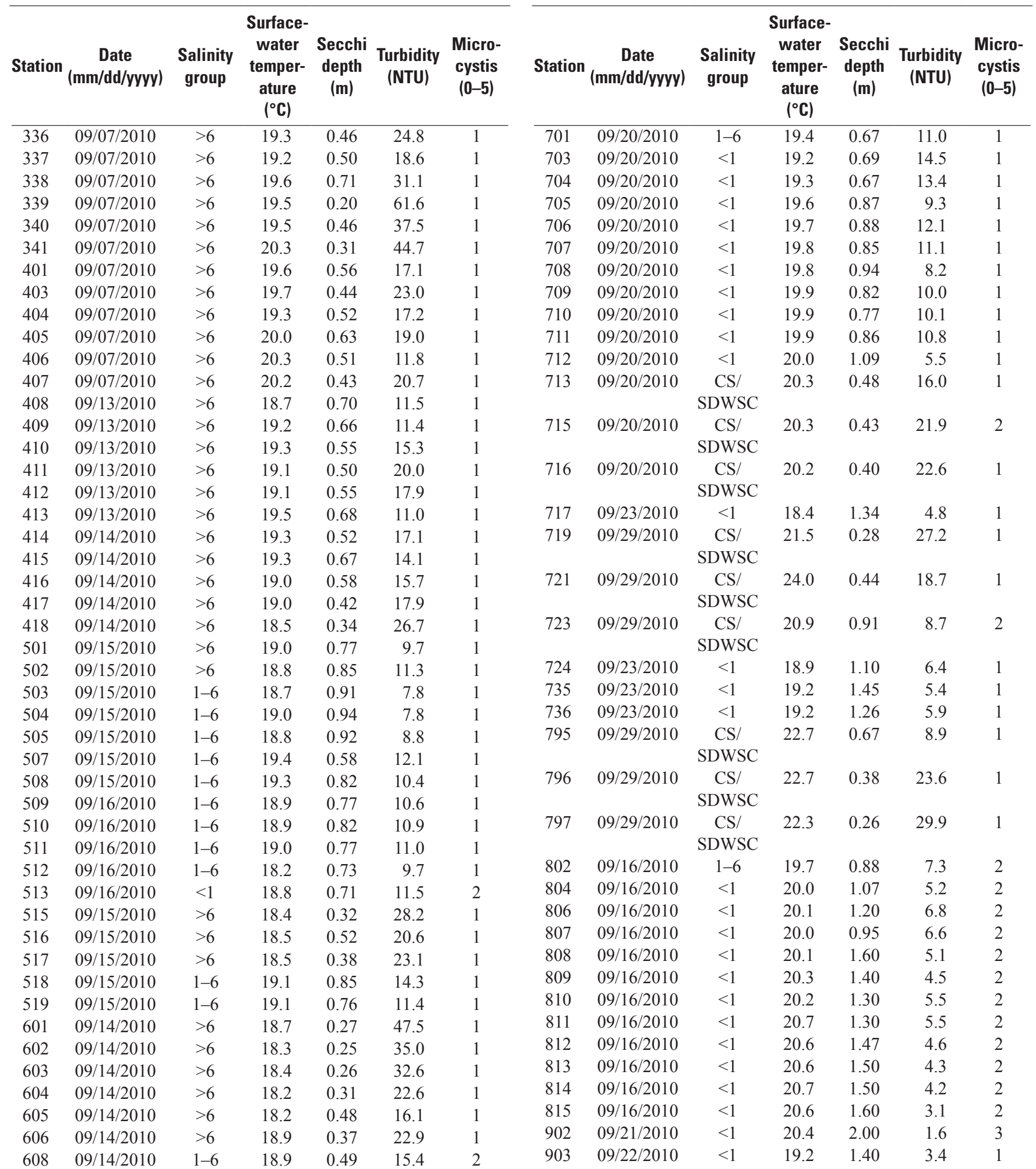


Table 4-2. Surface-water temperature, Secchi depth, turbidity, and Microcystis rating data collected during the fall midwater-trawl sampling survey in 2005, 2006, 2010, and 2011.-Continued

[Latitude and longitude of sampling stations are in table 4-1. Microcystis: see figure 5 for visual rating system. Data were analysed within salinity group. Data were analyzed within salinity groups. Abbreviations: CS, Cache Slough; SDWSC, Sacramento River Deepwater Ship Channel; m, meter; mm/dd/yyyy, month/day/year; NTU, nephelometric turbidity unit; ${ }^{\circ} \mathrm{C}$, degree Celsius; - , missing data; <, less than; >, greater than]

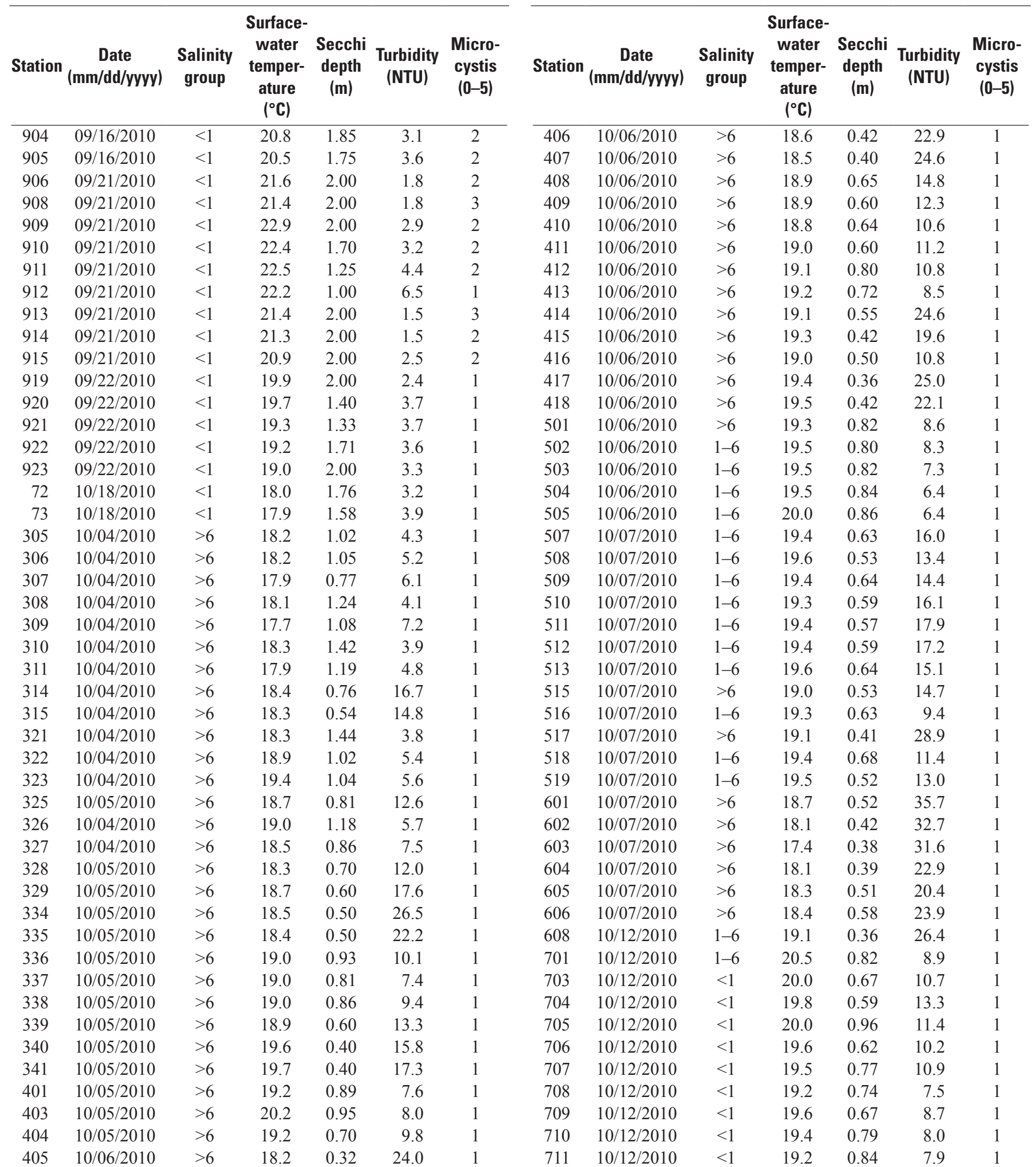


Table 4-2. Surface-water temperature, Secchi depth, turbidity, and Microcystis rating data collected during the fall midwater-trawl sampling survey in 2005, 2006, 2010, and 2011. - Continued

[Latitude and longitude of sampling stations are in table 4-1. Microcystis: see figure 5 for visual rating system. Data were analysed within salinity group. Data were analyzed within salinity groups. Abbreviations: CS, Cache Slough; SDWSC, Sacramento River Deepwater Ship Channel; m, meter; mm/dd/yyyy, month/day/year; NTU, nephelometric turbidity unit; ${ }^{\circ} \mathrm{C}$, degree Celsius; - , missing data; $<$, less than; $>$, greater than]

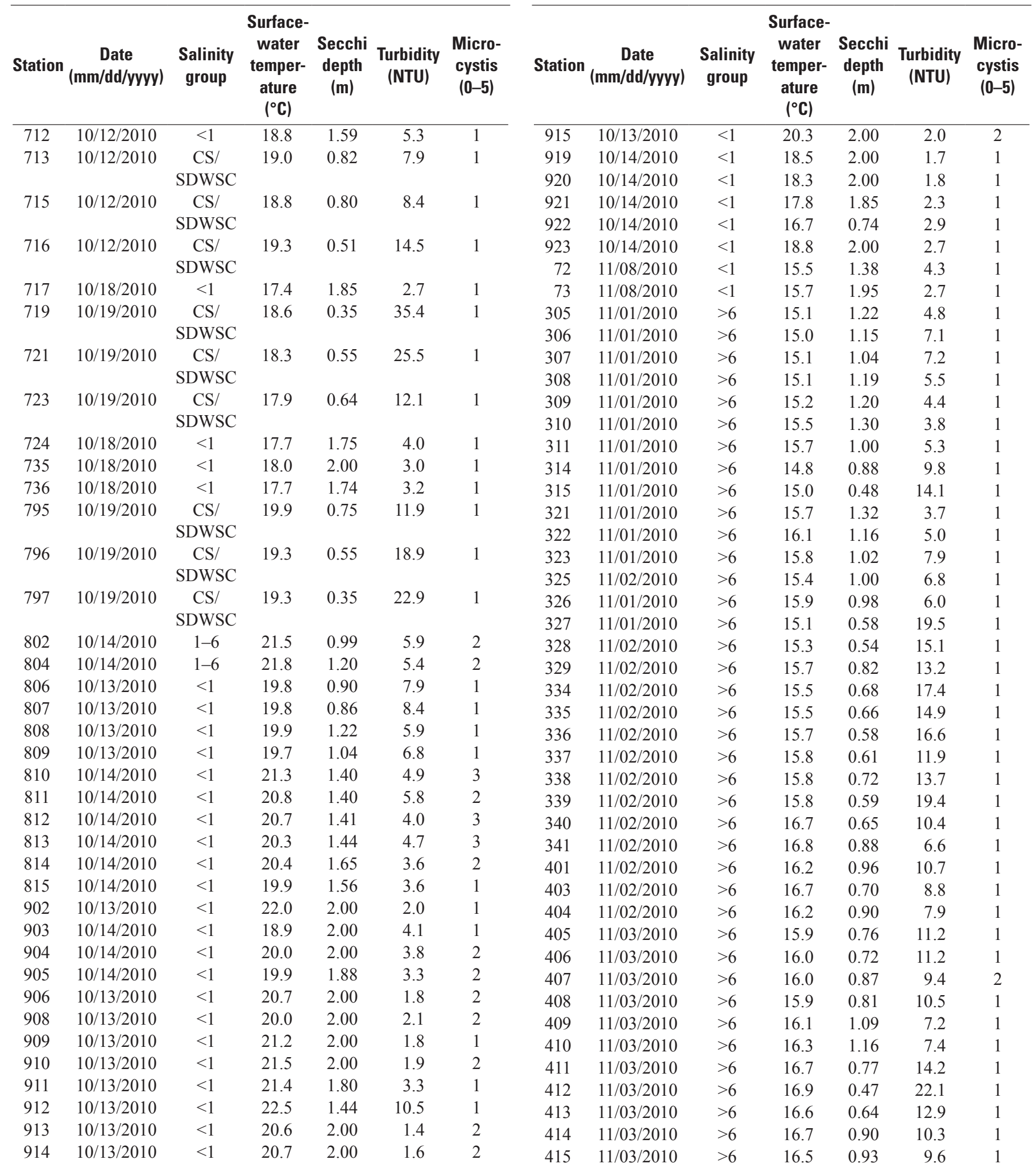


Table 4-2. Surface-water temperature, Secchi depth, turbidity, and Microcystis rating data collected during the fall midwater-trawl sampling survey in 2005, 2006, 2010, and 2011.-Continued

[Latitude and longitude of sampling stations are in table 4-1. Microcystis: see figure 5 for visual rating system. Data were analysed within salinity group. Data were analyzed within salinity groups. Abbreviations: CS, Cache Slough; SDWSC, Sacramento River Deepwater Ship Channel; m, meter; mm/dd/yyyy, month/day/year; NTU, nephelometric turbidity unit; ${ }^{\circ} \mathrm{C}$, degree Celsius; - , missing data; <, less than; >, greater than]

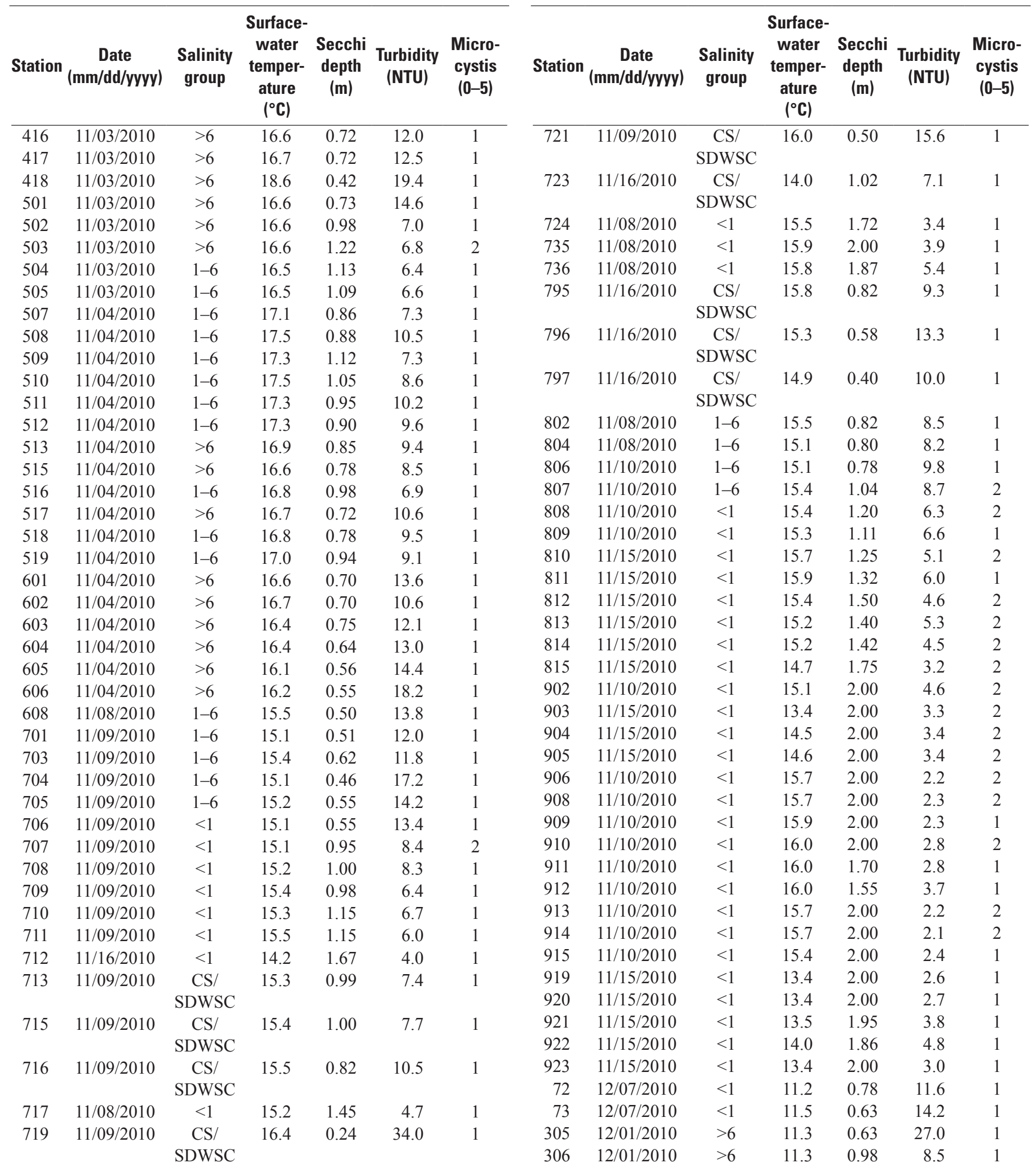


Table 4-2. Surface-water temperature, Secchi depth, turbidity, and Microcystis rating data collected during the fall midwater-trawl sampling survey in 2005, 2006, 2010, and 2011. - Continued

[Latitude and longitude of sampling stations are in table 4-1. Microcystis: see figure 5 for visual rating system. Data were analysed within salinity group. Data were analyzed within salinity groups. Abbreviations: CS, Cache Slough; SDWSC, Sacramento River Deepwater Ship Channel; m, meter; mm/dd/yyyy, month/day/year; NTU, nephelometric turbidity unit; ${ }^{\circ} \mathrm{C}$, degree Celsius; - , missing data; <, less than; >, greater than]

\begin{tabular}{|c|c|c|c|c|c|c|c|c|c|c|c|c|c|}
\hline Station & $\begin{array}{c}\text { Date } \\
\text { (mm/dd/yyyy) }\end{array}$ & $\begin{array}{c}\text { Salinity } \\
\text { group }\end{array}$ & $\begin{array}{l}\text { Surface- } \\
\text { water } \\
\text { temper- } \\
\text { ature } \\
\left({ }^{\circ} \mathrm{C}\right)\end{array}$ & $\begin{array}{c}\text { Secchi } \\
\text { depth } \\
\text { (m) }\end{array}$ & $\begin{array}{c}\text { Turbidity } \\
\text { (NTU) }\end{array}$ & $\begin{array}{c}\text { Micro- } \\
\text { cystis } \\
(0-5)\end{array}$ & Station & $\begin{array}{c}\text { Date } \\
\text { (mm/dd/yyyy) }\end{array}$ & $\begin{array}{c}\text { Salinity } \\
\text { group }\end{array}$ & $\begin{array}{l}\text { Surface- } \\
\text { water } \\
\text { temper- } \\
\text { ature } \\
\left({ }^{\circ} \mathrm{C}\right)\end{array}$ & $\begin{array}{c}\text { Secchi } \\
\text { depth } \\
\text { (m) }\end{array}$ & $\begin{array}{c}\text { Turbidity } \\
\text { (NTU) }\end{array}$ & $\begin{array}{c}\text { Micro- } \\
\text { cystis } \\
(0-5)\end{array}$ \\
\hline 307 & $12 / 01 / 2010$ & $>6$ & 11.3 & 0.76 & 9.8 & 1 & 509 & $12 / 07 / 2010$ & $1-6$ & 10.7 & 0.67 & 12.1 & 1 \\
\hline 308 & $12 / 01 / 2010$ & $>6$ & 11.2 & 0.37 & 27.0 & 1 & 510 & $12 / 07 / 2010$ & $1-6$ & 10.8 & 0.64 & 12.9 & 1 \\
\hline 311 & $12 / 02 / 2010$ & $>6$ & 11.0 & 0.70 & 15.9 & 1 & 513 & $12 / 07 / 2010$ & $1-6$ & 10.7 & 0.76 & 13.8 & 1 \\
\hline 314 & $12 / 01 / 2010$ & $>6$ & 11.2 & 0.64 & 10.3 & 1 & 515 & $12 / 06 / 2010$ & $>6$ & 11.6 & 0.58 & 12.9 & 1 \\
\hline 315 & $12 / 01 / 2010$ & $>6$ & 11.3 & 0.71 & 10.5 & 1 & 516 & $12 / 07 / 2010$ & $1-6$ & 10.3 & 0.68 & 11.5 & 1 \\
\hline 321 & $12 / 02 / 2010$ & $>6$ & 11.0 & 1.24 & 6.5 & 1 & 517 & $12 / 07 / 2010$ & $1-6$ & 10.6 & 0.51 & 22.9 & 1 \\
\hline 322 & $12 / 02 / 2010$ & $>6$ & 10.7 & 0.78 & 13.2 & 1 & 518 & $12 / 07 / 2010$ & $1-6$ & 10.9 & 0.51 & 27.8 & 1 \\
\hline 323 & $12 / 02 / 2010$ & $>6$ & 11.1 & 0.82 & 14.5 & 1 & 519 & $12 / 07 / 2010$ & $1-6$ & 10.4 & 0.77 & 9.6 & 1 \\
\hline 328 & $12 / 01 / 2010$ & $>6$ & 11.0 & 0.71 & 9.0 & 1 & 604 & $12 / 06 / 2010$ & $>6$ & 11.5 & 0.61 & 19.6 & 1 \\
\hline 329 & $12 / 02 / 2010$ & $>6$ & 10.8 & 0.52 & 20.0 & 1 & 605 & $12 / 06 / 2010$ & $1-6$ & 11.3 & 0.47 & 23.3 & 1 \\
\hline 334 & $12 / 01 / 2010$ & $>6$ & 11.0 & 0.68 & 11.3 & 1 & 606 & $12 / 06 / 2010$ & $1-6$ & 11.5 & 0.34 & 30.7 & 1 \\
\hline 335 & $12 / 01 / 2010$ & $>6$ & 11.1 & 0.70 & 11.0 & 1 & 608 & $12 / 07 / 2010$ & $1-6$ & 11.3 & 0.59 & 16.6 & 1 \\
\hline 336 & $12 / 02 / 2010$ & $>6$ & 10.4 & 0.59 & 13.4 & 1 & 701 & $12 / 06 / 2010$ & $1-6$ & 10.5 & 0.61 & & 1 \\
\hline 337 & $12 / 02 / 2010$ & $>6$ & 11.1 & 0.77 & 11.5 & 1 & 703 & $12 / 06 / 2010$ & $<1$ & 10.4 & 0.76 & & 1 \\
\hline 338 & $12 / 02 / 2010$ & $>6$ & 11.0 & 0.68 & 10.7 & 1 & 704 & $12 / 06 / 2010$ & $<1$ & 10.3 & 0.67 & & 1 \\
\hline 339 & $12 / 02 / 2010$ & $>6$ & 11.2 & 0.54 & 23.0 & 1 & 705 & $12 / 06 / 2010$ & $<1$ & 10.1 & 0.78 & & 1 \\
\hline 340 & $12 / 02 / 2010$ & $>6$ & 11.0 & 0.28 & 73.5 & 1 & 706 & $12 / 06 / 2010$ & $<1$ & 10.4 & 0.92 & & 1 \\
\hline 341 & $12 / 02 / 2010$ & $>6$ & 11.0 & 0.38 & 35.0 & 1 & 707 & $12 / 06 / 2010$ & $<1$ & 10.4 & 1.11 & & 1 \\
\hline 401 & $12 / 03 / 2010$ & $>6$ & 10.8 & 0.77 & 11.5 & 1 & 708 & $12 / 06 / 2010$ & $<1$ & 10.7 & 0.95 & & 1 \\
\hline 411 & $12 / 03 / 2010$ & $>6$ & 11.0 & 0.58 & 19.2 & 1 & 716 & $12 / 06 / 2010$ & $\mathrm{CS} /$ & 10.7 & 0.98 & & 1 \\
\hline 412 & $12 / 03 / 2010$ & $>6$ & 10.9 & 0.39 & 29.0 & 1 & & & SDWSC & & & & \\
\hline 413 & $12 / 03 / 2010$ & $>6$ & 10.9 & 0.50 & 23.2 & 1 & 717 & $12 / 07 / 2010$ & $<1$ & 10.9 & 0.72 & 9.2 & 1 \\
\hline 414 & $12 / 06 / 2010$ & $>6$ & 11.0 & 0.62 & 18.8 & 1 & 719 & $12 / 08 / 2010$ & $\mathrm{CS} /$ & 10.9 & 0.38 & 26.4 & 1 \\
\hline 415 & $12 / 06 / 2010$ & $>6$ & 11.1 & 0.60 & 19.7 & 1 & & & SDWSC & & & & \\
\hline 416 & $12 / 06 / 2010$ & $>6$ & 11.0 & 0.59 & 16.7 & 1 & 721 & $12 / 06 / 2010$ & $\mathrm{CS} /$ & 11.3 & 0.72 & & 1 \\
\hline 417 & $12 / 06 / 2010$ & $>6$ & 11.0 & 0.69 & 13.5 & 1 & & & SDWSC & & & & \\
\hline 418 & $12 / 06 / 2010$ & $>6$ & 11.2 & 0.53 & 14.8 & 1 & 723 & $12 / 08 / 2010$ & $\mathrm{CS} /$ & 11.1 & 1.04 & 8.1 & 1 \\
\hline 501 & $12 / 03 / 2010$ & $>6$ & 11.0 & 0.52 & 18.8 & 1 & & & SDWSC & & & & \\
\hline 502 & $12 / 03 / 2010$ & $>6$ & 10.8 & 0.49 & 22.5 & 1 & 724 & $12 / 07 / 2010$ & $<1$ & 11.3 & 0.66 & 14.8 & 1 \\
\hline 503 & $12 / 03 / 2010$ & $>6$ & 10.7 & 0.59 & 17.2 & 1 & 735 & $12 / 07 / 2010$ & $<1$ & 11.9 & 0.70 & 11.1 & 2 \\
\hline 504 & $12 / 03 / 2010$ & $>6$ & 10.6 & 0.42 & 27.2 & 1 & 736 & $12 / 07 / 2010$ & $<1$ & 11.7 & 0.65 & 11.9 & 2 \\
\hline 505 & $12 / 07 / 2010$ & $1-6$ & 10.6 & 0.89 & 7.6 & 1 & 795 & $12 / 08 / 2010$ & $\mathrm{CS} /$ & 11.9 & 0.68 & 9.7 & 1 \\
\hline 507 & $12 / 07 / 2010$ & $1-6$ & 10.7 & 0.79 & 9.0 & 1 & & & SDWSC & & & & \\
\hline 508 & $12 / 07 / 2010$ & $1-6$ & 10.8 & 0.67 & 10.7 & 1 & & & & & & & \\
\hline
\end{tabular}


Table 4-2. Surface-water temperature, Secchi depth, turbidity, and Microcystis rating data collected during the fall midwater-trawl sampling survey in 2005, 2006, 2010, and 2011.-Continued

[Latitude and longitude of sampling stations are in table 4-1. Microcystis: see figure 5 for visual rating system. Data were analysed within salinity group. Data were analyzed within salinity groups. Abbreviations: CS, Cache Slough; SDWSC, Sacramento River Deepwater Ship Channel; m, meter; mm/dd/yyyy, month/day/year; NTU, nephelometric turbidity unit; ${ }^{\circ} \mathrm{C}$, degree Celsius; - , missing data; <, less than; >, greater than]

\begin{tabular}{|c|c|c|c|c|c|c|c|c|c|c|c|c|c|}
\hline Station & $\begin{array}{c}\text { Date } \\
\text { (mm/dd/yyyy) }\end{array}$ & $\begin{array}{c}\text { Salinity } \\
\text { group }\end{array}$ & $\begin{array}{l}\text { Surface- } \\
\text { water } \\
\text { temper- } \\
\text { ature } \\
\left({ }^{\circ} \mathrm{C}\right)\end{array}$ & $\begin{array}{c}\text { Secchi } \\
\text { depth } \\
\text { (m) }\end{array}$ & $\begin{array}{l}\text { Turbidity } \\
\text { (NTU) }\end{array}$ & $\begin{array}{c}\text { Micro- } \\
\text { cystis } \\
(0-5)\end{array}$ & Station & $\begin{array}{c}\text { Date } \\
\text { (mm/dd/yyyy) }\end{array}$ & $\begin{array}{c}\text { Salinity } \\
\text { group }\end{array}$ & $\begin{array}{l}\text { Surface- } \\
\text { water } \\
\text { temper- } \\
\text { ature } \\
\left({ }^{\circ} \mathrm{C}\right)\end{array}$ & $\begin{array}{c}\text { Secchi } \\
\text { depth } \\
\text { (m) }\end{array}$ & $\begin{array}{c}\text { Turbidity } \\
\text { (NTU) }\end{array}$ & $\begin{array}{c}\text { Micro- } \\
\text { cystis } \\
(0-5)\end{array}$ \\
\hline \multirow[t]{2}{*}{796} & $12 / 08 / 2010$ & $\mathrm{CS} /$ & 11.3 & 0.42 & 25.0 & 1 & 323 & $09 / 06 / 2011$ & $>6$ & 19.1 & 0.82 & 8.2 & 1 \\
\hline & & SDWSC & & & & & 325 & 09/07/2011 & $>6$ & 18.9 & 0.82 & 12.6 & 1 \\
\hline 797 & $12 / 08 / 2010$ & $\mathrm{CS} /$ & 11.1 & 0.31 & 51.4 & 1 & 326 & 09/06/2011 & $>6$ & 20.6 & 0.89 & 6.4 & 1 \\
\hline 802 & $12 / 01 / 2010$ & $<1$ & 10.2 & 1.05 & 6.8 & 1 & 328 & 09/07/2011 & $>6$ & 18.6 & 0.66 & 14.6 & 1 \\
\hline 804 & $12 / 01 / 2010$ & $<1$ & 10.4 & 0.99 & 6.8 & 1 & 329 & 09/07/2011 & $>6$ & 18.8 & 0.68 & 12.1 & 1 \\
\hline 806 & $12 / 01 / 2010$ & $<1$ & 10.3 & 1.24 & 6.1 & 1 & 334 & 09/07/2011 & $>6$ & 18.5 & 0.42 & 30.5 & 1 \\
\hline 807 & $12 / 01 / 2010$ & $<1$ & 10.5 & 1.32 & 6.2 & 1 & 335 & 09/07/2011 & $>6$ & 18.6 & 0.33 & 35.8 & 1 \\
\hline 808 & $12 / 01 / 2010$ & $<1$ & 10.6 & 1.35 & 4.8 & 1 & 336 & 09/07/2011 & $>6$ & 19.2 & 0.48 & 16.4 & 1 \\
\hline 809 & $12 / 01 / 2010$ & $<1$ & 10.3 & 1.36 & 5.3 & 1 & 337 & 09/07/2011 & $>6$ & 19.2 & 0.78 & 9.2 & 1 \\
\hline 813 & $12 / 03 / 2010$ & $<1$ & 10.1 & 1.72 & 3.7 & 1 & 341 & 09/07/2011 & $>6$ & 19.9 & 0.51 & 24.2 & 1 \\
\hline 814 & $12 / 03 / 2010$ & $<1$ & 10.0 & 1.68 & 4.4 & 1 & 401 & 09/07/2011 & $>6$ & 20.2 & 0.77 & 14.7 & 1 \\
\hline 815 & $12 / 03 / 2010$ & $<1$ & 9.8 & 1.70 & 3.7 & 1 & 403 & 09/07/2011 & $>6$ & 21.0 & 0.38 & 30.8 & 1 \\
\hline 902 & $12 / 01 / 2010$ & $<1$ & 9.8 & 2.00 & 1.5 & 1 & 404 & 09/07/2011 & $>6$ & 19.8 & 0.45 & 21.0 & 1 \\
\hline 903 & $12 / 02 / 2010$ & $<1$ & 9.4 & 1.30 & 6.0 & 1 & 405 & 09/08/2011 & $1-6$ & 19.1 & 0.27 & 104.0 & 1 \\
\hline 904 & $12 / 03 / 2010$ & $<1$ & 9.7 & 1.90 & 3.5 & 1 & 406 & $09 / 08 / 2011$ & $1-6$ & 19.1 & 0.24 & 88.9 & 1 \\
\hline 905 & $12 / 03 / 2010$ & $<1$ & 9.7 & 1.68 & 3.6 & 1 & 407 & 09/08/2011 & $1-6$ & 19.4 & 0.29 & 81.2 & 1 \\
\hline 906 & $12 / 03 / 2010$ & $<1$ & 9.8 & 2.00 & 3.0 & 1 & 408 & 09/08/2011 & $1-6$ & 19.4 & 0.23 & 60.3 & 2 \\
\hline 908 & $12 / 03 / 2010$ & $<1$ & 9.8 & 1.82 & 3.7 & 1 & 409 & 09/08/2011 & $1-6$ & 19.6 & 0.42 & 47.8 & 2 \\
\hline 909 & $12 / 02 / 2010$ & $<1$ & 9.9 & 2.00 & 2.0 & 1 & 410 & 09/08/2011 & $1-6$ & 19.6 & 0.41 & 44.7 & 2 \\
\hline 910 & $12 / 02 / 2010$ & $<1$ & 9.7 & 2.00 & 2.2 & 1 & 411 & 09/08/2011 & $1-6$ & 19.7 & 0.66 & 60.6 & 2 \\
\hline 911 & $12 / 02 / 2010$ & $<1$ & 10.6 & 1.99 & 2.2 & 1 & 412 & 09/08/2011 & $1-6$ & 19.8 & 0.32 & 68.6 & 1 \\
\hline 922 & $12 / 02 / 2010$ & $<1$ & 10.3 & 2.00 & 2.8 & 1 & 502 & 09/08/2011 & $1-6$ & 20.1 & 0.32 & 50.5 & 2 \\
\hline 923 & $12 / 02 / 2010$ & $<1$ & 9.4 & 0.84 & 8.2 & 1 & 503 & 09/08/2011 & $1-6$ & 20.7 & 0.32 & 56.0 & 2 \\
\hline 72 & 09/19/2011 & $<1$ & 21.3 & 1.40 & 11.5 & 1 & 504 & 09/08/2011 & $1-6$ & 20.6 & 0.39 & 61.7 & 2 \\
\hline 73 & 09/19/2011 & $<1$ & 20.3 & 1.26 & 16.7 & 1 & 505 & $09 / 08 / 2011$ & $1-6$ & 20.3 & 0.32 & 49.1 & 2 \\
\hline 305 & 09/06/2011 & $>6$ & 17.8 & 0.98 & 8.2 & 1 & 507 & 09/13/2011 & $<1$ & 20.5 & 0.47 & 48.4 & 2 \\
\hline 306 & 09/06/2011 & $>6$ & 18.2 & 0.99 & 6.4 & 1 & 508 & $09 / 13 / 2011$ & $<1$ & 20.9 & 0.43 & 47.8 & 2 \\
\hline 307 & 09/06/2011 & $>6$ & 18.0 & 1.09 & 6.5 & 1 & 509 & 09/13/2011 & $<1$ & 20.8 & 0.51 & 43.4 & 2 \\
\hline 308 & 09/06/2011 & $>6$ & 18.2 & 1.19 & 5.7 & 1 & 510 & 09/13/2011 & $<1$ & 20.9 & 0.58 & 43.3 & 2 \\
\hline 309 & $09 / 06 / 2011$ & $>6$ & 18.5 & 1.05 & 5.6 & 1 & 511 & 09/13/2011 & $<1$ & 21.1 & 0.48 & 43.3 & 2 \\
\hline 310 & $09 / 06 / 2011$ & $>6$ & 18.8 & 1.05 & 5.8 & 1 & 512 & 09/13/2011 & $<1$ & 20.9 & 0.41 & 52.6 & 2 \\
\hline 311 & $09 / 06 / 2011$ & $>6$ & 18.6 & 1.00 & 6.2 & 1 & 513 & $09 / 13 / 2011$ & $<1$ & 21.0 & 0.49 & 44.3 & 2 \\
\hline 314 & $09 / 06 / 2011$ & $>6$ & 17.9 & 0.75 & 9.6 & 1 & 515 & 09/13/2011 & $1-6$ & 19.4 & 0.39 & 59.4 & 2 \\
\hline 315 & 09/06/2011 & $>6$ & 18.4 & 0.93 & 14.7 & 1 & 516 & 09/13/2011 & $1-6$ & 19.6 & 0.31 & 111.0 & \\
\hline 321 & 09/06/2011 & $>6$ & 19.7 & 0.92 & 7.2 & 1 & 517 & 09/13/2011 & $1-6$ & 19.9 & 0.28 & 97.0 & 2 \\
\hline 322 & 09/06/2011 & $>6$ & 18.9 & 0.72 & 7.2 & 1 & 518 & 09/13/2011 & $1-6$ & 19.9 & 0.21 & 85.0 & 2 \\
\hline
\end{tabular}


Table 4-2. Surface-water temperature, Secchi depth, turbidity, and Microcystis rating data collected during the fall midwater-trawl sampling survey in 2005, 2006, 2010, and 2011. - Continued

[Latitude and longitude of sampling stations are in table 4-1. Microcystis: see figure 5 for visual rating system. Data were analysed within salinity group. Data were analyzed within salinity groups. Abbreviations: CS, Cache Slough; SDWSC, Sacramento River Deepwater Ship Channel; m, meter; mm/dd/yyyy, month/day/year; NTU, nephelometric turbidity unit; ${ }^{\circ} \mathrm{C}$, degree Celsius; - , missing data; $<$, less than; $>$, greater than]

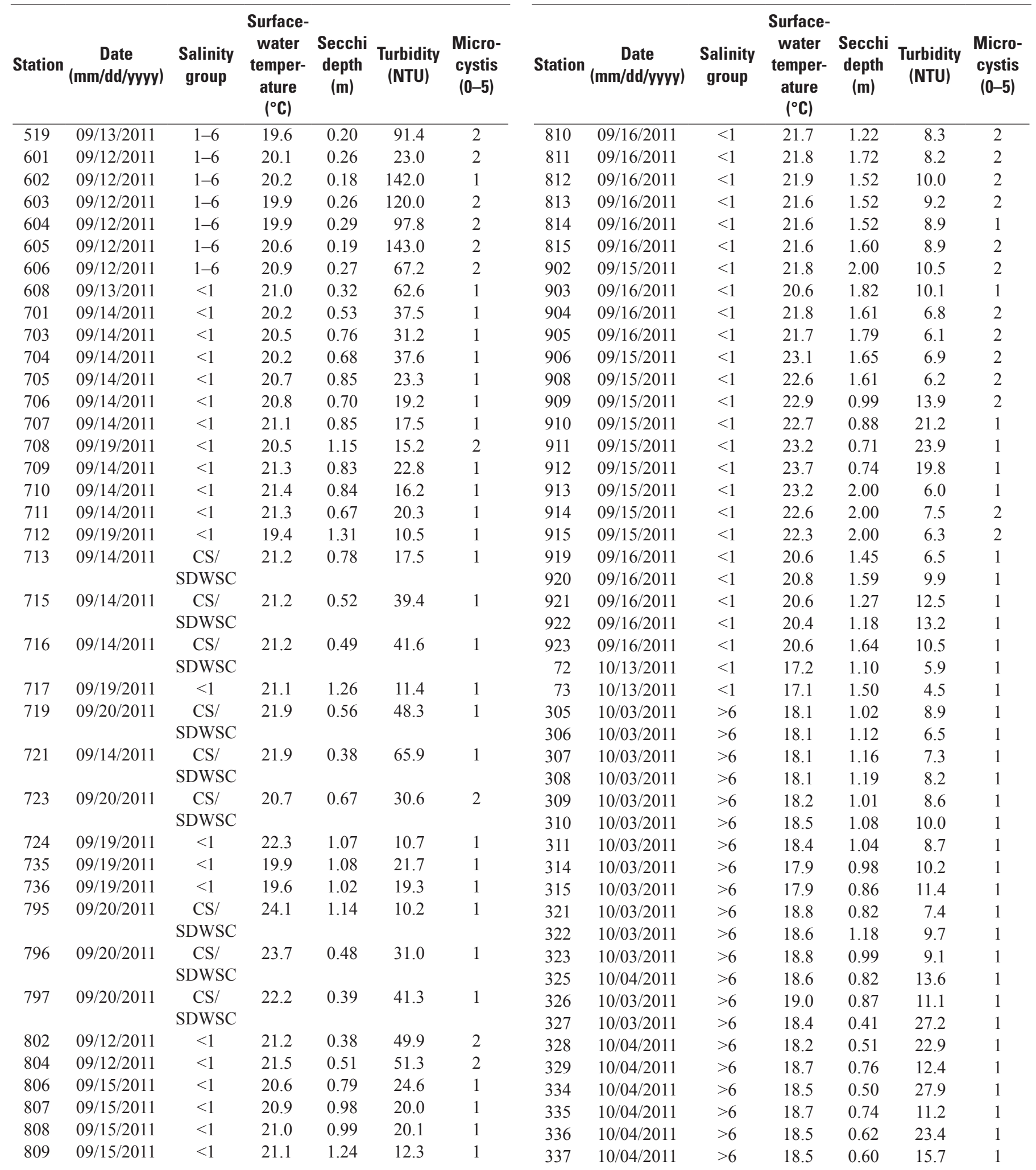


Table 4-2. Surface-water temperature, Secchi depth, turbidity, and Microcystis rating data collected during the fall midwater-trawl sampling survey in 2005, 2006, 2010, and 2011.-Continued

[Latitude and longitude of sampling stations are in table 4-1. Microcystis: see figure 5 for visual rating system. Data were analysed within salinity group. Data were analyzed within salinity groups. Abbreviations: CS, Cache Slough; SDWSC, Sacramento River Deepwater Ship Channel; m, meter; mm/dd/yyyy, month/day/year; NTU, nephelometric turbidity unit; ${ }^{\circ} \mathrm{C}$, degree Celsius; - , missing data; <, less than; >, greater than]

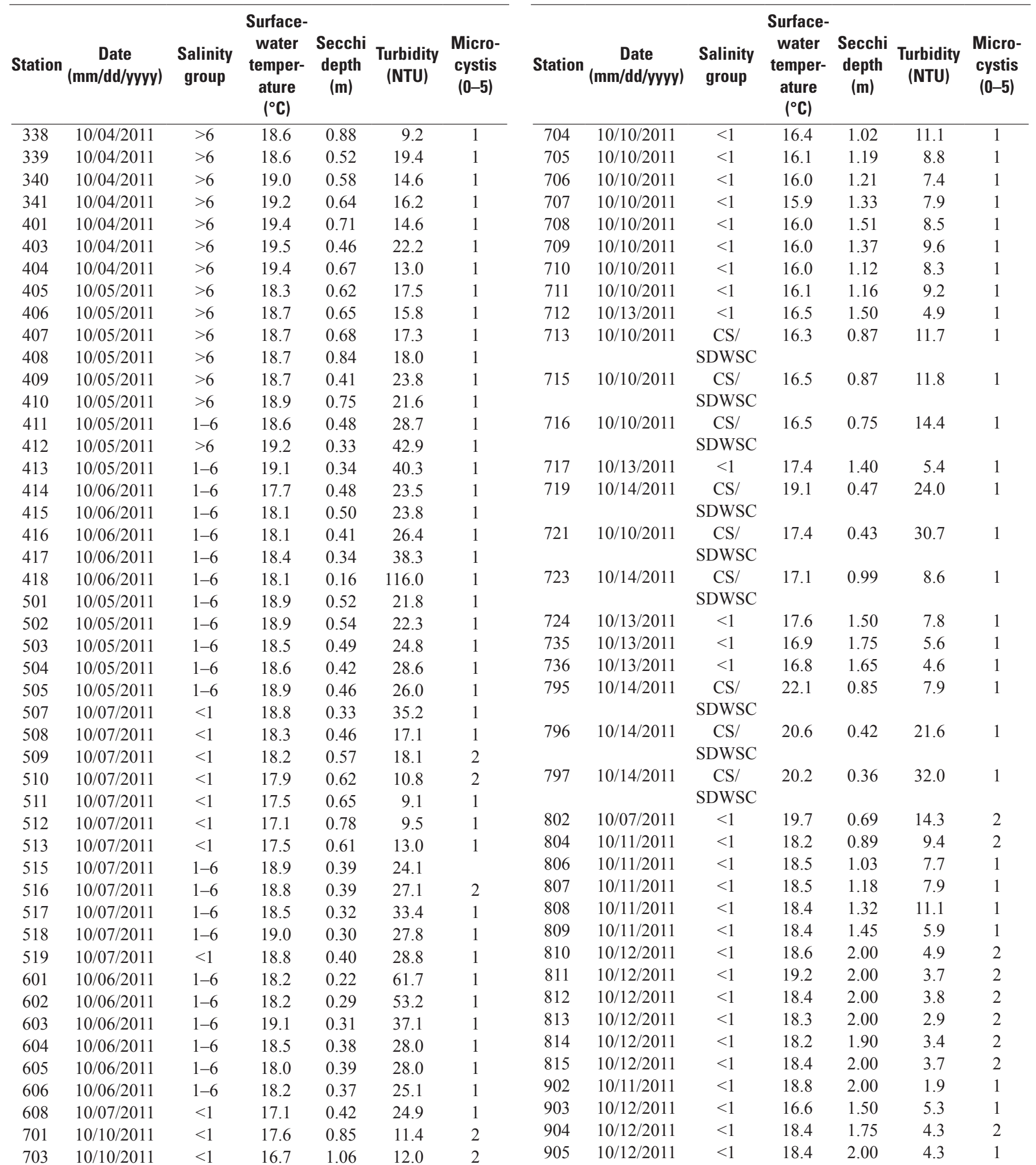


Table 4-2. Surface-water temperature, Secchi depth, turbidity, and Microcystis rating data collected during the fall midwater-trawl sampling survey in 2005, 2006, 2010, and 2011. - Continued

[Latitude and longitude of sampling stations are in table 4-1. Microcystis: see figure 5 for visual rating system. Data were analysed within salinity group. Data were analyzed within salinity groups. Abbreviations: CS, Cache Slough; SDWSC, Sacramento River Deepwater Ship Channel; m, meter; mm/dd/yyyy, month/day/year; NTU, nephelometric turbidity unit; ${ }^{\circ} \mathrm{C}$, degree Celsius; - , missing data; $<$, less than; $>$, greater than]

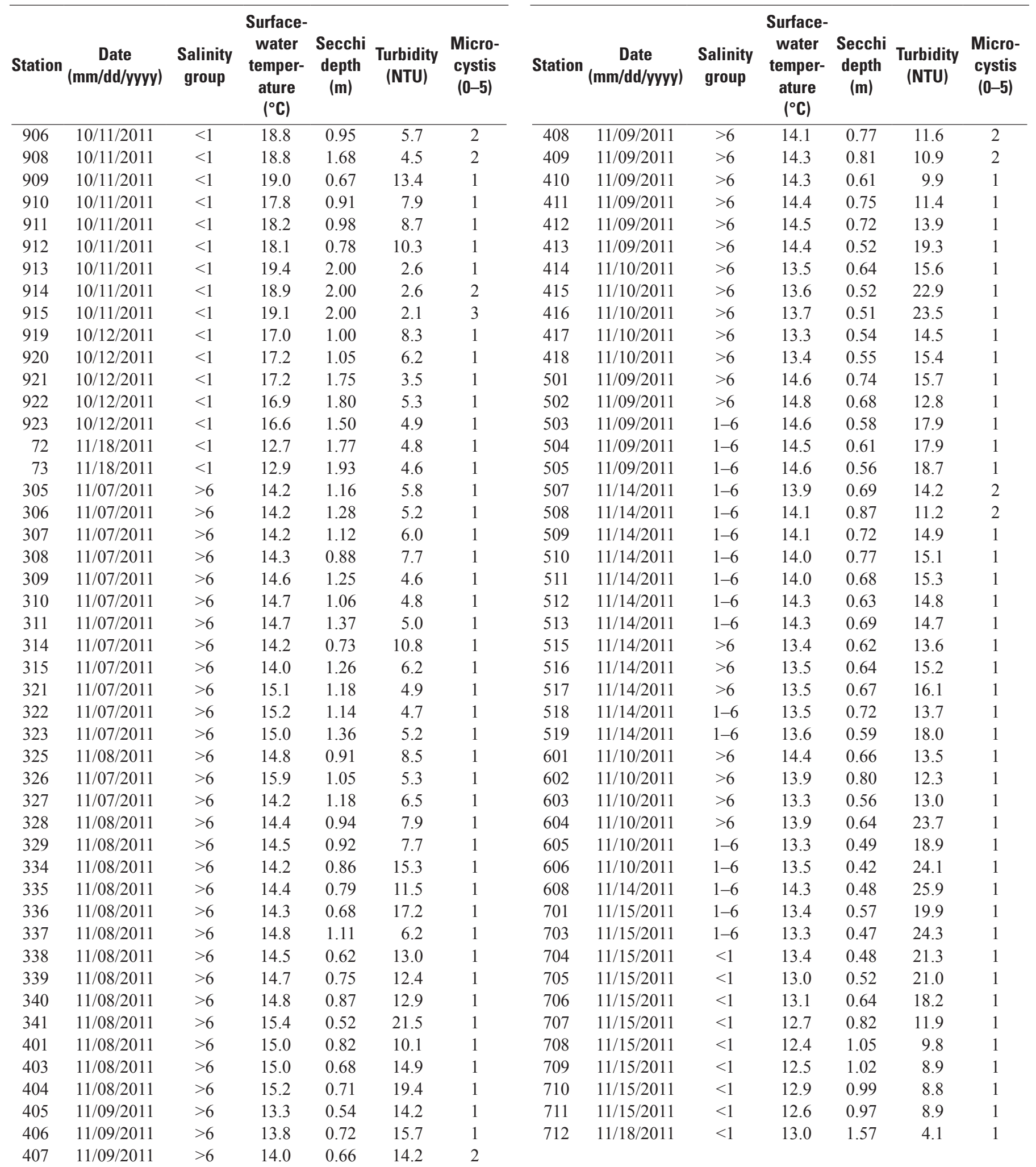


Table 4-2. Surface-water temperature, Secchi depth, turbidity, and Microcystis rating data collected during the fall midwater-trawl sampling survey in 2005, 2006, 2010, and 2011.-Continued

[Latitude and longitude of sampling stations are in table 4-1. Microcystis: see figure 5 for visual rating system. Data were analysed within salinity group. Data were analyzed within salinity groups. Abbreviations: CS, Cache Slough; SDWSC, Sacramento River Deepwater Ship Channel; m, meter; mm/dd/yyyy, month/day/year; NTU, nephelometric turbidity unit; ${ }^{\circ} \mathrm{C}$, degree Celsius; - , missing data; <, less than; >, greater than]

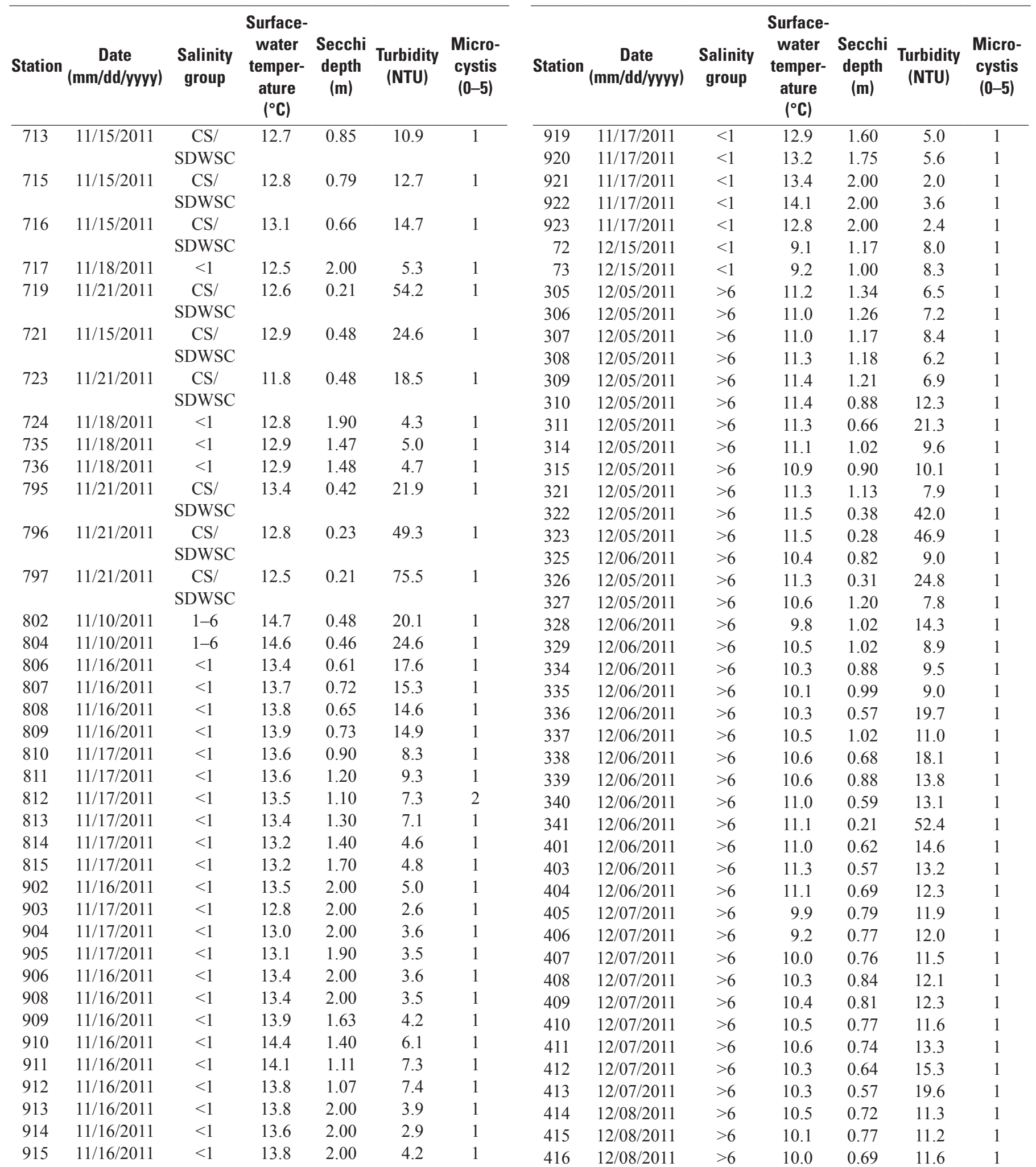


Table 4-2. Surface-water temperature, Secchi depth, turbidity, and Microcystis rating data collected during the fall midwater-trawl sampling survey in 2005, 2006, 2010, and 2011.-Continued

[Latitude and longitude of sampling stations are in table 4-1. Microcystis: see figure 5 for visual rating system. Data were analysed within salinity group. Data were analyzed within salinity groups. Abbreviations: CS, Cache Slough; SDWSC, Sacramento River Deepwater Ship Channel; m, meter; mm/dd/yyyy, month/day/year; NTU, nephelometric turbidity unit; ${ }^{\circ} \mathrm{C}$, degree Celsius; - , missing data; <, less than; >, greater than]

\begin{tabular}{|c|c|c|c|c|c|c|c|c|c|c|c|c|c|}
\hline Station & $\begin{array}{c}\text { Date } \\
\text { (mm/dd/yyyy) }\end{array}$ & $\begin{array}{c}\text { Salinity } \\
\text { group }\end{array}$ & $\begin{array}{l}\text { Surface- } \\
\text { water } \\
\text { temper- } \\
\text { ature } \\
\left({ }^{\circ} \mathrm{C}\right)\end{array}$ & $\begin{array}{c}\text { Secchi } \\
\text { depth } \\
\text { (m) }\end{array}$ & $\begin{array}{c}\text { Turbidity } \\
\text { (NTU) }\end{array}$ & $\begin{array}{l}\text { Micro- } \\
\text { cystis } \\
(0-5)\end{array}$ & Station & $\begin{array}{c}\text { Date } \\
\text { (mm/dd/yyyy) }\end{array}$ & $\begin{array}{c}\text { Salinity } \\
\text { group }\end{array}$ & $\begin{array}{c}\text { Surface- } \\
\text { water } \\
\text { temper- } \\
\text { ature } \\
\left({ }^{\circ} \mathrm{C}\right)\end{array}$ & $\begin{array}{c}\text { Secchi } \\
\text { depth } \\
\text { (m) }\end{array}$ & $\begin{array}{l}\text { Turbidity } \\
\text { (NTU) }\end{array}$ & $\begin{array}{l}\text { Micro- } \\
\text { cystis } \\
(0-5)\end{array}$ \\
\hline 417 & $12 / 08 / 2011$ & $>6$ & 10.3 & 0.63 & 12.5 & 1 & 719 & $12 / 16 / 2011$ & $\mathrm{CS} /$ & 8.9 & 0.32 & 37.8 & 1 \\
\hline 418 & $12 / 08 / 2011$ & $>6$ & 10.6 & 0.59 & 32.6 & 1 & & & SDWSC & & & & \\
\hline 501 & $12 / 07 / 2011$ & $>6$ & 10.4 & 0.74 & 20.7 & 1 & 721 & $12 / 12 / 2011$ & CS/ & 8.2 & 0.52 & 19.8 & 1 \\
\hline 502 & $12 / 07 / 2011$ & $>6$ & 10.6 & 0.72 & 10.6 & 1 & & & SDWSC & & & & \\
\hline 503 & $12 / 07 / 2011$ & $>6$ & 10.9 & 0.52 & 15.6 & 1 & 723 & $12 / 16 / 2011$ & CS/ & 8.6 & 0.83 & 10.1 & 1 \\
\hline 504 & $12 / 07 / 2011$ & $>6$ & 10.6 & 0.58 & 13.5 & 1 & & & SDWSC & & & & \\
\hline 505 & $12 / 07 / 2011$ & $>6$ & 10.6 & 0.66 & 12.6 & 1 & 724 & $12 / 15 / 2011$ & $<1$ & 9.2 & 1.00 & 7.9 & 1 \\
\hline 507 & $12 / 09 / 2011$ & $1-6$ & 9.8 & 0.65 & 15.1 & 1 & 735 & 12/15/2011 & $<1$ & 9.5 & 1.10 & 8.5 & 1 \\
\hline 508 & $12 / 09 / 2011$ & $1-6$ & 10.0 & 0.68 & 15.9 & 1 & 736 & $12 / 15 / 2011$ & $<1$ & 9.2 & 1.09 & 9.3 & 1 \\
\hline 509 & $12 / 09 / 2011$ & $1-6$ & 10.2 & 0.72 & 12.9 & 1 & 795 & 12/16/2011 & $\mathrm{CS} /$ & 10.4 & 0.77 & 9.4 & 1 \\
\hline 510 & $12 / 09 / 2011$ & $1-6$ & 10.1 & 0.79 & 12.9 & 1 & & & SDWSC & & & & \\
\hline 511 & $12 / 09 / 2011$ & $1-6$ & 10.2 & 0.78 & 16.7 & 1 & 796 & $12 / 16 / 2011$ & $\mathrm{CS} /$ & 9.5 & 0.24 & 37.8 & 1 \\
\hline 512 & $12 / 09 / 2011$ & $1-6$ & 10.3 & 0.70 & 17.8 & 1 & & & SDWSC & & & & \\
\hline 513 & $12 / 09 / 2011$ & $1-6$ & 10.5 & 0.63 & 13.4 & 1 & 797 & $12 / 16 / 2011$ & $\mathrm{CS} /$ & 9.1 & 0.17 & 72.7 & 1 \\
\hline 515 & $12 / 09 / 2011$ & $>6$ & 9.3 & 0.63 & 21.3 & 1 & & & SDWSC & & & & \\
\hline 516 & $12 / 09 / 2011$ & $1-6$ & 9.5 & 0.61 & 21.8 & 1 & 802 & $12 / 09 / 2011$ & $1-6$ & 10.8 & 0.78 & 14.4 & 1 \\
\hline 517 & $12 / 09 / 2011$ & $1-6$ & 9.4 & 0.53 & 12.8 & 1 & 804 & 12/13/2011 & $1-6$ & 8.8 & 0.73 & 12.6 & 1 \\
\hline 518 & $12 / 09 / 2011$ & $1-6$ & 9.8 & 0.63 & 18.5 & 1 & 806 & 12/13/2011 & $<1$ & 8.5 & 0.84 & 10.4 & 1 \\
\hline 519 & $12 / 09 / 2011$ & $1-6$ & 9.6 & 0.62 & 16.7 & 1 & 807 & $12 / 13 / 2011$ & $<1$ & 8.9 & 0.99 & 8.1 & 1 \\
\hline 601 & $12 / 08 / 2011$ & $>6$ & 11.3 & 0.73 & 13.9 & 1 & 808 & $12 / 13 / 2011$ & $<1$ & 9.2 & 1.02 & 8.8 & 1 \\
\hline 602 & $12 / 08 / 2011$ & $>6$ & 10.9 & 0.49 & 21.2 & 1 & 809 & $12 / 13 / 2011$ & $<1$ & 9.3 & 0.98 & 8.7 & 1 \\
\hline 603 & $12 / 08 / 2011$ & $>6$ & 10.7 & 0.39 & 23.7 & 1 & 810 & 12/14/2011 & $<1$ & 9.5 & 1.34 & 8.1 & 1 \\
\hline 604 & $12 / 08 / 2011$ & $>6$ & 11.2 & 0.48 & 12.0 & 1 & 811 & $12 / 14 / 2011$ & $<1$ & 9.3 & 1.22 & 7.6 & 1 \\
\hline 605 & $12 / 08 / 2011$ & $>6$ & 10.2 & 0.49 & 15.2 & 1 & 812 & $12 / 14 / 2011$ & $<1$ & 9.3 & 1.08 & 8.3 & 1 \\
\hline 606 & $12 / 08 / 2011$ & $>6$ & 10.1 & 0.41 & 23.0 & 1 & 813 & $12 / 14 / 2011$ & $<1$ & 9.3 & 1.28 & 7.6 & 1 \\
\hline 608 & $12 / 09 / 2011$ & $1-6$ & 9.6 & 0.38 & 35.6 & 1 & 814 & $12 / 14 / 2011$ & $<1$ & 9.3 & 1.22 & 6.8 & 1 \\
\hline 701 & $12 / 12 / 2011$ & $1-6$ & 9.9 & 0.82 & 11.9 & 1 & 815 & $12 / 14 / 2011$ & $<1$ & 9.3 & 1.41 & 6.5 & 1 \\
\hline 703 & $12 / 12 / 2011$ & $1-6$ & 9.7 & 0.48 & 30.9 & 1 & 902 & 12/13/2011 & $<1$ & 9.0 & 2.00 & 3.2 & 1 \\
\hline 704 & $12 / 12 / 2011$ & $<1$ & 9.5 & 0.82 & 12.3 & 1 & 903 & $12 / 14 / 2011$ & $<1$ & 8.6 & 2.00 & 6.2 & 1 \\
\hline 705 & $12 / 12 / 2011$ & $<1$ & 9.3 & 0.91 & 11.6 & 1 & 904 & 12/14/2011 & $<1$ & 9.4 & 1.38 & 6.0 & 1 \\
\hline 706 & $12 / 12 / 2011$ & $<1$ & 9.4 & 0.83 & 10.5 & 1 & 905 & $12 / 14 / 2011$ & $<1$ & 9.2 & 1.42 & 6.2 & 1 \\
\hline 707 & $12 / 12 / 2011$ & $<1$ & 9.0 & 1.13 & 10.3 & 1 & 906 & 12/13/2011 & $<1$ & 9.3 & 1.69 & 4.3 & 1 \\
\hline 708 & $12 / 12 / 2011$ & $<1$ & 8.9 & 1.09 & 9.3 & 1 & 908 & $12 / 13 / 2011$ & $<1$ & 9.4 & 1.21 & 6.8 & 1 \\
\hline 709 & $12 / 12 / 2011$ & $<1$ & 9.0 & 1.12 & 8.6 & 1 & 909 & $12 / 13 / 2011$ & $<1$ & 9.3 & 2.00 & 4.1 & 1 \\
\hline 710 & $12 / 12 / 2011$ & $<1$ & 8.9 & 1.03 & 9.7 & 1 & 910 & 12/13/2011 & $<1$ & 9.5 & 1.30 & 5.7 & 1 \\
\hline 711 & $12 / 12 / 2011$ & $<1$ & 8.9 & 1.12 & 9.1 & 1 & 911 & $12 / 13 / 2011$ & $<1$ & 9.6 & 1.39 & 5.1 & 1 \\
\hline 712 & $12 / 15 / 2011$ & $<1$ & 9.0 & 1.39 & 7.7 & 1 & 912 & 12/13/2011 & $<1$ & 9.4 & 1.62 & 4.3 & 1 \\
\hline \multirow[t]{2}{*}{713} & $12 / 12 / 2011$ & CS/ & 8.8 & 0.96 & 11.4 & 1 & 913 & $12 / 13 / 2011$ & $<1$ & 9.4 & 1.76 & 3.7 & 1 \\
\hline & & SDWSC & & & & & 914 & $12 / 13 / 2011$ & $<1$ & 9.2 & 2.00 & 3.4 & 1 \\
\hline \multirow[t]{2}{*}{715} & $12 / 12 / 2011$ & CS/ & 8.7 & 0.90 & 11.1 & 1 & 915 & $12 / 13 / 2011$ & $<1$ & 9.0 & 2.00 & 4.3 & 1 \\
\hline & & SDWSC & & & & & 919 & $12 / 14 / 2011$ & $<1$ & 8.0 & 1.04 & 9.4 & 1 \\
\hline \multirow[t]{2}{*}{716} & $12 / 12 / 2011$ & CS/ & 8.6 & 0.75 & 13.8 & 1 & 920 & $12 / 14 / 2011$ & $<1$ & 8.1 & 0.78 & 12.6 & 1 \\
\hline & & SDWSC & & & & & 921 & $12 / 14 / 2011$ & $<1$ & 7.9 & 1.79 & 4.7 & 1 \\
\hline \multirow[t]{2}{*}{717} & 12/15/2011 & $<1$ & 9.0 & 1.23 & 7.5 & 1 & 922 & 12/14/2011 & $<1$ & 7.5 & 2.00 & 4.9 & 1 \\
\hline & & & & & & & 923 & $12 / 14 / 2011$ & $<1$ & 8.7 & 1.60 & 6.2 & 1 \\
\hline
\end{tabular}




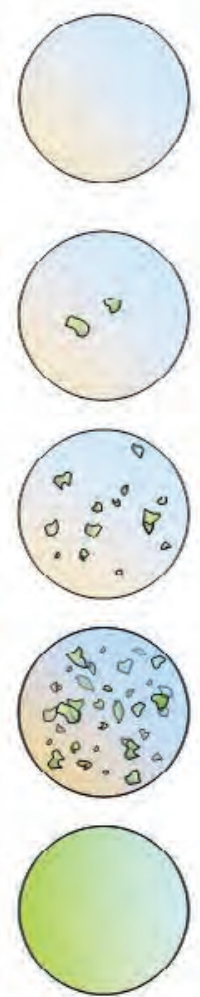

(1) absent

(2) Low-widely scattered colonies

(3) Medium-adjacent colonies

(4) High-contiguous colonies

(5) Very high-concentration of contiguous colonies forming mats and scum

Figure 4-2. Microcystis abundance visual-ranking system utilized during the fall midwater-trawl sampling. 
Table 4-3. Nitrite plus nitrate as nitrogen, ammonium as nitrogen, and chlorophyll- $\alpha$, by salinity group, from water samples collected during the fall midwater-trawl sampling survey in 2011.

[Latitude and longitude of sampling stations are in table 4-1. Abbreviations: CS-SRDWSC, Cache Slough-Sacramento River Deep Water Ship Channel; mg/L, milligrams per liter; mm/dd/yyyy, month/day/year; N, nitrogen; $\mu \mathrm{g} / \mathrm{L}$, micrograms per liter; <, less than; >, greater than; +, plus]

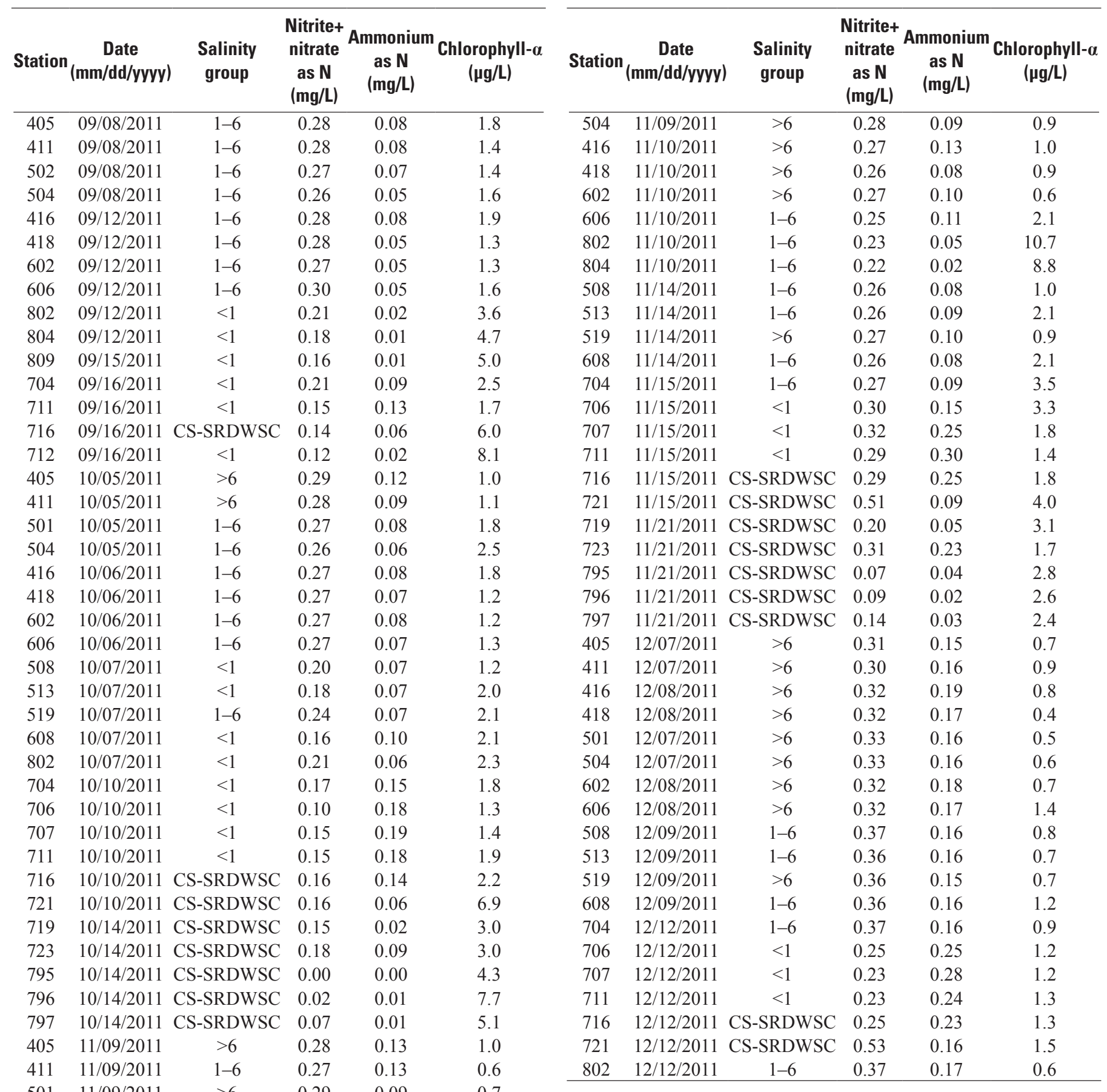




\section{Appendix 5. U.S. Geological Survey Sediment Monitoring and Analysis}

\section{Foreward}

The material presented in this appendix was provided by David Schoellhamer and others specifically for this report. Only the major points related to the predictions in the report were excerpted from the provided material. These major points are summarized at the beginning of the material presented in this appendix. The original material from Schoellhamer and others consisted largely of a series of figures with results and interpretive text provided in extensive figure captions. The material presented here has been edited to move text out of the captions and into regular text where possible.

Data sources and site identifiers are provided in table 5-1. Generally, data were collected with continuously recording instruments at fixed stations. At the Mallard Island site (USGS station 11185185), turbidity and suspended-sediment concentrations at 1-meter below the surface were recorded at 15-minute intervals, according to methods in Buchanan and Morgan (2012). Turbidity instruments were calibrated by using prepared standards. Suspended-sediment concentrations determined from water samples and analyzed at the U.S. Geological Survey (USGS) sediment laboratory, Marina, Calif., were used to calibrate the suspended-sediment sensors. See Buchanan and Morgan (2012) for additional detail. Specific-conductance measurements at Mallard Island were obtained from the California Department of Water Resources, which has instruments co-located with USGS instruments at this site. Methods used at Grizzly Bay (USGS station 380605122012101) and Suisun Cutoff (USGS station 380530122003501 ) were similar and are documented in Cuetera and others (2001); however, instruments at these sites were positioned 1.2 meters above the bottom in 1995 and 0.8 meters above the bottom in 2011. Methods used at Cache Slough sites, including lower Cache Slough (USGS station 11455350), upper Cache Slough (USGS station 11455280), Deep Water Ship Channel adjacent shallows (USGS station 11455335), and Liberty Island shallows (USGS station 381504121404001 ) are described in detail by Morgan-King and Schoellhamer (2013). Methods were essentially the same as for Buchanan and Morgan (2012); however, instruments were located 1.2 meters above the bottom, except at Deep Water Ship Channel adjacent shallows, where the instrument was located $0.6 \mathrm{~m}$ above the bottom because of the shallowness of the water at the site.

\section{Preliminary Analysis of Suspended-Sediment Concentration and Turbidity in the Fall Low- Salinity Zone of the San Francisco Estuary}

\author{
By David H. Schoellhamer, Tara L. Morgan-King, \\ Maureen A. Downing-Kunz, Scott A. Wright, and \\ Gregory G. Shellenbarger
}

\section{Summary}

- X2, the horizontal distance in kilometers from the Golden Gate up the axis of the estuary to where tidally averaged near-bottom salinity is 2 , does not affect fall suspended-sediment concentration at Mallard Island.

- Fall suspended-sediment concentration at Mallard Island decreased by about one-half from 1994 to 2011.

- Suisun Bay was usually more turbid than the confluence in fall 1994-2011.

- Suisun Bay was usually more turbid than the Cache Slough complex in fall 2011.

- Turbidity at Mallard Island was greater in fall 2011 than 2010, but in the Cache Slough complex, the opposite was observed, and turbidity was greater in fall 2010 than 2011.

\section{Does X2 Position Affect Suspended-Sediment Concentration?}

A plot of suspended-sediment concentration relative to $\mathrm{X} 2$ (fig. 5-1) does not indicate an obvious effect of X2 on near-surface suspended-sediment concentration at Mallard Island.

\section{Has Suspended-Sediment Concentration Changed Between 1994 and 2011?}

September-October SSC decreased about 50 percent from 1994-2011 (fig. 5-2). Total suspended-solids concentration (equivalent to SSC in this estuary) in the Delta decreased 50 percent from 1975 to 1995 (Jassby and others, 2002). In 1999, there was a 36-percent step decrease in SSC in San Francisco Bay as the threshold from transport to supply regulation was crossed because an anthropogenic erodible sediment pool was depleted (Schoellhamer, 2011). Thus, the decrease shown at Mallard Island is consistent with other observations in the estuary. Diminished supply from hydraulic mining debris, reservoirs, flood bypasses, and armoring of river banks are all likely contributors to the decrease. 


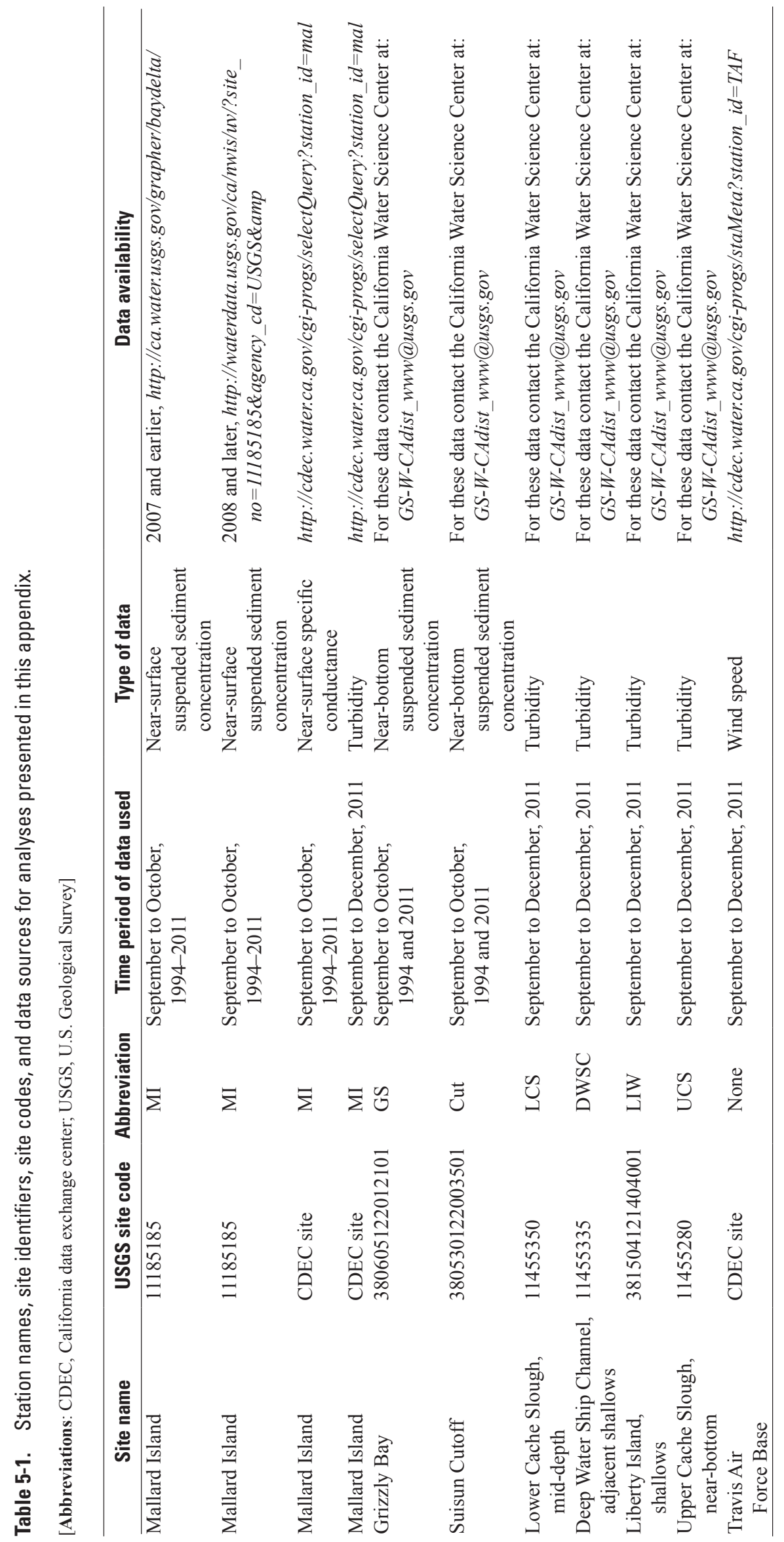




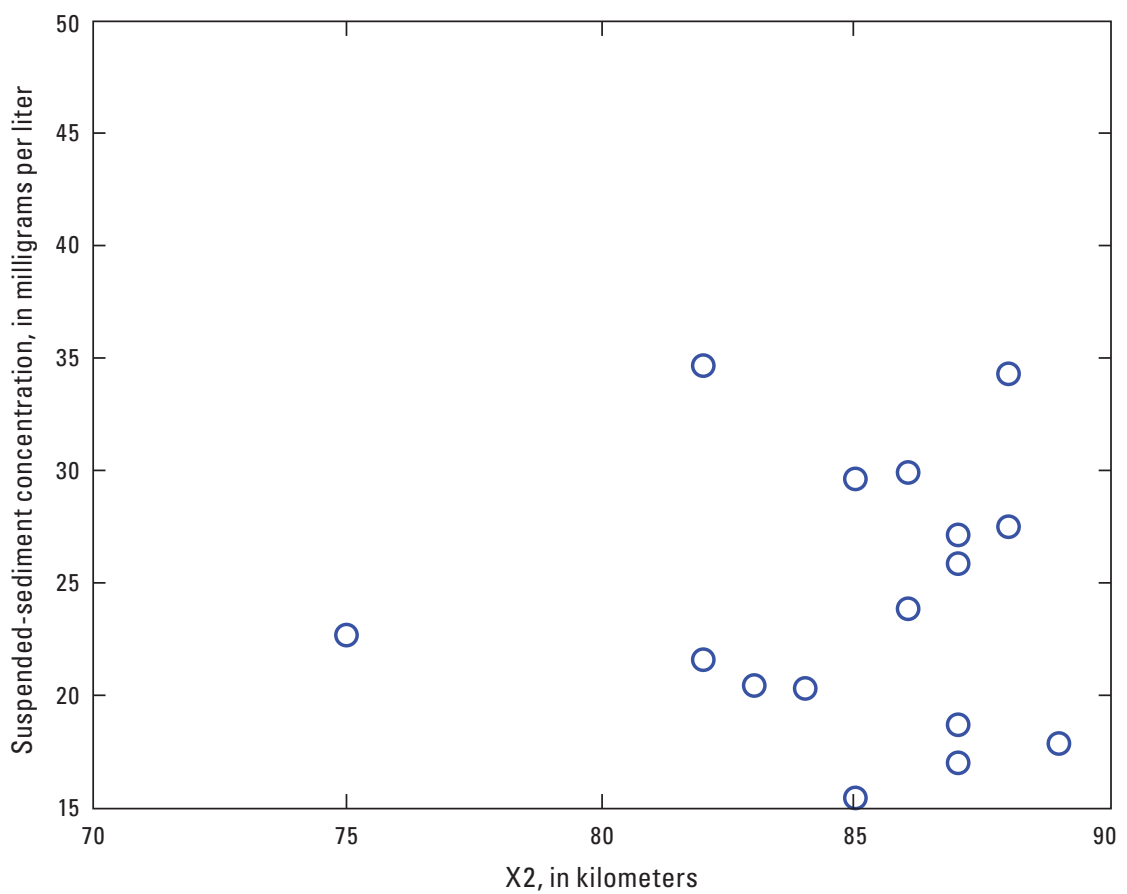

Figure 5-1. Near-surface suspended-sediment concentration (SSC) at Mallard Island (USGS station 11185185) as a function of X2, September-0ctober mean values, 1994-2011 (sample number is 5,856 each year). SSC data are collected at a 15-minute interval 1 meter below the water surface (Buchanan and Morgan, 2012). The year 1995 is not included as a result of insufficient SSC data. X2 is the horizontal distance in kilometers from the Golden Gate up the axis of the estuary to where tidally averaged near-bottom salinity is 2.

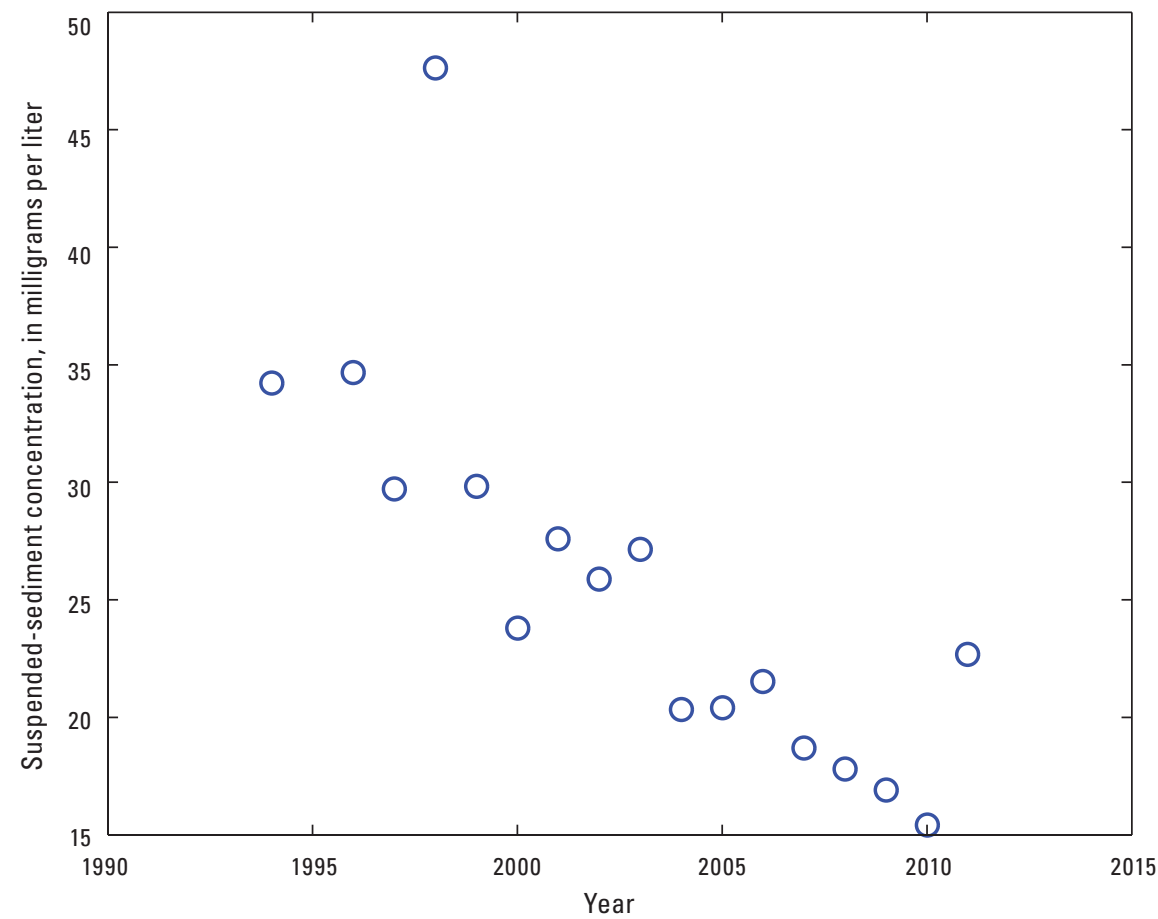

Figure 5-2. Near-surface suspended-sediment concentration (SSC) at Mallard Island (USGS station 11185185), September-0ctober mean values, 1994-2011 (sample number is 5,856 each year). SSC data were collected at a 15-minute interval 1 meter below the water surface (Buchanan and Morgan, 2012). 1995 is not included because of insufficient SSC data. 
Data collected at Suisun Cutoff (fig. 5-3) and Grizzly Bay (fig. 5-4) also support the trend of decreasing SSC, although there was less change at Suisun Cutoff compared to Grizzly Bay. For Suisun Cutoff, mean SSC in 2011 (66 mg/L) was 94 percent less than in 1995 (121 mg/L). For Grizzly Bay, the lower quartile decreased the most with $69 \mathrm{mg} / \mathrm{L}$ in 1995 and $52 \mathrm{mg} / \mathrm{L}$ in 2011, a decrease of 25 percent. For Grizzly Bay, the upper quartile decreased the least with $101 \mathrm{mg} / \mathrm{L}$ in 1995 and $97 \mathrm{mg} / \mathrm{L}$ in 2011, a decrease of 4 percent. Brennan and others (2002) found that tidal asymmetry in Suisun Cutoff caused greater SSC during flood tide. The highs were comparably high, perhaps because the tidal asymmetry mechanism was still present, but the lows were lower than before (SSC in Grizzly Bay and at Mallard Island have decreased almost one-half from the mid-1990s to 2011), perhaps because clearer water from elsewhere was transported into Suisun Cutoff. SSC decreases with distance from the bed, and 2011 data were collected 0.4 meters closer to the bottom than in 1995, which could account for some of the decrease in SSC observed from 1995 to 2011. Overall, data from multiple sites indicated that fall SSC declined from 1994 to 2011.

\section{Is the Confluence or Suisun Bay More Turbid?}

Determining whether the confluence or Suisun Bay was more turbid during the fall was addressed by evaluating deviations from tidally averaged mean values of specific conductance and suspended-sediment concentration at Mallard Island (fig. 5-5). Positive deviation of specific conductance indicates water from seaward of Mallard Island (Suisun Bay), and negative deviation indicates water from landward of Mallard Island (confluence). Tidally averaged time series were calculated with singular spectrum analysis for time series with missing data and a 40-hour window (Schoellhamer, 2001). The modes with the greatest variability ( 40.1 percent for specific conductance and 47.6 percent for SSC) contained periodicity greater than 40 hours. All other significant modes contained tidal signals, so the first modes are tidally averaged time series. The second and third modes were semidiurnal modes (37.2 percent of variability for specific conductance, 12.4 percent for SSC), indicating that advection was the most important tidal process. For SSC, quarter diurnal modes, which are indicative of tidal

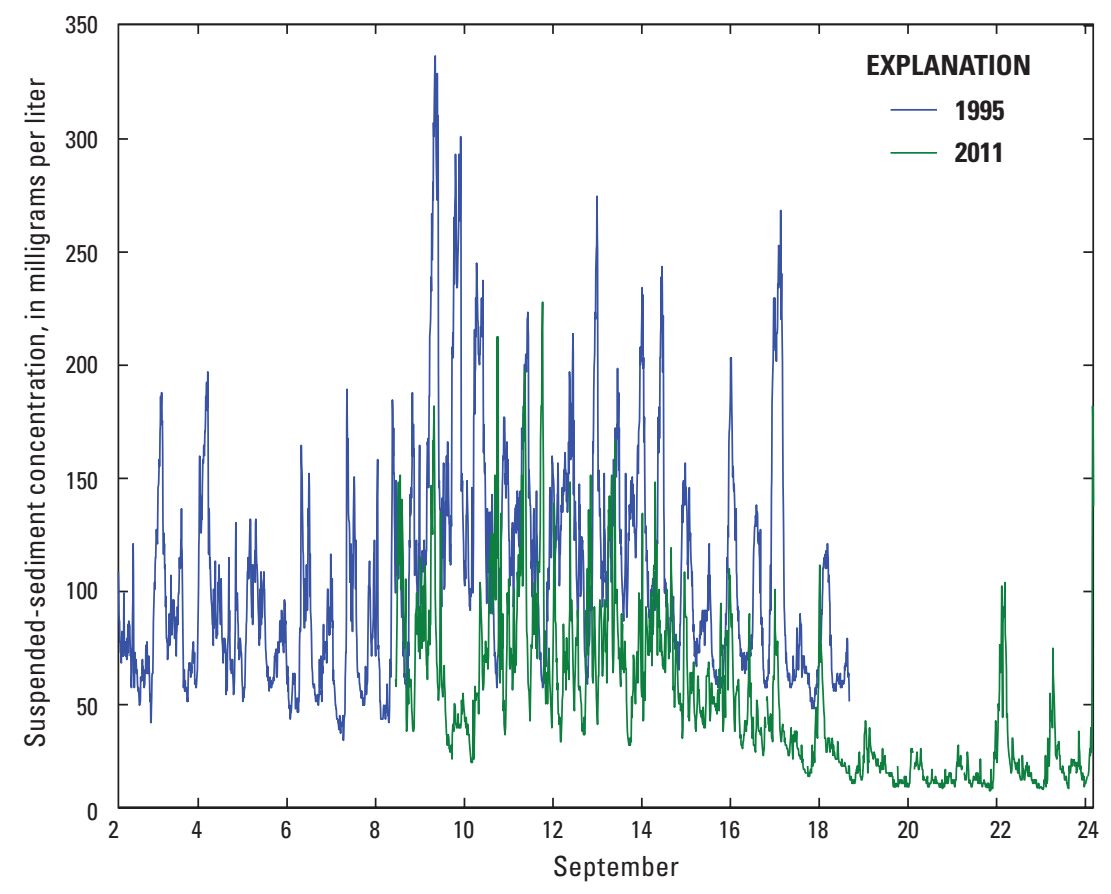

Figure 5-3. Suspended-sediment concentration (SSC) near the bottom of Suisun Cutoff (USGS station 380530122003501), SeptemberOctober 1995 (sample number is 1,475) and 2011 (sample number is 984). Data were collected at a 15-minute intervals 1.2 meters above the bottom in 1995, and 0.8 meters above the bottom in 2011 (Cuetara and others, 2001). The period for which data have overlapping calendar dates is 33 days. 


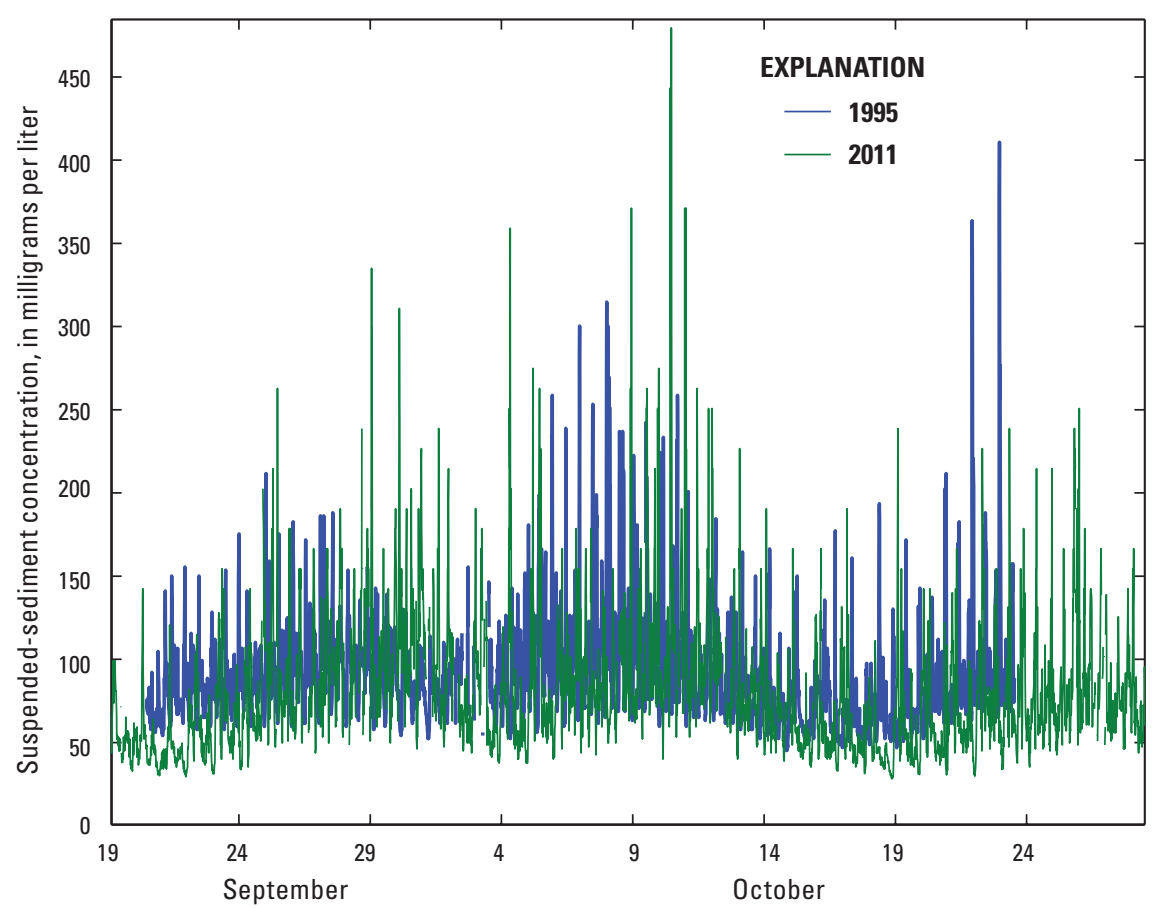

Figure 5-4. Suspended-sediment concentration (SSC) in Grizzly Bay (USGS station 380605122012101), September 1995 (sample number is 4,759) and 2011 (sample number is 2,172). Data were collected at a 15-minute interval, 0.6 meters above the bottom in 1995 and 0.5 meters above the bottom in 2011 (Cuetara and others, 2001). The period for which data have overlapping calendar dates spans 10.2 days.

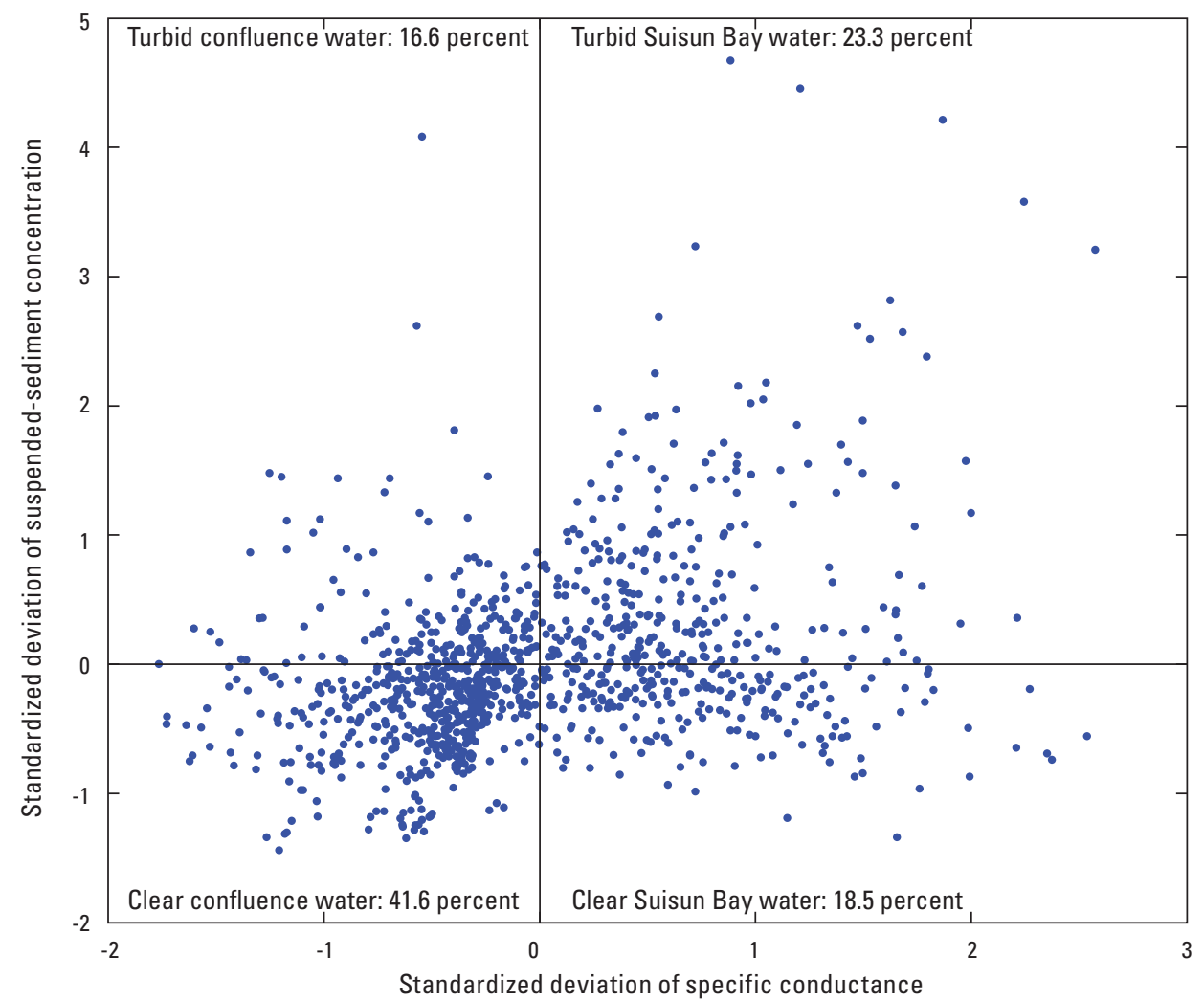

Figure 5-5. Standardized deviations of near-surface hourly specific conductance and suspended-sediment concentration (SSC) from tidally averaged values at Mallard Island (USGS station 11185185), September-0ctober $2011(n=1,464)$. SSC data are collected at a 15-minute interval 1 meter below the water surface (Buchanan and Morgan, 2012). Specific conductance data were collected by the California Department of Water Resources (http://cdec.water.ca.gov/). 
resuspension, accounted for only 7.4 percent of the variability. About 65 percent of the data fell in the upper right or lower left quadrants (fig. 5-5), indicating relatively turbid water from Suisun Bay or relatively clear water from the confluence present at Mallard Island, respectively. Thus, Suisun Bay usually was more turbid than the confluence. This analysis assumes that advection is the dominant sediment transport mechanism.

The results depicted in figure 5-5 are for hourly data; however, consideration of these data on a daily time step could be more useful as an indicator of general water-quality conditions. This was accomplished by calculating the product of signs (positive or negative) of the hourly deviations of specific conductance and suspended-sediment concentration from tidally averaged values. Positive values of the product indicate instantaneous salinity and SSC are either both positive (relatively turbid Bay water) or negative (relatively clear confluence water). Negative values indicate that deviations of specific conductance and SSC have opposite signs (relatively clear Bay or relatively turbid confluence). The number of positive hourly values per day was then divided by 24 to determine the daily percentage shown in figure 5-6. This analysis assumes that advection is the dominant sediment transport mechanism. The magnitude of the deviations is not considered. The relative turbidity of Suisun Bay and the confluence varies with time, such that Suisun Bay is more turbid than the confluence in the early fall, September to mid-October. Several factors can affect this percentage, including windwave resuspension, the salinity field, river discharge, and the spring-neap tidal cycle.
The results shown in figure 5-5 appear to be independent of X2 (fig. 5-7), specific conductance (fig. 5-8) and windspeed (fig. 5-9). In general, 50-65 percent of the data indicated that Suisun Bay is more turbid than the confluence annually, and this percentage appears to be independent of X2 (fig. 5-7). Similarly, the percentage appears to be independent of specific conductance (fig. 5-8). A possible decrease in the percentage at 6,000-9,000 microsiemens per centimeter $(\mu \mathrm{S} / \mathrm{cm})$ could be due to formation of a small estuarine turbidity maximum (ETM) landward of Mallard Island during neap tides around salinity 0-2 (0-4,000 $\mu \mathrm{S} / \mathrm{cm}$; Schoellhamer 2001). An ETM landward of Mallard Island on neap tides would decrease the percentage (which is the mean over two months). For specific conductance less than $4,000 \mu \mathrm{S} / \mathrm{cm}$ at Mallard Island, the ETM would be centered at or seaward of Mallard Island. For specific conductance greater than $9,000 \mu \mathrm{S} / \mathrm{cm}$, the ETM would be landward of Mallard, possibly far enough that it would not be transported to Mallard Island on an ebb tide, and thus the percentage remains high. The percentage also did not show an obvious relation to wind speed at Travis Airforce Base (fig. 5-9); however, the range of mean wind speed was only 4 miles per hour (mph), which could be insufficient to observe a relation. A preliminary hypothesis is that wind in September and October is usually capable of generating waves that resuspend sediment in Suisun Bay. This makes it more turbid than the confluence, except when a neap tide ETM is landward of Mallard Island and within a tidal excursion. Overall, the data indicated that Suisun Bay is usually more turbid than the confluence during the fall. However, this is not true every year, and in some years, the difference is not great.

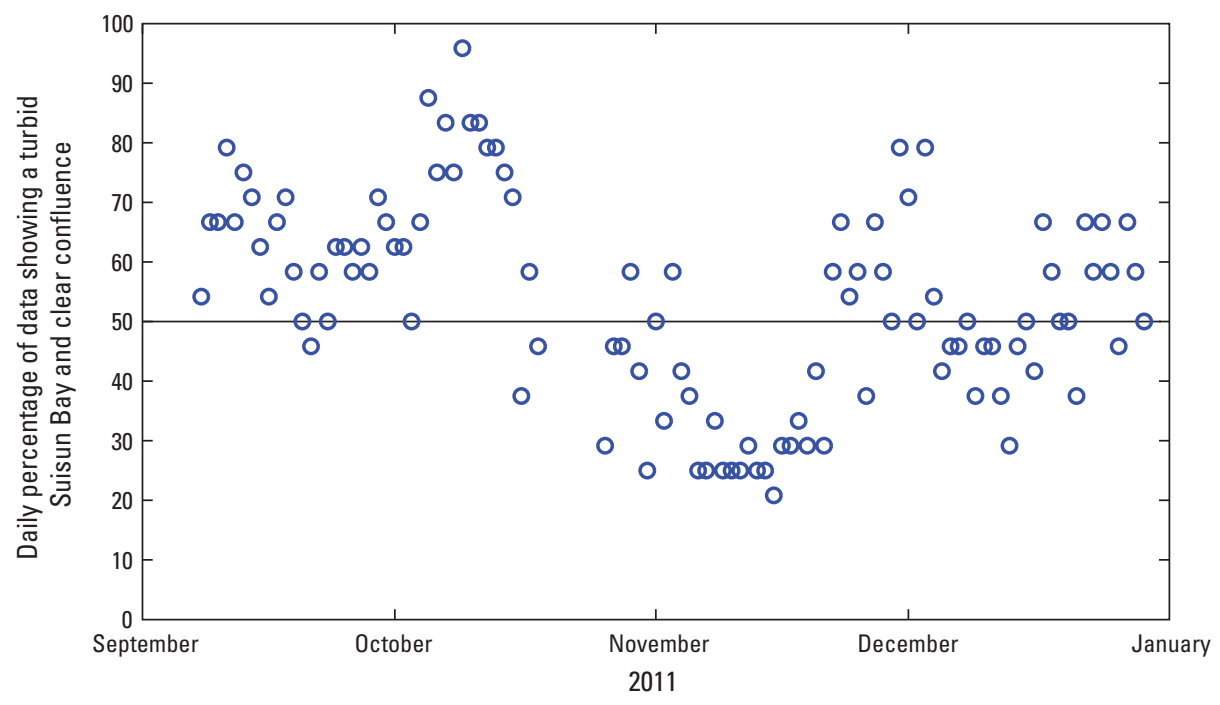

Figure 5-6. Percentage of data showing a turbid Suisun Bay and clear confluence, September-December 2011 ( $n=122)$. 


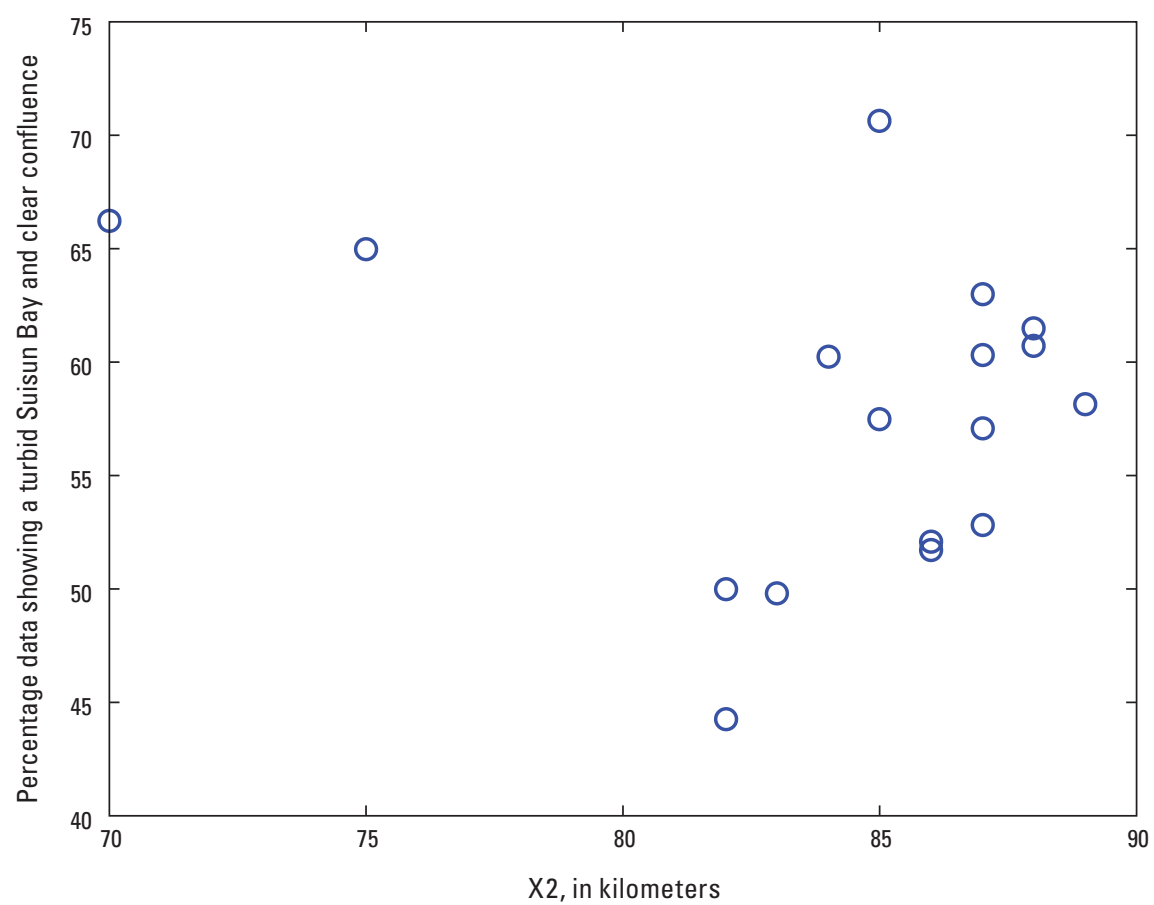

Figure 5-7. Annual percentage of specific conductance and suspended-sediment concentration (SSC) data from Mallard Island (USGS station 11185185) within the upper right and lower left quadrants of figure 5-5 showing turbid waters to the west of Mallard Island (Suisun Bay) and clear waters to the east (confluence), as a function of X2, September and October 1994-2011.1995 is not included because of insufficient SSC data. X2 is the mean for September and October. X2 is the horizontal distance in kilometers from the Golden Gate up the axis of the estuary to where tidally averaged near-bottom salinity is 2.

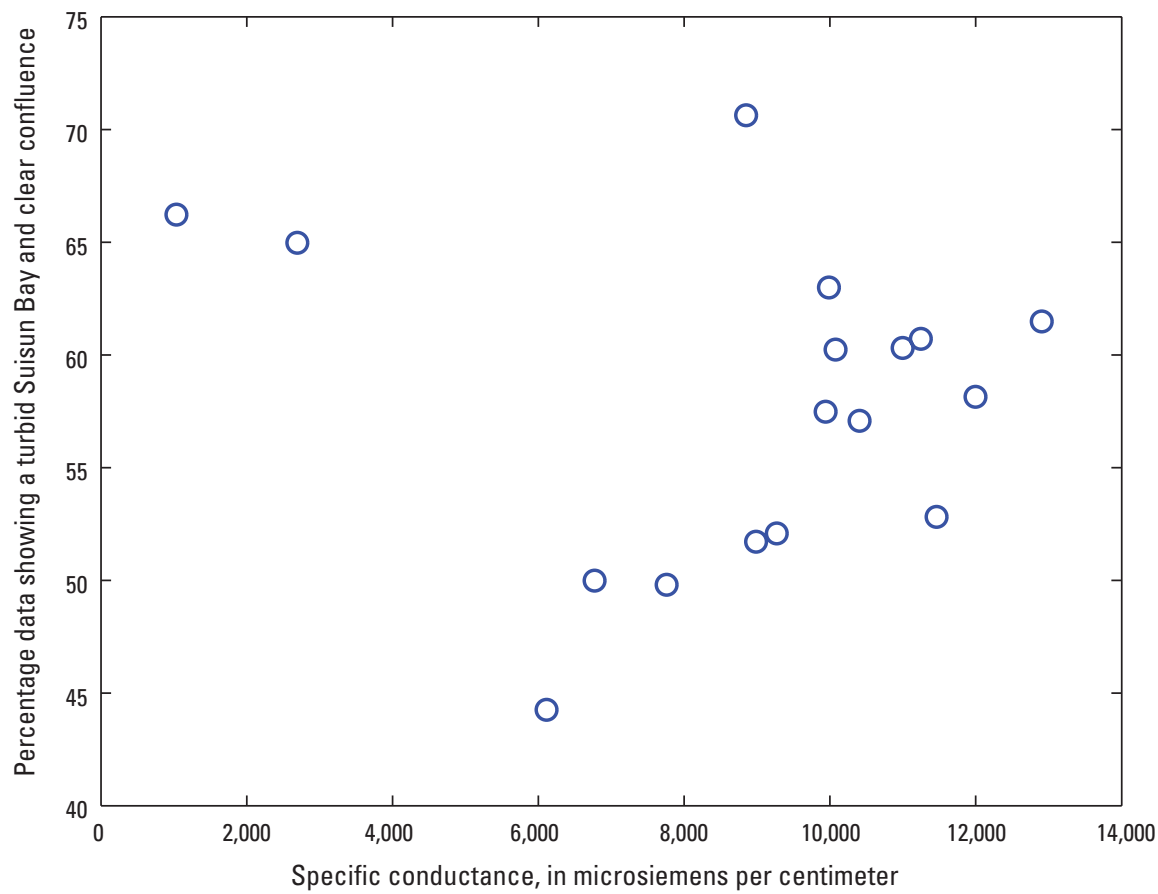

Figure 5-8. Annual percentage of specific conductance and suspended-sediment concentration (SSC) data from Mallard Island (USGS station 11185185) within the upper right and lower left quadrants of figure 5-5 showing turbid waters to the west of Mallard Island (Suisun Bay) and clear waters to the east (confluence), as a function of mean specific conductance, September-0ctober 1994-2011. 1995 is not included because of insufficient SSC data. 


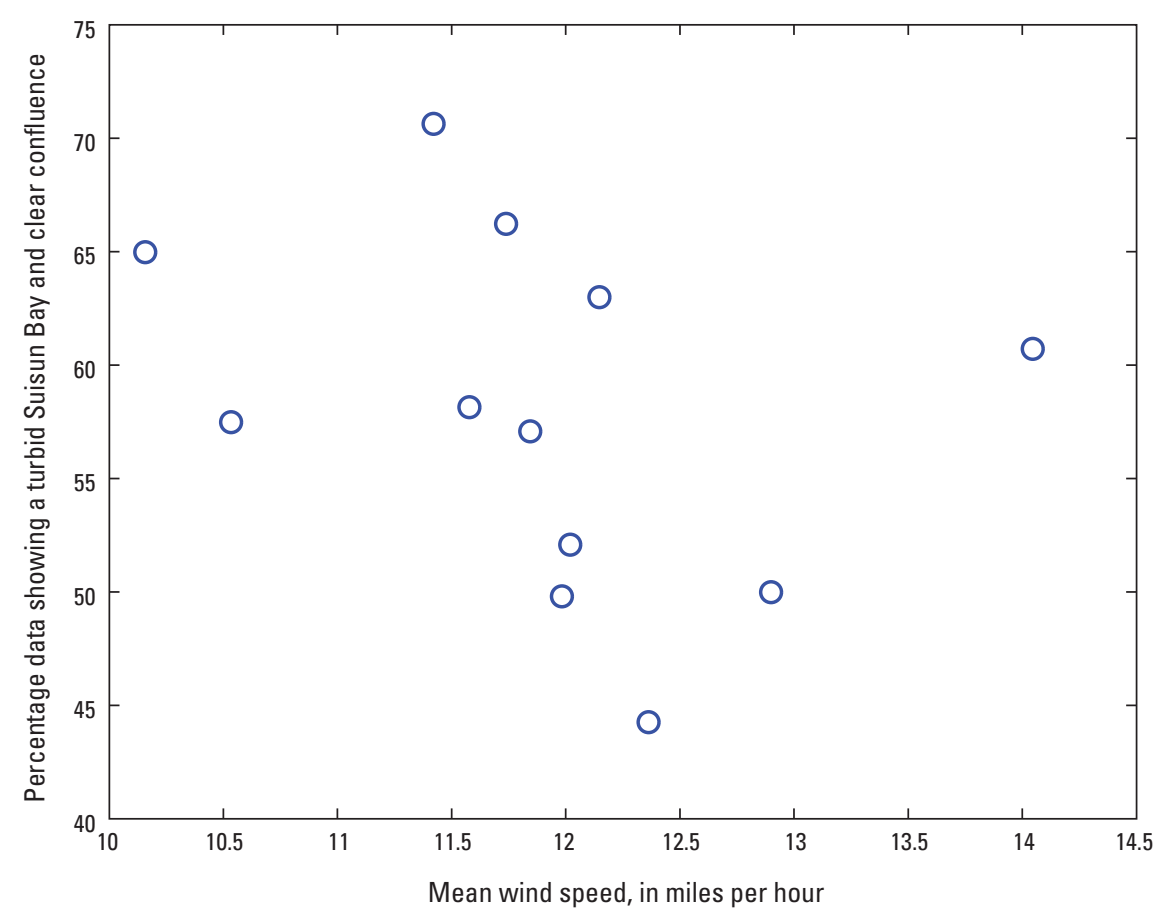

Figure 5-9. Annual percentage of specific conductance and suspended-sediment concentration (SSC) data from Mallard Island (USGS station 11185185) within the upper right and lower left quadrants of figure 5-5 showing turbid waters to the west of Mallard Island (Suisun Bay) and clear waters to the east (confluence), as a function of mean wind speed, September-0ctober 1994-2011. 1995 is not included because of insufficient SSC data. Wind speed was measured hourly at Travis Air Force Base. No wind-speed data were available for 2000-2004.

\section{Is Suisun Bay or the Cache Slough/Liberty Island Complex More Turbid?}

Suspended-sediment concentration and, therefore, turbidity increase with water depth at a given site, so sensor position in the water column is important to consider when comparing turbidities among sites. For shallow sites during September-December 2011, Grizzly Bay was more turbid than Liberty Island (LIW) and the Deep Water Ship Channel (DWSC; fig. 5-10). For near-bottom sites, Suisun Cutoff (Cut) was more turbid than Upper Cache Slough (UCS). And for near-surface and mid-depth sites, Mallard Island (MI) was more turbid than Lower Cache Slough (LCS). For all these comparisons, Suisun Bay sites were more turbid than Cache Slough complex sites. The same pattern was observed when only September-October 2011 data were considered (fig. 5-11). Wind speed does appear to affect this pattern (fig. 5-12). Turbidity at Mallard Island is usually greater than in the Cache Slough complex, except during some windy events when wind-wave resuspension in Liberty Island increases turbidity in the Deep Water Ship Channel and Lower Cache Slough. Wind direction was not considered in this initial analysis.
There were differences in suspended-sediment concentration, and therefore turbidity, between 2010 and 2011, when data were available (fig. 5-13). As noted above, suspendedsediment concentration, and therefore turbidity, increase with water depth at a given site, so sensor position in the water column is important to consider when analyzing these results. Mallard Island was more turbid in 2011 than 2010, and Cache Slough complex sites were less turbid in 2011 compared to 2010. In 2010, Mallard Island was about as turbid as Lower Cache Slough and less turbid than the remaining Cache Slough complex sites. In 2011, Mallard Island was more turbid than all Cache Slough complex sites, except Upper Cache Slough. A hypothesis for the difference between 2010 and 2011 is that Yolo Bypass flow, in 2011, reduced sediment deposition in the Cache Slough complex, and greater watershed sediment supply in 2011 increased deposition in Suisun Bay, and this more seaward deposition in 2011 accounts for the observed turbidity. Another hypothesis is that, in 2010, the estuarine turbidity maximum (Schoellhamer, 2001) was landward of Mallard Island at all times, while it was often present at Mallard Island in 2011, leading to greater turbidity in 2011. Overall, Suisun Bay was usually more turbid than the Cache Slough complex in Fall 2011, and turbidity at Mallard Island was greater in fall 2011 than 2010, but in the Cache Slough complex, turbidity was greater in fall 2010 than 2011. 


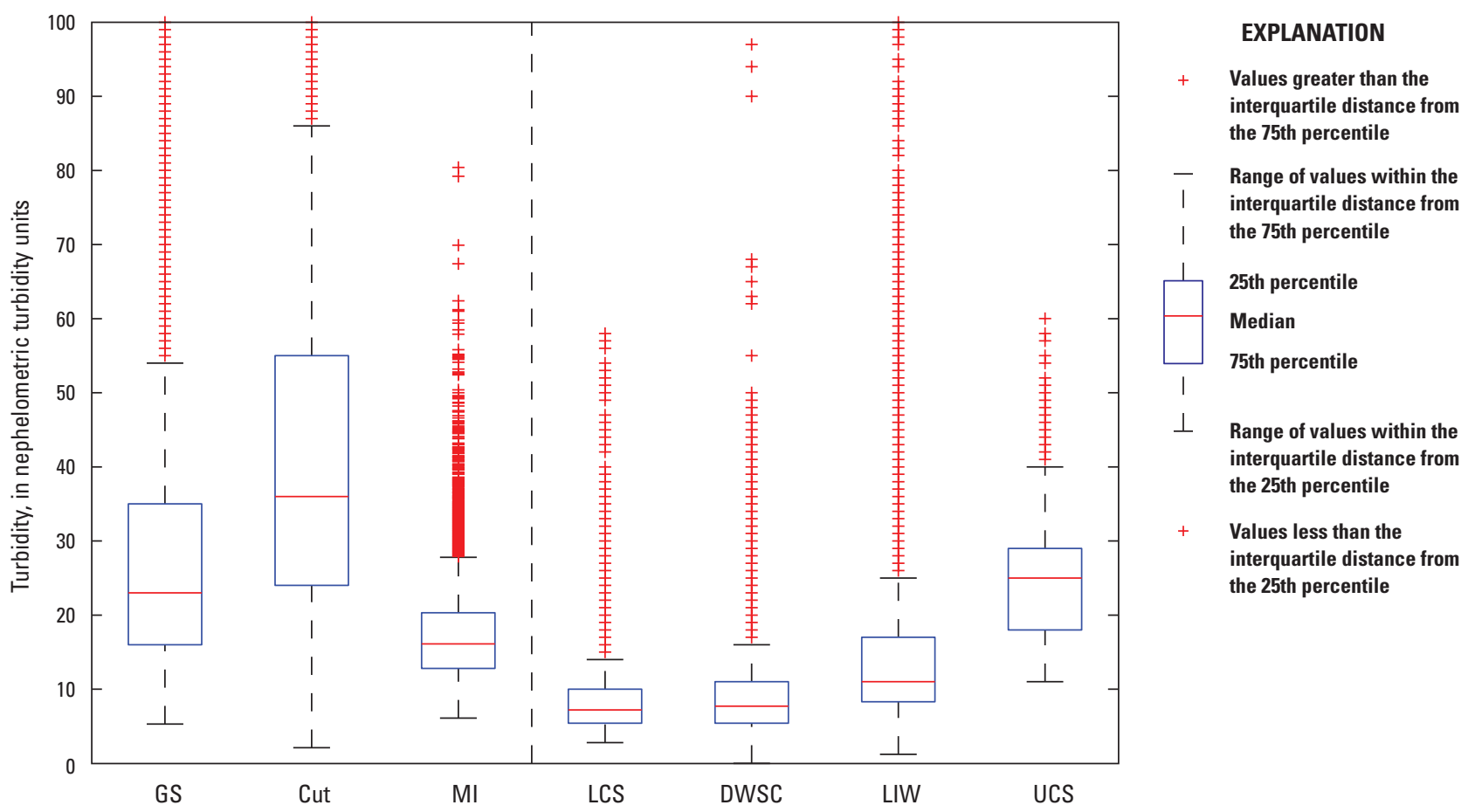

Figure 5-10. Boxplots of turbidity in Suisun Bay and the Cache Slough complex, September-December 2011. Data were collected every 15 minutes, and only times for which all seven sites had valid data are considered (sample number is 8,257 for each boxplot). Data points with turbidity greater than 100 nephelometric turbidity units are not shown. Suisun Bay sites are Grizzly Bay shallows (GS, USGS station 380605122012101), Suisun Cutoff near-bottom (Cut, USGS station 380530122003501), and Mallard Island near-surface (MI, USGS station 11185185). Mallard Island turbidity data are from California Data Exchange Center (http://cdec.water.ca.gov/cgi-progs/ staMeta?station_id=MAL). USGS measured turbidity at all the other sites. The vertical dashed line separates Suisun Bay and Cache Slough complex sites. Cache Slough complex sites are Lower Cache Slough mid-depth (LCS, USGS station 11455350), Deep Water Ship Channel adjacent shallows (DWSC, USGS station 11455335), Liberty Island shallows (LIW, USGS station 381504121404001), and upper Cache Slough near-bottom (UCS, USGS station 11455280). Morgan-King and Schoellhamer (2013) described data collection in Cache Slough. 


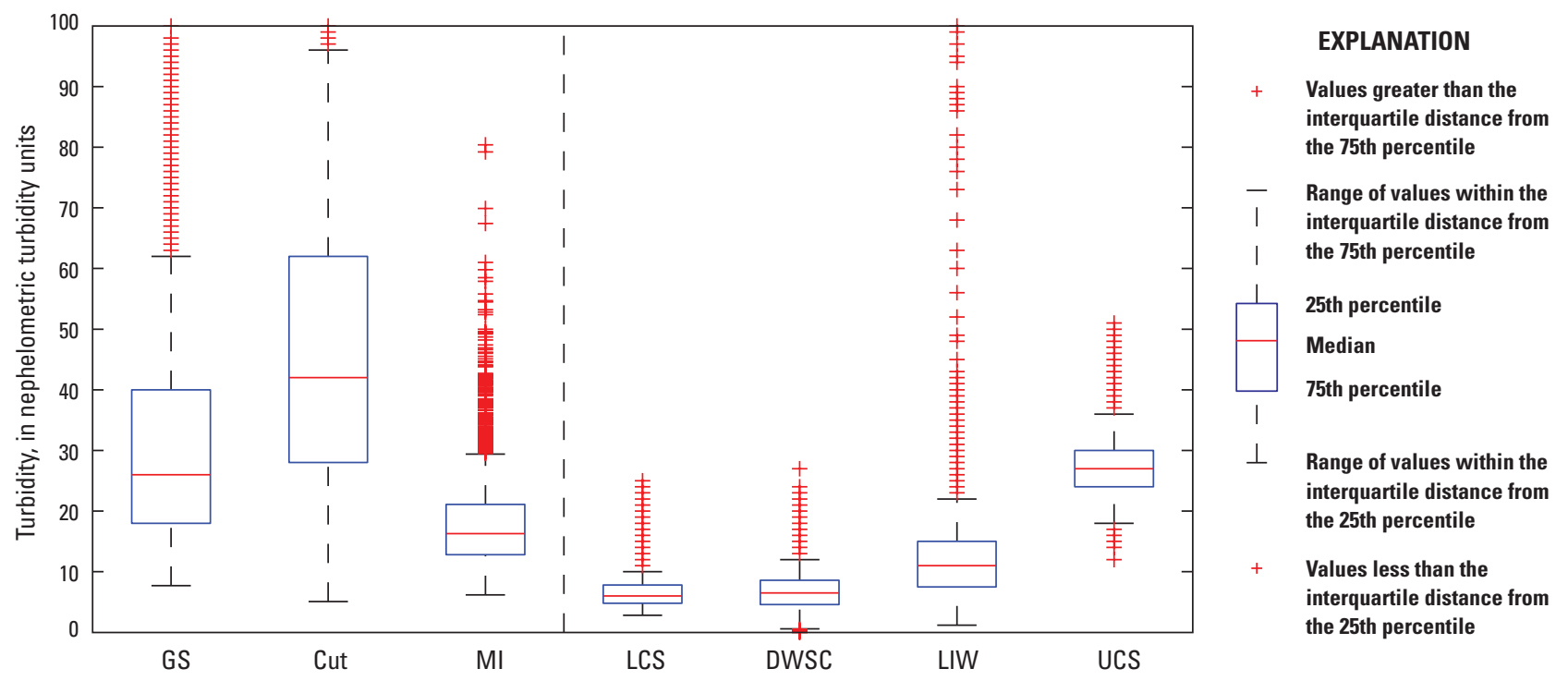

Figure 5-11. Boxplots of turbidity in Suisun Bay and the Cache Slough complex, September-October 2011. This figure is a subset of the previous figure. Data were collected every 15 minutes, and only times for which all seven sites had valid data are considered (sample number is 4557 for each boxplot). Data points with turbidity greater than 100 nephelometric turbidity units are not shown. Suisun Bay sites are Grizzly Bay shallows (GS, USGS station 380605122012101), Suisun Cutoff near-bottom (Cut, USGS station 380530122003501), and Mallard Island near-surface (MI, USGS station 11185185). Mallard Island turbidity data are from California Data Exchange Center (http://cdec.water.ca.gov/cgi-progs/staMeta?station_id=MAL). USGS measured turbidity at all the other sites. The vertical dashed line separates Suisun Bay and Cache Slough complex sites. Cache Slough complex sites are Lower Cache Slough mid-depth (LCS, USGS station 11455350), Deep Water Ship Channel adjacent shallows (DWSC, USGS station 11455335), Liberty Island shallows (LIW, USGS station 381504121404001), and Upper Cache Slough near-bottom (UCS, USGS station 11455280). Morgan-King and Schoellhamer (2013) described data collection in Cache Slough. 

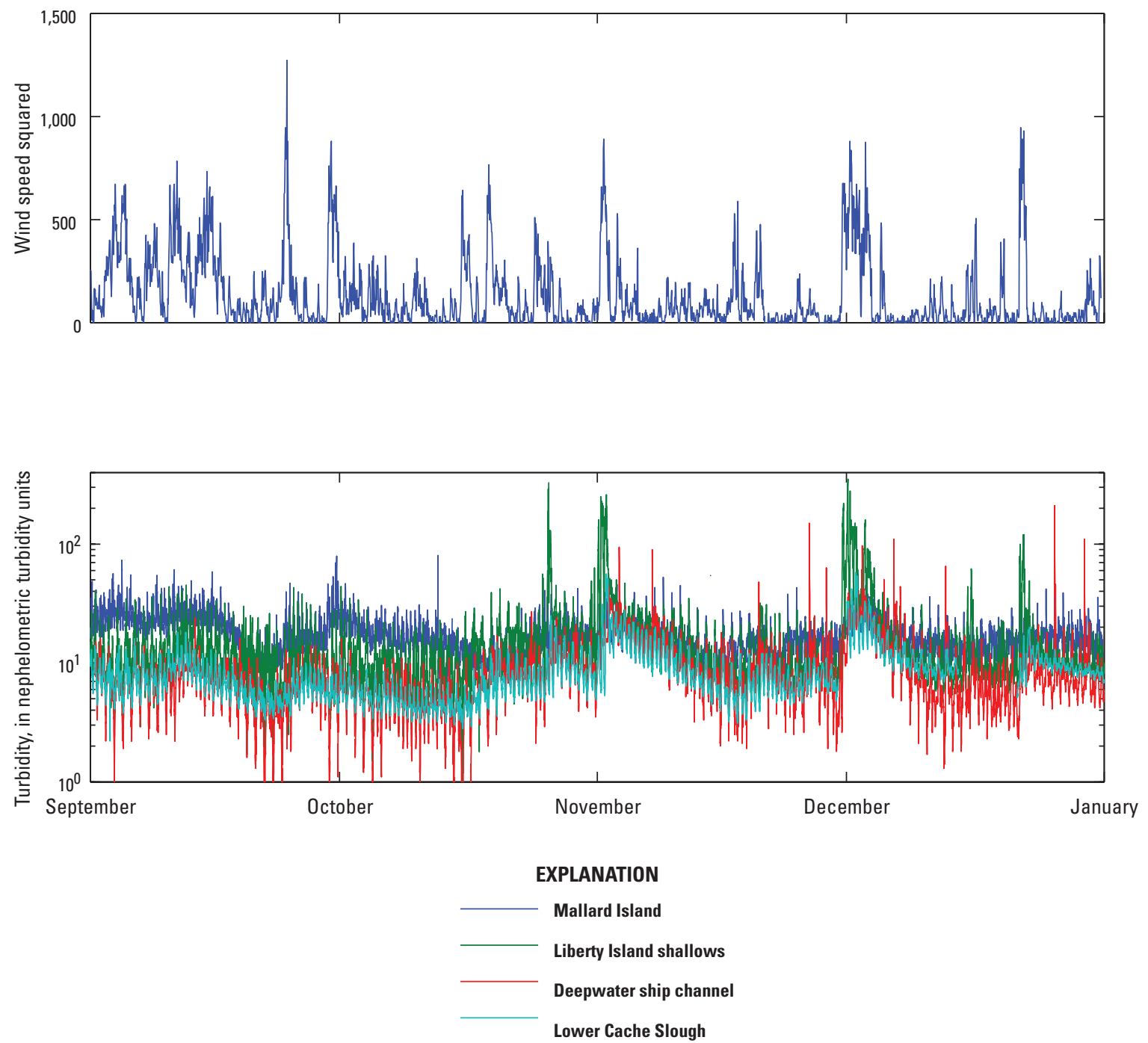

Figure 5-12. Wind-speed squared and turbidity, September-December 2011. Wind speed was measured hourly in miles per hour at Travis Air Force Base (http://cdec.water.ca.gov/cgi-progs/staMeta?station_id=TAF) (sample number is 2,928). Wind-shear stress on the water surface is roughly proportional to the square of the wind speed. Turbidity is shown at four sites: Mallard Island (USGS station 11185185), Liberty Island shallows (USGS station 381504121404001), Deepwater ship channel (USGS station 11455335), and Lower Cache Slough (USGS station 11455350). Morgan-King and Schoellhamer (2013) described data collection in Cache Slough. Note that a logarithmic scale is used for turbidity. 


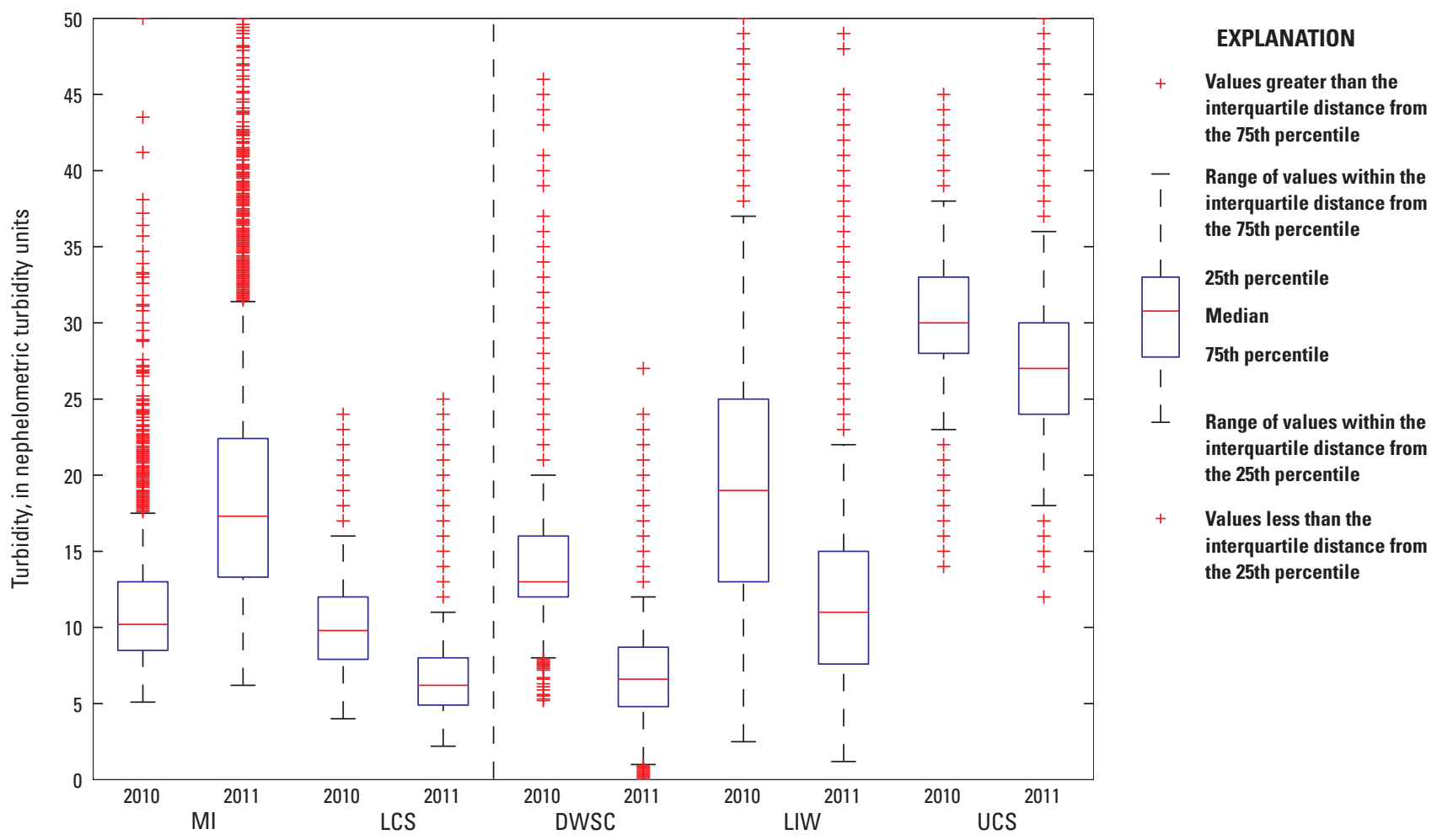

Figure 5-13. Boxplots of turbidity at Mallard Island and the Cache Slough complex, September-October 2010 and 2011. Data were collected every 15 minutes, and only times for which all five sites in a given water year had valid data are considered (sample number is 2,418 for each boxplot in 2010 and sample number is 5,452 for each boxplot in 2011). Data points with turbidity greater than 50 nephelometric turbidity units are not shown. Mallard Island (MI) turbidity data are from the California Data Exchange Center (http:// cdec.water.ca.gov/cgi-progs/staMeta?station_id=MAL). USGS measured turbidity at all the other sites. Cache Slough complex sites are Lower Cache Slough mid-depth (LCS, USGS station 11455350), Deep Water Ship Channel adjacent shallows (DWSC, USGS station 11455335), Liberty Island shallows (LIW, USGS station 381504121404001), and Upper Cache Slough near-bottom (UCS, USGS station 11455280). Morgan-King and Schoellhamer (2013) described data collection in Cache Slough. Gray shading is used to delineate sites. 


\section{References Cited}

Brennan, M.L., Schoellhamer, D.H., Burau, J.R., and Monismith, S.G., 2002, Tidal asymmetry and variability of bed shear stress and sediment bed flux at a site in San Francisco Bay, USA, in Winterwerp, J.C. and Kranenburg, C., ed., Fine sediment dynamics in the marine environment: Elsevier Science B.V., p. 93-108.

Buchanan, P.A., and Morgan, T.L., 2012, Summary of suspended-sediment concentration data, San Francisco Bay, California, water year 2009: U.S. Geological Survey Data Series Report 634, http://pubs.usgs.gov/ds/744/.

Cuetara, J.I., Burau,J.R., and Schoellhamer, D.H., 2001, Hydrodynamic and suspended-solids concentration measurements in Suisun Bay, California, 1995; U.S. Geological Survey Open File Report 01-4086, http://water.usgs.gov/ pubs/wri/wri014086/.

Jassby, A.D., Cloern, J.E., and Cole, B.E., 2002, Annual primary production: Patterns and mechanisms of change in a nutrient-rich tidal ecosystem: Limnology and Oceanography, v. 47 , p. $698-712$.

Morgan-King, T.L., and Schoellhamer, D.H., 2013, Suspended-sediment flux and retention in a backwater tidal slough complex near the landward boundary of an estuary: Estuaries and Coasts, v. 36, no. 2, p. 300-318.

Schoellhamer, D.H., 2001, Singular spectrum analysis for time series with missing data: Geophysical Research Letters, v. 28 , no. 16 , p. 3187-3190.

Schoellhamer, D.H., 2001, Influence of salinity, bottom topography, and tides on locations of estuarine turbidity maxima in northern San Francisco Bay, in McAnally, W.H. and Mehta, A.J., ed., Coastal and estuarine fine sediment transport processes: Elsevier Science B.V., p. 343-357.

Schoellhamer, D.H., 2011, Sudden clearing of estuarine waters upon crossing the threshold from transport to supply regulation of sediment transport as an erodible sediment pool is depleted: San Francisco Bay, 1999: Estuaries and Coasts, v. 34 , p. $885-899$. 
This page intentionally left blank. 


\section{Appendix 6. Environmental Monitoring Program}

The Environmental Monitoring Program (EMP) is carried out cooperatively by several IEP agencies. Sampling is performed monthly. The following information is excerpted from this web site: http://www.water.ca.gov/iep/activities/emp. $c f m$. Additional information on zooplankton sampling can be obtained at the following website: http://www.water.ca.gov/ bdma/meta/zooplankton.cfm.

The Environmental Monitoring Program (EMP) for the Sacramento-San Joaquin Delta, Suisun Bay, and San Pablo Bay is carried out under the auspices of the Interagency Ecological Program (IEP). The EMP was initiated in 1971 in compliance with California State Water Resources Control Board (SWRCB) Water Right Decision D-1379 and continued from 1978 through 1999 under D-1485. Currently, it is mandated by Water Right Decision D-1641. The program is carried out jointly by the two water-right permittees operating the California water projects: the United States Bureau of Reclamation (USBR) and the California Department of Water Resources (CDWR). Assistance is provided by the California Department of Fish and Wildlife (CDFW) and the United States Geological Survey (USGS). The primary purpose of the IEP EMP is to provide necessary information for compliance with flow-related water-quality standards specified in the water-right permits. In addition, the EMP provides information on a wide range of chemical, physical, and biological baseline variables. EMP's discrete water-quality stations are sampled monthly by using a research vessel and a laboratory van. EMP also operates eight multi-parameter continuous "real-time" water-quality stations. In addition, the EMP collects and analyzes benthos, phytoplankton, and zooplankton samples. Monitoring listed as "continuous recorder sites" in D-1641 is not part of the EMP; these sites are operated by the USBR, the USGS, or the Department of Water Resources (DWR).

We used data from six discrete sites in the EMP sampling network (fig. 6-1). Latitude and longitude of sites are provided in table 6-1. We also included data from two "floating" sites, EZ2 and EZ6. These samples were taken at locations where near-bottom specific conductances were 2,000 and $6,000 \mu \mathrm{S} / \mathrm{cm}$, respectively. We used data for ammonium as nitrogen $(\mathrm{N})$, nitrite plus nitrate as $\mathrm{N}$, and chlorophyll- $\alpha$, (table 6-2). Water-quality data were determined from samples collected 1 meter below the surface. Details of methods are available at http://www.water.ca.gov/bdma/meta/discrete.cfm. We also used continuous 15-minute flouresence measurements from two continuous monitoring sites, Rio Vista Bridge, and Mallard Island (table 6-3), which are near discrete sites D10 and D24, respectively (fig. 6-1, table 6-1). Data were provided by Mike Dempsey, California Department of Water Resources.

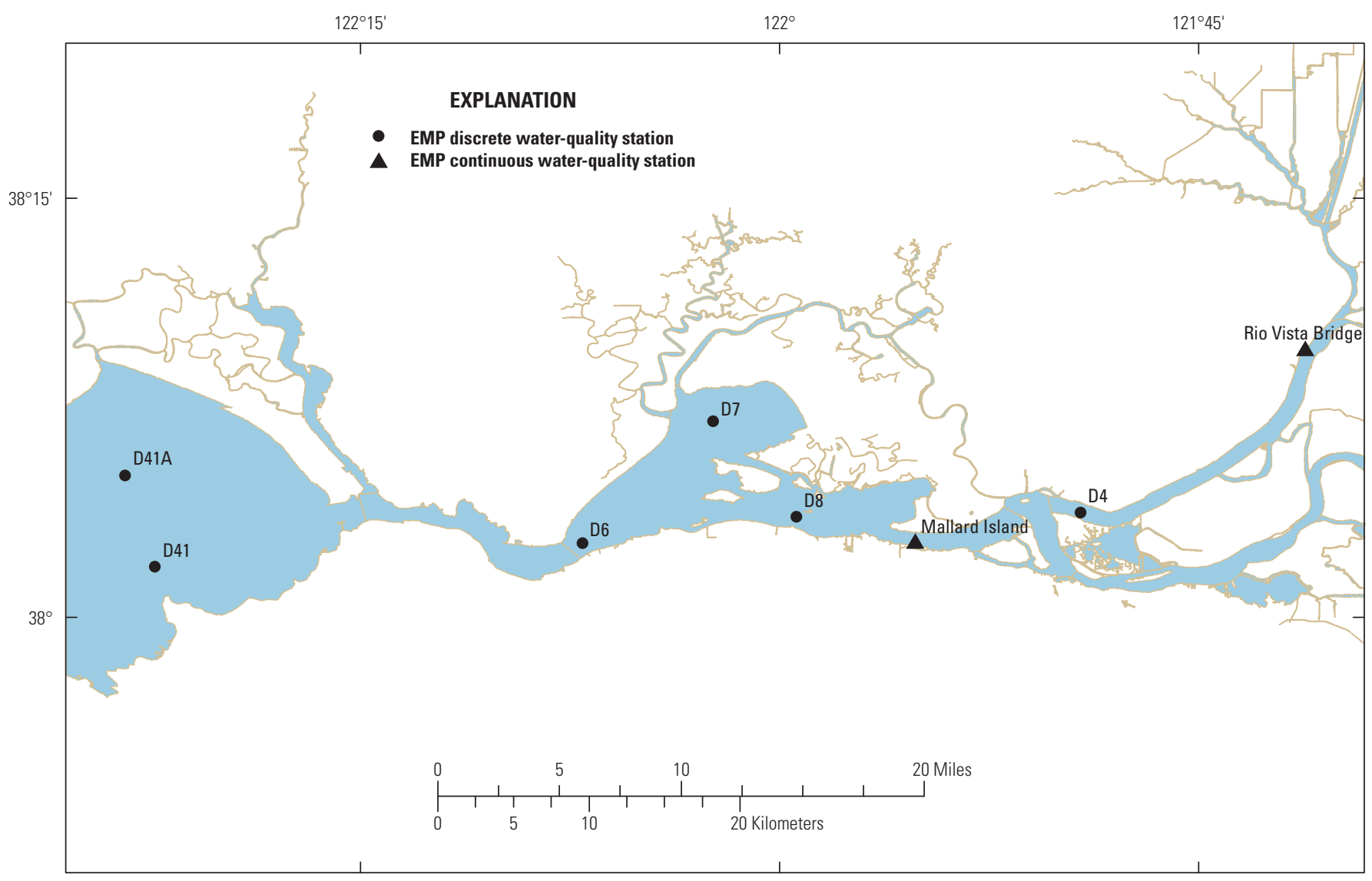

Figure 6-1. Sites sampled by the Environmental Monitoring Program for water-quality constituents that were included in data analysis for this report. See table 6-1 for latitude and longitude of each site. 
Table 6-1. Latitude and longitude of Environmental Monitoring Program discrete and continuous water-quality monitoring sites utilized in this report.

\begin{tabular}{lcc}
\hline Station & $\begin{array}{c}\text { North latitude } \\
\text { (decimal degrees) }\end{array}$ & $\begin{array}{c}\text { West longitude } \\
\text { (decimal degrees) }\end{array}$ \\
\hline D7 & 38.1171 & 122.0397 \\
D4 & 38.0625 & 121.8205 \\
D6 & 38.0444 & 122.1177 \\
D8 & 38.0599 & 121.9900 \\
D41 & 38.0302 & 122.3729 \\
D41A & 38.0847 & 122.3907 \\
Rio Vista Bridge & 38.1597 & 121.6864 \\
Mallard Island & 38.0440 & 121.9190 \\
\hline
\end{tabular}

Table 6-2. Nitrite plus nitrate as nitrogen, ammonium as nitrogen, and chlorophyll- $\alpha$, by salinity group, from water samples collected during Environmental Monitoring Program sampling in 2005, 2006, 2010, and 2011.

[Latitude and longitude of sampling stations are in table 6-1, except for EZ2 and EZ6. These samples were taken at locations where near-bottom specific conductances were 2,000 and 6,000 $\mu \mathrm{S} / \mathrm{cm}$, respectively. Abbreviations: mg/L, milligram per liter; mm/dd/yyyy, month/day/year; N, nitrogen; $\mu \mathrm{g} / \mathrm{L}$, microgram per liter; - , missing data; <, less than; >, greater than; +, plus]

\begin{tabular}{|c|c|c|c|c|c|c|c|c|c|c|c|}
\hline Station & $\begin{array}{c}\text { Date } \\
\text { (mm/dd/yyyy) }\end{array}$ & $\begin{array}{l}\text { Salinity } \\
\text { group }\end{array}$ & $\begin{array}{c}\text { Ammonia } \\
\text { as N } \\
\text { (mg/L) }\end{array}$ & $\begin{array}{c}\text { Nitrite }+ \\
\text { nitrate as } \mathbf{N} \\
(\mathrm{mg} / \mathrm{L})\end{array}$ & $\begin{array}{l}\text { Chlorophyll- } \alpha \\
(\mu \mathrm{g} / \mathrm{L})\end{array}$ & Station & $\begin{array}{c}\text { Date } \\
\text { (mm/dd/yyyy) }\end{array}$ & $\begin{array}{c}\text { Salinity } \\
\text { group }\end{array}$ & $\begin{array}{c}\text { Ammonia } \\
\text { as } N \\
(\mathrm{mg} / \mathrm{L})\end{array}$ & $\begin{array}{c}\text { Nitrite }+ \\
\text { nitrate as } \mathbf{N} \\
(\mathrm{mg} / \mathrm{L})\end{array}$ & $\begin{array}{c}\text { Chlorophyll- } \alpha \\
(\mu \mathrm{g} / \mathrm{L})\end{array}$ \\
\hline$\overline{\mathrm{D} 7}$ & $09 / 23 / 2005$ & $>6$ & 0.05 & 0.32 & 1.84 & $\overline{\mathrm{D} 6}$ & $09 / 14 / 2006$ & $>6$ & 0.09 & 0.34 & 1.60 \\
\hline D4 & $09 / 26 / 2005$ & $<1$ & 0.06 & 0.25 & 1.54 & D8 & $09 / 14 / 2006$ & $1-6$ & 0.07 & 0.30 & 1.13 \\
\hline D6 & $09 / 26 / 2005$ & $>6$ & 0.05 & 0.26 & 2.24 & $\mathrm{EZ2}$ & $09 / 14 / 2006$ & $1-6$ & - & - & 2.04 \\
\hline D8 & $09 / 26 / 2005$ & $1-6$ & 0.05 & 0.28 & 1.20 & EZ6 & $09 / 14 / 2006$ & $1-6$ & - & - & 1.38 \\
\hline D41 & 09/27/2005 & $>6$ & 0.02 & 0.21 & 3.04 & D7 & $10 / 12 / 2006$ & $>6$ & 0.07 & 0.37 & 1.26 \\
\hline D41A & 09/27/2005 & $>6$ & & 0.16 & 7.90 & D4 & $10 / 16 / 2006$ & $1-6$ & 0.06 & 0.35 & 1.72 \\
\hline D7 & $10 / 24 / 2005$ & $>6$ & 0.09 & 0.35 & 1.42 & D6 & $10 / 16 / 2006$ & $>6$ & 0.09 & 0.39 & 1.70 \\
\hline D4 & $10 / 25 / 2005$ & $1-6$ & 0.08 & 0.34 & 1.25 & D8 & $10 / 16 / 2006$ & $>6$ & 0.07 & 0.37 & 1.54 \\
\hline D6 & $10 / 25 / 2005$ & $>6$ & 0.11 & 0.33 & 1.45 & $\mathrm{EZ2}$ & $10 / 16 / 2006$ & $<1$ & - & - & 1.55 \\
\hline D8 & $10 / 25 / 2005$ & $>6$ & 0.09 & 0.35 & 1.59 & EZ6 & $10 / 16 / 2006$ & $1-6$ & - & - & 1.58 \\
\hline D41A & $10 / 26 / 2005$ & $>6$ & 0.09 & 0.29 & 3.04 & D4 & $11 / 14 / 2006$ & $1-6$ & 0.11 & 0.46 & 0.85 \\
\hline D7 & $11 / 21 / 2005$ & $>6$ & 0.14 & 0.47 & 1.14 & D6 & $11 / 14 / 2006$ & $>6$ & 0.12 & 0.41 & 0.79 \\
\hline D4 & $11 / 22 / 2005$ & $1-6$ & 0.14 & 0.51 & 0.61 & D8 & $11 / 14 / 2006$ & $>6$ & 0.11 & 0.44 & 1.00 \\
\hline D6 & $11 / 22 / 2005$ & $>6$ & 0.14 & 0.44 & 1.17 & EZ2 & $11 / 14 / 2006$ & $<1$ & - & - & 1.46 \\
\hline D8 & $11 / 22 / 2005$ & $>6$ & 0.13 & 0.48 & 0.85 & EZ6 & $11 / 14 / 2006$ & $1-6$ & - & - & 0.97 \\
\hline EZ2 & $11 / 22 / 2005$ & $<1$ & - & - & 1.26 & D41 & $11 / 15 / 2006$ & $>6$ & 0.10 & 0.30 & 1.43 \\
\hline EZ6 & $11 / 22 / 2005$ & $1-6$ & - & - & 0.62 & D41A & $11 / 15 / 2006$ & $>6$ & 0.10 & 0.36 & 1.54 \\
\hline D41 & $11 / 23 / 2005$ & $>6$ & 0.11 & 0.32 & 2.82 & D7 & $12 / 11 / 2006$ & $>6$ & 0.14 & 0.51 & 0.95 \\
\hline D41A & $11 / 23 / 2005$ & $>6$ & 0.13 & 0.38 & 1.71 & D4 & $12 / 12 / 2006$ & $1-6$ & 0.16 & 0.50 & 1.00 \\
\hline D7 & $12 / 21 / 2005$ & $>6$ & 0.20 & 0.52 & 0.68 & D6 & $12 / 12 / 2006$ & $>6$ & 0.15 & 0.47 & 1.00 \\
\hline D4 & $12 / 22 / 2005$ & $1-6$ & 0.25 & 0.50 & 0.92 & D8 & $12 / 12 / 2006$ & $>6$ & 0.12 & 0.42 & 1.22 \\
\hline
\end{tabular}


Table 6-2. Nitrite plus nitrate as nitrogen, ammonium as nitrogen, and chlorophyll- $\alpha$, by salinity group, from water samples collected during Environmental Monitoring Program sampling in 2005, 2006, 2010, and 2011.—Continued

[Latitude and longitude of sampling stations are in table 6-1. Abbreviations: mg/L, milligram per liter; mm/dd/yyyy, month/day/year; N, nitrogen; $\mu \mathrm{g} / \mathrm{L}$, microgram per liter; - , missing data; <, less than; >, greater than; +, plus]

\begin{tabular}{|c|c|c|c|c|c|c|c|c|c|c|c|}
\hline Station & $\begin{array}{c}\text { Date } \\
\text { (mm/dd/yyyy) }\end{array}$ & $\begin{array}{l}\text { Salinity } \\
\text { group }\end{array}$ & $\begin{array}{c}\text { Ammonia } \\
\text { as N } \\
\text { (mg/L) }\end{array}$ & $\begin{array}{c}\text { Nitrite + } \\
\text { nitrate as } \mathbf{N} \\
\text { (mg/L) }\end{array}$ & 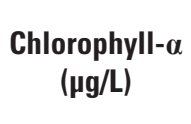 & Station & $\begin{array}{c}\text { Date } \\
\text { (mm/dd/yyyy) }\end{array}$ & $\begin{array}{l}\text { Salinity } \\
\text { group }\end{array}$ & $\begin{array}{c}\text { Ammonia } \\
\text { as } N \\
\text { (mg/L) }\end{array}$ & $\begin{array}{c}\text { Nitrite + } \\
\text { nitrate as } \mathbf{N} \\
\text { (mg/L) }\end{array}$ & $\begin{array}{c}\text { Chlorophyll- } \alpha \\
(\mu \mathrm{g} / \mathrm{L})\end{array}$ \\
\hline$\overline{\mathrm{D} 7}$ & $09 / 16 / 2010$ & $>6$ & 0.03 & 0.29 & 5.55 & $\overline{\mathrm{EZ2}}$ & $09 / 21 / 2011$ & $<1$ & 0.04 & 0.20 & 4.76 \\
\hline D41 & 09/17/2010 & $>6$ & 0.06 & 0.29 & 3.16 & EZ6 & $09 / 21 / 2011$ & $<1$ & 0.03 & 0.20 & 2.71 \\
\hline D41A & 09/17/2010 & $>6$ & 0.08 & 0.34 & 1.69 & D7 & $09 / 22 / 2011$ & $>6$ & 0.05 & 0.20 & 1.47 \\
\hline D6 & 09/17/2010 & $>6$ & 0.07 & 0.32 & 2.69 & D41 & $09 / 23 / 2011$ & $>6$ & 0.02 & 0.18 & 3.76 \\
\hline EZ2 & $10 / 14 / 2010$ & $<1$ & 0.05 & 0.27 & 2.02 & D4 & $10 / 19 / 2011$ & $<1$ & 0.06 & 0.21 & 4.08 \\
\hline EZ6 & $10 / 14 / 2010$ & $1-6$ & 0.04 & 0.27 & 2.34 & D8 & $10 / 19 / 2011$ & $1-6$ & 0.08 & 0.25 & 1.50 \\
\hline D7 & $10 / 15 / 2010$ & $>6$ & 0.07 & 0.29 & 1.83 & EZ2 & $10 / 19 / 2011$ & $<1$ & 0.07 & 0.19 & 2.39 \\
\hline D41 & $10 / 18 / 2010$ & $>6$ & 0.06 & 0.31 & 2.26 & EZ6 & $10 / 19 / 2011$ & $1-6$ & 0.07 & 0.25 & 2.20 \\
\hline D41A & $10 / 18 / 2010$ & $>6$ & 0.07 & 0.32 & 1.83 & D7 & $10 / 20 / 2011$ & $1-6$ & 0.08 & 0.26 & 1.03 \\
\hline EZ6 & $11 / 15 / 2010$ & $1-6$ & 0.09 & 0.44 & 1.31 & D8 & $11 / 18 / 2011$ & $>6$ & 0.10 & 0.26 & 1.05 \\
\hline D7 & $11 / 16 / 2010$ & $>6$ & 0.11 & 0.41 & 0.94 & EZ2 & $11 / 18 / 2011$ & $<1$ & 0.13 & 0.26 & 5.13 \\
\hline D41 & $11 / 17 / 2010$ & $>6$ & 0.10 & 0.29 & 2.52 & EZ6 & $11 / 18 / 2011$ & $1-6$ & 0.10 & 0.25 & 2.71 \\
\hline D41A & $11 / 17 / 2010$ & $>6$ & 0.10 & 0.38 & 2.72 & D7 & $11 / 21 / 2011$ & $>6$ & 0.12 & 0.27 & 1.50 \\
\hline D6 & $11 / 17 / 2010$ & $>6$ & 0.12 & 0.38 & 1.47 & D41 & $11 / 22 / 2011$ & $>6$ & 0.10 & 0.25 & 1.95 \\
\hline D4 & $12 / 15 / 2010$ & $<1$ & 0.14 & 0.32 & 1.21 & D41A & $11 / 22 / 2011$ & $>6$ & 0.12 & 0.27 & 2.48 \\
\hline D8 & $12 / 15 / 2010$ & $1-6$ & 0.14 & 0.29 & 0.57 & D6 & $11 / 22 / 2011$ & $>6$ & 0.13 & 0.29 & 1.31 \\
\hline EZ2 & $12 / 15 / 2010$ & $<1$ & 0.14 & 0.31 & 1.08 & D4 & $12 / 19 / 2011$ & $1-6$ & 0.16 & 0.17 & 0.59 \\
\hline EZ6 & $12 / 15 / 2010$ & $1-6$ & 0.13 & 0.29 & 0.79 & D8 & $12 / 19 / 2011$ & $>6$ & 0.16 & 0.20 & 0.69 \\
\hline D7 & $12 / 16 / 2010$ & $1-6$ & 0.18 & 0.41 & 0.64 & EZ2 & $12 / 19 / 2011$ & $<1$ & 0.19 & 0.14 & 1.29 \\
\hline D41 & $12 / 17 / 2010$ & $>6$ & 0.13 & 0.36 & 2.31 & EZ6 & $12 / 19 / 2011$ & $1-6$ & 0.17 & 0.19 & 0.85 \\
\hline
\end{tabular}

Table 6-3. In-situ fluoresence at Rio Vista Bridge and Mallard Island for September-December 2011. 


\section{Appendix 7. U.S. Geological Survey Water-Quality Monitoring}

The U.S. Geological Survey (USGS) maintains a comprehensive database documenting the methods and results for long-term monitoring of the San Francisco estuary (http://sfbay.wr.usgs.gov/access/wqdata/index.html). Sampling is performed monthly. We used data from seven sites (fig. 7-1; table 7-1) where discrete water samples were taken for analysis of chlorophyll- $\alpha$ and nutrients. Data from site 5 were used when data from site 6 were not available. These sites were considered to be representative of water quality in the fall range of delta smelt. We utilized data from water samples collected 2 meters below the surface to be comparable with samples collected near the surface by the Environmental Monitoring Program (EMP) and during the fall midwater trawl (FMWT). We used data for ammonium as nitrogen, nitrite plus nitrate as nitrogen, and chlorophyll- $\alpha$ (table 7-2). Ammonium and nitrite plus nitrate are presented in terms of micromoles in the USGS database. For purposes of comparison, we converted these molar concentrations to milligrams per liter $(\mathrm{mg} / \mathrm{L})$ of ammonium as nitrogen and nitrite plus nitrate as nitrogen. Water samples were analyzed in the laboratory of Dr. Richard Dugdale of the Romberg-Tiburon Canter of San Francisco State University.

Chlorophyll- $a$ samples were filtered onto glass microfiber (GF/F) filters and immediately frozen. Filters were then stored at $-80{ }^{\circ} \mathrm{C}$ for less than 1 month until analyzed. Samples were extracted for 24 hours in acetone prior to determination of chlorophyll- $a$ concentration by using a Turner laboratory fluorometer (Parsons and others, 1984). Chlorophyll- $\alpha$ was reported as milligrams per cubic meter in the original database, which is equivalent to values of micrograms per liter reported in this report.

Nutrient samples were filtered through 0.4-micron polycarbonate filters and frozen until analyzed for nitrite plus nitrate, and ammonium. Nitrite plus nitrate concentrations were determined by using a Bran and Lubbe AutoAnalyzer II (Whitledge and others, 1981), and ammonium was determined by using a spectrophotometer according to Solorzano (1969). Water samples were prefiltered by using precombusted GF/F filters before ammonium analysis.

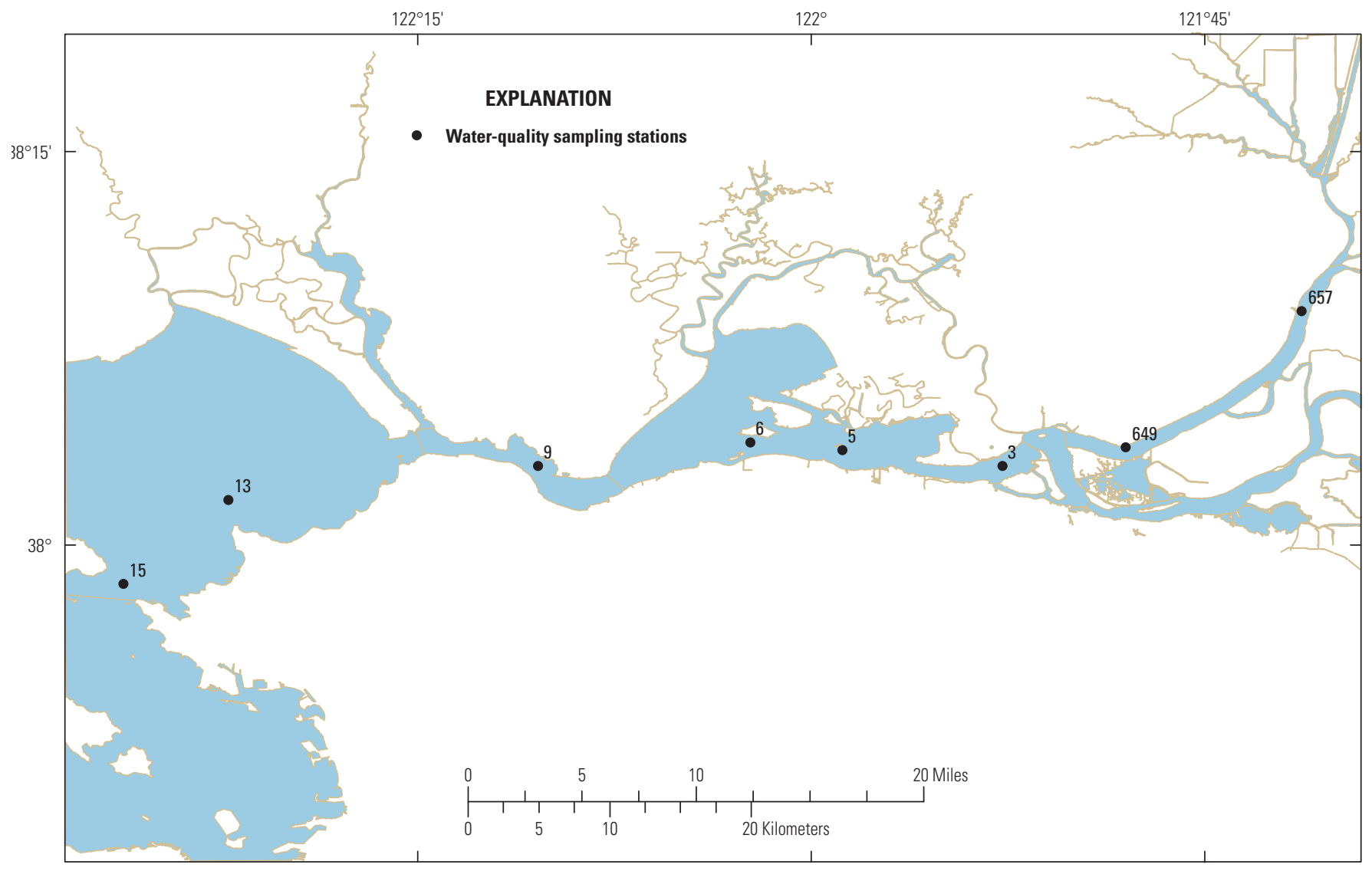

Figure 7-1. Sites sampled by the U.S. Geological Survey water-quality monitoring program for water-quality constituents. 
Table 7-1. Latitude and longitude of U.S. Geologic Survey water-quality monitoring sites utilized in this report.

[Abbreviations: ${ }^{\circ}$, degree; ’, minute]

\begin{tabular}{|c|c|c|}
\hline Station & $\begin{array}{c}\text { North } \\
\text { latitude }\end{array}$ & $\begin{array}{c}\text { West } \\
\text { longitude }\end{array}$ \\
\hline 657 & $38^{\circ} 8.9^{\prime}$ & $121^{\circ} 41.3^{\prime}$ \\
\hline 649 & $38^{\circ} 3.7^{\prime}$ & $121^{\circ} 48.0^{\prime}$ \\
\hline 5 & $38^{\circ} 3.6^{\prime}$ & $121^{\circ} 58.8^{\prime}$ \\
\hline 6 & $38^{\circ} 3.9^{\prime}$ & $122^{\circ} 2.3^{\prime}$ \\
\hline 15 & $37^{\circ} 58.5^{\prime}$ & $122^{\circ} 26.2^{\prime}$ \\
\hline
\end{tabular}


Table 7-2. Ammonium, ammonium as nitrogen, nitrite plus nitrate, nitrite plus nitrate as nitrogen, and chlorophyll- $\alpha$, by salinity group, from water samples collected by the U.S. Geological Survey in 2005, 2006, 2010, and 2011.

[Latitude and longitude of sampling stations are in table 7-1. Chlorophyll- $\alpha$ determined from fluorescence data rather than analysis of pigments from discrete water samples. Abbreviations: hh:mm, hour:minute; mg/L, milligram per liter; mm/dd/yyyy, month/day/year; N, nitrogen; $\mu \mathrm{g} / \mathrm{L}, \mathrm{microgram}$ per liter; $\mu \mathrm{M} / \mathrm{L}$, micromole per liter; +, plus]

\begin{tabular}{|c|c|c|c|c|c|c|c|c|}
\hline Station & $\begin{array}{c}\text { Date } \\
\text { (mm/dd/yyyy) }\end{array}$ & $\begin{array}{c}\text { Time } \\
\text { (hh:mm) }\end{array}$ & $\begin{array}{l}\text { Salinity } \\
\text { region }\end{array}$ & $\begin{array}{c}\text { Ammonium } \\
(\mu \mathrm{M} / \mathrm{L})\end{array}$ & $\begin{array}{c}\text { Ammonium } \\
\text { as } \mathbf{N} \\
\text { (mg/L) }\end{array}$ & $\begin{array}{c}\text { Nitrite + } \\
\text { nitrate } \\
(\mu \mathrm{M} / \mathrm{L})\end{array}$ & $\begin{array}{c}\text { Nitrite + } \\
\text { nitrate as } \mathbf{N} \\
\text { (mg/L) }\end{array}$ & $\begin{array}{c}\text { Chlorophyll- } \alpha \\
(\mu \mathrm{g} / \mathrm{L})\end{array}$ \\
\hline 15 & $09 / 07 / 2005$ & $11: 38$ & $>6$ & 3.71 & 0.05 & 14.68 & 0.21 & $3.6 \mathrm{a}$ \\
\hline 13 & $09 / 07 / 2005$ & $12: 14$ & $>6$ & 4.48 & 0.06 & 18.75 & 0.26 & 2.3 \\
\hline 9 & 09/07/2005 & $13: 31$ & $>6$ & 5.34 & 0.07 & 24.11 & 0.34 & 3.0 \\
\hline 6 & 09/07/2005 & $14: 30$ & $>6$ & 2.7 & 0.04 & 23.44 & 0.33 & 4.0 \\
\hline 13 & $10 / 12 / 2005$ & $13: 00$ & $>6$ & 1.62 & 0.02 & 13.65 & 0.19 & 6.7 \\
\hline 9 & $10 / 12 / 2005$ & $14: 29$ & $>6$ & 5.69 & 0.08 & 19.38 & 0.27 & 2.0 \\
\hline 6 & $10 / 12 / 2005$ & $15: 45$ & $>6$ & 5.45 & 0.08 & 22.69 & 0.32 & 3.3 \\
\hline 3 & $10 / 12 / 2005$ & $16: 52$ & $1-6$ & 6 & 0.08 & 21.96 & 0.31 & 1.9 \\
\hline 15 & $11 / 08 / 2005$ & $11: 59$ & $>6$ & 5.24 & 0.07 & 20.07 & 0.28 & 4.9 \\
\hline 13 & $11 / 08 / 2005$ & $12: 38$ & $>6$ & 5.87 & 0.08 & 20.60 & 0.29 & 3.3 \\
\hline 15 & $12 / 07 / 2005$ & $11: 43$ & $>6$ & 5.62 & 0.08 & 23.99 & 0.34 & 4.1 \\
\hline 13 & $12 / 07 / 2005$ & $12: 24$ & $>6$ & 8.77 & 0.12 & 26.84 & 0.38 & 2.4 \\
\hline 9 & $12 / 07 / 2005$ & $14: 07$ & $>6$ & 12.02 & 0.17 & 31.74 & 0.44 & 1.9 \\
\hline 6 & $12 / 07 / 2005$ & $15: 19$ & $>6$ & 11.42 & 0.16 & 32.90 & 0.46 & 0.9 \\
\hline 3 & $12 / 07 / 2005$ & $16: 21$ & $1-6$ & 11.04 & 0.15 & 29.71 & 0.42 & 1.1 \\
\hline 15 & $09 / 12 / 2006$ & $11: 38$ & $>6$ & 5.23 & 0.07 & 20.36 & 0.29 & 4.5 \\
\hline 13 & $09 / 12 / 2006$ & $12: 14$ & $>6$ & 6.12 & 0.09 & 19.46 & 0.27 & 3.0 \\
\hline 9 & $09 / 12 / 2006$ & $13: 33$ & $>6$ & 5.93 & 0.08 & 23.70 & 0.33 & 3.1 \\
\hline 6 & $09 / 12 / 2006$ & $14: 46$ & $1-6$ & 3.96 & 0.06 & 18.36 & 0.26 & 2.8 \\
\hline 3 & $09 / 12 / 2006$ & $15: 41$ & $<1$ & 3.34 & 0.05 & 15.74 & 0.22 & 3.2 \\
\hline 649 & $09 / 12 / 2006$ & $16: 21$ & $<1$ & 4.66 & 0.07 & 15.26 & 0.21 & 4.8 \\
\hline 15 & $11 / 14 / 2006$ & $11: 53$ & $>6$ & 6.27 & 0.09 & 21.86 & 0.31 & 2.1 \\
\hline 13 & $11 / 14 / 2006$ & $12: 34$ & $>6$ & 6.47 & 0.09 & 23.11 & 0.32 & 3.2 \\
\hline 9 & $11 / 14 / 2006$ & $14: 14$ & $>6$ & 7.48 & 0.10 & 26.25 & 0.37 & 2.2 \\
\hline 6 & $11 / 14 / 2006$ & $15: 33$ & $>6$ & 7.87 & 0.11 & 30.15 & 0.42 & 1.4 \\
\hline 3 & $11 / 14 / 2006$ & $16: 48$ & $1-6$ & 8.02 & 0.11 & 32.23 & 0.45 & 1.2 \\
\hline 649 & $11 / 14 / 2006$ & $17: 29$ & $1-6$ & 9.79 & 0.14 & 33.50 & 0.47 & 1.7 \\
\hline 657 & $11 / 14 / 2006$ & $18: 29$ & $<1$ & 20.79 & 0.29 & 28.53 & 0.40 & 1.5 \\
\hline 15 & $12 / 12 / 2006$ & $11: 59$ & $>6$ & 5.51 & 0.08 & 28.60 & 0.40 & 4.9 \\
\hline 13 & $12 / 12 / 2006$ & $12: 41$ & $>6$ & 7.88 & 0.11 & 28.56 & 0.40 & 2.8 \\
\hline 9 & $12 / 12 / 2006$ & $14: 28$ & $>6$ & 11.15 & 0.16 & 33.14 & 0.46 & 2.2 \\
\hline 6 & $12 / 12 / 2006$ & $15: 45$ & $>6$ & 10.28 & 0.14 & 36.13 & 0.51 & 1.5 \\
\hline 3 & $12 / 12 / 2006$ & $16: 56$ & $1-6$ & 11.99 & 0.17 & 36.94 & 0.52 & 1.5 \\
\hline 649 & $12 / 12 / 2006$ & $17: 31$ & $<1$ & 15.54 & 0.22 & 34.01 & 0.48 & 1.7 \\
\hline 657 & $12 / 12 / 2006$ & $18: 29$ & $<1$ & 18.66 & 0.26 & 27.92 & 0.39 & 2.4 \\
\hline 15 & 09/14/2010 & $11: 59$ & $>6$ & 4.27 & 0.06 & 20.98 & 0.29 & 8.2 \\
\hline 13 & 09/14/2010 & $12: 39$ & $>6$ & 4.72 & 0.07 & 22.66 & 0.32 & 5.6 \\
\hline
\end{tabular}


Table 7-2. Ammonium, ammonium as nitrogen, nitrite plus nitrate, nitrite plus nitrate as nitrogen, and chlorophyll- $\alpha$, by salinity group, from water samples collected by the U.S. Geological Survey in 2005, 2006, 2010, and 2011.-Continued

[Latitude and longitude of sampling stations are in table 7-1. Chlorophyll- $\alpha$ determined from fluorescence data rather than analysis of pigments from discrete water samples. Abbreviations: hh:mm, hour:minute; mg/L, milligram per liter; mm/dd/yyyy, month/day/year; N, nitrogen; $\mu \mathrm{g} / \mathrm{L}, \mathrm{microgram}$ per liter; $\mu \mathrm{M} / \mathrm{L}$, micromole per liter; +, plus]

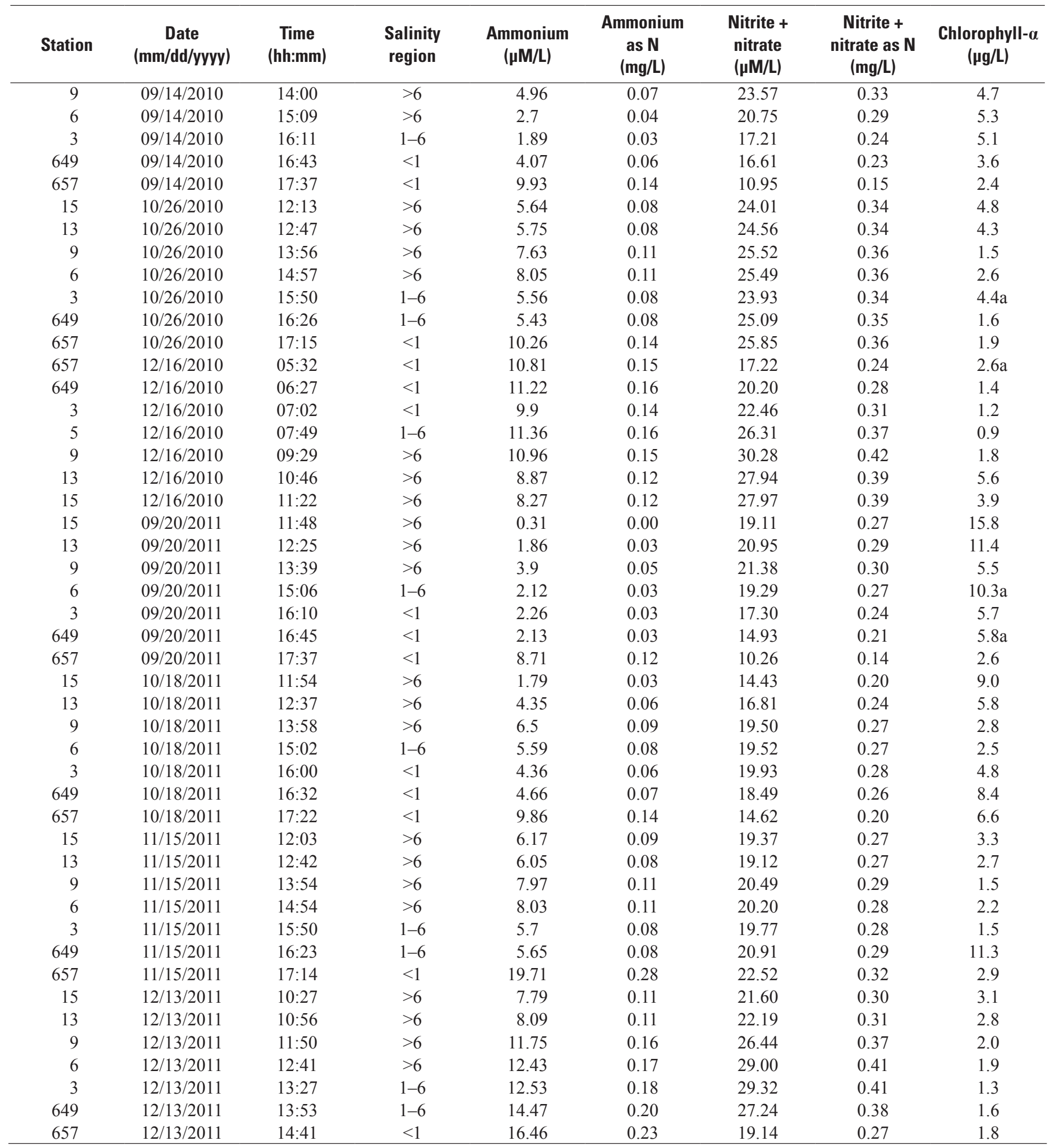




\section{References Cited}

Parsons, T.R., Maita, Y., and Lalli, C.M., 1984, A manual of chemical and biological methods for seawater analysis:

Pergamon Press, New York, 173 p.

Solorzano, L., 1969, A method for measuring ammonium in seawater: Limnolology and Oceanography, v. 14, p. 799-801.

Whitledge, T.E., Malloy, S.C., Patton, C.J., and Wirick, C.D., 1981, Automated nutrient analysis in seawater: Report BNL 51398, Brookhaven National Laboratory, Upton, New York, $216 \mathrm{p}$. 


\section{Appendix 8. California Department of Fish and Wildlife Fish Sampling}

In addition to the fall midwater-trawl survey (appendix 4), the California Department of Fish and Wildlife (CDFW) performs other surveys of the delta smelt population. The spring Kodiak trawl (SKT) samples mature and spawning adults. For convenience, we are providing here the general description of the SKT sampling available at http://www.dfg.ca.gov/delta/projects.asp? ProjectID $=S K T$. The text has been edited from the original to be consistent with format and usage in this report. We also include a map (fig. 8-1) of the sampling sites. Values of the SKT delta smelt abundance index are given in table 8-1.

The spring Kodiak-trawl survey (SKT) has sampled annually since its inception in 2002. The SKT determines the relative abundance and distribution of spawning delta smelt (Hypomesus transpacificus). The SKT samples 40 stations each month from January to May. These 40 stations range in location from the Napa River upstream to Stockton on the San Joaquin River, Walnut Grove on the Sacramento River, and the Sacramento Deep Water Ship Channel. Each 'Delta-wide' survey takes approximately 4-5 days per month to complete.
Historically, 'Delta-wide' surveys were followed by a 'Supplemental' survey two weeks later to intensively sample areas of the highest delta smelt concentration to estimate the proportion of male and female delta smelt that were in pre-spawning, spawning, and spent maturation stages. Beginning in 2008, in an effort to minimize take of spawning adults, routine 'Supplemental' surveys were discontinued and are now only done under the recommendation of the Smelt Working Group and the approval of managers. 'Delta-wide' surveys are numbered consecutively, beginning with number 1, and 'Supplemental' surveys are numbered consecutively beginning with number 11.

The Kodiak-trawl net has mouth dimensions of 25 -ft wide by 6 -ft high when stretched taught. Net mesh sizes graduate in five sections from 2-inch stretch-mesh at the mouth to 0.25 -inch stretch-mesh at the cod-end. A 10-minute surface tow is carried out at each station with two boats that spread the net mouth fully open. All fish, shrimp, and jellyfish collected in the tow are identified and enumerated. Delta smelt are further processed to identify gender and maturity. Water temperature, electrical conductivity (specific conductance), Secchi depth, and turbidity are collected at the beginning of each tow.

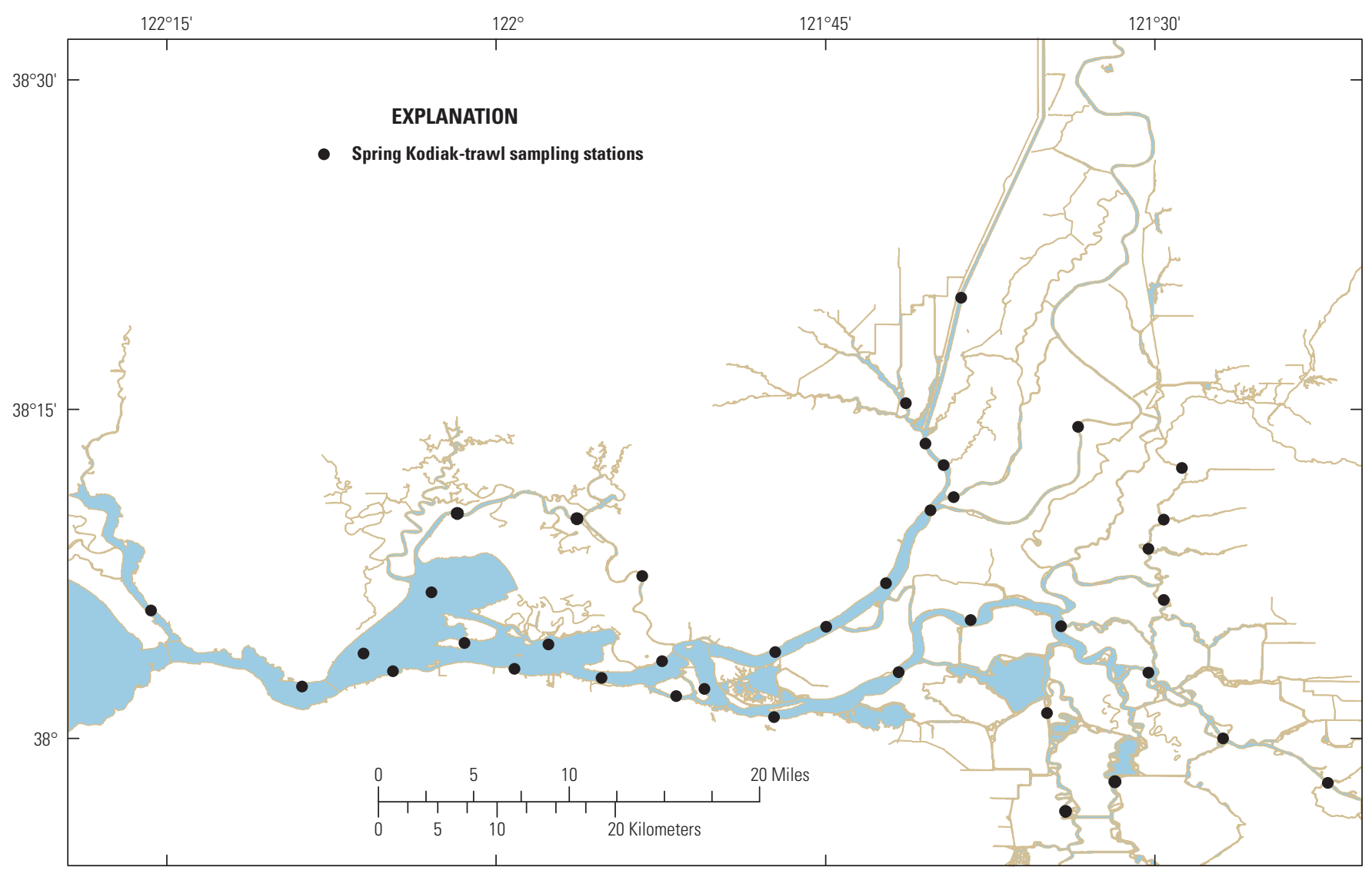

Figure 8-1. Sites sampled by the California Department of Fish and Wildlife spring Kodiak-trawl survey 
Table 8-1. Annual values of delta smelt abundance indices for the fall midwater-trawl survey, spring Kodiak-trawl survey, 20-millimeter $(\mathrm{mm})$ survey, and summer townet survey and values for selcted ratios of abundance indices.

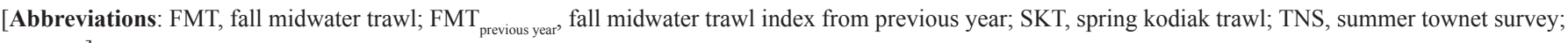
-, none]

\begin{tabular}{|c|c|c|c|c|c|c|c|c|c|}
\hline Year & FMT & SKT & 20-mm & TNS & FMT/TNS & $\mathrm{SKT}_{\text {FMT }}$ previous year & 20-mm/SKT & TNS/SKT & $\mathrm{TNS} \mathrm{FMT}_{\text {previous year }}$ \\
\hline 1959 & - & - & - & 12.1 & - & - & - & - & - \\
\hline 1960 & - & - & - & 25.4 & - & - & - & - & - \\
\hline 1961 & - & - & - & 21.3 & - & - & - & - & - \\
\hline 1962 & - & - & - & 24.9 & - & - & - & - & - \\
\hline 1963 & - & - & - & 1.8 & - & - & - & - & - \\
\hline 1964 & - & - & - & 24.6 & - & - & - & - & - \\
\hline 1965 & - & - & - & 6 & - & - & - & - & - \\
\hline 1966 & - & - & - & - & - & - & - & - & - \\
\hline 1967 & 408 & - & - & - & - & - & - & - & - \\
\hline 1968 & 696 & - & - & - & - & - & - & - & - \\
\hline 1969 & 313 & - & - & 2.5 & 125.2000 & - & - & - & 0.0036 \\
\hline 1970 & 1,673 & - & - & 32.5 & 51.4769 & - & - & - & 0.1038 \\
\hline 1971 & 1,303 & - & - & 12.5 & 104.2400 & - & - & - & 0.0075 \\
\hline 1972 & 1,265 & - & - & 11.1 & 113.9640 & - & - & - & 0.0085 \\
\hline 1973 & 1,145 & - & - & 21.3 & 53.7559 & - & - & - & 0.0168 \\
\hline 1974 & - & - & - & 13 & - & - & - & - & 0.0114 \\
\hline 1975 & 697 & - & - & 12.2 & 57.1311 & - & - & - & - \\
\hline 1976 & 359 & - & - & 50.6 & 7.0949 & - & - & - & 0.0726 \\
\hline 1977 & 480 & - & - & 25.8 & 18.6047 & - & - & - & 0.0719 \\
\hline 1978 & 572 & - & - & 62.5 & 9.1520 & - & - & - & 0.1302 \\
\hline 1979 & - & - & - & 13.3 & - & - & - & - & 0.0233 \\
\hline 1980 & 1,654 & - & - & 15.8 & 104.6835 & - & - & - & - \\
\hline 1981 & 374 & - & - & 19.8 & 18.8889 & - & - & - & 0.0120 \\
\hline 1982 & 333 & - & - & 10.7 & 31.1215 & - & - & - & 0.0286 \\
\hline 1983 & 132 & - & - & 2.9 & 45.5172 & - & - & - & 0.0087 \\
\hline 1984 & 182 & - & - & 1.2 & 151.6667 & - & - & - & 0.0091 \\
\hline 1985 & 110 & - & - & 0.9 & 122.2222 & - & - & - & 0.0049 \\
\hline 1986 & 212 & - & - & 7.9 & 26.8354 & - & - & - & 0.0718 \\
\hline 1987 & 280 & - & - & 1.4 & 200.0000 & - & - & - & 0.0066 \\
\hline 1988 & 174 & - & - & 1.2 & 145.0000 & - & - & - & 0.0043 \\
\hline 1989 & 366 & - & - & 2.2 & 166.3636 & - & - & - & 0.0126 \\
\hline 1990 & 364 & - & - & 2.2 & 165.4545 & - & - & - & 0.0060 \\
\hline 1991 & 689 & - & - & 2 & 344.5000 & - & - & - & 0.0055 \\
\hline 1992 & 156 & - & - & 2.6 & 60.0000 & - & - & - & 0.0038 \\
\hline 1993 & 1,078 & - & - & 8.2 & 131.4634 & - & - & - & 0.0526 \\
\hline 1994 & 102 & - & - & 13 & 7.8462 & - & - & - & 0.0121 \\
\hline 1995 & 899 & - & 4.4 & 3.2 & 280.9375 & - & - & - & 0.0314 \\
\hline 1996 & 127 & - & 33.9 & 11.1 & 11.4414 & - & - & - & 0.0123 \\
\hline 1997 & 303 & - & 19.3 & 4 & 75.7500 & - & - & - & 0.0315 \\
\hline 1998 & 420 & - & 7.7 & 3.3 & 127.2727 & - & - & - & 0.0109 \\
\hline 1999 & 864 & - & 39.7 & 11.9 & 72.6050 & - & - & - & 0.0283 \\
\hline 2000 & 756 & - & 23.8 & 8 & 94.5000 & - & - & - & 0.0093 \\
\hline 2001 & 603 & - & 11.3 & 3.5 & 172.2857 & - & - & - & 0.0046 \\
\hline 2002 & 139 & - & 8 & 4.7 & 29.5745 & - & - & - & 0.0078 \\
\hline 2003 & 210 & 80.6 & 13.1 & 1.6 & 131.2500 & 0.5799 & 0.1625 & 0.0199 & 0.0115 \\
\hline 2004 & 74 & 97.3 & 8.2 & 2.9 & 25.5172 & 0.4633 & 0.0843 & 0.0298 & 0.0138 \\
\hline 2005 & 26 & 51.2 & 15.4 & 0.3 & 86.6667 & 0.6919 & 0.3008 & 0.0059 & 0.0041 \\
\hline 2006 & 41 & 18.2 & 9.9 & 0.4 & 102.5000 & 0.7000 & 0.5440 & 0.0220 & 0.0154 \\
\hline 2007 & 28 & 32.5 & 1 & 0.4 & 70.0000 & 0.7927 & 0.0308 & 0.0123 & 0.0098 \\
\hline 2008 & 23 & 24.1 & 2.9 & 0.6 & 38.3333 & 0.8607 & 0.1203 & 0.0249 & 0.0214 \\
\hline 2009 & 17 & 44.6 & 2.3 & 0.3 & 56.6667 & 1.9391 & 0.0516 & 0.0067 & 0.0130 \\
\hline 2010 & 29 & 27.4 & 3.8 & 0.8 & 36.2500 & 1.6118 & 0.1387 & 0.0292 & 0.0471 \\
\hline 2011 & 343 & 20 & 8 & 2.2 & 155.9091 & 0.6897 & 0.4000 & 0.1100 & 0.0759 \\
\hline 2012 & 42 & 147.3 & 11.1 & 0.9 & 46.6667 & 0.4294 & 0.0754 & 0.0061 & 0.0026 \\
\hline
\end{tabular}


The U.S. Fish and Wildlife Service's Biological Opinion for delta smelt has criteria pertaining to delta smelt protection based on SKT survey results. Those survey results, provided in near-real time, are used by state and federal resource managers to assess the risk of entrainment of delta smelt at the Central Valley and State Water projects.

The 20-millimeter ( $\mathrm{mm}$ ) survey samples post-larval delta smelt. For convenience we are providing here the general description of the 20-mm survey sampling available at: $h t t p: / /$ www.dfg.ca.gov/delta/projects.asp? ProjectID $=20 \mathrm{~mm}$. We also include a map (fig. 8-2) of the sampling sites. The text has been edited from the original to be consistent with format and usage in this report. Values of the 20 -mm delta smelt abundance index are provided in table 8-1.

This study monitors postlarval-juvenile delta smelt distribution and relative abundance throughout their historical spring range in the Sacramento-San Joaquin Delta and San Francisco estuary. Delta smelt in the central and south Delta areas can be entrained into the pumps of the State Water Project (SWP) and the Central Valley Project (CVP). This survey gets its name from the size (20-mm) at which delta smelt are retained and readily identifiable at the fish facilities associated with the state and federal pumps. The 2004 Biological Opinion requires this survey to provide "recent time" (within 72 hours) information on the distribution and relative abundance of delta smelt throughout the Delta and the upper estuary. These data can be found under Delta Smelt Distribution and Delta Smelt Length Frequency. Based upon the data, recommendations are made to protect delta smelt.

Methods: There are eight to ten fortnightly sampling surveys that cover stations throughout the delta and downstream to the eastern portion of San Pablo Bay and Napa River. Samples are collected by using an egg and larval, rigid-opening net constructed of 1,600 micrometer $(\mu \mathrm{m})$ mesh. Three 10-minute stepped-oblique (bottom to top) tows are completed at each station. Samples are preserved in neutral buffered formalin and then all fish larvae are sorted out and identified in a lab. The vast numbers of species (about 50) and amounts of detritus in the samples make this a labor-intensive process.

The summer townet survey (TNS) samples juvenile delta smelt. For convenience, we reprint here the general description of the summer townet survey, which is available at $h t t p: / / w w w$. dfg.ca.gov/delta/projects.asp? ProjectID=TOWNET . The text has been edited from the original to be consistent with format and usage in this report. We also include a map (fig. 8-3) of the sampling sites. Values of the TNS delta smelt abundance index are provided in table 8-1.

The TNS was initiated in 1959 to determine the relative distribution and abundance of young of the year (age-0) striped bass (Morone saxatilis) in the Delta. To predict fishery recruitment, the survey calculates an index to measure age-0 striped bass year-class strength. This index is based

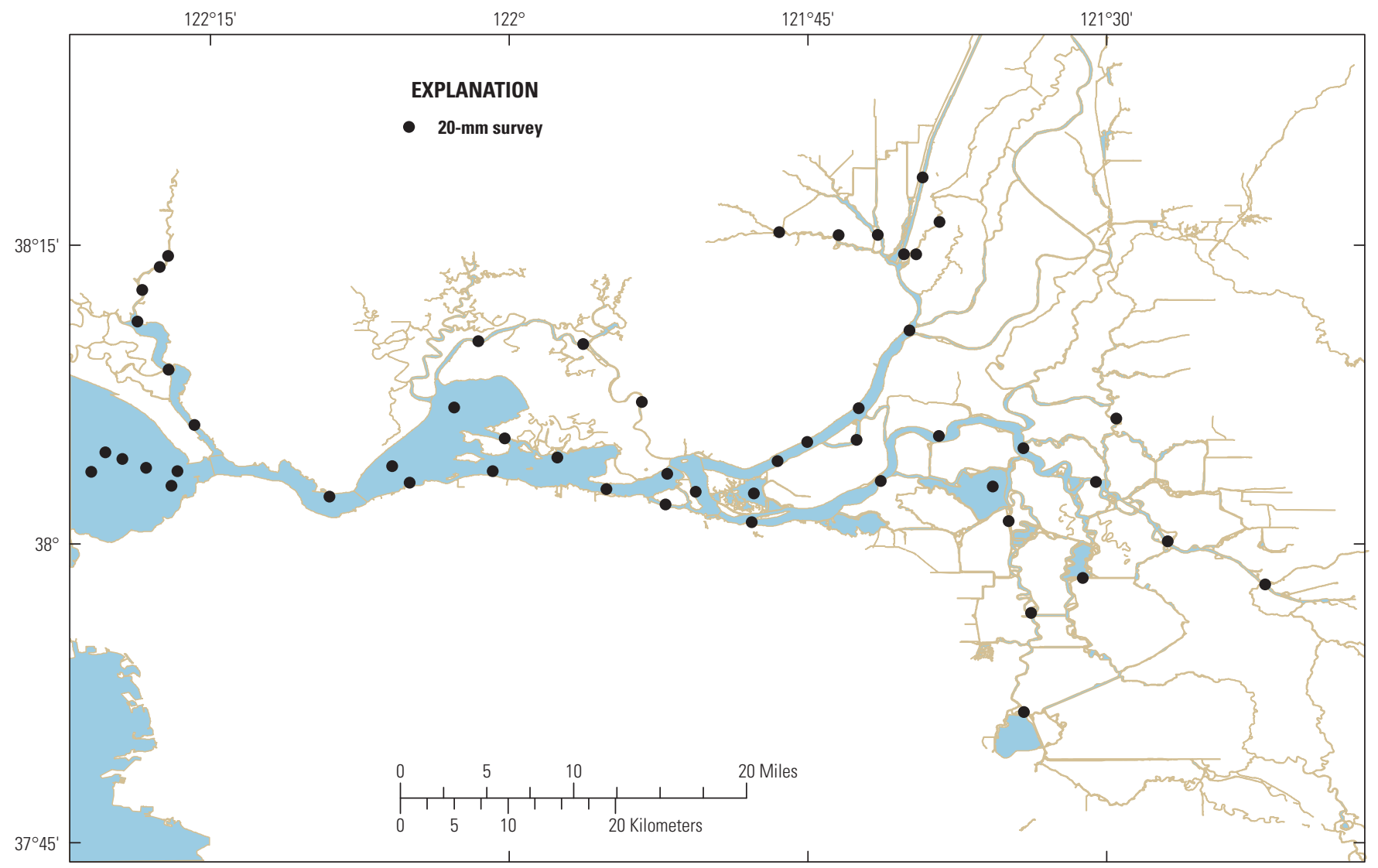

Figure 8-2. Sites sampled by the California Department of Fish and Wildlife 20-millimeter $(\mathrm{mm})$ survey. 


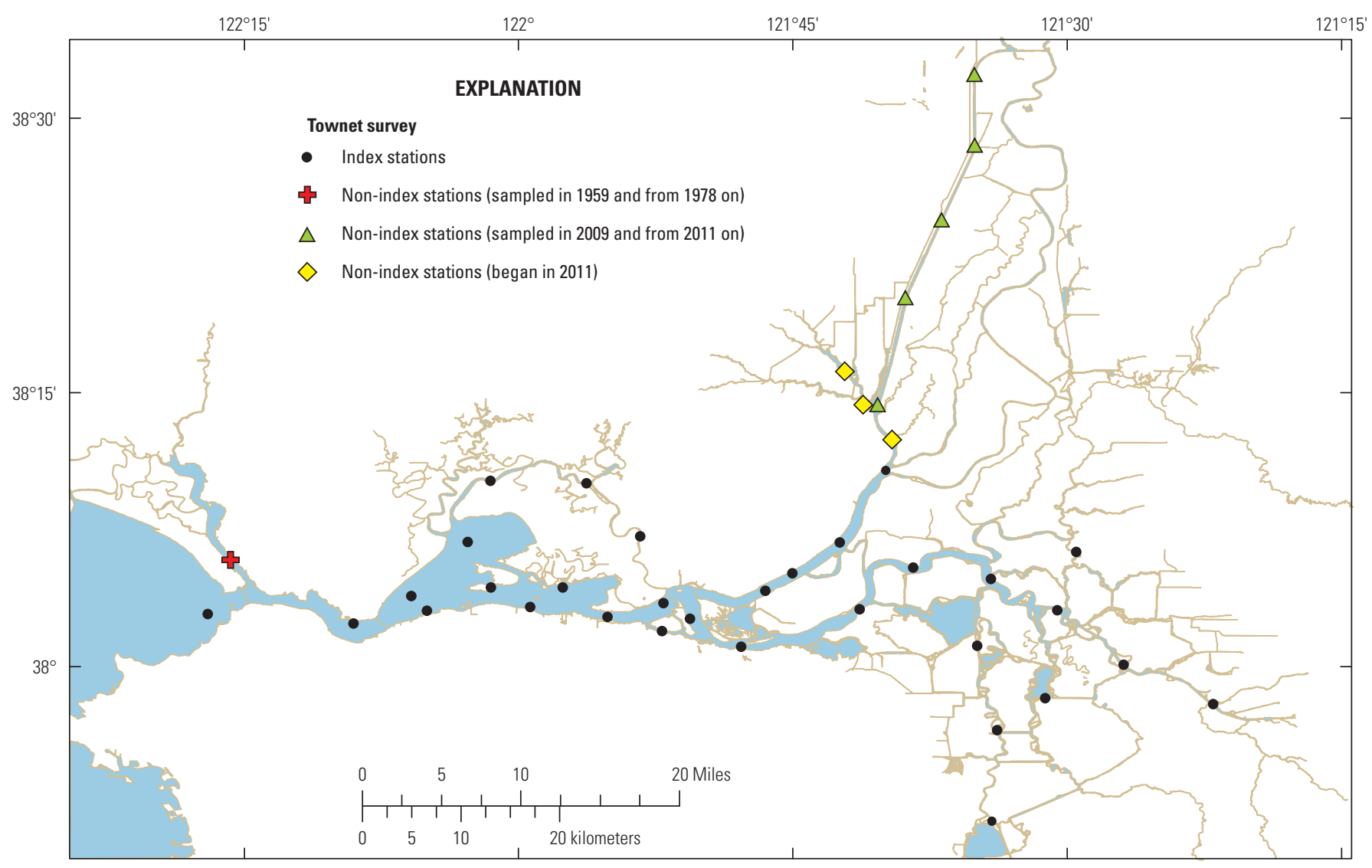

Figure 8-3. Sites sampled by the California Department of Fish and Wildlife summer townet survey.

on abundance when age- 0 striped bass attain a mean length of $38.1 \mathrm{~mm}$. In contrast, the delta smelt (Hypomesus transpacificus) index is the average of the first two survey indices. The delta smelt index was developed about 1990 in response to declining delta smelt abundance. It has proven valuable in gauging the health of the estuary; delta smelt abundance trend data were used as supporting evidence for their listing as threatened in 1992 under the Federal and State Endangered Species Acts.

TNS samples 32 historic stations, of which, 31 contribute to the indices, ranging from one in eastern San Pablo Bay to Rio Vista on the Sacramento River and to Stockton on the San Joaquin River. In 2011, to better describe delta smelt distribution, as well as that of other fishes, TNS added eight supplemental, non-index, stations in Cache Slough (three stations) and the Sacramento Deep Water Ship Channel (five stations). Historically, the TNS began sampling in mid to late June, when larva sampling near Antioch indicated youngof-the-year striped bass had achieved a mean size of $25 \mathrm{~mm}$. Annually, two to five surveys were completed, depending on how quickly striped bass achieved a mean length of $38.1 \mathrm{~mm}$. Beginning in 2003, CDFW standardized sampling to six surveys annually, starting in early June and continuing on alternate weeks through August.

The townet has two sections; the first is made of onehalf inch stretch, knotted, nylonmesh, 6-feet (ft) long, tapering to an additional two ft "fyke.". This "fyke" fits entirely within the second section, a 9-ft section of woven mesh with approximately eight holes per inch. The entire net measures approximately $15-\mathrm{ft}$, in total, and is lashed directly to a fixed metal "D" frame. The "D" frame is, in turn, mounted on a 22-pound sled. Since 2005, a modified Clarke-Bumpus net and housing have been attached to the top of the "D" frame to sample mesozooplankton prey availability during one of the fish tows at each station. Two 10-minute stepped oblique tows are performed at each station. At historic stations, a third tow is performed if any fish are captured during the first two tows. TNS enumerates all fishes and several invertebrate species. Fork length is measured to the nearest millimeter for all striped bass, all delta smelt, and the first 50 fish per tow for all other species.

TNS is mandated by the Delta Smelt Biological Opinion. Historically, TNS began in response to the development of Central Valley Project pumping plants exporting water from the south Delta. These exports created a need for information regarding distribution of young striped bass relative to the south Delta diversions. Alongside the collection of other data, TNS continues to monitor striped bass and delta smelt distribution in relation to water diversions for the coordinated operation of the Central Valley Project and the State Water Project.

In addition to the delta smelt abundance indices, we utilized several ratios of these values as indicators of survival and recruitment. These ratios are included in table 8-1. 
Prepared by the Sacramento Publishing Service Center.

For more information concerning this report, contact:

Director

U.S. Geological Survey

California Water Science Center

6000 J Street, Placer Hall

Sacramento, CA 95819

dc_ca@usgs.gov

or visit our Web site at:

http://ca.water.usgs.gov 


\section{嗬}

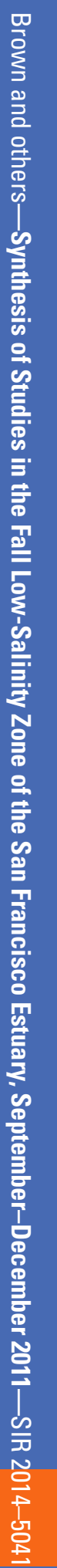

ISSN 2328-0328 (online) 